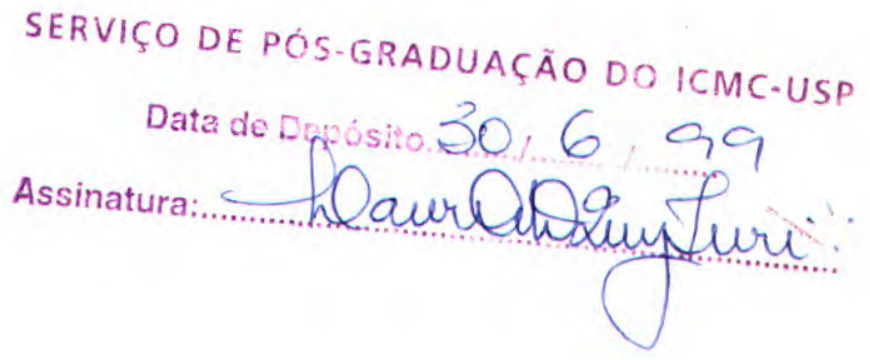

\title{
UMA ABORDAGEM INTEGRADA DE DESENVOLVIMENTO E TESTE DE SOFTWARE BASEADA NA UML
}

Thelma Elita Colanzi

Orientador: Prof. Dr. Paulo Cesar Masiero

Dissertação apresentada ao Instituto de Ciências Matemáticas e de Computação - USP como parte dos requisitos para a obtenção do título de Mestre em Ciências - Área de Ciências de Computação e Matemática Computacional. 


\section{AGRADECIMENTOS}

À Deus, pela proteção e por todas as bençãos concedidas a mim.

À minha família por acreditarem em mim, por todo o apoio e incentivo que sempre me deram.

Ao meu orientador, Prof. Dr. Paulo Cesar Masiero, pelo esforço, dedicação, orientação, amizade, ensinamentos e profissionalismo demonstrados ao longo desses dois anos e meio.

Ao Prof. Dr. José Carlos Maldonado, pela atenção, amizade e sugestões valiosas para a concretização deste trabalho.

Ao Prof. Dr. Álvaro José Periotto, "eterno tutor" do PET-Informática da UEM, pelo seu incentivo, pela sua amizade e pelas lições de vida que eu e os outros integrantes do PET tivemos e temos o privilégio de usufruir.

As minhas companheiras de república: Lu, Tati e Va, pela amizade, companheirismo e por todos os momentos inesquecíveis que passamos juntas. $\mathrm{E}$ também às MarinGirls por adoção: Andrea (Cabela) e Nilda.

Ao Nixon por ter sido meu porto seguro nos momentos mais difíceis. Sem me esquecer do seu apoio e da paciência e carinho com os quais sempre me tratou.

Ao Leo, pelo incentivo, pelo companheirismo, pela amizade e por compreender as minhas ausências na fase de conclusão deste trabalho.

Aos amigos: Araxá, Dani Bola, Dani, Guto, João Caldas, Jamaica, Matite, Júlio, Elder, Boni, Taboca, Pissioli, Mac, Cláudia, Mari, Roberto, Kutova, Ernesto, Carlos Eduardo, Alessandra, Omar, Chandler; aos amigos paranaenses: Alessandro, Gandhi, Simone, Emerson, Ellen, Auri, Simone, Paulo, Adenilso, William e Regiane; e especialmente ao Tanão, pela amizade, ajuda e por todas as divertidas festas que compartilhamos.

Ao pessoal do LABES: Janaína, Rosana, Sandra, Rurik, Emerson, Elisa, Ana Paula, Rejane, Rosângela, Delamaro, Vangrei, Willie.

Aos amigos da UNIPAR, pelo apoio principalmente na última fase deste trabalho.

Novamente, à Tati pela ajuda na revisão deste trabalho.

Às meninas da seção de Pós: Laura, Marília e Beth, e a todos os funcionários do ICMC, por toda prestatividade, simpatia e atenção dispensados. À Marlene por todos os nossos papos e à Prof ${ }^{2}$. Rosane Minghim pela amizade.

A todos que de alguma forma contribuíram para a conclusão deste trabalho.

A CAPES e a UNIPAR pelo suporte financeiro. 


\section{ÍNDICE}

2.1 A ABORDAGEM ORIENTADA A OBJETOS

2.1.1 EVOLUÇĀO DA ABORDAGEM OO

2.1.2 CONCEITOS BÁSICOS DO PARADIGMA ORIENTADO A OBJETOS _— 6

2.1.3 MÉTODOS ORIENTADOS A OBJETOS — 8

2.1.3.1 Método Fusion ___ 8

2.1.3.2 TeamFusion — 11

2.1.3.3 Unified Process___ 12

2.1.4 UML 14

2.2 TESTE DE SOFTWARE ORIENTADO A OBJETOS __ 16

2.2.1 TESTE DE SOFTWARE _ 17

2.2.1.1 Técnicas de Teste de Software__ 17

2.2.1.1.1 Técnica de Teste Funcional___ 18

2.2.1.1.2 Técnica de Teste Estrutural __ 18

2.2.1.1.3 Técnica de Teste Baseada em Erros _ 19

2.2.1.1.4 Técnica de Teste Baseado em Máquinas de Estados Finitos___ 19

2.2.2 PROBLEMÁTICA DE TESTE OO — 22

2.2.3 TESTE \& OO — 24

2.2.3.1 Axiomas de Teste $\longrightarrow 24$

2.2.3.2 Abordagens de Teste de Software Orientado a Objetos__ 27

2.2.3.2.1 Critério Baseado em Estados__ 28

2.2.3.2.2 Estratégia de Teste Incremental Hierárquica___ 30

2.2.3.2.3 Estratégia FREE — 37

2.2.3.2.4 Técnica de Teste de Fluxo de Dados para Classes ___ 40

2.2.3.2.5 Cenários de Teste ___ 41

2.2.3.2.6 Técnica de Teste Modal ___ ___ 43

2.3 CONSIDERAÇÕES FINAIS__ 
III - PROPOSTA DE UM RROCESSO DE DESENVOLVIMENTO ORIENTADO A OBJETOS

3.1 CONSIDERAÇÕES INICIAIS 46

3.2. O PROCESSO 48

3.2.1 ENGENHARIA DE REQUISITOS — 48

3.2.2 ANÁLISE —

3.2.3 PROJETO_— 61

3.2.4 IMPLEMENTAÇĀO

3.3 COMPARAÇĀO COM O FUSION CLÁSSICO _ 73

3.4 CONSIDERAÇÕES FINAIS___ 75

IV - USO E AVALIACÃO DO PRODES/UML

4.1 CONSIDERAÇŌES INICIAIS __ 76

4.2 REQUISITOS DO SISTEMA

4.3 FASE DE ENGENHARIA DE REQUISITOS _

4.4 FASE DE ANALISE__ 81

4.4.1 CENÁRIOS 81

4.4.2 DIAGRAMA DE CLASSES DA ANÁLISE___ 83

4.4.3 MODELO DE OPERAÇÕES _ 83

4.4.4 MODELO DE CICLO DE VIDA _ 85

4.5 FASE DE PROJETO _ 87

4.5.1 DIAGRAMAS DE COLABORAÇÃO __ 87

4.5.2 DIAGRAMA DE ESTADOS

4.5.3 DIAGRAMA DE VISIBILIDADE — 88

4.5.4 DIAGRAMA DE CLASSES DA ANÁLISE REFINADO _ 89

4.5.5 DESCRIÇÃO DE CLASSES _— 90

4.6 FASE DE IMPLEMENTAÇĀO___ 91

4.7 AVALIAÇĀO _ 94

4.7.1 NOTAÇĀo UML.

4.7.2 FERRAMENTA RATIONAL ROSE ___ 96

4.7.3 PRODES/UML _ 97

4.8 CONSIDERAÇÕES FINAIS___ 98

V-ABORDAGEM DE TESTE

5.1 CONSIDERAÇÖES INICIAIS____

5.2 ABORDAGEM DE TESTE

5.2.1 FASE DE ENGENHARIA DE REQUISITOS __ 103

5.2.1.1 Modelo de Teste dos Requisitos___ 103

5.2.1.2 Modelo de Avaliação do Teste___ 105

5.2.2 FASE DE ANÁLISE 105

5.2.2.1 Modelo de Teste da Análise___ 105

5.2.2.2 Modelo de Avaliação do Teste___ 108

5.2.3 FASE DE PROJETO 109

5.2.3.1 Modelo de Teste do Projeto — 109

5.2.3.2 Modelo de Avaliação do Teste____ 114 
5.2.4 FASE DE IMPLEMENTAÇÃO 114

5.2.4.1 Modelo de Teste da Implementação

5.2.4.2 Modelo de Avaliação do Teste

5.3 USO DA ABORDAGEM DE TESTE

5.3.1 IMPLEMENTAÇÃO

5.3.2 EXEMPLO DE USO PARA O SAPES

5.3.2.1 Fase de Engenharia de Requisitos

5.3.2.2 Fase de Análise

5.3.2.3 Fase de Projeto

5.3.2.4 Fase de Implementação

5.4 CONSIDERAÇŌES FINAIS

VI - CONCLUSĀO 128

6.1 CONSIDERAÇŌES INICIAIS 128

6.2 CONTRIBUIÇÕES DO TRABALHO 129

6.3 TRABALHOS FUTUROS 129

REFERENCIAS BIBLIOGRAFICAS 131

ANEXO A - DOCUMENTO DE REQUISITOS DO SAPES 136

ANEXO B - CÓDIGO DOS MÉTODOS TESTADOS 


\section{RESUMO}

Este trabalho propõe um processo de desenvolvimento de software orientado a objetos que utiliza a notação da Unified Modeling Language (UML). Para cada fase do ciclo de vida de um software são apresentados os diagramas que auxiliam na organização das informações referentes ao software a ser desenvolvido e as diretrizes de uso desses diagramas. O processo utiliza conceitos e princípios utilizados em alguns métodos orientado a objetos, como por exemplo, o Fusion, o Objectory e o TeamFusion.

O processo introduz uma abordagem de teste que fornece diretrizes para a geração de modelos de teste ao longo do desenvolvimento do software. Para cada fase são identificadas técnicas e critérios de teste passíveis de aplicação, sendo que para cada fase indica-se um critério de teste visando a cobertura dos requisitos mínimos de teste para garantir que o produto desenvolvido seja confiável.

Para ilustrar o emprego do processo foi realizado um estudo de caso com o Sistema de Apoio à Escrita - SAPES, para gerenciamento das informações relativas às publicações de um pesquisador. A partir de um modelo de requisitos é feita toda a modelagem do SAPES, desde a fase de engenharia de requisitos até a fase de implementação. Somente parte do sistema foi implementada. A abordagem de teste foi aplicada para produzir os modelos de teste que foram utilizados para avaliar a confiabilidade do software obtido com a utilização do processo. 


\section{ABSTRACT}

This work proposes an object-oriented software development process that employs the UML notation. Diagrams and guidelines for their use are presented for the each phase of the software life cycle. This process is defined combining concepts used in some existing object-oriented methods, like Fusion, Objectory and TeamFusion.

The process also introduces an approach for testing that provides guidelines for the generation of test models during software development. For each development phase we identify applicable test techniques and criteria. A test criterion that covers the minimum test requirements is recommended to obtain a reliable final product.

To illustrate the process development we use a case study based on a system called SAPES (Sistema de Apoio à Escrita) - that manages information on researcher's publications. Taking a requirements document as the starting point, the whole modeling of SAPES was developed, from Requirements Engineering to Implementation. The system was implemented partially. The test approach was applied to produce test models that allowed the evaluation of the final product reliability. 


\section{CAPÍtUlo I}

\section{INTRODUÇÃO}

\subsection{CONTEXTO}

As expectativas de qualidade de produtos de software têm aumentado cada vez mais, enquanto restrições de custo e recursos humanos estão diminuindo (Murphy et al., 1994). Muitas empresas têm incorporado tecnologia orientada a objetos no seu processo de desenvolvimento de software com a perspectiva de aprimorar a qualidade dos produtos de software. Com a crescente aceitação da orientação a objetos, o número de pesquisas sobre a abordagem orientada a objetos aumentou. Surgiram então muitos métodos de análise e projeto e muitas linguagens de programação que apóiam essa abordagem.

Cada um dos vários métodos que apóiam o ciclo de vida do software orientado a objetos propõe os seus modelos e o seu processo de desenvolvimento. Em cada fase desse processo são gerados modelos (diagramáticos ou textuais) que visam a representar os requisitos do software năauela fase. Porém, com essa diversidade de métodos não existe um padrão de modelos para as atividades do desenvolvimento de software. Com o objetivo de padronizar a notação dos modelos utilizados ao longo do desenvolvimento de software Jacobson, Rumbaugh e Booch desenvolveram a Unified Modeling Language (UML) (Rational, 1997a). A UML é uma 
linguagem de modelagem orientada a objetos que não estabelece um padrão de processo de desenvolvimento. Dessa forma, organizações e projetos que se enquadram em diferentes processos de desenvolvimento podem utilizar a mesma notação para os seus modelos.

No entanto, para que um produto de software atinja um grau de qualidade aceitável, são necessárias atividades de garantia de qualidade, tais como verificação e validação, sendo a atividade de teste uma das mais utilizadas, constituindo-se em um dos elementos para fornecer evidências da confiabilidade do software em complemento a outras atividades (Pressman, 1992). Porém, no contexto de orientação a objetos, tem sido identificada a necessidade de novas técnicas e ferramentas que apoiem a atividade de teste de software e várias iniciativas e esforços de pesquisadores têm sido feitas nessa direção (Binder, 1995a; Binder, 1996a; Doong \& Frankl, 1991; Harrold et al., 1992; Harrold \& Rothermel, 1994; Morandini, 1996; Murphy et al., 1994; Smith \& Robson, 1992; Vieira \& Travassos, 1998).

\subsection{MOTIVAÇÃO}

Como a UML é uma notação padrão para os modelos orientados a objetos, independente do processo de desenvolvimento a ser seguido, é necessário ou adaptar os processos de desenvolvimento de software existentes ou desenvolver novos processos que suportem a notação proposta pela UML. Alguns trabalhos nesta linha de pesquisa foram desenvolvidos em paralelo a este trabalho, como por exemplo, a nova versão do método Fusion (TeamFusion, 1997) e o Unified Process (Jacobson et al., 1999).

Mesmo sendo uma atividade de grande importância, o teste de software orientado a objetos (OO) é um assunto que tem recebido mais atenção há poucos anos. A maioria das abordagens de teste orientado a objetos é baseada em implementação, não sendo propostas técnicas de teste $\mathrm{OO}$ baseadas em especificação. Existe então a necessidade de desenvolver abordagens que permitam a geração de conjuntos de teste baseados na especificação do software. É preciso também desenvolver estratégias de teste de software que apóiem todas as fases do desenvolvimento do software, ao contrário da maioria das estratégias existentes que apóiam o teste somente depois que o software foi programado. Além disso, existem poucas iniciativas em estabelecer frameworks para a organização da atividade de teste orientado a objetos.

Técnicas básicas de teste são aplicáveis a sistemas orientados a objetos com as necessárias mudanças. Algumas técnicas de teste orientado a objetos adaptam Máquinas de Estados Finitos (Gill, 1962) para modelar o comportamento do sistema e das classes. Por exemplo, Binder desenvolveu uma técnica para teste do fluxo de dados intra-classe que combina procedimentos de teste de fluxo de dados e teste baseado em máquina de estados (Binder, 1995b). Essa técnica oferece um método sistemático para exercitar todos os possíveis fluxos de dados por todas as sequiências de ativação de métodos.

O Grupo de Engenharia de Software do Instituto de Ciências Matemáticas de São Carlos - ICMC-USP, em colaboração com o Grupo de Engenharia de Software do DCA/FEE/UNICAMP, vem desenvolvendo atividades de pesquisa concentradas no estudo de princípios, estratégias, métodos e critérios de teste e validação na produção de software, assim como na especificação e implementação de ferramentas de teste que apoiem a realização das atividades de teste e viabilizem a avaliação do aspecto complementar desses critérios, por meio de estudos empíricos. Vários trabalhos científicos foram publicados em revistas e congressos 
nacionais e intemacionais tanto na área de Teste Baseado em Fluxo de Dados como nas áreas de Teste Baseado em Erros e Teste e Validação de Sistemas Reativos.

Em um trabalho de mestrado do ICMC-USP foi realizada a implementação de uma ferramenta de geração de seqüências de testes baseadas em Máquinas de Estados Finitos (MEF) denominada MGASET (Nakazato, 1995). Como citado anteriormente, algumas técnicas de teste orientado a objetos usam MEFs para modelar o comportamento do sistema e das classes, e a disponibilidade desta ferramenta viabiliza o emprego de um desses critérios, o Critério W (Chow, 1978).

Mais recentemente, o Grupo de Engenharia de Software do ICMC-USP tem desenvolvido pesquisas sobre teste de software orientado a objetos, na tentativa de definir algumas estratégias para esse tipo de teste e de implementar ferramentas que automatizem o teste OO. No entanto, muitos desses trabalhos ainda estão em andamento.

\subsection{OBJETIVOS}

Este trabalho tem como objetivo o desenvolvimento de um processo de desenvolvimento de software baseado no método Fusion (Coleman et al., 1994) e que utilize a notação UML (Rational, 1997a). Eventualmente, características de outros métodos de desenvolvimento de software orientados a objetos podem ser utilizadas no processo a ser proposto.

Propõe-se uma abordagem de teste de software $O O$ que permite o estabelecimento de requisitos de teste baseados em especificações UML. O desenvolvimento dessa abordagem de teste consiste em analisar as técnicas e os critérios de teste $0 O$ propostos na literatura e identificar as fases em que esses critérios podem ser utilizados.

Com o objetivo de garantir a qualidade do software, ao fim de cada fase do processo deve-se fornecer diretrizes para checagens dos modelos, gerados pelo processo e pela abordagem de teste, levando em consideração os modelos utilizados como fonte para a sua criação.

Apresenta-se também um estudo de caso: o Sistema de Apoio à Escrita (SAPES). A partir do documento de requisitos do sistema, apresentado no Anexo A, aplica-se o processo de desenvolvimento e a abordagem de teste para ilustrar o uso de ambos.

\subsection{ORGANIZAÇÃO DO TRABALHO}

Neste capítulo são apresentadios o contexto em que este trabalho se insere, os fatores que motivam o seu desenvolvimento e os objetivos que devem ser atingidos durante a sua realização.

No Capítulo 2 é apresentada a abordagem orientada a objetos como um todo, enfocando alguns métodos orientados a objetos e a UML. Aborda-se também o teste de software; são mencionadas as principais técnicas tradicionais de teste de software: as técnicas funcional, estrutural, baseada em erros e baseada em máquinas de estados finitos. Em cada uma delas alguns critérios consolidados são destacados. É abordada a problemática existente no teste orientado a objetos, considerando a atividade de verificação, validação e teste no contexto de orientação a objetos. São apresentados os Axiomas de Teste que avaliam a adequação de 
conjuntos de casos de teste. Algumas das principais abordagens de teste de software orientado a objetos propostas na literatura são apresentadas.

No Capítulo 3 é apresentado o processo de desenvolvimento de software orientado a objetos proposto neste trabalho. A apresentação está organizada em fases, para as quais existem diretrizes para o desenvolvimento de cada um dos seus produtos (modelos). Ao final de cada fase apresentam-se algumas checagens que devem ser feitas para garantir a consistência dos modelos gerados em relação aos modelos que serviram como fonte de informação.

O processo de desenvolvimento foi utilizado para desenvolver o SAPES, parte da documentação gerada é apresentada no Capítulo 4, como exemplo de uso do processo. É apresentada ainda uma avaliação do processo e da notação UML, bem como da ferramenta CASE Rose 98, da Rational Software Corporation, usada para a modelagem do sistema.

A abordagem de teste proposta neste trabalho é apresentada no Capítulo 5. Assim como o processo de desenvolvimento, a apresentação da abordagem de teste também está organizada em fases. Além dos Modelos de Teste gerados em cada fase existe também o Modelo de Avaliação do Teste que é comum a todas as fases e que engloba as atividades de validação da atividade de teste, ou seja, os modelos de teste gerados são confrontados com os modelos que serviram como fonte de informação para garantir que os requisitos de teste foram estabelecidos adequadamente. É apresentado também um exemplo da aplicação da abordagem de teste para uma parte do SAPES.

No Capítulo 6 são apresentadas as conclusões do trabalho e propostas algumas linhas de pesquisa que dão continuidade a este trabalho. 


\section{CAPÍTULO II}

\section{REVISÃO BIBLIOGRÁFICA}

\subsection{A ABORDAGEM ORIENTADA A OBJETOS}

Os usuários estão desejando melhor funcionalidade e desempenho de seus sistemas computacionais, além de ambientes mais simples e fáceis de serem utilizados. A orientação a objetos viabiliza esses desejos do usuário pois, de acordo com Khoshafian \& Abnous (Khoshafian \& Abnous, 1990), ela proporciona melhores paradigmas e ferramentas para:

Modelar o "mundo real" da melhor forma possível segundo a perspectiva do usuário;

$>$ Permitir fácil interação do usuário com o ambiente computacional;

$>$ Construir biblioteca extensível de módulo de software.

Segundo Khoshafian \& Abnous, por esses motivos, a abordagem orientada a objetos tem se difundido na comunidade de software, sendo o foco de muitas pesquisas e projetos. Neste capítulo são abordados a evolução e os principais conceitos dessa abordagem, apresenta alguns dos diversos métodos de desenvolvimento orientado a objetos e a linguagem de modelagem UML. 


\subsubsection{Evolução da Abordagem OO}

Inicialmente, no fim da década de 60 , a programação orientada a objetos foi discutida pelos programadores que trabalhavam com a linguagem Simula. Nos anos 70, ela foi uma parte importante da linguagem Smalltalk desenvolvida pela Xerox PARC. Nessa época, a análise estruturada era usada para a análise e projeto de software e as linguagens de programação mais utilizadas eram Cobol e Fortran. Poucas pesquisas enfatizavam o projeto orientado a objetos e praticamente nenhuma enfocava a análise orientada a objetos (Yourdon \& Coad, 1991).

Nos anos 80, Bjarne Stroustrup da AT\&T Bell Laboratories estendeu a linguagem C para criar $\mathrm{C}++$, uma linguagem que apóia a programação orientada a objetos. Essa linguagem se tornou popular, pois não foi feita somente para microcomputadores, mas para a maioria das arquiteturas de computadores. No início da década de 80 versões comerciais da linguagem C++ da AT\&T propiciaram a difusão da programação orientada a objetos na comunidade de software em geral. Pois, com $\mathrm{C}++$ os programadores estavam aptos a aprender a orientação a objetos sem ter que investir em ambientes e linguagens de computação novos e diferentes (Winblad et al., 1990).

Um dos primeiros materiais sobre análise orientada a objetos foi publicado por Sally Shlaer e Stephen Mellor (Shlaer \& Mellor, 1988). O número de linguagens de modelagem para análise orientada a objetos aumentou de menos de 10 para mais de 50 durante o período entre 1989 e 1994. Muitos usuários de métodos OO tiveram problemas para se satisfazer totalmente com uma das linguagens de modelagem disponíveis, iniciando a chamada "guerra dos métodos". Pelo meio da década de 90, alguns métodos começaram a incorporar técnicas uns dos outros e, dessa forma, alguns deles emergiram como, por exemplo, o método de Booch (Booch, 1993), o Fusion (Coleman et al., 1994) e a UML (Rational, 1997a).

\subsubsection{Conceitos Básicos do Paradigma Orientado a Objetos}

Historicamente, criar software envolve definir processos que agem sobre um conjunto de dados separados. A orientação a objetos muda o foco do processo de programação de procedimentos para objetos e classes, além de incorporar um conjunto de conceitos, tais como herança, polimorfismo, amarração dinâmica (dynamic binding) e encapsulamento de dados, que são definidos a seguir.

Objetos são módulos que contêm tanto os dados como os procedimentos que agem sobre os dados. Os procedimentos contidos nos objetos ganham um novo nome - métodos. Os objetos podem agir e ser ativados por mensagens de outros objetos. Uma mensagem é uma solicitação para que o objeto execute uma de suas operações (métodos).

Classe consiste de uma interface que caracteriza os objetos e define a lista de operações permitidas a um objeto daquela classe; da implementação destas operações, chamadas de métodos ou funções membro; e, das instâncias de variáveis que armazenam o estado de um objeto. Cluster é um agrupamento de classes que cooperam entre si.

Herança é a relação entre classes que permite que a definição e a implementação de uma classe sejam baseadas nas definições de outras classes já existentes. Com a utilização de herança, as classes são inseridas em uma hierarquia de especialização, de tal forma que uma classe mais especializada herde todas as propriedades da classe mais geral a que ela imediatamente se 
subordina na hierarquia. A classe mais geral é denominada de superclasse, classe-pai ou classebase e a classe mais especializada é denominada subclasse ou classe-filho. A herança é o mecanismo pelo qual uma classe-filho herda características de sua classe-pai e as estende ou restringe de algum modo.

Nesse contexto, cada classe é declarada como uma subclasse de uma ou mais superclasses. Quando existe mais de uma superclasse, a relação de herança é denominada herança múltipla. Podem existir problemas de conflito entre informações herdadas por uma subclasse provenientes de diferentes superclasses, como por exemplo, serem herdadas variáveis com mesmo nome, mas de tipos diferentes. Este tipo de conflito já é tratado pela maioria das linguagens orientadas a objetos. Na Figura 2.1 encontra-se um exemplo ilustrativo das relações de herança e de herança múltipla. A classe $\mathrm{R}$ herda características da classe S1 e da classe S2. A classe $\mathrm{T}$ herda características das classes $\mathrm{R}$ e $\mathrm{S}$. Tanto a classe $\mathrm{R}$ como a classe $\mathrm{T}$ caracterizam a Herança Múltipla. A classe S herda características apenas da classe S3, determinando a Herança Simples.

O Polimorfismo geralmente representa a qualidade ou estado de um objeto ser capaz de assumir diferentes formas. Quando aplicado às linguagens de programação indica que a mesma construção da linguagem pode assumir diferentes tipos ou manipular objetos de diferentes tipos. Por exemplo, um operador "t" pode ser usado com inteiros, pontos-flutuantes, ou até mesmo strings (Morandini, 1996).

A Amarração Dinâmica é uma conseqüência do polimorfismo e uma das vantagens mais freqüentemente utilizadas na programação orientada a objetos. Devido ao fato do sistema "amarrar" os seletores de mensagens aos métodos que os implementam em tempo de execução (ao invés disso ser feito em tempo de compilação como ocorre nas linguagens procedimentais), podem ser tiradas vantagens práticas, principalmente para a reutilização de métodos por diversas classes. O mesmo nome de método pode ser sobrecarregado com diferentes semânticas e implementações; por exemplo, um método print pode ser aplicado a inteiros, matrizes ou cadeias de caracteres. Para esse exemplo, podem existir três diferentes implementações do método print. Com isso, podem-se ter três métodos diferentes que possuem o mesmo nome, sendo que para cada um deles são passados parâmetros diferentes (Morandini, 1996).

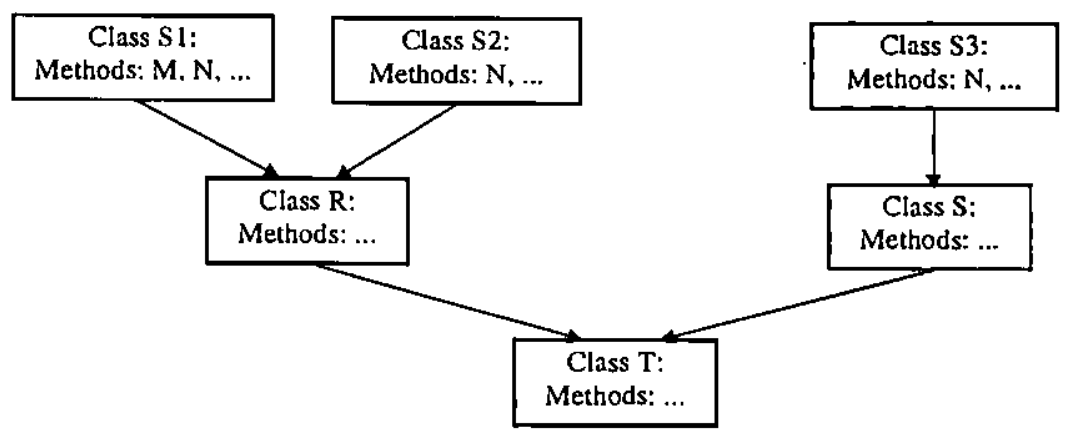

Figura 2.1 - Exemplo das Relaçōes de Herança e Herança Múltipla

O comportamento de uma classe é especificado e utilizado nos métodos associados às instâncias dessa classe. Os métodos ou funções membro são operações que podem utilizar e/ou atualizar o estado de um objeto. Em uma hierarquia de herança, um método definido por uma classe é herdado por suas subclasses; o que implica que os métodos herdados sejam parte da interface que manipula as instâncias da subclasse e possam ser invocados por elas. Com a 
finalidade de manter a interface e a implementação dos métodos separadas pode ser utilizada a técnica de encapsulamento de dados.

Encapsulamento de dados é uma técnica empregada para garantir o ocultamento de informações, em que a interface e a implementação de uma unidade são sintaticamente separadas. Desta forma, somente os próprios métodos do objeto poderão fazer acesso aos dados encapsulados. Isso permite ao programador esconder as decisōes de projeto dentro da implementação e apontar as possíveis interdependências com outros componentes da interface. $\mathrm{O}$ encapsulamento encoraja a modularidade do programa, isola as unidades desenvolvidas e restringe as implicações de possíveis mudanças. Em particular, se um programador mudar a implementação de uma unidade, mantendo a interface da mesma, as outras unidades não devem ser afetadas por essa mudança.

\subsubsection{Métodos Orientados a Objetos}

Embora existam muitos métodos de desenvolvimento orientados a objetos e cada um tenha as suas particularidades, todos eles têm o objetivo de oferecer mecanismos que captem melhor as informações para a elaboração de um modelo, a partir do mundo real, a fim de melhorar a manutenibilidade e o entendimento de sistemas. Nesta seção são apresentados brevemente os métodos Fusion (Coleman et al., 1994), TeamFusion (TeamFusion, 1997) e Unified Process (Jacobson et al., 1999), e a recente UML - Unified Modeling Language (Rational, 1997a).

\subsubsection{Método Fusion}

Fusion é um método para a análise e projeto orientado a objetos desenvolvido por Coleman (Coleman et al., 1994) a partir de outros métodos existentes, tais como OMT, Booch e CRC. Esse método abrange as fases de análise, projeto e implementação. Segundo Coleman, o conjunto de modelos sugeridos pelo método é conciso e a passagem de uma fase para outra é bem definida, sendo sempre seguida de sugestões de atividades de inspeção para checagem da consistência dos modelos produzidos (Coleman et al., 1994).

O método Fusion recomenda que um dicionário de dados seja usado durante todo o desenvolvimento do software para definir de forma única os elementos de cada modelo e dessa forma completar a semântica de cada identificador relevante do sistema. O dicionário de dados pode ser representado por uma tabela, que contém as informações relevantes de cada componente do sistema, por exemplo, o nome, o tipo e uma breve descrição do componente.

Na Figura 2.2 é mostrada a interação existente entre as três fases do método, os documentos (modelos) produzidos em cada uma delas e a origem das informações para a produção de cada modelo. Inicialmente, supõe-se que $\circ$ usuário $e$, possivelmente, os profissionais envolvidos no projeto, definam o Documento de Requisitos do Sistema que servirá como fonte de informações para a fase de análise.

\section{Análise}

O comportamento do sistema é especificado na fase de análise, para isso o método utiliza o Modelo de Objetos e o Modelo de Interface. O Modelo de Interface define a interface do 
sistema através do Modelo de Operações e do Modelo de Ciclo de Vida. O primeiro define as operações que podem ser executadas e o segundo determina as seqüências permitidas dessas operações.

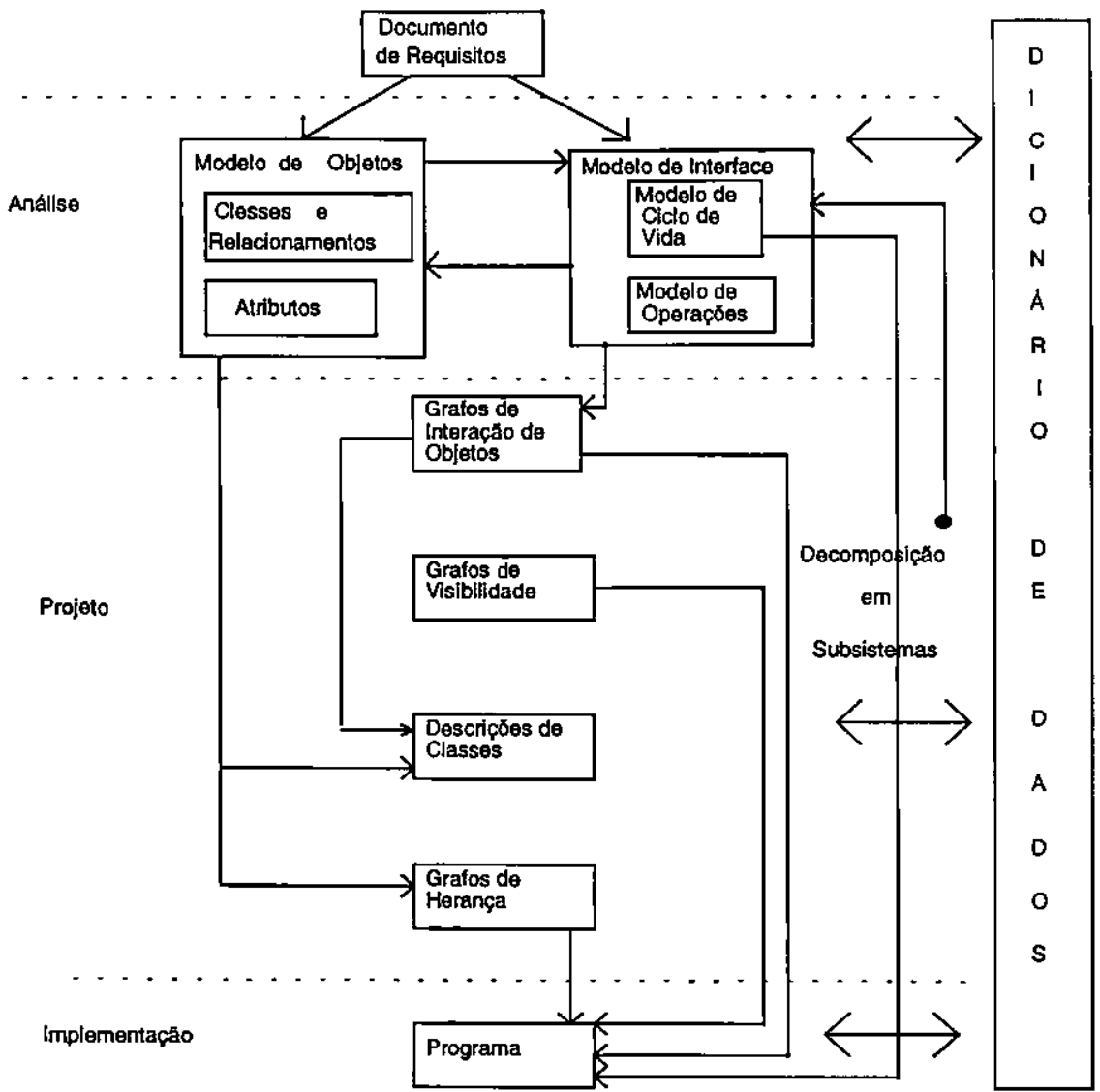

Figura 2.2 - Visão Geral do Método Fusion (Coleman et al., 1994)

O Modelo de Objetos representa as classes de objetos existentes no domínio da aplicação e os relacionamentos existentes entre elas. A sua notação é semelhante à do modelo de objetos do método OMT. O modelo permite representar classes, atributos e relacionamentos entre classes, incluindo agregação e especialização/generalização. A análise deve iniciar em um nível mais alto de abstração, sendo que os detalhes devem ser inseridos só depois que a estrutura geral for considerada satisfatória.

Para determinar a Interface do Sistema é preciso identificar os agentes, operações e eventos e refinar o modelo de objetos do sistema construído no passo anterior adicionando-lhes limites. Para determinar o Modelo de Interface é necessário elaborar o Modelo de Ciclo de Vida e o Modelo de Operações.

O Modelo de Ciclo de Vida descreve todo o comportamento do sistema, desde a sua criação até o seu término. Este modelo tem a sintaxe geral exibida pela Figura 2.3, na qual Nome especifica o nome do sistema. As expressões regulares determinam as sequiências permitidas de interações com o ambiente em que o sistema pode participar durante toda a sua vida.

\section{life cycle [Nome:] Expressão-Regular \\ (nome-local $=$ Expressão-Regular)}

Figura 2.3 - Modelo de Ciclo de Vida 
O Modelo de Operações é decorrente do Modelo de Ciclo de Vida. Ele especifica o comportamento de uma operação de forma declarativa em termos de mudança de estado do sistema e geração de eventos de saída. Por meio de uma notação textual são especificados: os dados que são fornecidos junto com os eventos de entrada; os objetos acessados pela operação; os eventos de saída gerados pela operação; e, as pré e pós-condições que devem ser satisfeitas.

Após ter desenvolvido todos os modelos de análise, deve-se verificar se eles são consistentes e completos. Um modelo está consistente se não existem contradições implícita ou explicitamente entre as partes do modelo. Um modelo é completo se todas as abstrações significativas do domínio foram captadas e se o modelo de análise é condizente com o Documento de Requisitos.

\section{Projeto}

$\mathrm{Na}$ fase de projeto define-se como uma classe pode se referir a outras e completam-se os atributos de cada classe. Podem ser criadas relações de herança e objetos de projeto não existentes no domínio da aplicação. Nessa fase deve-se desenvolver Grafos de Interação de Objetos para cada operação do Modelo de Operações. Cada um dos grafos mostra os objetos que participam da execução de uma operação e a sequiência de trocas de mensagens entre eles. Para facilitar o entendimento do grafo pode-se utilizar a descrição textual da operação armazenada no dicionário de dados.

Para cada uma das classes existentes deve-se construir um Grafo de Visibilidade, este grafo deve especificar os objetos que uma instância de classe pode referenciar e o tipo apropriado de referência. Essa informação é sintetizada a partir da análise de todos os grafos de interação de objetos.

O próximo passo da fase de projeto é elaborar a Descrição de Classes, que usa uma notação textual abstrata para especificar os atributos de cada objeto e sua interface externa (métodos). As informações para esta descrição são obtidas a partir do Modelo de Objetos, dos Grafos de Interação de Objetos, dos Grafos de Visibilidade, dos Grafos de Herança e do Dicionário de Dados.

Para complementar as descrições de classes deve-se construir os Grafos de Herança, os quais usam a mesma notação do Modelo de Objetos. Na realidade, o Grafo de Herança é o próprio Modelo de Objetos do Sistema acrescido das relações de generalização/especialização acrescentadas na fase de projeto e daquelas do domínio que se decidiu preservar. Depois de desenvolver os Grafos de Herança é necessário atualizar a Descrição de Classe com as novas informaçōes de herança.

\section{Implementação}

A fase de implementação Fusion oferece diretrizes para transformar o projeto em código. Em especial como implementar herança, referências e atributos como classes de linguagens de programação $O O$, como implementar interações entre objetos através de métodos e como implementar a interface do sistema definida pelas sequiências permitidas de operações, usando MEFs. 
O resultado da fase de implementação deverá ser condizente com o projeto e deve satisfazer os requisitos funcionais e não funcionais do software. A fase de implementação pode ser subdividida em três passos: codificação, desempenho e revisão. Na codificação o resultado do projeto é traduzido em código na linguagem de programação, para isso quatro elementos são utilizados: modelo de ciclo de vida, descrições de classe, o corpo dos métodos e o dicionário de dados. O desempenho deve ser considerado durante as três fases do desenvolvimento: análise, projeto e implementação. Partes do código que são menos eficientes e usam muitos recursos devem ser identificadas e melhoradas. Na revisão recomenda-se que o código produzido seja revisado por inspeções e testes, na tentativa de detectar erros antes que o código seja liberado.

O método Fusion tem uma grande preocupação com aspectos de qualidade, por isso são recomendadas revisões ao final de cada fase, que visam principalmente a checar a completitude da especificação e a consistência interna entre os modelos.

Uma ferramenta que apoia o desenvolvimento de sistemas orientados a objetos utilizando o método Fusion é a FusionCase da SoftCASE Consulting.

\subsubsection{TeamFusion}

O Teamfusion é uma extensão do método Fusion que possibilita o uso da UML como notação. O novo Fusion tem cinco atividades separadas que são comentadas brevemente a seguir (TeamFusion, 1997).

\section{Requisitos}

$\mathrm{Na}$ fase de requisitos captura os requisitos do usuário para o sistema. Esses requisitos incluem os casos de uso e características e requisitos não funcionais. Como saída dessa fase temse o diagrama de casos de uso e suas especificações. O primeiro passo dessa fase é produzir uma lista contendo todos os requisitos do sistema, que devem ser descritos em linguagem natural de forma clara e concisa. A seguir deve-se produzir as matrizes de requisitos. Essas matrizes tem como objetivo mostrar o quanto um requisito não funcional deve ser satisfeito em relação a um requisito funcional, por exemplo, a confiabilidade de um determinado requisito funcional deve ser indicada na matriz como alta. O terceiro passo é a definição do diagrama de casos de uso, seguida da definição da escala do sistema que deve ser anexada ao diagrama de casos de uso. Definir a escala do sistema implica em determinar o número de atores, instâncias de casos de uso e concorrência que o sistema poderá tratar em tempo de execução. O próximo passo envolve a definição das especificações dos casos de uso. Uma especificação de caso de uso deve conter o objetivo do caso de uso, os atores envolvidos, a seqüência de passos envolvidos na interação entre o(s) ator(es) e o sistema, fonte de informação para construir o caso de uso e requisitos não funcionais para o caso de uso. A seguir as especificações dos casos de uso devem ser estruturadas de acordo com os relacionamentos de extensão (uses, extends, etc.). O último passo consiste em revisar e refinar os modelos desta fase.

\section{Análise}

A fase de análise define quais operações e objetos estarão presentes no sistema sem se preocupar com a forma como essas operações e objetos serão implementados. A saída desta fase inclui o diagrama de classes do sistema e a interface do sistema. O primeiro passo desta fase é o desenvolvimento do diagrama de classes do domínio e para isso deve-se capturar os conceitos existentes no domínio da aplicação para representá-los como classes, atributos e associações entre as classes. O segundo passo visa a definição da interface do sistema por meio da análise 
dos casos de uso e determinação das operações do sistema. A seguir deve ser desenvolvido o diagrama de classes da análise, que é equivalente ao Modelo de Objetos do Sistema do Fusion Clássico. O quarto passo envolve o desenvolvimento das especificações das operações do sistema e dos eventos de saída. O quinto e último passo consiste em revisar todos os documentos produzidos na análise.

\section{Arquitetura}

Essa fase identifica os componentes nos quais o sistema é dividido, ela define questões que envolvem o tratamento de concorrência e sincronização. Como saída da fase tem-se o diagrama de arquitetura que define os componentes, suas interações e interfaces entre os componentes. Nesta fase são produzidas descrições arquiteturais em dois níveis de abstração: a arquitetura conceitual que descreve informalmente o sistema em termos de colaborações entre componentes e em um alto nível de abstração e a arquitetura lógica que especifica as colaborações em termos de interfaces de mensagens. Primeiramente deve-se selecionar estilos arquiteturais aplicáveis e depois fazer um projeto informal da arquitetura. O próximo passo é desenvolver a arquitetura conceitual e então a arquitetura lógica. Essa fase de fornecer ao projeto algumas diretrizes de projeto relacionadas a mecanismos de comunicação, políticas de segurança e tratamento de erros e exceções.

\section{Projeto}

$\mathrm{Na}$ fase de projeto operações são associadas aos objetos e são tomadas decisões sobre herança, visibilidade e representação das associações. As saídas dessa fase são o diagrama de classes de projeto, diagramas de colaboração entre objetos e configuração inicial dos objetos. Deve-se criar o diagrama de classes de projeto para o componente em questão e a seguir construir os diagramas de colaboração entre os objetos incluídos neste componente. $O$ próximo passo consiste em analisar todos os diagramas de colaboração a fim de detectar a visibilidade existente entre os objetos. Posteriormente, o diagrama de classes do projeto deve ser racionalizado buscando encontrar objetos, classes e comportamentos comuns. Os diagramas de colaboração devem servir de fonte para a criação da configuração inicial dos objetos, que consiste dos objetos presentes no momento do início da operação do sistema e os valores dos seus atributos. Antes de passar para a fase de implementação todos os modelos devem ser checados.

\section{Implementação}

$\mathrm{Na}$ implementação o projeto é traduzido em código. Essa fase possui uma estratégia de gerenciamento de recursos e análise de desempenho. Ela também fornece diretrizes para a codificação das descrições de classes, dos corpos dos métodos e de alguns tipos, predicados e funções do dicionário de dados. Na tentativa de evitar futuros problemas de manutenção, todo o código deve ser revisado para estabelecer um certo nível de corretitude e qualidade.

O TeamFusion também incorpora dois processos suplementares: o Projeto GUI e o Projeto de Banco de Dados (TeamFusion, 1997).

\subsubsection{Unified Process}

O Unified Process é um processo de desenvolvimento orientado a objetos desenvolvido pelos mesmos autores da UML (Jacobson et al., 1999). Trata-se de um processo iterativo e incremental, dirigido por casos de uso e que enfoca a arquitetura do software. Além disso, ele utiliza a notação UML em seus modelos. Baseando-se no método Objectory (Jacobson et al., 
1992), este processo inclui o modelo de casos de uso, que engloba todas as possíveis formas de uso do sistema, substituindo a especificação funcional tradicional do software. A abordagem iterativa permite aumentar o entendimento do problema por meio de refinamentos sucessivos e produzir incrementalmente uma solução efetiva ao longo das múltiplas iterações. A arquitetura de um software é descrita em diferentes visões do sistema em construção. Ela incorpora a maioria dos aspectos significativos dinâmicos e estáticos do software.

Esse processo pode ser descrito em duas dimensões: ao longo do tempo e ao longo dos componentes de processo. A primeira dimensão, que representa os aspectos dinâmicos do processo, é expressada por ciclos, fases, iterações e marcos (milestones). A segunda dimensão é representada por aspectos estáticos do processo: como ele é descrito em termos de componentes de processo, atividades, workflows, e trabalhadores (workers).

Cada iteração engloba um miniprojeto que resulta em um incremento. As iterações se referem aos passos no workflow, e os incrementos, à evolução do produto. A Tabela 2.1 mostra as fases e as iterações envolvidas em um ciclo do Unified Process.

Tabela 2.1 - Fases em um ciclo do Unified Process (Jacobson et al., 1999)

\begin{tabular}{|c|c|c|c|c|c|c|c|}
\hline Inicial & \multicolumn{2}{|c|}{ Elaboração } & \multicolumn{3}{|c|}{ Construção } & \multicolumn{2}{|c|}{ Transição } \\
\hline \begin{tabular}{|l|l|} 
Iteração l & Iteração 2 \\
\end{tabular} & $\ldots$ & -- & -- & --- & $-\cdots$ & Iteração n-1 & Iteração $\mathrm{n}$ \\
\hline
\end{tabular}

O ciclo de vida do software é dividido em ciclos, cada ciclo trabalha em uma nova geração do produto. Cada ciclo é dividido em quatro fases consecutivas: Fase Inicial, Fase de Elaboração, Fase de Construção e Fase de Transição. Cada fase é concluída com um marco bem definido, isto é, um ponto no tempo no qual decisões críticas devem ser tomadas e objetivos devem ter sido alcançados. Para a conclusão de um ciclo precisa-se produzir todas as representaçōes do produto, que em conjunto representam o sistema como um todo. Estas representações são listadas a seguir:

$>$ Modelo de Caso de Uso, com todos os casos de uso e seus relacionamentos;

$>$ Modelo de Análise, que detalha os casos de uso e define o comportamento do sistema e considera todos os seus objetos;

$>$ Modelo de Projeto, que define a estrutura estática do sistema, tais como subsistemas, classes e interfaces. Os casos de uso são detalhados em colaborações entre os subsistemas e interfaces;

$>$ Modelo de Implementação, que inclui os componentes (representando código fonte) e mapeamento das classes para os componentes;

$>$ Modelo de Disponibilidade (Deployment), que define os nós físicos dos computadores e o mapeamento dos componentes naqueles nós;

$>$ Modelo de Teste, que descreve os casos de teste para verificar os casos de uso;

$>$ Representação da Arquitetura.

A seguir são descritas as fases do Unified Process.

Na Fase Inicial é criada a visão do produto e o escopo do projeto é delimitado. Para isso, são identificadas todas as entidades externas com que o sistema irá interagir (atores) e definida, em alto nível, a natureza dessa interação. Isso envolve identificar todos os casos de uso e descrever alguns dos mais significativos. Essa fase inclui também critérios de sucesso, avaliação 
de risco, estimativa dos recursos necessários e planejamento do cronograma. Ao fim da fase são examinados os objetivos do ciclo de vida e decide-se por continuar ou não o desenvolvimento.

A Fase de Elaboração consiste em analisar detalhadamente o sistema. Um plano de projeto é desenvolvido e os elementos de mais alto risco são eliminados. Uma arquitetura básica de sistema é definida e para isso a maioria dos casos de uso deve ser especificada. A arquitetura do sistema é expressa em visões de todos os modelos do sistema, por exemplo, uma visão dos casos de uso, uma visão do modelo de análise e assim por diante. A visão do modelo de implementação inclui componentes que provam que a arquitetura é executável. No fim dessa fase examinam-se os detalhes do escopo e dos objetivos do sistema, a escolha da arquitetura e a resolução dos principais riscos.

Na Fase de Construção desenvolve-se iterativa e incrementalmente o produto completo. Para isso é preciso descrever os casos de uso que ainda não foram especificados, terminar o projeto, completar a implementação e testar o software. No fim da fase é preciso decidir se o software e os usuários estão prontos para a operação do sistema.

A Fase de Transição entrega uma versão beta do produto a alguns usuários. A partir disso surgem requisitos do sistema que devem ser ajustados e alguns problemas não detectados que devem ser corrigidos. Esta fase envolve a instalação, configuração, treinamento, suporte e manutenção. O manual de usuário é escrito na fase anterior e normalmente é ampliado nesta fase.

Este processo trata o teste de forma gerencial, mostrando como as atividades devem ser organizadas e quais tarefas devem ser atribuídas a quais pessoas. No entanto, não mostra como derivar os casos de teste, ou seja, quais técnicas e critérios devem ser utilizados para a geração do conjunto de teste.

\subsubsection{UML}

A UML - Unified Modeling Language - consiste de um meta-modelo e uma notação, inteiramente descrita por um conjunto de documentos disponíveis pela Rational Software Corporation (Rational, 1997a). Trata-se de uma linguagem para especificação, construção, visualização e documentação de componentes de um sistema, especialmente aqueles fortemente ligados a software.

A UML visa a criar um padrão de notação com forte semântica para a especificação de sistemas complexos. Ela não especifica um padrão de processo intencionalmente, baseada no fato de que cada organização e cada projeto enquadram-se em diferentes tipos de processos. Baseada nos métodos Booch, OMT e OOSE, a UML remove as diferenças existentes entre as notações e terminologias que obscurecem as similaridades da maioria dos métodos.

Os esforços de unificação tiveram como meta manter a simplicidade, excluir elementos do Booch, OMT e OOSE que não funcionavam na prática, adicionar elementos de outros métodos que foram mais efetivos e criar novos elementos apenas quando uma solução não estava disponível.

Alguns novos conceitos foram incluídos como: responsabilidades, mecanismos de extensão (estereótipos, valor de propriedade e restrições), processos, distribuição e concorrência, 
colaborações, diagramas de atividades, clara distinção entre tipo, classe e instância, refinamento (para manipular relacionamentos entre níveis de abstração), interfaces e componentes. A Unified Modeling Language é definida pelos seguintes documentos:

$>$ UML Summary : trata-se de uma introdução à UML, apresenta as motivações para o projeto e um sumário dos resultados já obtidos;

$>$ UML Semantics : descreve o modelo preciso que está por baixo da UML, apresentado tanto textualmente como na própria notação UML. O propósito do meta-modelo ${ }^{1}$ era prover um enunciado único, simples e definitivo para a sintaxe e a semântica dos elementos da UML;

$>$ UML Notation Guide : é um guia de notação que descreve a notação UML e apresenta exemplos;

$>$ UML Process-Specific Extensions : este documento propõe certos valores processoespecíficos dos mecanismos de extensão da UML, por exemplo: estereótipos, valores de propriedades e restrições.

O documento referente a notação UML apresenta a representação visual da notação, que não será abordada neste trabalho por ser muito extensa. Ele deve ser usado em conjunto com a UML Semantics, que deve ser consultado para detalhes completos sobre a semântica. Os diagramas da UML estão agrupados no UML Notation Guide de acordo com seu tipo: estático, atividade, caso de uso, seqüência, de estado, colaboração e implementação. Uma breve descrição dos diagramas é dada a seguir.

Os diagramas de estrutura estática se dividem em diagramas de classe e diagramas de objetos. O primeiro é uma coleção de elementos estáticos do modelo declarativo (classes, tipos e seus relacionamentos). O segundo é um grafo de instâncias. Um diagrama de objetos estático é uma instância de um diagrama de classe que mostra o estado detalhado do sistema em um ponto no tempo. Um diagrama de objetos dinâmico é mostrado como um diagrama de colaboração, detalhando o estado do sistema em um certo período de tempo. Na Figura 2.4 são mostrados um diagrama de classes e um possível diagrama de objetos para esse diagrama de classes.

Um diagrama de casos de uso mostra o relacionamento entre os atores (entidades externas e outros sistemas que interagem com o sistema) e os casos de uso dentro de um sistema.

Um diagrama de sequiência mostra uma interação arranjada em uma sequiência de tempo, mostra os objetos participando na interação pelas suas linhas de vida e as mensagens que eles trocam nessa sequiência de tempo. Este diagrama não mostra a associação entre os objetos.

Os diagramas de colaboração mostram uma interação organizada em torno dos objetos na interação e os links de uns para outros. Ao contrário dos diagramas de seqüências, os diagramas de colaboração mostram o relacionamento entre objetos, mas não mostram o tempo como uma dimensão separada, por isso, a sequiência de mensagens e os threads concorrentes devem ser determinados usando-se números de sequiência.

Um diagrama de estado representa a sequiência de estados pela qual um objeto ou uma interação passa durante a sua vida, em resposta a um estímulo recebido, junto com suas respostas e ações. A semântica e- a notação desse diagrama são substancialmente as mesmas dos Statecharts (Harel, 1987).

\footnotetext{
${ }^{1}$ Meta-modelo é uma linguagem para especificar um modelo (neste caso um modelo de objetos).
} 


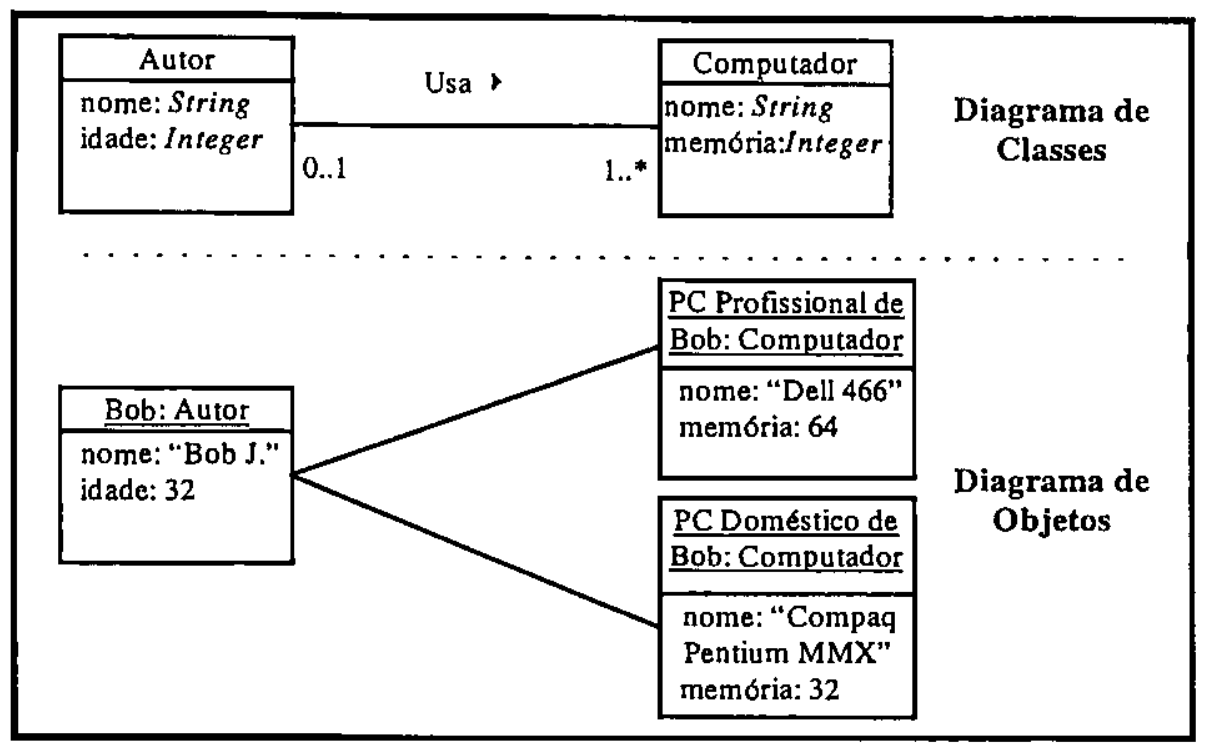

Figura 2.4 - Diagrama de Classes mostrando as classes e um Diagrama de Objetos com instâncias dessas classes (Ericksson \& Penker, 1997)

Um diagrama de atividade é um caso especial de diagrama de estado no pelo menos a maioria dos estados são estados de ação e pelo menos a maioria das transições são disparadas pela finalização das ações nos estados fontes. Todo diagrama de atividade é conectado a uma classe ou a implementação de uma operação ou a um caso de uso. "Os diagramas de atividade são usados em situações onde todos ou a maioria dos eventos representam a conclusão das ações geradas internamente (fluxo de controle procedimental). Os diagramas de estados são usados em situações onde eventos assíncronos ocorrem.(Rational, 1997b)"

Os diagramas de implementação referem-se a aspectos de implementação, inclusive estrutura de código fonte e estrutura de implementação em tempo de execução. Eles aparecem em duas formas: diagramas de componentes, que mostram a estrutura do código em si e diagramas de disponibilidade, que mostram a estrutura do sistema em tempo de execução.

Como resultado, obteve-se uma linguagem de especificação mais limpa, expressiva e mais uniforme que os outros métodos. Isto significa que há vantagens em se adotar a UML, porque ela permitirá projetos que modelam elementos que não poderiam ser modelados anteriormente. Existem ferramentas que suportam a UML, entre elas a Rose, da Rational Software Corporation, e a Paradigm Plus, da Platinum Technology.

Exemplos dos diagramas e detalhes da notação de cada um deles são dados no próximo capítulo, no qual é apresentado o processo de desenvolvimento que utiliza a notação UML.

\subsection{TESTE DE SOFTWARE ORIENTADO A OBJETOS}

Muitas pesquisas têm sido realizadas sobre análise, projeto e implementação de produtos de software orientados a objetos, porém tem-se pesquisado pouco sobre as etapas do ciclo de vida que consomem maior tempo e custo: teste e manutenção. É necessário que a orientação a objetos forneça suporte total à produção de software, por isso é preciso adaptar ou desenvolver critérios de teste para software $\mathrm{OO}$, pois, todo software deverá ser testado antes de sua liberação. 
Smith e Robson definem teste de software orientado a objetos como o "processo de exercitar rotinas de um objeto com o objetivo de descobrir erros na implementação das rotinas, no estado do objeto ou em ambos" (Smith \& Robson, 1992). Nesse contexto, neste capítulo são enfatizadas a problemática de teste orientado a objetos e algumas das abordagens encontradas na literatura sobre esse tipo de teste. Na próxima seção é definido o teste de software e são apresentadas as principais técnicas de teste de software de forma geral.

\subsubsection{Teste de Software}

O processo de desenvolvimento de software envolve uma série de atividades em que, apesar das técnicas, métodos e ferramentas empregadas, erros no produto ainda podem ocorrer. Com isso, a atividade de teste é de fundamental importância para a identificação e eliminação de erros que persistem. Ela representa a última revisão da especificação, projeto e codificação. Pressman afirma que o objetivo da atividade de teste é projetar testes que descubram sistematicamente diferentes classes de erros com uma quantidade de tempo e esforço mínimos (Pressman, 1992).

A atividade de teste de software, do ponto de vista procedimental, pode ser considerada como uma série de três passos. O primeiro deles é o teste de unidade, em que cada módulo do software é testado individualmente, buscando evidências de que ele funciona adequadamente. $\mathrm{O}$ segundo passo, o teste de integração, é uma técnica sistemática para integrar os módulos componentes da estrutura do software, visando a identificar erros de interface entre tais módulos. O último passo é o teste de sistema, que verifica se todos os elementos do sistema combinam-se adequadamente e se a função/desempenho global do mesmo é atingida (Pressman, 1992).

Na tentativa de reduzir os custos associados ao teste, é necessária a aplicação de técnicas e critérios que indiquem como testar o software, quando parar o teste e que, se possível, forneçam uma medida objetiva do nível de confiança e de qualidade alcançados com os testes realizados. Estas técnicas devem facilitar a determinação dos casos de teste visando a maximização do número de erros encontrados e a minimização do número de casos de teste. Apesar de não ser possível, por meio de testes, provar que um programa está correto, esses contribuem para aumentar a confiança de que o software desempenha as funções especificadas.

\subsubsection{Técnicas de Teste de Software}

Entre as várias técnicas propostas para a condução e avaliação da qualidade da atividade de teste encontram-se as técnicas de teste funcional, estrutural, baseadas em erros e baseadas em máquinas de estados finitos. Tais técnicas se diferenciam, basicamente, pela origem da informação utilizada para avaliar ou construir conjuntos de casos de teste (Maldonado, 1991). Com isso, nenhuma delas é, em geral, suficiente para garantir a qualidade da atividade de teste; elas devem ser aplicadas em conjunto para se tentar assegurar um teste de qualidade. É importante ressaltar que essas técnicas devem ser vistas como complementares e a questão está na maneira de utilizá-las a fim de que as vantagens de cada uma levem à determinação de uma atividade de teste de boa qualidade.

Na técnica funcional utiliza-se a especificação para derivar os requisitos de teste; na técnica estrutural os requisitos são derivados a partir dos aspectos de implementação do 
software; na técnica baseada em erros os elementos requeridos para caracterizar a atividade de teste são baseados nos erros mais comuns que o programador ou projetista pode cometer durante o desenvolvimento do software; e na técnica baseada em máquina de estados finitos os requisitos de teste são derivados das sequiências de eventos possíveis da máquina de estados em questão.

$O$ fato de as informações utilizadas para construir o conjunto de casos de teste serem diferentes faz com que as técnicas revelem erros diferentes. O teste funcional descobre classes de erro ao passo que o teste estrutural descobre um erro associado a um teste específico (Pressman, 1992).

\subsection{Técnica de Teste Funcional}

O teste funcional também é conhecido como teste de caixa preta porque este tipo de teste trata o software como uma caixa cujo conteúdo é desconhecido, sendo possível somente visualizar o lado externo.

Além de procurar descobrir erros, esta técnica pretende demonstrar que os requisitos funcionais do software são satisfeitos, que a entrada é adequadamente aceita, que a saída esperada é produzida e que a integridade das informações externas é mantida. Não existe preocupação com a estrutura lógica interna do sistema (Pressman, 1992).

O teste funcional envolve dois passos principais: identificar as funções que o software deve realizar e criar casos de teste capazes de checar se essas funções estão sendo realizadas pelo software (Pressman, 1992). As funções que o software possui são identificadas a partir de sua especificação. Assim, uma especificação correta e de acordo com os requisitos do usuário é essencial para esse tipo de teste.

Alguns exemplos de critérios de teste funcional são:

$>$ Particionamento em Classes de Equivalência: divide o domínio de entrada de um programa em classes de dados a partir das quais os casos de teste são derivados. Um caso de teste bem projetado irá descobrir uma classe de erros, por exemplo, processamento incorreto de todos os dados do tipo caractere.

$>$ Análise do Valor Limite: é um complemento ao critério anterior pois testa os limites de cada classe de equivalência, já que o maior número de erros tende a ocorrer nas fronteiras das classes.

$>$ Grafo de Causa-Efeito: possibilita que o testador valide conjuntos complexos de condições e ações. São levantadas as possíveis condições de entrada (causas) e as possíveis ações (efeitos) do programa. Um grafo causa-efeito é construído e convertido em uma tabela de decisão a partir da qual são derivados os casos de teste (Pressman, 1992).

\subsection{Técnica de Teste Estrutural}

A técnica de teste estrutural é baseada no conhecimento da estrutura interna da implementação do software e procura caracterizar um conjunto de componentes elementares do software que devem ser exercitados (Vilela et al., 1997). Essa técnica também é chamada de teste de caixa branca, pois a estrutura interna do programa é conhecida. 
Em geral, a maioria dos critérios dessa técnica utiliza uma representação do programa conhecida como grafo de fluxo de controle. Um grafo de fluxo de controle é um grafo orientado, com um único nó de entrada e um único nó de saída, no qual cada vértice representa um bloco de comandos que são sempre executados seqüencialmente e cada aresta representa uma transferência de controle entre esse blocos. O grafo de fluxo de controle permite escolher os componentes que devem ser executados, caracterizando assim o teste estrutural.

Os critérios de teste estrutural baseiam-se em diferentes tipos de estruturas para determinar quais partes do programa devem ser executadas. Esses critérios podem ser classificados em:

$>$ Critérios Baseados em Complexidade: utilizam informações sobre a complexidade do programa para derivar os requisitos de teste. Um critério bastante conhecido é o Critério de McCabe, que utiliza a complexidade ciclomática para derivar os casos de teste.

$>$ Critérios Baseados em Fluxo de Controle: utilizam características de controle da execução do programa, como comandos ou desvios, para determinar quais estruturas são necessárias. Os critérios mais conhecidos dessa classe são Todos-Nós, TodosRamos e Todos-Caminhos (Pressman, 1992).

$>$ Critérios Baseados em Fluxo de Dados: informações sobre o fluxo de dados do programa são utilizadas para determinar os casos de teste. Esses critérios envolvem a identificação de declaração, definição e uso de variáveis. Alguns critérios dessa classe são Potenciais-Usos, Todas-Definições e Todos-Usos (Maldonado, 1991; Rapps \& Weyuker, 1982; Rapps \& Weyuker, 1985).

\subsection{Técnica de Teste Baseada em Erros}

A técnica de teste baseada em erros utiliza informações sobre os tipos de erros mais freqüentes no processo de desenvolvimento de software. A ênfase da técnica está nos erros que o programador pode cometer durante o desenvolvimento e nas abordagens que podem ser usadas para detectar sua ocorrência. Alguns critérios desta técnica são: Semeadura de Erros (Error Seeding) e Análise de Mutantes (Mutation Analysis).

O critério Semeadura de Erros se baseia na inserção de erros artificiais no programa que será testado e classificação dos erros em artificiais ou naturais, no momento em que forem encontrados na fase de teste. Com isso, espera-se estimar o número de erros restantes no programa por meio da relação entre o número de erros naturais e erros artificiais descobertos.

O critério Análise de Mutantes utiliza um conjunto de programas com pequenas modificações, obtidos a partir de determinado programa $P$, para avaliar quando o conjunto de casos de teste $T$ é adequado para o teste de $P$. Esses programas modificados são chamados de mutantes. O objetivo deste critério é encontrar um conjunto de casos de teste que consiga revelar as diferenças de comportamento existentes entre $P$ e seus mutantes não equivalentes (Vincenzi et al., 1997).

\subsection{Técnica de Teste Baseado em Máquinas de Estados Finitos}

O Teste Baseado em Máquinas de Estados Finitos utiliza uma máquina de estados finitos para modelar o comportamento do sistema ou unidade que será testada. 
Tendo criado a MEF, os casos de teste serão as seqüências de eventos válidas da MEF. No entanto, existem vários critérios de geração de seqüências de teste baseadas em máquinas de estados finitos, cada um deles exige que a MEF satisfaça algumas propriedades, além de selecionar diferentemente as seqüências de eventos válidas.

Fujiwara et al. afirmam que um critério de geração de sequiências de teste tem como objetivo oferecer a possibilidade de executar atividades de teste e validação em sistemas modelados de acordo com alguma técnica de modelagem, de forma sistemática, usando procedimentos bem definidos para a geração dessas sequiências e fazendo com que os produtos se apresentem de forma mais segura e com maior qualidade (Fujiwara et al., 1991).

Esses critérios de geração de seqüências de teste baseadas em MEF devem apresentar as seguintes características:

$>$ um número pequeno de sequiências; cada sequiência tendo uma aplicação rápida e de fácil execução;

$>$ as seqüências de teste devem identificar todas as falhas que a especificação possa conter.

O Método W é um critério de geração de seqüências de teste baseado em máquinas de estados finitos, descrito a seguir (Chow, 1978). Assim como o W, podem ser encontrados na literatura os critérios DS (Gönenç, 1970), UIO (Sabnani \& Dahbura, 1988) e Wp (Fujiwara et al., 1991).

\section{Critério W}

Este critério proposto por Chow permite a geração de sequiências de teste baseadas na MEF que modela o sistema (Chow, 1978). O critério checa somente a estrutura de controle do projeto e não exige uma especificação executável. Para que este critério possa ser aplicado a MEF deve ser completamente especificada, determinística, minimal, máquina de Mealy, com um estado inicial fixo e todos os estados devem ser alcançáveis a partir do estado inicial. A definição dessas propriedades pode ser encontrada em (Nakazato et al., 1994a). Para aplicar o critério W deve-se encontrar um conjunto de caracterização W, gerar a árvore de teste e gerar as seqüências de teste.

O conjunto de caracterização é formado por seqüências de entrada que podem distinguir entre os comportamentos de todos os pares de estados em um autômato minimal (Chow, 1978). Para o autômato da Figura 2.5 um conjunto de caracterização possível é $\left\{/{ }^{*}\right\}$; o comportamento dos estados do autômato para esse conjunto é mostrado na Tabela 2.2. A máquina de estados finitos apresentada 'na Figura 2.5 representa um sistema de impressão de comentários na linguagem de programação Pascal, o símbolo $v$ representa qualquer caractere com exceção de "/ "e "*".

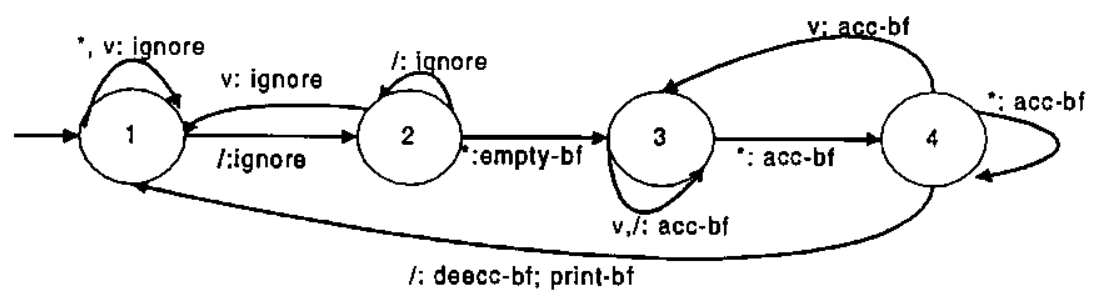

Figura 2.5 - Diagrama de Transição de Estados 
A árvore de teste é gerada da seguinte maneira: para cada transição fora do nó raiz um ramo é desenhado para o nó que representa um estado resultante. Isso é repetido para cada nó de estado resultante sem que este tenha sido previamente desenhado e não seja um estado final. A árvore de transição obtida para a MEF da Figura 2.5 é apresentada na Figura 2.6.

No caso mais simples, o último passo do projeto de teste é transcrever as sequiências de teste da árvore de teste. Cada ramo parcial ou completo da árvore concatenado com o conjunto de caracterização é um caso de teste. Para a aplicação dessas sequiências sobre a MEF da Figura 2.5 é necessário que para cada seqüência aplicada a máquina retorne ao estado inicial.

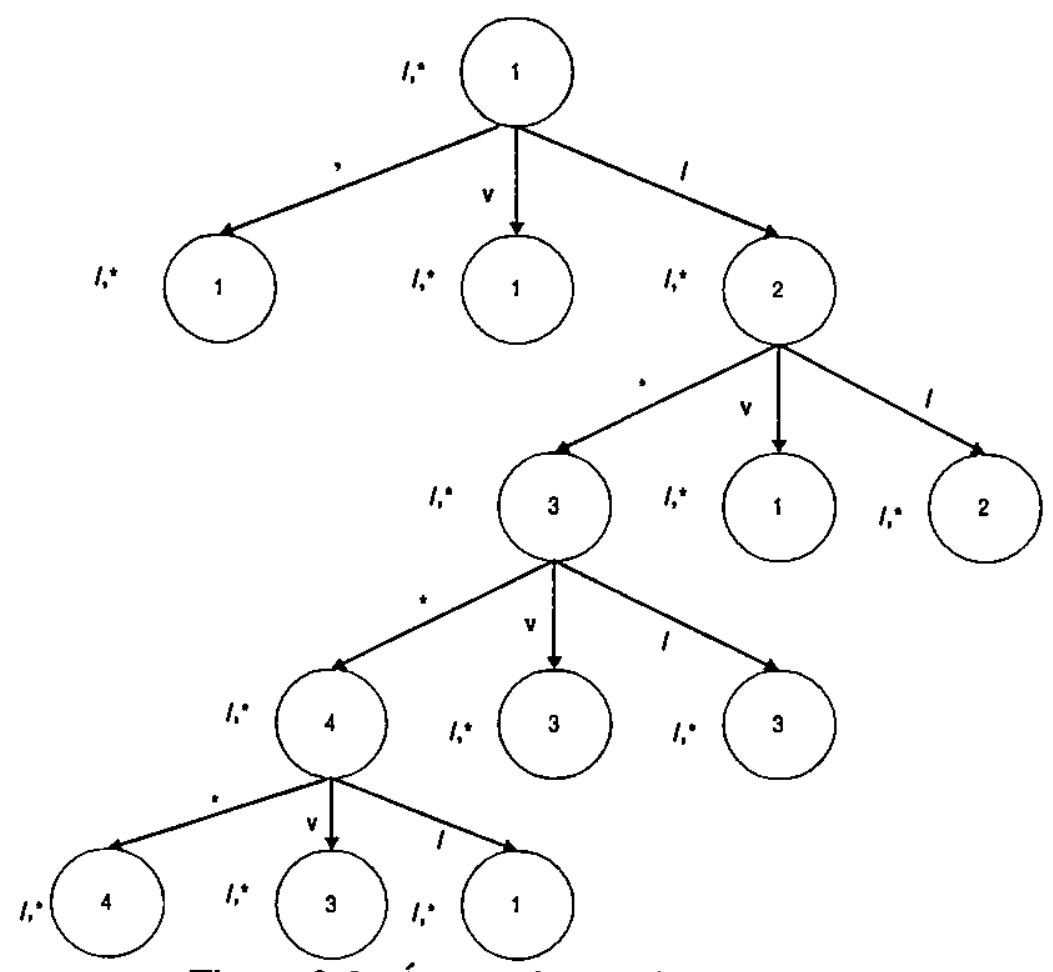

Figura 2.6 - Árvore de transição

Tabela 2.2 - Respostas dos Estados para o conjunto de caracterização (Chow, 1978)

\begin{tabular}{|c|c|c|}
\hline Estado Entrada & $/$ & $*$ \\
\hline 1 & Ignore & Ignore \\
\hline 2 & Ignore & Empty-bf \\
\hline 3 & Acc-bf & Acc-bf \\
\hline 4 & Deacc-bf, print-bf & Acc-bf \\
\hline
\end{tabular}

As sequiências de teste geradas com o conjunto de caracterização $\{/, *\}$ para a máquina de estados apresentada na Figura 2.5 são as seguintes:

$$
\begin{aligned}
& \bullet\left\{/,^{*}\right\} \\
& \bullet * .\{/, *\} \\
& \bullet \mathrm{v} .\{/, *\} \\
& \bullet / .\left\{/,{ }^{*}\right\} \\
& \bullet / * * / .\{/, *\}
\end{aligned}
$$

$\bullet /{ }^{*} .\left\{/{ }^{*}\right\}$

$\bullet / \mathrm{v} .\{/, *\}$

$\bullet / / .\{/, *\}$

- /**. $\{/, *\}$ $\bullet / * \mathrm{v} .\{/, *\}$

$\bullet / \%,\{/, *\}$

$\bullet / * *,\{/, *\}$

- /**v. $\{/, *\}$ 


\subsubsection{Problemática de Teste 00}

Um dos objetivos da Engenharia de Software é produzir software de alta qualidade. Para isso são necessárias atividades de garantia de qualidade, tais como verificação e validação, durante todo o processo de desenvolvimento. A validação checa se o sistema que está sendo construído satisfaz aos requisitos do usuário. A verificação visa a verificar se o software está sendo construído corretamente. Dentre as técnicas de verificação e validação, a atividade de teste é a mais utilizada; essa atividade visa a revelar a presença de defeitos do sistema. Esta seção considera a aplicabilidade de técnicas tradicionais de verificação e validação ao desenvolvimento de software OO, especialmente a atividade de teste de software orientado a objetos.

Um dos principais problemas do teste de software é determinar um critério de seleção de um conjunto de casos de teste. Deve-se minimizar o esforço em produzir os testes em termos de custo e tempo, minimizar o número de testes produzidos, minimizar o tempo e o custo despendidos com a execução, maximizar o número de erros revelados e maximizar a evidência de que o código foi testado (Smith \& Robson, 1992).

Um outro problema é como demonstrar que o processo de teste foi executado e que ele pode revelar erros. Considerando que testar exaustivamente $100 \%$ de um software é uma tarefa, em geral, impraticável em função de tempo e custo, vários critérios e técnicas como Semeadura de Erros, Análise de Mutantes e Estatísticas de Erros tem sido investigados.

Alguns dos trabalhos sobre teste de sistemas $O O$ propõem estratégias de teste com a finalidade de estender as técnicas e critérios do teste de programas procedimentais para programas orientados a objetos. Entretanto, encontram-se diversos problemas para que as mesmas técnicas e critérios sejam utilizadas, principalmente pelo fato de sistemas orientados a objetos poderem ser considerados, do ponto de vista do testador, em diferentes níveis de abstração. Esses níveis são definidos abaixo de acordo com Smith e Robson (Smith \& Robson, 1992):

$>$ o nível algorítmico considera o código escrito do método, concentrando-se na manipulação de dados dentro do método, o que é basicamente procedimental;

$>$ o nível de classe consiste na interação entre os métodos e os dados que esses encapsulam;

$>$ o nível de cluster considera a interação entre grupos de classes que cooperam entre si, também pode ser considerado como o relacionamento entre classes que pertencem a uma mesma hierarquia de herança (simples ou múltipla);

$>$ o nível de sistema contém o código de todas as classes, das rotinas independentes e do programa principal necessários para executar o sistema.

Nos níveis de classe e de cluster os objetos e as classes contêm métodos e estruturas de dados que fazem acesso e atualizam o estado dos objetos. Os objetos e classes de um modelo OO contêm rotinas e possíveis estruturas de dados que contêm o estado de um objeto. Considerando que a ordem de invocação das operações não é especificada explicitamente quando um objeto é criado, não há uma sequiência do tipo entrada, processamento e saída no qual métodos de teste possam ser adaptados. As técnicas de teste de software procedimental nem sempre podem ser diretamente aplicáveis em programas OO, como acontece com as técnicas estruturais, pois é difícil analisar o fluxo de controle e o fluxo de dados desses programas. Para o teste de classes, foi verificado que muitas das abordagens tradicionais destinadas aos testes baseados em 
especificações são incompletas, pois não levam em conta o estado dos objetos. O problema de teste pode ser visto como a busca da ordem correta necessária para descobrir o erro (Smith \& Robson, 1992).

É necessário considerar as características de herança no teste orientado a objetos, pois a herança é o principal mecanismo de reuso de software, podendo uma classe ter simplesmente uma definição idêntica à classe pai ou acrescentar alguma mudança ou novos métodos e atributos. Assim o teste de uma classe filho pode ser simplificado, sempre que possível, pelo uso de casos de testes da classe pai mais alguns casos que exercitem as modificações.

Berard aponta que existem algumas complicações para o teste de integração em um ambiente orientado a objetos. Por exemplo, em produtos de software procedimentais sempre existem as hierarquias de invocações (módulo A chama módulo $\mathrm{B}$, que eventualmente retoma o controle para o módulo $\mathrm{A}$ ). Os produtos de software $\mathrm{OO}$ não suportam uma hierarquia de invocação tão rigorosa, ou seja, o objeto A pode interagir diretamente com o objeto $B$, sem necessariamente ter que passar por um objeto intermediário (de controle). A falta de um módulo de controle de invocação dificulta a aplicação das técnicas de teste de integração existentes, já que essas assumem a existência desse módulo (Berard, 1992).

Segundo Harel, a verificação da consistência e completitude de um sistema não previne a ocorrência de erros lógicos (Harel, 1992). Portanto, é importante avaliar a satisfação dos requisitos exigidos para o sistema. Uma opção para a validação de sistemas orientados a objetos seria a modelagem do sistema ou de suas classes como uma MEF ou um Statecharts e a execução do modelo gerado para avaliar o comportamento obtido. A execução do modelo tem como prérequisito a disponibilidade de uma semântica formal que contenha informação suficiente para definir com precisão o estado do sistema a cada passo da execução. Dessa forma, Statecharts são validados frequientemente por meio das diversas formas de simulação que foram propostas baseadas na necessidade de apoio às atividades de teste de especificações em Statecharts: simulação interativa, que com o apoio de uma ferramenta automatizada, possibilita que o usuário represente o meio ambiente do sistema gerando, passo a passo, eventos que provocam alteração no mesmo; simulação em batch, em que a simulação é realizada de modo iterativo e não mais interativo, com base em um conjunto de eventos pré-determinados; simulação programada, que permite analisar o modelo sob condiçōes geradas aleatoriamente, e onde podem ser definidos pontos de modo que a ferramenta execute determinadas ações quando ocorrem situações específicas; simulação exaustiva, que teoricamente consiste em executar o modelo gerando-se todos os possíveis eventos extemos e todas as alterações nos valores das condições e variáveis. Essas formas de simulação de Statecharts podem ser aplicadas às máquinas de estados finitos, pois os Statecharts são modelos formados por MEFs. Portanto, uma MEF pode ser considerada como um Statecharts que possui somente um componente.

As diversas abordagens de simulação são consideradas formas de validação de Sistemas Reativos em geral e necessitam de ferramentas para que possam ser utilizadas (Harel, 1992). Uma questão relevante para a atividade de teste que não é considerada por essas formas de validação é o aspecto de cobertura. Esse aspecto foi abordado em relação às especificações baseadas em MEF por Petrenko e Bochmann, que salientam a. relevância de pesquisas nessa direção, já que com a análise de cobertura a qualidade da atividade de teste pode ser quantificada (Petrenko \& Boochmann, 1996). 
Considerando os problemas abordados nesta seção, a próxima seção apresenta algumas das abordagens de teste de software orientado a objetos propostas na literatura.

\subsubsection{Teste \& OO}

Existem várias pesquisas que procuram definir estratégias e critérios de teste para sistemas orientados a objetos. Algumas tentam estabelecer regras de gerenciamento da atividade de teste e outras propõem ferramentas de teste. Muitos destes trabalhos têm adaptado técnicas e critérios de teste já existentes às novas abordagens propostas.

Nesta seção são apresentados: os axiomas de teste propostos por Weyuker (Weyuker, 1986; Weyuker, 1988) e algumas abordagens de teste de software orientado a objetos. Dentre as abordagens apresentadas encontram-se o Critério de Teste Baseado em Estados (Binder, 1995a) e a Estratégia de Teste Incremental Hierárquica que aproveita a história do teste da superclasse para reduzir os testes necessários para a subclasse (Harrold et al., 1992). Nesta seção são apresentados ainda a Estratégia de Teste FREE (Binder, 1996a) que, assim como o Critério Teste Baseado em Estados, baseia-se em Máquinas de Estados Finitos para gerar o conjunto de casos de teste, a Técnica de Teste de Fluxo de Dados para Classes (Harrold \& Rothermel, 1994), os Cenários de Teste (Vieira \& Travassos, 1998) e a Técnica de Teste Modal (Binder, 1996b). O Critério baseado em Estados é parte da estratégia de teste FREE.

\subsubsection{Axiomas de Teste}

Perry e Kaiser discutiram os onze axiomas propostos por Weyuker, que checam a adequação dos conjuntos de casos de teste (Perry \& Kaiser, 1990; Weyuker, 1986; Weyuker, 1988). Nesse artigo eles aplicaram os axiomas às características de linguagens $O O$, como encapsulamento de dados, sobreposição de métodos herdados e herança múltipla, para provar que os métodos herdados devem ser retestados na maioria dos contextos de reuso. Os onze axiomas são descritos a seguir.

$1^{\circ}$ Axioma - Aplicabilidade: Para todo programa, existe um conjunto de teste adequado.

$2^{\circ}$ Axioma - Aplicabilidade não-exaustiva: Há um programa $\mathrm{P}$ e um conjunto de teste $\mathrm{T}$ tal que $\mathrm{P}$ é adequadamente testado por T, e T não é um conjunto de teste exaustivo.

$3^{\circ}$ Axioma - Monotonicidade: Se T é adequado para $\mathrm{P}, \mathrm{e} \mathrm{T}$ é um subconjunto de T' então T' é adequado para $P$.

$4^{\circ}$ Axioma - Conjunto Vazio Inadequado: $O$ conjunto vazio não é um conjunto de teste adequado para algum programa.

$5^{\circ}$ Axioma - Antiextensionalidade: Se existirem dois algoritmos diferentes que computem a mesma função, um conjunto de teste adequado para um algoritmo não é necessariamente adequado para o outro. Isso mostra que ao se substituir um método herdado por um método definido localmente que realize a mesma função, o conjunto de casos de teste para o método herdado não é necessariamente adequado para o método definido localmente.

$6^{\circ}$ Axioma - Mudança geral múltipla: Se dois programas possuem o mesmo formato, um conjunto de casos de teste que seja adequado para um não é adequado para o outro. Dois 
programas têm o mesmo formato se um pode ser transformado no outro por uma mudança simples de um ou mais operadores relacionais para outros operadores relacionais, de constantes para outras constantes e de operadores aritméticos para outros operadores aritméticos. Esse axioma mostra que quando os mesmos itens são herdados de ancestrais diferentes (via mudança de ordem de precedência em um esquema de herança múltipla) conjuntos de casos de teste diferentes são necessários.

$7^{\circ}$ Axioma - Antidecomposição: Algo que for testado em um contex to deve ser retestado se o contexto mudar. Por exemplo, supõe-se que um método seja testado completamente dentro do contexto de uma classe, que seja criada uma especialização (uma subclasse) baseada nessa classe e que a especialização herde o método testado na generalização (na superclasse). Mesmo que o método tenha sido testado na superclasse, não pode ser garantida sua adequação dentro do contexto da subclasse, a não ser que esse método já tenha sido testado nesse contexto.

$8^{\circ}$ Axioma - Anticomposição: $O$ teste adequado de cada unidade isoladamente é insuficiente para testar adequadamente o programa inteiro (integrado). Supondo que seja mudada a implementação de um objeto, mas que seja mantida a sua interface, devem ser retestadas todas as unidades dependentes desse objeto. Neste caso, as unidades dependentes são subclasses e unidades que referenciem direta ou indiretamente o objeto modificado.

$9^{\circ}$ Axioma - Renomeação: Seja $\mathrm{P}$ uma renomeação de Q. Então $\mathrm{T}$ é adequado para $\mathrm{P}$ se e somente se $\mathrm{T}$ é adequado para $\mathrm{Q}$.

$10^{\circ}$ Axioma - Complexidade: Para todo $n$ existe um programa $\mathrm{P}$ tal que $\mathrm{P}$ é adequadamente testado por um conjunto de teste de tamanho $n$, mas não é adequadamente testado por um conjunto de teste de tamanho $n-1$.

$11^{\circ}$ Axioma - Cobertura de Declaração: Se $\mathrm{T}$ é adequado para $\mathrm{P}$, então $\mathrm{T}$ faz com que toda declaração executável de $P$ seja executada.

Os quatro primeiros axiomas são aplicáveis a todos os programas independentemente da linguagem de programação ou do paradigma utilizado para a implementação e se aplicam tanto no teste baseado em especificação como no teste baseado em implementação. $O$ maior interesse está nos axiomas de: antiextensionalidade, mudança geral múltipla, antidecomposição e anticomposição. Eles podem ser considerados axiomas negativos, pois expõem a inadequação e não a garantia da adequação.

\section{Encapsulamento nas Classes}

Nesta e nas duas próximas subseções são apresentados os pontos discutidos por Perry e Kaiser em relação a encapsulamento de dados, sobreposição de métodos herdados e herança múltipla, respectivamente (Perry \& Kaiser, 1990).

Se um programador muda a implementação de uma unidade sem modificar sua interface, outras unidades não deveriam ser afetadas por essas mudanças. No entanto, de acordo com o axioma de anticomposição é necessário retestar tanto a unidade modificada como todas as suas unidades dependentes. Isso significa que o teste de integração é sempre necessário. 
Quando uma superclasse é modificada é necessário retestar todas as suas subclasses, já que estas herdam os métodos da superclasse. O que não se espera é o que afirma o axioma de antidecomposição: quando uma nova subclasse é adicionada, ou uma subclasse existente é modificada, deve-se retestar os métodos herdados de cada uma das suas superclasses ancestrais. Um exemplo desse caso é ilustrado pela Figura 2.7. Inicialmente tem-se a classe $C$, cujo método $\mathrm{J}$ foi testado adequadamente. É então criada a classe $\mathrm{D}$, que é subclasse de $\mathrm{C}$ e não modifica J. Se o método $\mathrm{J}$ não for retestado no contexto de $\mathrm{D}$ o erro em relação à iniciação da instância da variável $v$ não será detectado.

O único caso que não exige o reteste de métodos herdados da superclasse se dá quando é adicionada uma nova subclasse que é uma extensão pura da superclasse. Isto é, novas instâncias de variáveis e novos métodos são adicionados mas não há interações entre as novas instâncias de variáveis e métodos e alguma instância de variável e métodos herdados.

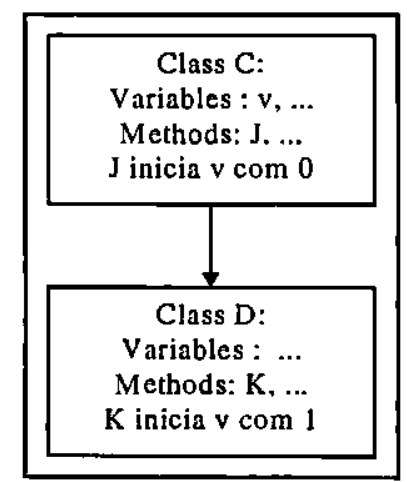

Figura 2.7 - Erro de iniciação da variável v (Perry \& Kaiser, 1990)

\section{Sobreposição de Métodos}

Quase todas as linguagens orientadas a objetos permitem trocar um método herdado por um método localmente definido com o mesmo nome, embora algumas exijam que o método tenha a mesma interface.

A sobreposição de métodos exige reteste e um novo conjunto de casos de teste. Isso é expressado pelo axioma de antiextensionalidade: embora os dois métodos computem semanticamente funções próximas, um conjunto de teste adequado para um não é necessariamente adequado para o outro. Um exemplo é encontrado na Figura 2.8, no qual a classe $C$ tem uma subclasse $D$ e um método $M$ definido em $C$ mas não em $D$, sendo que $M$ já foi adequadamente testado. Se a classe $D$ for modificada para possuir seu próprio método $M$ que é similar a C.M, a classe $\mathrm{D}$ deverá ser testada novamente. $\mathrm{O}$ axioma de antiextensionalidade afirma que os dados de teste usados anteriormente podem não ser adequados agora. Então é necessário desenvolver novos casos de teste por dois motivos:

1. teste baseado em implementação considera detalhes do código do método, portanto pode ser que nem todos os ramos ou caminhos de $M$ sejam percorridos no novo método utilizando-se os casos de teste anteriores;

2. é possível que uma sobreposição de métodos altere não somente a estrutura interna do método inas também a especificação funcional. 


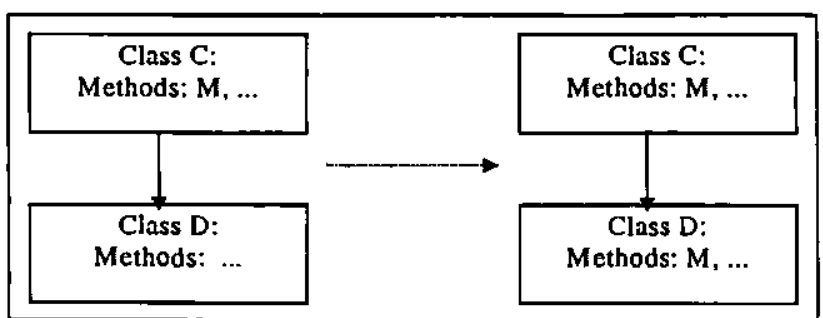

Figura 2.8 - Sobreposição de Métodos (Perry \& Kaiser, 1990)

\section{Herança Múltipla}

Algumas linguagens suportam herança múltipla, em que cada classe pode ter um número arbitrário de superclasses. O problema da herança múltipla pode ocorrer quando o mesmo componente pode ser herdado por caminhos ancestrais diferentes. Uma solução para este problema é definir uma ordem de precedência que lineariza o conjunto de ancestrais de forma a haver uma seleção única, evitando conflitos quando há métodos herdados (Perry \& Kaiser, 1990). Esta solução causa mudanças sintáticas muito pequenas que tem consequiências semânticas importantes. No entanto, o axioma da mudança geral múltipla afirma que programas sintaticamente similares usualmente requerem conjuntos de testes diferentes.

A Figura 2.9 apresenta a classe D com superclasses $C$ e $B$ (a linguagem impõe a ordem de precedência $\mathrm{C}, \mathrm{B})$. $\mathrm{O}$ método $\mathrm{M}$ é definido por $\mathrm{C}$ e $\mathrm{B}$, mas não por $\mathrm{D}$. A classe $\mathrm{D}$ é então mudada tal que a ordem das superclasses seja $B$ e $C$ (ordem de precedência $B, C$ ). Não só a classe D deve ser retestada já que agora usa B.M em vez de C.M mas um novo conjunto de teste deve ser usado, já que os métodos C.M e B.M podem não ser sintática e semanticamente similares.

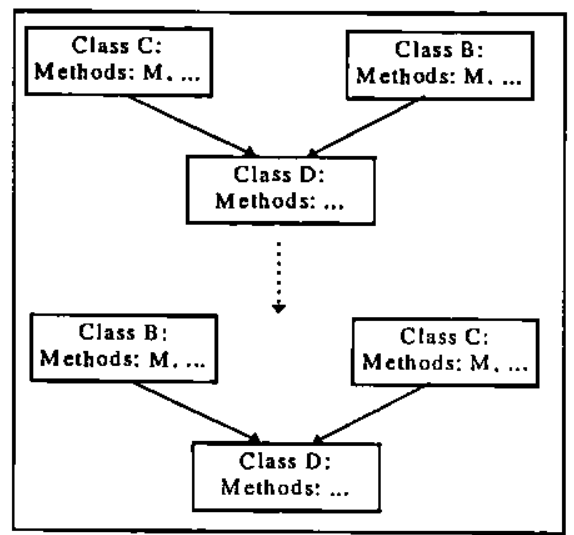

Figura 2.9 - Ordem de Precedência de Classes (Perry \& Kaiser, 1990)

\subsubsection{Abordagens de Teste de Software Orientado a Objetos}

Considerando os problemas encontrados no teste de software $\mathrm{OO}$ e a conseqüente necessidade de novas técnicas de teste ou adaptação das técnicas existentes, muitos pesquisadores tem proposto novas formas de se testar os produtos de software orientado a objetos. Algumas das abordagens incorporam procedimentos de técnicas e critérios de teste de software procedimental e adequam esses procedimentos ao contexto de orientação a objetos. Essa subseção apresenta algumas das abordagens de teste de software OO encontradas na literatura. 


\subsection{Critério Baseado em Estados}

O teste baseado em estados permite derivar casos de teste tendo como base a modelagem de uma classe como uma máquina de estados. Os métodos resultam em transições de estados. $\mathrm{O}$ modelo de estados define as seqüências de transições permitidas, por exemplo, uma instância deve ser criada antes que ela possa ser alterada ou removida. Casos de teste são gerados para executar cada uma das transiçōes permitidas (Binder, 1994).

Binder afirma que os sistemas orientados a objetos são bem adequados ao teste baseado em estados por duas razões (Binder, 1994):

1. O comportamento da classe é facilmente modelado por máquinas de estados finitos. Os métodos da classe devem ser usados seqüencialmente. Pode haver um número infinito de possíveis sequiências de ativação de métodos. Algumas podem ser proibidas pela especificação ou podem causar falhas na implementação.

2. Um modelo de software usado para teste deve auxiliar na detecção de falhas. O teste baseado em estados é um método direto para desenvolver conjuntos de casos de testes que podem revelar erros de comportamento individual (classes) e coletivo (sistema integrado).

As classes são projetadas para aceitar certas seqüências de mensagens e rejeitar outras. Elas podem responder diferentemente a conjuntos particulares de valores encapsulados caracterizando o seu comportamento. O comportamento de uma classe pode ser controlado por valores encapsulados, por sequiências de mensagens ou ambos. É necessário testar todas as possíveis combinações para garantir que o comportamento correto é produzido para todas elas.

O teste baseado em estados pode ser usado para verificar o comportamento de uma classe com poucos casos de teste. Um estado pode ser definido por um subconjunto de valores combinacionais que compartilham uma mesma propriedade de interesse (Binder, 1995a).

Binder afirma que as diversas restrições de comportamento de uma classe podem ser modeladas por um diagrama de transição de estados (Binder, 1995a). Para modelar pré e póscondições basta colocar expressões condicionais nas transições. Se o prefixo da expressão for o nome de um método, ela é uma pré-condição. Se o sufixo da expressão for um nome de método ela é uma pós-condição. A geração das sequiências de teste é feita de acordo com o critério W, apresentado anteriormente.

Na Figura 2.10 é apresentada uma máquina de transição de estados para a classe Conta, que representa uma conta bancária. Os requisitos para esta conta são:

$>$ Permitir transações para abrir, debitar, creditar, relatório de saldo, bloquear/ desbloquear, desativar, liquidar e fechar uma conta.

$>$ Uma conta aberta deve permitir todas as transações menos a transação liquidar.

$>$ Quando o saldo está negativo, a conta está negativa (sem fundos).

$>$ Uma conta negativa só pode aceitar consulta de saldo, créditos e débitos de taxas do banco.

$>$ Uma conta bloqueada só pode relatar seu saldo ou ser desbloqueada.

$>$ Uma conta sem atividades por 5 anos fica inativa e só pode aceitar a transação liquidar. 
Para ser fechada uma conta deve ter saldo igual a zero. Depois de fechada nenhuma transação é válida.

Com o modelo de estados (MEF), o primeiro passo no projeto de casos de teste é preparar a árvore de transição. Como já foi mencionado na subseção 3.1.1.4, para cada transição fora do nó raiz um ramo é desenhado para o nó que representa um estado resultante, e esse processo é repetido para cada nó de estado resultante sem que este tenha sido previamente desenhado e que ele não seja um estado final. A árvore de transição obtida para a MEF da Figura 2.10 é apresentada na Figura 2.11.

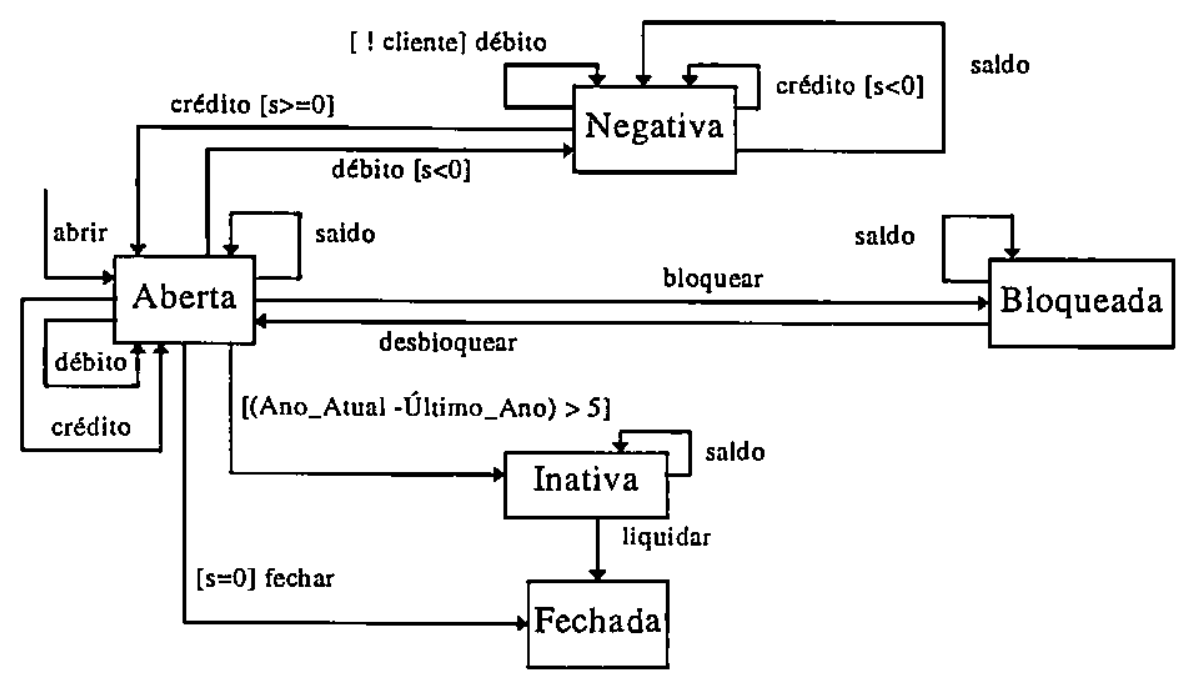

Figura 2.10 - Diagrama de Transição de Estados para a classe Conta (Binder, 1995a)

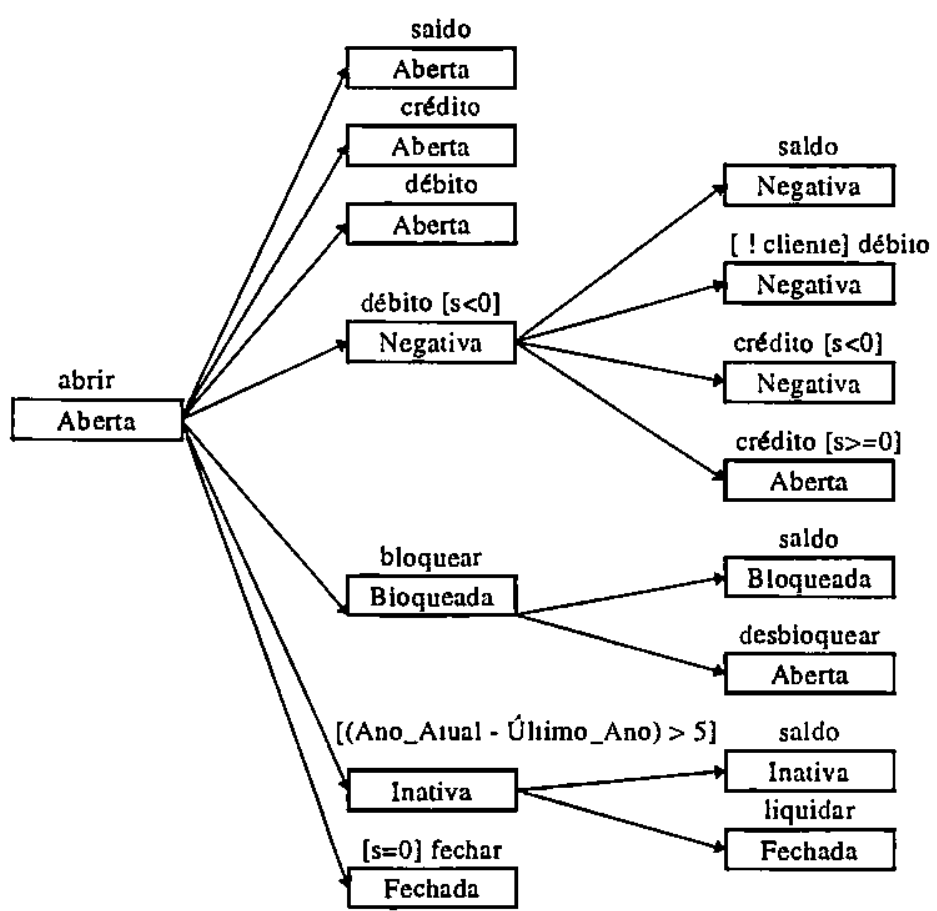

Figura 2.11 - Árvore de Transição para a classe Conta (Binder, 1995a) 


\subsection{Estratégia de Teste Incremental Hierárquica}

Harrold et al. propuseram uma estratégia que visa a esquematizar a atividade de teste de software $O O$ utilizando a relação de herança para diminuir o esforço de teste (Harrold et al., 1992). Esta estratégia de teste de classe explora a natureza hierárquica da relação de herança para testar grupos de classes reusando informações de teste da classe pai para conduzir o teste da subclasse. O principal benefício desta estratégia é que a subclasse não é totalmente testada, pois a história de teste da classe pai é reusada no projeto de casos de teste da subclasse, consequientemente o tempo para projetar os casos de teste e o tempo para testar a subclasse é menor.

A proposta é testar inicialmente a superclasse testando cada método individualmente e então testar a interação entre os métodos. Os casos de teste e as informações da execução são salvas em uma história de teste (testing history). Então, quando uma subclasse é definida a história do teste de seu pai, a definição do modificador e o mapeamento hereditário da linguagem de implementação são utilizados para determinar quais atributos devem ser testados (ou retestados) na subclasse e quais casos de testes da classe pai podem ser reutilizados. Segundo Harrold et al. essa estratégia é hierárquica por ser guiada pela ordem da relação de hereditariedade, e é incremental porque usa o resultado obtido em um nível de teste na hierarquia para reduzir o esforço necessário em níveis subsequientes (Harrold et al., 1992).

\section{Atributos inseridos pela Herança}

Com o mecanismo de herança, uma subclasse pode ser definida como um modificador que altera as características (atributos e métodos) da classe pai. A Figura 2.12 ilustra a herança como uma técnica de modificação incremental que altera a classe pai $\mathrm{P}$ acrescentando um modificador $\mathrm{M}$ e gera uma classe resultante $\mathrm{R}$.

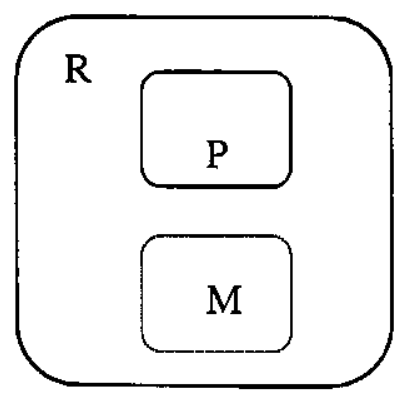

Figura 2.12 - Técnica de Modificação Incremental (Harrold et al., 1992)

O projetista da classe controla a especificação do modificador enquanto a herança controla a combinação do modificador com a classe pai para obter a classe resultante. Harrold et al. afirmam que essa especificação pode conter vários tipos de atributos que alteram a superclasse (Harrold et al., 1992). Esses tipos de atributos são:

-Atributo Novo: A é um atributo definido em $\mathrm{M}$ e não em $\mathrm{P}$ ou $\mathrm{A}$ é um atributo de função membro (método) em $\mathrm{M}$ e $\mathrm{P}$ mas a lista de argumentos de A é diferente em $\mathrm{M}$ e $\mathrm{P}$. Nesse caso, A é limitado ao atributo definido na classe resultante $R$ mas não em $P$.

-Atributo Recursivo: o atributo A é definido em P mas não em M. Nesse caso A é limitado ao atributo definido em $\mathrm{P}$ e está disponível em $\mathrm{R}$. 
-Atributo Redefinido: A é definido em $\mathrm{P}$ e M e a lista de argumentos de A é a mesma em $P$ e M. Nesse caso A é limitado à definição de atributo em M, que bloqueia a definição do atributo em $P$.

-Atributo Virtual-Novo: A é especificado em M mas sua implementação pode estar incompleta para permitir posterior definição ou A é especificado em $\mathrm{M}$ e $\mathrm{P}$ e sua implementação pode estar incompleta em $P$ para permitir posterior definição, mas a lista de argumentos de A é diferente em M e P. Nesse caso A é limitado ao atributo definido em $R$ mas não em $P$.

-Atributo Virtual-Recursivo: A é especificado em $P$ mas sua implementação pode estar incompleta em $P$ para permitir posterior definição e A não está definido em $M$. Nesse caso A é limitado ao atributo definido na classe $P$ e está disponível na classe resultante $R$.

-Atributo Virtual-Redefinido: A é especificado em P mas sua implementação pode estar incompleta para permitir posterior definição e A é definido em $\mathrm{M}$, mantendo algumas características de A definido em P. Nesse caso A é limitado ao atributo definido em $\mathrm{M}$ que bloqueia os pontos em comum entre as definições.

A Figura 2.13 exemplifica alguns tipos de atributos.

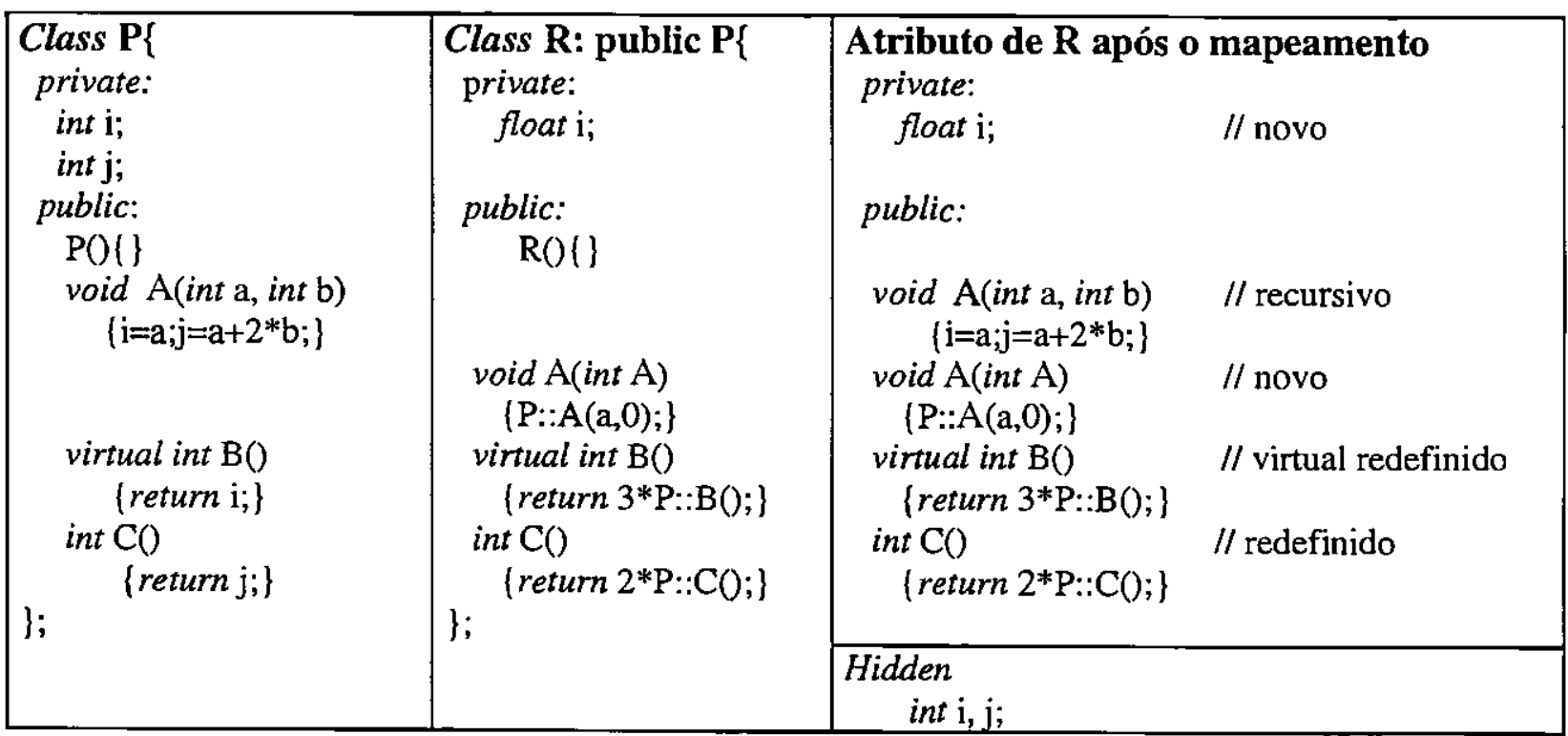

Figura 2.13 - Classe P à esquerda, Especificação (centro) e Atributos (à direita) da subclasse R (Harrold et al., 1992)

A relação de herança determina a visibilidade, a disponibilidade e o formato dos atributos de $P$ em R. Uma linguagem pode permitir mais que um mapeamento de herança, permitindo a especificação de um parâmetro que determina qual mapeamento deve ser usado para uma definição particular. É o caso, por exemplo, em $\mathrm{C}++$, das definições public e private como parte da especificação do relacionamento de herança que determina a visibilidade do atributo em subclasses.

\section{Teste da Classe Base}

É evidente a importância de testar muito bem as classes base pois, pela herança, um erro pode ser propagado às subclasses definidas a partir delas. No teste da classe base usam-se técnicas tradicionais de teste de unidade para testar individualmente os métodos da classe. $O$ teste é feito tanto baseado em especificação quanto em implementação. Assim, a história do teste consiste em uma tripla (m,(TSi,teste?),(TPi,teste?)) em que m é o método, TSi é o conjunto de 
teste baseado em especificação e TPi é o conjunto de teste baseado em programa, e 'teste?' indica se o teste deve ser executado. O campo "teste?" pode ter três respostas diferentes, $\mathrm{S}$ indica que todo o conjunto de testes é reusado, $\mathrm{P}$ indica que somente os casos de teste identificados como partes afetadas do teste da subclasse são reusados e $\mathrm{N}$ indica que o conjunto de testes não é reusado.

Além de testar cada método, interações entre eles devem ser testadas (interações intraclasse). Deve-se testar também chamadas inter-classes, ou seja, funções que chamam funções membro de outras classes. O teste intra-classe é conduzido pelo grafo da classe, em que cada nó representa um método e cada arco representa a mensagem trocada por eles. Para testar a classe base, essa estratégia permite utilizar teste baseado em especificação e teste baseado em implementação. Assim, a história deve conter o nó raiz do grafo da classe representando um subgrafo de interações entre métodos. A história desse tipo de teste é representada pela seguinte tripla (mi,(TISi,teste?),(TIPi,teste?)), em que m corresponde ao nó raiz do subgrafo, TISi é o conjunto de testes de integração baseado em especificação, TIPi é conjunto de testes de integração baseado no programa, e "teste? " indica se o conjunto de teste deve ser executado ou não.

Já o teste inter-classes é conduzido pela interação de classes que resulta da interação de um método de uma classe com um método de outra classe. Esse tipo de interação ocorre quando um método em uma classe é passado por uma instância de outra classe como um parâmetro e então envia uma mensagem àquela instância, ou quando uma instância de uma classe é parte da representação de outra classe e então manda aquela instância como uma mensagem. A estratégia de teste é a mesma utilizada para interações intra-classes.

A Figura 2.14-a mostra a declaração de uma classe abstrata Forma que permite a criação de classes derivadas. A Figura 2.14-b apresenta o grafo da classe declarada na Figura 2.14-a na qual as setas contínuas representam as mensagens intra-classe $\mathrm{e}$ as setas pontilhadas as mensagens inter-classes.

A classe Forma define vários métodos que descrevem o comportamento de uma figura e inclui duas funções membro virtuais, área() e desenhar(), que contribuem para uma interface comum para todas as classes na estrutura de hereditariedade. A função desenhar() é uma função membro virtual definida com um valor inicial 0 e sem implementação. $O$ método área() tem uma implementação inicial que pode ser mudada numa subseqüente declaração de subclasse.

As funções membro colocar_ponto_referência() e obter_ponto_referência() fornecem acesso controlado aos dados; as funções membro forma(Point) e forma() são construtores de instâncias da classe; e a função membro mover() move uma figura para uma nova localização.

Por se tratar da classe base é necessário testar todos os métodos e todas as interações intra-classe e inter-classes. A Tabela 2.3 mostra a história de teste para a classe Forma declarada na Figura 2.14-a. O conjunto de teste baseado em especificação para a função membro desenhar() pode ser gerado mas não pode ser executado, pois não há implementação para ela. Se houver uma implementação inicial para a função área() um conjunto de teste baseado em especificação e um conjunto de teste baseado em implementação podem ser gerados e executados. Observa-se que Harrold et al. omitiram alguns dos testes de integração nas Tabelas 2.4 e 2.5 , no entanto, todos eles devem ser testados (Harrold et al., 1992). 


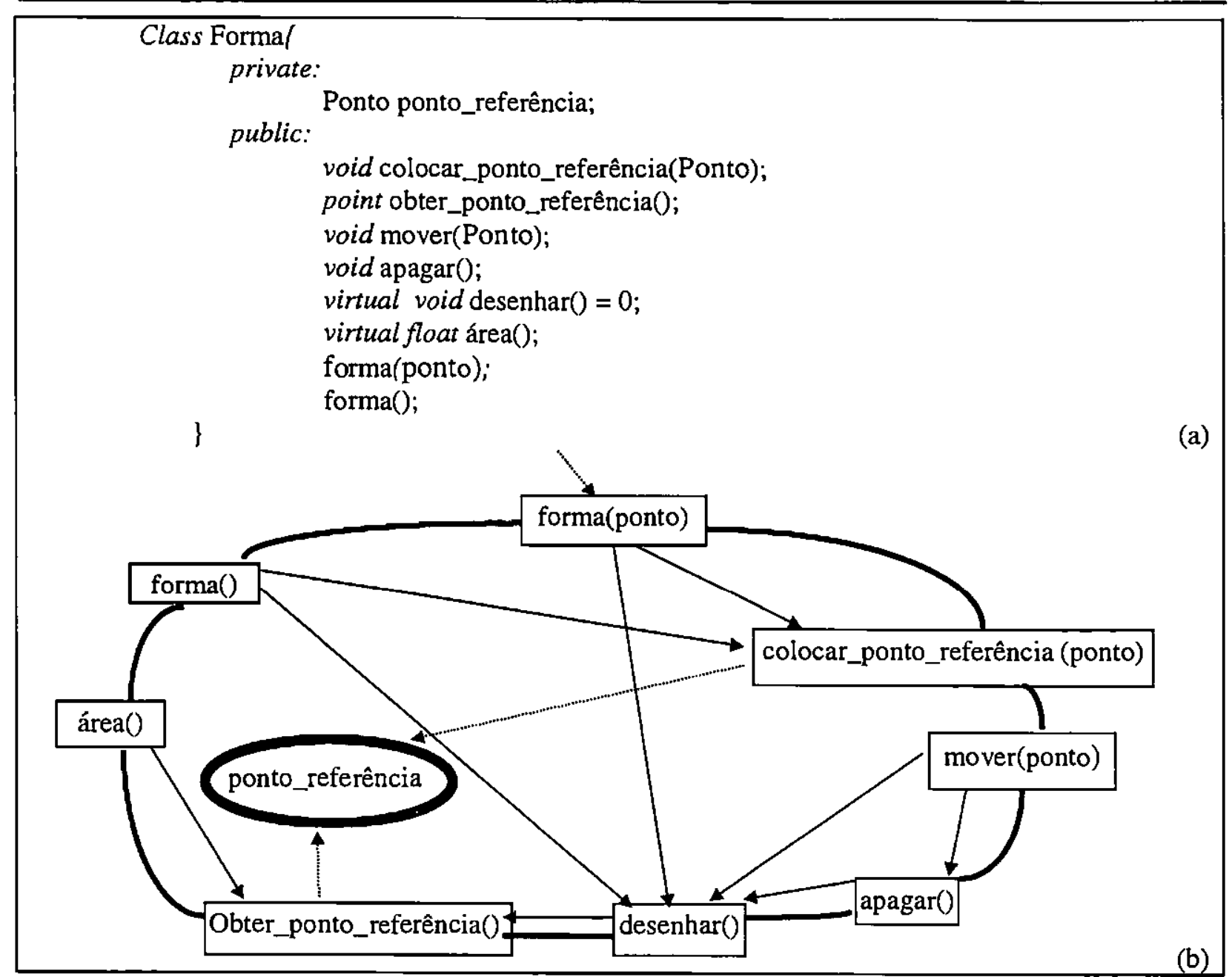

Figura 2.14 - (a) Definição da Classe Forma, (b) Grafo da Classe Forma (Harrold et al., 1992)

Tabela 2.3 - História de Teste para a classe Forma (Harrold et al., 1992)

\begin{tabular}{|lll|}
\hline Atributo & $\begin{array}{l}\text { Conjunto de teste baseado } \\
\text { em especificação }\end{array}$ & $\begin{array}{l}\text { Conjunto de teste baseado } \\
\text { em implementação }\end{array}$ \\
\hline & Funções individuais & \\
\hline colocar_ponto_referência & $\left(\mathrm{TS}_{1}, \mathrm{~S}\right)$ & $\left(\mathrm{TP}_{1}, \mathrm{~S}\right)$ \\
obter_ponto_referência & $\left(\mathrm{TS}_{2}, \mathrm{~S}\right)$ & $\left(\mathrm{TP}_{2}, \mathrm{~S}\right)$ \\
mover & $\left(\mathrm{TS}_{3}, \mathrm{~S}\right)$ & $\left(\mathrm{TP}_{3}, \mathrm{~S}\right)$ \\
apagar & $\left(\mathrm{TS}_{4}, \mathrm{~S}\right)$ & $\left(\mathrm{TP}_{4}, \mathrm{~S}\right)$ \\
desenhar & $\left(\mathrm{TS}_{5}, \mathrm{~S}\right)$ & $\left.-\mathrm{TP}_{6}, \mathrm{~S}\right)$ \\
área & $\left(\mathrm{TS}_{6}, \mathrm{~S}\right)$ & $\left(\mathrm{TP}_{7}, \mathrm{~S}\right)$ \\
forma & $\left(\mathrm{TS}_{7}, \mathrm{~S}\right)$ & $\left(\mathrm{TP}_{8}, \mathrm{~S}\right)$ \\
Forma & $\left(\mathrm{TS}_{8}, \mathrm{~S}\right)$ & \\
\hline & $\mathrm{Interação} \mathrm{entre} \mathrm{funções}$ & $\left(\mathrm{TP}_{9}, \mathrm{~S}\right)$ \\
\hline Mover & $\left(\mathrm{TIS}_{9}, \mathrm{~S}\right)$ & $\left(\mathrm{TPP}_{10}, \mathrm{~S}\right)$ \\
\hline Apagar & $\left(\mathrm{TIS}_{10}, \mathrm{~S}\right)$ & \\
\hline
\end{tabular}

\section{Teste de Subclasse}

Para gerar o teste de subclasse considera-se a história da classe pai (P), o grafo da classe pai e um modificador (M). O algoritmo TestSubClass (apresentado na Figura 2.15) transforma a história de teste da classe pai $\mathrm{P}$ na história de teste da subclasse. Para isso, o algoritmo aceita 
como entrada a história da classe $\mathrm{P}$, o grafo da classe $\mathrm{P}$ e um modificador $\mathrm{M}$. As ações de TestSubclass dependem do tipo do atributo e do tipo de modificação feita àquele atributo pelo mapeamento de herança. Para cada tipo de atributo (novo, recursivo, redefinido, virtual novo, virtual recursivo e virtual redefinido) diferentes ações podem ocorrer.

Um atributo (ou uma função membro) NOVO ou VIRTUAL-NOVO deve ser totalmente testado já que foi definido em $\mathrm{M}$ e ainda não foi testado. Um atributo (ou uma função membro) RECURSIVO ou VIRTUAL-RECURSIVO requer um reteste limitado pois já foi testado em $P$. É necessário testar, por exemplo, o caso em que uma função membro recursiva acessa uma função membro redefinida. Um atributo (ou uma função membro) REDEFINIDO ou VIRTUALREDEFINIDO exige reteste, mas os casos de teste baseados em especificação podem ser reusados se possível.

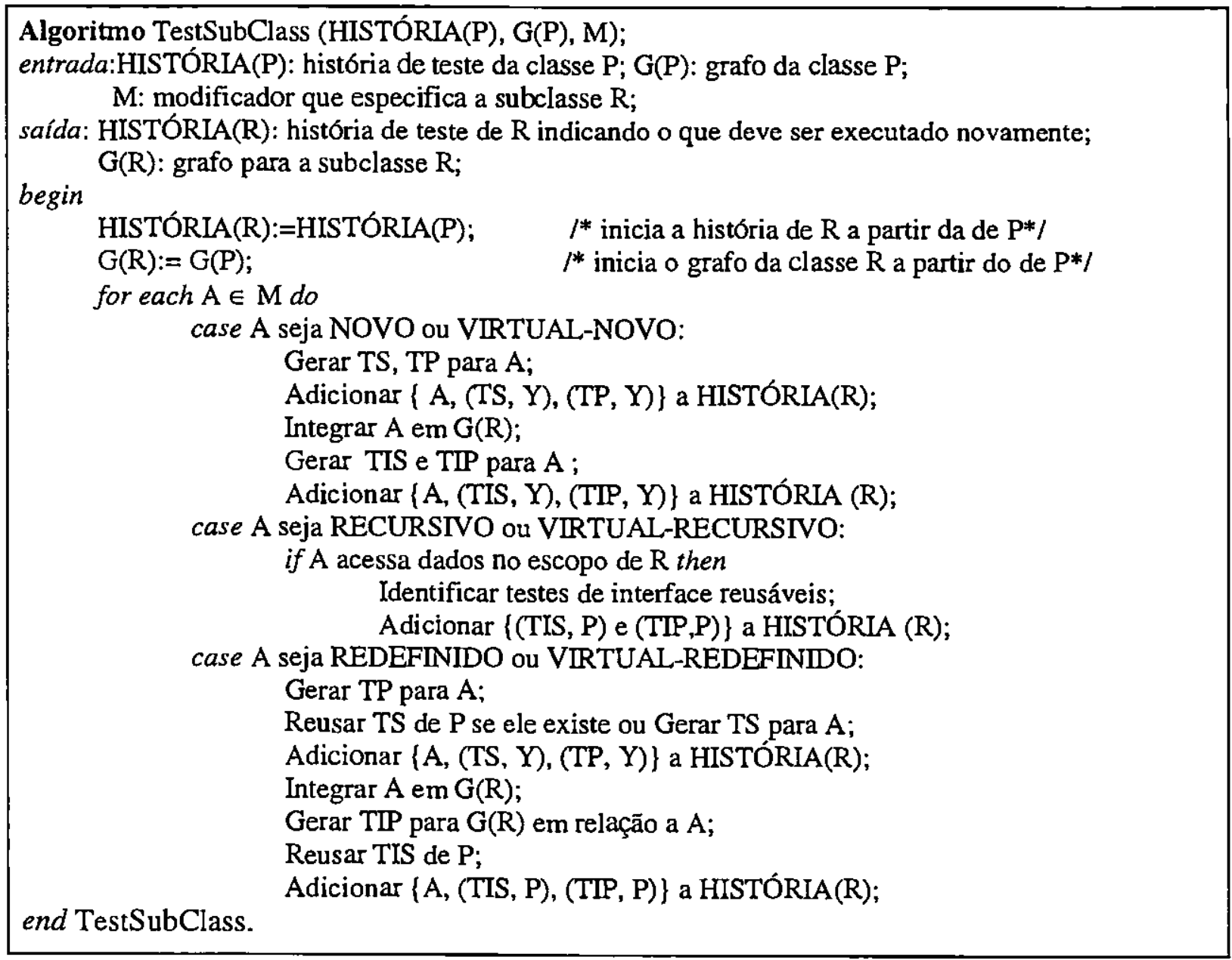

Figura 2.15- Algoritmo TestSubClass que determina a história de teste (HISTÖRIA) de R incrementalmente atualizando a história de sua classe pai. HISTÓRIA é usada para testar a subclasse (Harrold et al., 1992).

A definição e a história de teste de uma classe Triângulo feita a partir da classe Forma, anteriormente definida, são apresentadas na 2.16 e na Tabela 2.4 , respectivamente.

Nenhum dos conjuntos de casos de teste das funções colocar_ponto_referência() e obter_ponto_referência() foi executado novamente, pois elas são funções membro recursivas. Os casos de teste das funções membro adicionadas à classe Triângulo devem ser executados, pois 
essas funções ainda não foram testadas. As funções membro desenhar() e área() devem ser testadas novamente pois foram redefinidas.

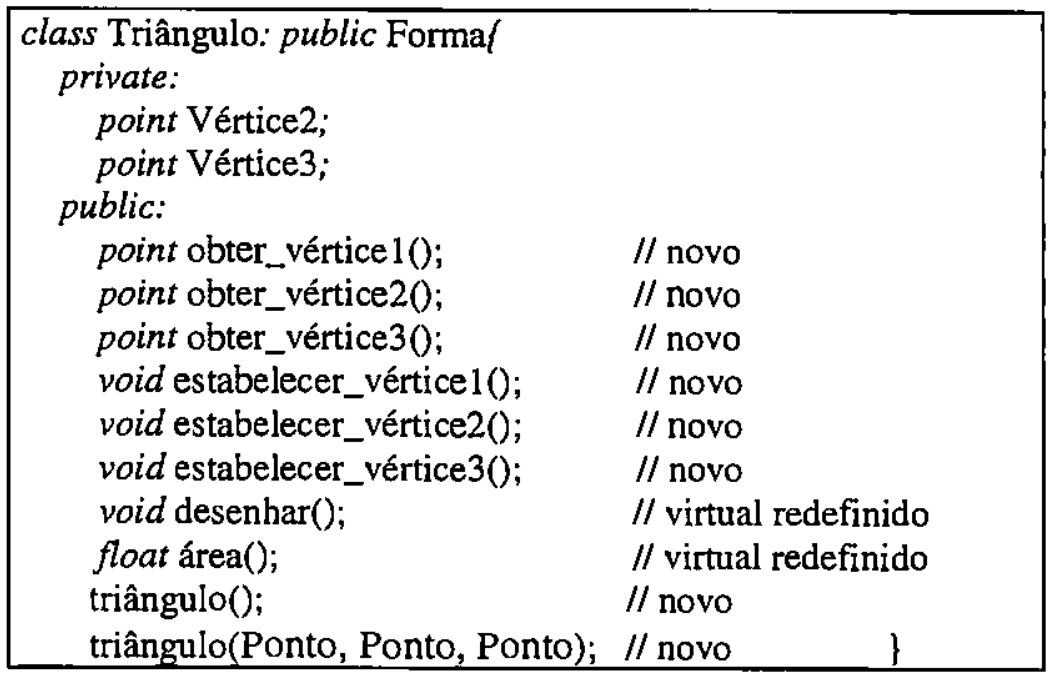

Figura 2.16 - Definição da classe Triângulo (Harrold et al., 1992)

Tabela 2.4 - História de Teste para a classe Triângulo (Harrold et al., 1992)

\begin{tabular}{|lll|}
\hline Atributo & $\begin{array}{l}\text { Conjunto de teste baseado } \\
\text { em especificação }\end{array}$ & $\begin{array}{l}\text { Conjunto de teste baseado } \\
\text { em implementação }\end{array}$ \\
\hline & Funções individuais & \\
\hline colocar_ponto_referência & $\left(\mathrm{TS}_{1}, \mathrm{~N}\right)$ & $\left(\mathrm{TP}_{1}, \mathrm{~N}\right)$ \\
obter_ponto_referência & $\left(\mathrm{TS}_{2}, \mathrm{~N}\right)$ & $\left(\mathrm{TP}_{2}, \mathrm{~N}\right)$ \\
mover & $\left(\mathrm{TS}_{3}, \mathrm{~N}\right)$ & $\left(\mathrm{TP}_{3}, \mathrm{~N}\right)$ \\
apagar & $\left(\mathrm{TS}_{4}, \mathrm{~N}\right)$ & $\left(\mathrm{TP}_{4} \mathrm{~N}\right)$ \\
desenhar & $\left(\mathrm{TS}_{5}, \mathrm{~S}\right)$ & $\left(\mathrm{TP}_{4}, \mathrm{~S}\right)$ \\
área & $\left(\mathrm{TS}_{6}, \mathrm{~S}\right)$ & $\left(\mathrm{TP}_{5}, \mathrm{~S}\right)$ \\
forma & $\left(\mathrm{TS}_{7}, \mathrm{~N}\right)$ & $\left(\mathrm{TP}_{7}, \mathrm{~N}\right)$ \\
forma & $\left(\mathrm{TS}_{8}, \mathrm{~N}\right)$ & $\left(\mathrm{TP}_{8}, \mathrm{~N}\right)$ \\
obter_vérticel & $\left(\mathrm{TS}_{11}, \mathrm{~S}\right)$ & $\left(\mathrm{TP}_{11}, \mathrm{~S}\right)$ \\
obter_vértice2 & $\left(\mathrm{TS}_{12}, \mathrm{~S}\right)$ & $\left(\mathrm{TP}_{12}, \mathrm{~S}\right)$ \\
obter_vértice3 & $\left(\mathrm{TS}_{13}, \mathrm{~S}\right)$ & $\left(\mathrm{TP}_{13}, \mathrm{~S}\right)$ \\
colocar_vérticel & $\left(\mathrm{TS}_{14}, \mathrm{~S}\right)$ & $\left(\mathrm{TP}_{14}, \mathrm{~S}\right)$ \\
colocar_vértice2 & $\left(\mathrm{TS}_{15}, \mathrm{~S}\right)$ & $\left(\mathrm{TP}_{15}, \mathrm{~S}\right)$ \\
colocar_vértice3 & $\left(\mathrm{TS}_{16}, \mathrm{~S}\right)$ & $\left(\mathrm{TP}_{16}, \mathrm{~S}\right)$ \\
triângulo & $\left(\mathrm{TS}_{17}, \mathrm{~S}\right)$ & $\left(\mathrm{TP}_{17}, \mathrm{~S}\right)$ \\
triângulo & $\left(\mathrm{TS}_{18}, \mathrm{~S}\right)$ & $\left(\mathrm{TP}_{18}, \mathrm{~S}\right)$ \\
\hline & $\mathrm{Interação} \mathrm{entre} \mathrm{funções}$ & \\
\hline mover & $\left(\mathrm{TIS}_{9}, \mathrm{P}\right)$ & $\left(\mathrm{TPP}_{9}, \mathrm{P}\right)$ \\
apagar & $\left(\mathrm{TIS}_{10}, \mathrm{P}\right)$ & $\left(\mathrm{TP}_{10}, \mathrm{P}\right)$ \\
área & $\left(\mathrm{TIS}_{19}, \mathrm{~S}\right)$ & $\left(\mathrm{TP}_{19}, \mathrm{~S}\right)$ \\
obter_vérticel & $\left(\mathrm{TIS}_{20}, \mathrm{~S}\right)$ & $\left(\mathrm{TP}_{20}, \mathrm{~S}\right)$ \\
colocar_vértice1 & $\left(\mathrm{TIS}_{21}, \mathrm{~S}\right)$ & $\left(\mathrm{TP}_{21}, \mathrm{~S}\right)$ \\
\hline & & \\
\hline
\end{tabular}

Por intermédio de uma nova redefinição, pode-se especificar uma classe de Triângulos Equiláteros, como apresenta a Figura 2.17. Como a classe Triângulo_equilátero redefine a implementação de área() é necessário retestá-la. Casos de teste de integração para testar as interações entre funções membro novas e redefinidas com atributos herdados também são executados. A história de teste para esta classe é mostrada na Tabela 2.5. 
class Triângulo_equilátero: public Triângulo/ public:

$$
\begin{array}{ll}
\text { float área(); } & \text { // redefinido } \\
\text { triângulo_equilátero(); } & / / \text { novo } \\
\text { triângulo_equilátero(Ponto,Ponto,Ponto); } / / \text { novo }
\end{array}
$$

\begin{tabular}{|c|c|c|}
\hline Atributo & $\begin{array}{l}\text { Conjunto de teste baseado } \\
\text { em especificação }\end{array}$ & $\begin{array}{l}\text { Conjunto de teste baseado } \\
\text { em implementação }\end{array}$ \\
\hline & \multicolumn{2}{|l|}{ Funçōes individuais } \\
\hline colocar_ponto_referência & $\left(\mathrm{TS}_{1}, \mathrm{~N}\right)$ & $\left(\mathrm{TP}_{1}, \mathrm{~N}\right)$ \\
\hline obter_ponto_referência & $\left(\mathrm{TS}_{2}, \mathrm{~N}\right)$ & $\left(\mathrm{TP}_{2}, \mathrm{~N}\right)$ \\
\hline mover & $(\mathrm{TS} 3, \mathrm{~N})$ & $(\mathrm{TP} 3, \mathrm{~N})$ \\
\hline apagar & $(\mathrm{TS} 4, \mathrm{~N})$ & (TP4N) \\
\hline desenhar & (TS5,N) & $\left(\mathrm{TP}_{4}, \mathrm{~N}\right)$ \\
\hline área & $(\mathrm{TS} 6, \mathrm{~S})$ & $(\mathrm{TP} 5, \mathrm{~S})$ \\
\hline forma & $(\mathrm{TS} 7, \mathrm{~N})$ & $(\mathrm{TP} 7, \mathrm{~N})$ \\
\hline forma & (TS8,N) & $(\mathrm{TP} 8, \mathrm{~N})$ \\
\hline obter_vértice 1 & $(\mathrm{TS} 11, \mathrm{~N})$ & $(\mathrm{TP} 11, \mathrm{~N})$ \\
\hline obter_vértice 2 & $(\mathrm{TS} 12, \mathrm{~N})$ & $(\mathrm{TP} 12, \mathrm{~N})$ \\
\hline obter_vértice3 & $(\mathrm{TS} 13, \mathrm{~N})$ & $(\mathrm{TP} 13, \mathrm{~N})$ \\
\hline colocar_vértice 1 & $(\mathrm{TS} 14, \mathrm{~N})$ & $(\mathrm{TP} 14, \mathrm{~N})$ \\
\hline colocar_vértice2 & $(\mathrm{TS} 15, \mathrm{~N})$ & $(\mathrm{TP} 15, \mathrm{~N})$ \\
\hline colocar_vértice3 & $(\mathrm{TS} 16, \mathrm{~N})$ & (TP16,N) \\
\hline triângulo & $(\mathrm{TS} 17, \mathrm{~N})$ & $(\mathrm{TP} 17, \mathrm{~N})$ \\
\hline triângulo & $(\mathrm{TS} 18, \mathrm{~N})$ & (TP18,N) \\
\hline triângulo_equilátero & $(\mathrm{TS} 22, \mathrm{~S})$ & $(\mathrm{TP} 22, \mathrm{~S})$ \\
\hline \multirow[t]{2}{*}{ triângulo_equilátero } & $(\mathrm{TS} 23, \mathrm{~S})$ & $(\mathrm{TP} 23, \mathrm{~S})$ \\
\hline & \multicolumn{2}{|l|}{ Interação entre funções } \\
\hline mover & $\left(\mathrm{TIS}_{9}, \mathrm{P}\right)$ & $\left(\mathrm{TIP}_{9}, \mathrm{P}\right)$ \\
\hline apagar & $\left(\mathrm{TIS}_{10}, \mathrm{P}\right)$ & $\left(\mathrm{TIP}_{10}, \mathrm{P}\right)$ \\
\hline área & $\left(\mathrm{TIS}_{19}, \mathrm{P}\right)$ & $\left(\mathrm{TIP}_{19}, \mathrm{P}\right)$ \\
\hline
\end{tabular}

Figura 2.17 - Definição da classe Triângulo_equilátero (Harrold et al., 1992)

Tabela 2.5 - História de Teste para a Classe Triângulo_equilátero (Harrold et al., 1992)

\section{Resultados Obtidos}

Para determinar as vantagens ganhas no teste, Harrold et al. utilizaram uma hierarquia de classes em $\mathrm{C}++$ definida na biblioteca de classes de interfaces gráficas InterViews. Esta hierarquia é composta pela superclasse Interactor e suas subclasses Scene, MonoScene e Dialog (Scene é uma subclasse de Interactor, MonoScene é uma subclasse de Scene e Dialog é uma subclasse de MonoScene) (Harrold et al., 1992). Os resultados apresentados na Tabela 2.6 mostram que em uma hierarquia de classes, o uso da Estratégia Incremental Hierárquica reduz significativamente o esforço de teste. Muitos métodos que devem ser retestados reutilizam os casos de teste que foram desenvolvicos para suas superclasses. A reutilização de conjuntos de testes da superclasse resulta em uma melhoria no tempo de realização de todo o processo de teste. 
Tabela 2.6 - Número de métodos a serem testados nas interações intra-classe (Harrold et al., 1992)

\begin{tabular}{|c|c|c|c|}
\hline Classe & $\begin{array}{c}\text { Reteste de Todos } \\
\text { os Métodos }\end{array}$ & $\begin{array}{c}\text { Técnica } \\
\text { Incremental }\end{array}$ & $\begin{array}{c}\text { Razão entre as duas } \\
\text { Técnicas }\end{array}$ \\
\hline Interactor & 93 & 93 & $100 \%$ \\
\hline Scene & 96 & 36 & $38 \%$ \\
\hline MonoScene & 99 & 9 & $9 \%$ \\
\hline Dialog & 103 & 6 & $6 \%$ \\
\hline
\end{tabular}

\subsection{Estratégia FREE}

FREE (Flattened REgular Expressions) é uma estratégia baseada em estados que possibilita o desenvolvimento de conjuntos de casos de testes de sistema, integração e unidade para software orientado a objetos. A FREE cobre todos os escopos básicos de teste: teste de classe baseado em implementação, teste de classe baseado em representação, integração de subsistema/cluster baseado em arquitetura e teste de sistema baseado em casos de uso, porque além de garantir que cada componente se comporta corretamente é preciso garantir que o comportamento coletivo também é correto. As informações mais detalhadas sobre esta estratégia podem ser encontradas em (Binder, 1996a).

Uma classe (ou um cluster) sob teste é modelada como uma máquina de estados FREE, que é uma máquina de estados plana. $\mathrm{O}$ modelo de estados FREE apresentado a seguir apoia teste baseado em representação e teste baseado em implementação. As sequiências de teste são geradas de forma a cobrir todos os ciclos de transição de estado para a classe em teste. Essas seqüuências são expressões regulares da máquina de estados plana da classe em teste.

\section{O Modelo de Estados FREE}

Binder afirma que os modelos usados pelos métodos de análise e projeto orientados a objetos não exigem informação completa, uso consistente ou integração útil com o resto do modelo. Esses modelos não são test-ready, ou seja, falta-lhes conteúdo e consistência necessária para produzir casos de teste executáveis. Modelos de métodos OO colocam diversos obstáculos para a atividade de teste porque são ambíguos quanto à definição de estado, evento, ação e transição e são incompletos porque não definem todos os componentes necessários para um modelo comportamental bem formado (Binder, 1996a). Binder afirma ainda que o teste baseado em estados requer uma especificação de estados testável e o modelo de estados FREE proporciona isto. A semântica deste modelo é apresentada a seguir.

Os estados de uma classe são subconjuntos do conjunto de todas as possíveis combinações de valores de atributos. Transições são definidas por um par de estados invariantes. Cada transição é o resultado de um evento e resulta em uma ou mais açōes. Um evento representa algum tipo de estímulo que pode ser apresentado a um objeto. Uma ação representa a resposta que um objeto produzirá como resultado de um evento, ela pode ser modelada por expressōes regulares.

O modelo possui quatro estados especiais (alfa, beta, gama e zeta) que são usados para facilitar o teste de construtores e destrutores. Alfa é um estado nulo representando a declaração de um objeto antes de sua definição. Zeta é o estado final alcançado antes de um objeto ter sido destruído ou removido. Beta é o conjunto de estados legalmente alcançáveis a partir do estado 
alfa (por exemplo, vazio). Gama é o conjunto de estados ilegais. A união de beta e gama é o conjunto de todas as possíveis combinações de valores de uma instância de variável.

O modelo de estados FREE produz sequiências ordenadas de casos de teste de classes. A estratégia usada para gerar estas sequiências depende do comportamento seqüencial da classe em teste. Uma classe modal restringe a sequiência aceitável de mensagens, ou seja, só aceita sequiências de mensagens ordenadas. Por exemplo, o débito de uma conta bancária é aceito somente se o saldo for positivo. Uma classe não-modal não restringe a sequiência aceitável de mensagens. Sequiências de teste para classes modais são produzidas a partir do modelo de estados FREE e para as classes não-modais a partir do modelo de fluxo de dados da interface.

\section{Teste de classe baseado em implementação}

O fato de todos os métodos da subclasse e da superclasse fazerem acesso as mesmas instâncias de variáveis pode gerar uso inconsistente das mesmas. Estas falhas podem ser reveladas pela cobertura do fluxo de dados e de controle inter-métodos (intra-classe). $O$ grafo de fluxo FREE permite o teste de caminhos intra-classe. Esse grafo é construído a partir dos grafos de fluxo de cada método e do modelo de estados da classe.

Já que o estado é o resultado da ativação de um método, pode-se substituir os grafos de método dentro das transições de estado para obter um conjunto completo dos caminhos para a classe. O grafo de fluxo FREE é construído em três passos:

1. O modelo de estados FREE é desenvolvido para a classe em teste;

2. Um grafo de fluxo é desenvolvido para cada método na classe em teste;

3. Cada transição é trocada pelo grafo de fluxo do método correspondente. A transição entra no nó de entrada do método. Uma transição é adicionada a partir do nó de saída do método até o nó de estado resultante da transição.

Uma vez completo, o grafo de fluxo FREE representa todos os possíveis caminhos de fluxo entre segmentos de métodos. Este modelo pode ser usado para apoiar o desenvolvimento e a avaliação do conjunto de casos de testes baseado em caminhos, incluindo ramos, fluxo de dados e fluxo de informação.

\section{Teste de classe baseado em representação}

\section{Classes Modais}

O teste de classe baseado em representação para classes modais é aplicado com base no Critério de Teste baseado em Estados apresentada na Subseção 2.2.3.2.1. Esse teste deve mostrar que a classe se comporta de acordo com a máquina de estados que a representa. Nessa fase de teste, além de demonstrar a conformidade da classe com o seu modelo de comportamento, é preciso garantir que nenhum comportamento "excluído" é produzido. Para ter certeza de que isso ocorrerá pode-se adicionar testes condicionais e caminhos de saída.

Um caminho de saída é o erro na classe sob teste que permite uma transição ilegal. $O$ teste de caminhos de saída é feito enviando-se mensagens ilegais para a classe em teste. Uma transição ilegal é apresentada quando a classe em teste, em algum estado válido, aceita uma mensagem que não foi explicitamente especificada para aquele estado. Uma mensagem ilegal é 
uma mensagem válida que não deveria ser aceita dado o estado corrente da classe, se foi aceita, ela resulta em uma transição ilegal.

Para cada transição condicional é preciso desenvolver uma tabela verdade para as variáveis da condição. Um caso de teste adicional é desenvolvido para cada entrada na tabela verdade que não foi exercitada por conformidade ou por caminho de saída. Para condições com intervalos é importante testar os valores limitantes da condição.

\section{Classes Não-Modais}

Nas classes não modais não existe um padrão de ativação de sequiências; então a estratégia de seleção de sequiências de teste é a seguinte: modelar o caminho de fluxo de dados de interface e derivar os casos de teste para obter cobertura definição-uso. Cada interface que estabelece um método é modelada como uma operação "definição" (d1,d2,dn). Cada interface que recebe um método é modelada como uma operação "uso"(u1,u2,un). Uma expressão regular básica padrão é usada para gerar seqüências de teste.

\section{Integração de subsistema / cluster}

Um sistema é composto por objetos que cooperam entre si, pois um objeto muda de estado ao interagir com outros objetos. Mesmo que todos os componentes sejam individualmente corretos é possível detectar uma falha no sistema. A estratégia FREE usa uma máquina modal (mode machine) para modelar o comportamento do sistema como um todo e utiliza a mesma técnica de derivação de teste de classe. Uma máquina modal é um modelo de estados do sistema, ela precisa de um limite que defina o sistema em teste. Já que um sistema depende dos serviços fornecidos pelo sistema operacional ou outro sistema, as interações com esses sistemas definem o escopo do sistema em teste.

Um evento externo é uma mensagem que ativa um método e origina um componente fora do sistema. Um objeto que reconhece ou aceita um evento externo é chamado receptor. Uma resposta é a mensagem gerada pelo sistema para o servidor. Um objeto que produz uma resposta é chamado de emissor. Um modo de transição é o efeito coletivo da cadeia de transições de estado, sendo representado por um thread (caminho de execução). Um thread é um caminho possível de envio de mensagens do receptor para o emissor. Ele é uma cadeia de transições desencadeada por um evento externo até uma resposta, cada mensagem consumida internamente nessa cadeia causa uma mudança de estado em um objeto. O efeito em rede dessas mudanças é a mudança de estado do sistema. Traçando um thread identifica-se um novo estado alcançável.

A máquina modal permite que um sistema seja visto como uma rede de máquinas de estados. O componente de estados em algum dado momento define o estado da aplicação. Isso permite a determinação de todos os estados alcançáveis do sistema e a produção dos casos de teste para exercitar o controle de estados do sistema (Binder, 1996a). Para facilitar a derivação da máquina e gerar um modelo tratável, as classes auxiliares podem ser omitidas e os componentes podem ser modelados como clusters ou subsistemas ao invés de classes. A máquina modal pode ser usada para derivar casos de teste de integração. Cada caminho de evento/resposta deve ser exercitado. 


\section{Teste de sistema baseado em Casos de Uso Estendidos}

Um teste de sistema efetivo requer uma especificação de sistema testável e concreta. Um plano completo de teste de sistema pode ser preparado com casos de uso estendidos, pois eles incluem: todas as variáveis operacionais, a freqüência relativa de cada operação no caso de uso e os traços de evento que estão associados a cada operação. O teste de sistema da FREE pode ser aplicado em 3 níveis, quanto mais alto o nível maior a robustez e o custo do teste.

Nível 1: Conformidade com Casos de Uso. É desenvolvido um plano de teste formal para todos os traços de eventos e casos de uso. Se nenhum erro for detectado nos testes, o sistema está em conformidade com os casos de uso. Este nível tem 2 passos principais:

1. Desenvolver um modelo completo dos requisitos do sistema com casos de uso detalhados e diagramas de interação. Os casos de uso devem ser completos, consistentes e atuais.

2. Identificar variáveis operacionais para cada caso de uso considerando os cenários.

Nível 2: Otimização de Confiabilidade. O Nível 2 requer que o Nível 1 tenha sido executado com sucesso. Casos de uso e operações são posicionados de acordo com sua freqüência relativa, os recursos de teste são alocados de acordo com o perfil operacional do sistema. Os passos principais deste nível são:

3. Estimativa da frequiência relativa de cada caso de uso.

4. Estimativa da produtividade do teste.

5. Estabelecimento de um orçamento do teste do sistema.

Nível 3: Verificação de Integridade. O Nível 3 requer a demonstração que o Nível 2 proporciona a cobertura de threads. Este nível estabelece uma medida não ambígua da completitude do teste de sistema da mesma forma que estabelece a completitude de cobertura de código dos testes de unidade. Os passos deste nível incluem:

6. Identificar todos os threads de ativação fim-a-fim. Isto ajuda a sintetizar o modelo de estados do sistema e a identificar os traços de eventos no diagrama de ativação.

7. Avaliar a cobertura de threads do teste do Nível 2. Desenvolver testes adicionais para alcançar a cobertura completa dos threads.

A abordagem FREE é uma estratégia baseada em estados para o desenvolvimento de casos de teste baseados em representação para um sistema orientado a objetos independentemente do método de desenvolvimento adotado.

\subsection{Técnica de Teste de Fluxo de Dados para Classes}

Para complementar as técnicas de teste intra-classes é necessária uma técnica de teste baseada na implementação. Harrold propôs uma técnica de teste de fluxo de dados para testar classes (Harrold \& Rothermel, 1994). Para testar a classe deve ser construído um grafo de chamadas da classe representando a estrutura de controle da classe. O grafo de chamadas da classe é um grafo direcionado no qual os nós representam os métodos e os ramos representam as chamadas entre métodos.

A técnica propõe um algoritmo para a geração do grafo de fluxo de controle da classe. Esse algoritmo gera o grafo de chamadas da classe e a seguir, para facilitar a análise do fluxo de dados, o grafo de chamada da classe é inserido em um frame. O próximo passo é trocar cada nó do grafo de chamada pelo grafo de fluxo de controle do método correspondente. Depois, para cada grafo de fluxo de controle adicionado, deve-se trocar, nos grafos de fluxo de controle, cada 
chamada de um método por um nó de chamada e um nó de retorno. Para completar o grafo de fluxo de controle da classe deve-se conectar os nós de chamada dos frames ao início do grafo de fluxo de controle do método e os nós de saída do grafo de fluxo de controle do método aos nós de retorno dos frames (Harrold \& Rothermel, 1994).

O teste da classe é baseado no seu grafo de fluxo de controle. As classes devem ser testadas em três níveis, que são descritos a seguir:

$>$ Teste intra-método: testa os métodos individualmente. Este nível é equivalente ao teste de unidade em linguagens de programação procedimental;

$>$ Teste inter-método: testa os métodos públicos junto com os métodos da classes que são chamados por ele direta ou indiretamente;

$>$ Teste intra-classe: testa as interações dos métodos públicos em seqüências de chamadas variadas.

A técnica estabelece três tipos de pares definição-uso (def-use) que devem ser testados em uma classe, os quais correspondem aos níveis mencionados anteriormente. Os pares def-use intra-método ocorrem dentro de um único método e testam interações de definição-uso limitadas a esse método. Os pares def-use inter-método ocorrem quando métodos dentro de um contexto de chamada de um método público interagem direta ou indiretamente. Os pares def-use intraclasse ocorrem quando seqüências de métodos públicos são invocadas.

Para testar a classe deve-se gerar todos os três tipos de pares def-use, esta técnica de teste apresenta o algoritmo PLR, a partir do qual é possível gerar os pares def-use intra e inter método. Para gerar os pares def-use intra-classe deve-se considerar as interações que ocorrem quando as sequiências de métodos públicos são invocadas.

\subsection{Cenários de Teste}

Os cenários de teste constituem uma abordagem para teste do comportamento de sistemas OO. Essa abordagem usa como fonte de informações os Diagramas de Classes, que possuem a visão estática do sistema, os Diagramas de Interação, que apresentam os relacionamentos dinâmicos existentes entre os objetos do sistema e os Diagramas de Transição de Estados das classes que apresentam o comportamento da classe perante os eventos recebidos. As informações contidas nesses diagramas são utilizadas para a geração de cenários de teste.

Genericamente, um cenário pode ser definido como uma representação que descreve determinada situação que pode ocorrer durante o uso de um sistema. A Figura 2.18 mostra um cenário de teste genérico e as fontes de informação utilizadas para a sua criação.

A partir dos cenários de teste é possível gerar seqüências de teste que, segundo Vieira, têm o objetivo de permitir a possibilidade de se identificar falhas que uma especificação possa conter e de possuir um número pequeno de seqüências (Vieira \& Travassos, 1998).

Nesta abordagem de teste são extraídas sequiências de teste de duas formas: a partir dos Diagramas de Transição de Estados (DTE) e a partir dos cenários de teste. As sequiências extraídas dos DTE de cada classe permitem testar o comportamento de cada objeto do sistema. Essas sequiências são extraídas utilizando-se o Critério W, apresentado na Subseção 2.2.1.1.4. As seqüências extraídas dos cenários de teste descrevem um encadeamento de ações, 
especificamente, essas ações são representadas em termos de ativação de métodos pertencentes às classes do sistema, caracterizando uma das funcionalidades esperadas do sistema (Vieira \& Travassos, 1998). Para gerar essas sequiências é necessária a integração das informações dos três diagramas utilizados pela abordagem.

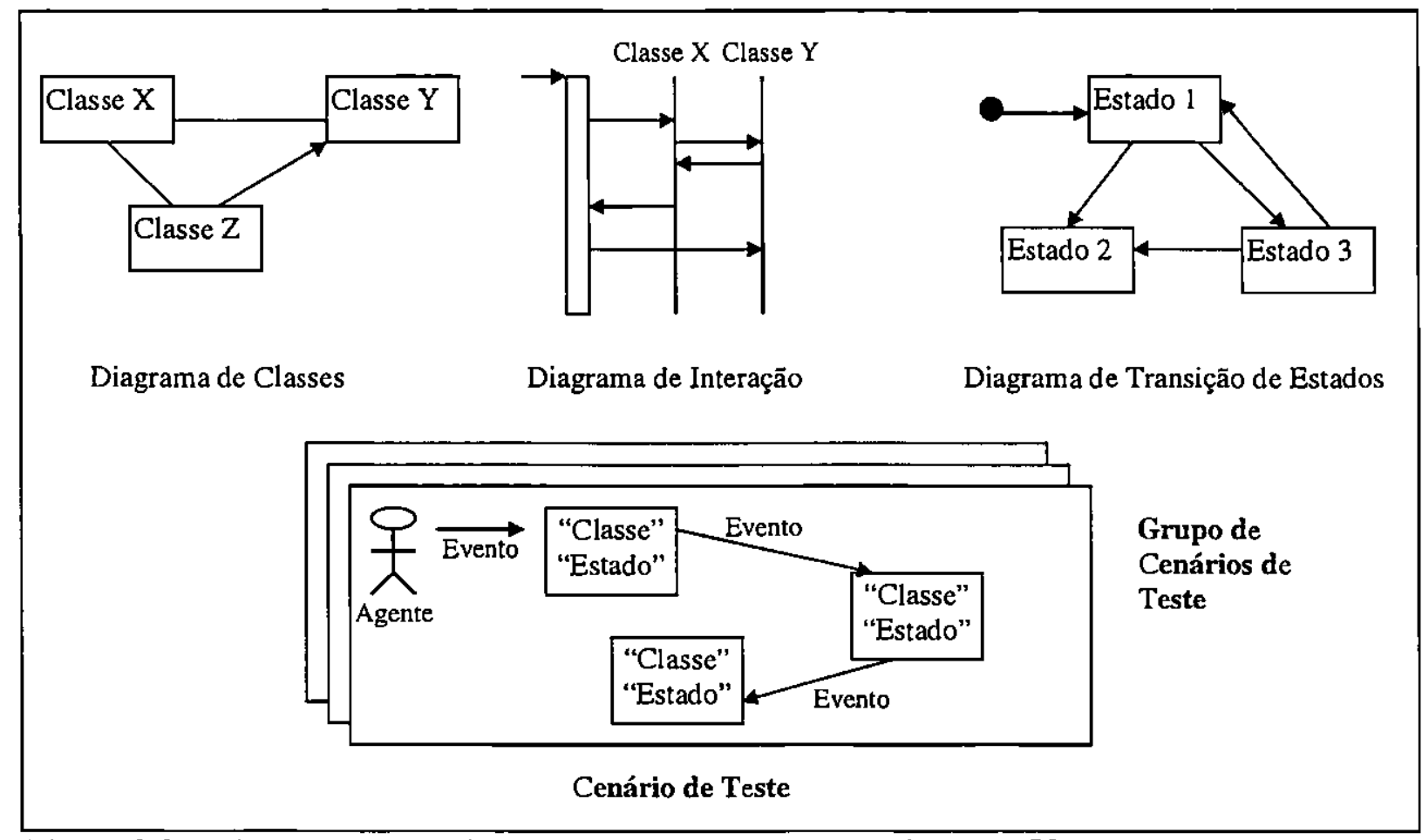

Figura 2.18 - Geração de Cenários de Teste a partir de modelos OO (Vieira \& Travassos, 1998)

Para gerar os cenários de teste inicialmente deve-se montar a árvore de cenários. Uma árvore de cenários de teste representa um grupo de cenários que serão gerados. Um grupo de cenários representa um conjunto dos cenários de teste que serão criados a partir de uma árvore baseada em um diagrama de interação entre objetos, cujas sequiências de ativação dos métodos foram representadas nos diagramas de interação. Desta forma, se existirem cinco diagramas de interação serão construídas cinco árvores de cenários de teste que representarão cinco grupos de cenários diferentes. Utiliza-se uma estrutura de grafo para a representação da árvore de cenários de teste. Cada nó descreve um estado no qual um objeto do sistema pode se encontrar, descritos pelo DTE desse objeto. As ligações representam a ocorrência de um tipo de evento (método), que pode ou não alterar este estado.

Os cenários são construídos a partir das árvores de cenários de teste. Cada cenário é composto pelo ator que inicia o cenário de teste, os eventos que representam a ativação de um método e as classes envolvidas no cenário apresentado que representam as classes dos objetos que estão recebendo os eventos. As informações descritas para cada classe são o nome da classe e o estado de suas instâncias após a ativação do evento, como pode ser visto na Figura 2.18.

Essa abordagem de teste é apoiada por uma ferramenta de automatização da atividade de teste, a FAC (Ferramenta de Apresentação e Extração de Cenários) (Vieira \& Travassos, 1998). Essa ferramenta extrai os cenários de teste a partir dos DTE, Diagramas de Interação e Diagrama de Classes do Sistema. 


\subsection{Técnica de Teste Modal}

No teste de software $O O$ é essencial um conjunto de teste que exercita suficientemente combinações de sequiuencias de mensagens e interações de estados suficientes para fornecer confiança necessária. Em alguns casos testes baseados em seqüências de mensagens ou estados é suficiente, mas usualmente ambas as visões se tornam necessárias (Binder, 1996b). A técnica de teste modal utiliza a noção de modalidade da classe, na qual as classes são classificadas de acordo com o seu comportamento, para estabelecer a estratégia de teste ideal. A modalidade de uma classe é determinada pelas suas restrições sobre a seqüência de mensagens e pelo conteúdo das instâncias de variáveis. Essa técnica considera quatro tipos de modalidades:

1. A classe não modal não impõe restriçōes sobre a seqüência de mensagens. Um exemplo é a classe DateTime que aceita qualquer sequiência dos métodos fornecer, comparar, atualizar, etc. Classes que implementam tipos de dados simples são frequentemente não modais.

2. Uma classe unimodal somente impõe restrições sobre a seqüência de mensagens. Por exemplo: a classe Semáfaro somente pode aceitar a mensagem Acender_Luz_Vermelha depois da mensagem Acender_Luz_Amarela. Classes que implementam aplicações de controle geralmente são dessa modalidade.

3. Uma classe quasimodal não restringe a sequiência de mensagens, mas impõe restrições sobre o domínio. Uma classe Pilha rejeitará a mensagem empilhar se a pilha estiver cheia mas aceitará qualquer outra mensagem. Essa modalidade é caracterizada por classes que representam coleções e containers.

4. Uma classe modal impõe restrições tanto sobre o domínio quanto sobre a seqüência de mensagens. Um exemplo de classe modal é a classe Conta. Um objeto dessa classe não aceitará uma mensagem de saque se o saldo for menor ou igual a zero, mas aceitará uma mensagem "congelar" se a conta não foi encerrada ou congelada. Enquadram-se nessa modalidade as classes que representam entidades do domínio do problema.

Diferentes tipos de erros podem ocorrer para diferentes modalidades, afinal um conjunto de teste baseado em transições de estados pode revelar todos os erros de controle de uma classe modal e não revelar erros para uma classe não modal, já que esta não impõe restrições sobre a seqüência de mensagens. Dessa forma, a técnica de teste modal aplica para classes não modais a prova do vértice, que consiste em estabelecer como casos de teste todos os pontos limitantes do domínio da classe. O conjunto de teste ideal é aquele que exercita todos os pontos da prova do vértice.

O teste para classes unimodais é composto por duas partes: teste de conformidade e teste de caminhos de desvio (sneak-paths). O teste de conformidade nada mais é do que o teste baseado em estados apresentado na Subseção 2.2.3.2.1. O teste de caminhos de desvio tem como objetivo garantir que seqüências de mensagens incorretas serão rejeitadas sem levar a classe a um estado incorreto. Esse teste consiste em enviar mensagens ilegais a todos os estados da classe.

Como as classes quasimodais baseiam sua resposta a uma mensagem no conteúdo do objeto e não na última mensagem enviada, o seu teste deve ser baseado em cada variação das restrições sequienciais causadas pelas variações em seu domínio. Sendo assim, a estratégia de 
teste segue os seguintes passos: (1) caracterizar os estados pelas suas restrições (no caso da classe Pilha, as restrições envolvem o número atual de elementos e o número máximo de itens), (2) aplicar a prova do vértice para os parâmetros e (3) identificar valores específicos que resultarão em sequiências serem exercitadas.

Finalmente, para classes modais, a estratégia de teste consiste do teste de conformidade, do teste de caminhos de desvio e da prova do vértice para os pontos limitantes que não foram cobertos pelo teste de conformidade.

\subsection{Considerações FinaIS}

Neste capítulo apresentou-se uma breve história da orientação a objetos, ressaltando a falta de pesquisa sobre análise e projeto $O O$ no início da utilização das linguagens de programação orientadas a objetos. No entanto, na década de 80 , surgiram tantos métodos de desenvolvimento orientado a objetos que alguns se fundiram para formar métodos mais completos, por exemplo o método Fusion e a UML. Foram definidos os principais conceitos utilizados na orientação a objetos, tais como, Classes, Herança, Polimorfismo e Encapsulamento de Dados.

Foi apresentada a UML que é uma linguagem de modelagem que não define um processo de desenvolvimento padrão. Por esse motivo os métodos OO que foram apresentados tem suas fases de desenvolvimento de software enfatizadas, já que para se utilizar a UML é preciso escolher um processo de desenvolvimento. Os métodos abordados foram o Fusion, o TeamFusion e o Unified Process, sendo que os dois últimos usam a notação UML.

Neste capítulo foi enfatizada também uma das atividades de garantia de qualidade mais utilizadas, a atividade de teste. Foram apresentadas as Técnicas de: Teste Funcional, Teste Estrutural, Teste Baseado em Erros e Teste Baseado em Máquinas de Estados Finitos. O teste de software orientado a objetos foi enfatizado, abordando a problemática existente e apresentando algumas abordagens de teste de software orientado a objetos propostas na literatura.

Neste capítulo apresentou-se as principais técnicas de teste de software procedimental, destacando alguns dos seus principais critérios. Os problemas com teste de software oO foram comentados, abordando aspectos de Validação, Verificação e Testes em relação a essa abordagem. Algumas diferenças entre software $0 O$ e software procedimental e a necessidade de técnicas de teste que considerem aspectos particulares da orientação a objetos também foram destacadas.

Em todas as abordagens de teste $O O$ apresentadas pôde-se perceber a utilização e adaptação de técnicas tradicionais de teste de software. Diante disso, é possível afirmar que as técnicas de teste já existentes podem contribuir para o desenvolvimento de técnicas de teste orientado a objetos efetivas.

A Estratégia de Teste Incremental Hierárquica se apóia nos Axiomas de Teste para afirmar que as classes devem ser testadas na maioria dos contextos de reuso. Essa estratégia ressalta a necessidade ou não de teste e a necessidade de geração de um novo conjunto de casos de teste. No entanto, nenhum critério de geração de testes é indicado, ficando o testador livre para escolher os critérios desejados, tanto para o teste baseado em especificação como para o teste baseado em implementação. Portanto, ela trata o gerenciamento da atividade de teste de 
classes e não os critérios de geração de casos de teste. Essa estratégia enfatiza o reuso de conjuntos de teste.

O Critério Baseado em Estados é a parte da estratégia FREE que trata o teste de classes. A Técnica de Teste Modal usa o Critério Baseado em Estados para o teste de conformidade e os Cenários de Teste usam o Critério $\mathrm{W}$ para o teste de classe. Essas quatro abordagens permitem a geração de casos de teste a partir de uma máquina de transição de estados. A Técnica de Teste de Fluxo de Dados para classes e parte da Estratégia FREE são baseadas na implementação do software.

$\mathrm{Na}$ Tabela 2.7 apresenta-se uma comparação entre as abordagens de teste apresentadas neste capítulo.

Tabela 2.7 - Comparação entre as abordagens de teste orientado a objetos apresentadas

\begin{tabular}{|c|c|c|c|}
\hline ABOORDAGEM & TAPO DE TESTE & $\begin{array}{l}\text { GSSIFICACAO } \\
\text { OA ABOROAAGEM }\end{array}$ & $\begin{array}{l}\text { BASE PARA AAGERACAO } \\
\text { DOSOCASOSDETESTEE }\end{array}$ \\
\hline Critério Baseado em Estados & classe & Critério & MEF \\
\hline $\begin{array}{l}\text { Estratégia Incremental } \\
\text { Hierárquica }\end{array}$ & classe & Estratégia & Herança \\
\hline FREE & $\begin{array}{l}\text { classe, integração e } \\
\text { sistema }\end{array}$ & Estratégia & MEF \\
\hline $\begin{array}{l}\text { Técnica de Teste de Fluxo de } \\
\text { Dados para Classes }\end{array}$ & classe & Critério & $\begin{array}{l}\text { Grafo de fluxo de controle } \\
\text { da classe }\end{array}$ \\
\hline Cenários de Teste & classe e integração & Estratégia & MEF e cenários de teste \\
\hline Técnica de Teste Modal & classe & Critério & $\begin{array}{c}\text { MEF e/ou pontos limitantes } \\
\text { da classe }\end{array}$ \\
\hline
\end{tabular}

No próximo capítulo é apresentado o processo de desenvolvimento de software proposto neste trabalho. 


\section{CAPÍTULO III}

\section{Proposta de UM PROCEsso de DESENVOLVIMENTO ORIENTADO A OBJETOS}

\subsection{CONSIDERAÇÕES INICIAIS}

Neste capítulo é apresentado um processo de desenvolvimento de software orientado a objetos que utiliza a notação UML, o ProDeS/UML - Processo de Desenvolvimento de Software para UML. O processo apresentado aqui é uma evolução do método Fusion (Coleman et al., 1994), valendo a pena ressaltar que diferentemente do Fusion, este processo não possui sua própria notação, é conduzido por casos de uso e dá maior ênfase à fase de Teste, auxiliando na elaboração de modelos de teste ao Iongo de todo o ciclo de vida do software.

Este processo integra modelos propostos pelo Fusion Clássico (Coleman et al., 1994), pelo TeamFusion (TeamFusion, 1997), pelo Objectory (Jacobson et al., 1992) e pelo processo proposto por Larman em (Larman, 1997). O processo proposto pelo TeamFusion é uma extensão do método Fusion para utilizar a notação UML, no entanto, ele ainda se encontra em andamento e por isso não há detalhes sobre a sua estruturaçāo. O processo proposto por Larman também 
utiliza a UML e tem algumas similaridades com o TeamFusion. Na Tabela 3.1 é apresentada a origem de cada modelo do processo, alguns modelos têm dois métodos como origem, isso acontece porque os métodos têm alguns pontos em comum.

Tabela 3.1 - Origem dos Modelos do Processo

\begin{tabular}{|l|c|c|c|c|}
\hline \multicolumn{1}{|c|}{ Modelos do Processo } & Objectory & $\begin{array}{c}\text { Fusion } \\
\text { Clássico }\end{array}$ & $\begin{array}{c}\text { TeamFusion } \\
\text { Processo de } \\
\text { Larman }\end{array}$ \\
\hline Diagrama de Casos de Uso & $\checkmark$ & & & $\checkmark$ \\
\hline Especificação dos Casos de Uso & & & & $\checkmark$ \\
\hline Diagrama de Classes do Domínio & & & $\checkmark$ & $\checkmark$ \\
\hline Diagrama de Classes da Análise & & $\checkmark$ & $\checkmark$ & \\
\hline Cenários & & $\checkmark$ & & \\
\hline Modelo de Operações & & $\checkmark$ & & \\
\hline Diagramas de Colaboração & & $\checkmark$ & & $\checkmark$ \\
\hline Diagramas de Visibilidade & & $\checkmark$ & & \\
\hline Diagrama de Classes da Análise Refinado & & $\checkmark$ & & \\
\hline Descrição de Classes & & $\checkmark$ & & $\checkmark$ \\
\hline Implementação de Classes & & $\checkmark$ & & \\
\hline
\end{tabular}

O ProDeS/UML é composto por quatro fases: Engenharia de Requisitos, Análise, Projeto e Implementação. A atividade de teste é iniciada juntamente com a Engenharia de Requisitos, estendendo-se por todo o processo de desenvolvimento, isto é, a atividade de teste é distribuída por todo o processo de desenvolvimento do software. Cada fase é descrita sucintamente a seguir.

Na fase de Engenharia de Requisitos são eliciados os requisitos do sistema em termos de casos de uso; isso é feito a partir do documento de requisitos do sistema, que deve ser elaborado pelo usuário e/ou pelo analista. Como essa fase envolve a definição dos requisitos do software, deve-se desenvolver um diagrama de classes do domínio que contém as classes de objetos do domínio da aplicação e os relacionamentos existentes entre elas. A saída dessa fase inclui a produção do diagrama de casos de uso, das especificações de cada um dos casos de uso e do diagrama de classe do domínio. Nessa fase deve-se elaborar um modelo de teste que contenha informações sobre a funcionalidade esperada das classes e do sistema, além de estabelecer prioridades para a satisfação dos requisitos de teste.

Na fase de Análise deve ser elaborado o diagrama de classes de análise, que se trata do diagrama de classes do domínio gerado na fase anterior acrescido de classes necessárias para a implementação do software. Nessa fase define-se a interface do sistema com o ambiente, por intermédio das operações que podem ser executadas. Para detectar as operações e os eventos de saída do sistema podem ser elaborados cenários de uso do sistema. Um modelo de operações deve ser construído, identificando as alterações causadas pela execução da operação, pré e póscondições envolvidas na operação, etc. As informações contidas nos cenários devem ser utilizadas para expandir o modelo de teste criado na fase anterior a fim de definir com maior precisão os requisitos funcionais das classes e do sistema.

Na fase de Projeto especifica-se cumo uma operação pode ser implementada por intermédio da interação de vários objetos que trocam mensagens entre si (diagramas de colaboração). Relações de agregação/especialização e herança e objetos de projeto podem ser criados, constituindo o diagrama de classes da análise refinado. Também faz parte do projeto a 
definição de como uma classe pode se referir a outras, ou seja, a visibilidade existente entre elas e a descrição abstrata das classes. O modelo de teste elaborado nesta fase tem como objetivo estabelecer diretrizes para testar a interação entre os métodos de uma classe e a interação entre as classes. Esse modelo pode ser representado por um diagrama de estados, por um grafo que ilustra as interaçōes intraclasse e interclasses ou ainda por cenários de teste (Vieira \& Travassos, 1998).

$\mathrm{Na}$ fase de Implementação deve-se transformar o projeto em código e gerar o Modelo de Teste da Implementação. Para a codificação do projeto pode-se utilizar as diretrizes fornecidas pelo método Fusion. O Modelo de Teste da Implementaçāo deve considerar os aspectos de implementação do sistema, como as características de herança, por exemplo. Ele deve determinar a abrangência dos conjuntos de teste que deverão ser gerados tanto para classes isoladas como para as suas interações (teste de integração), avaliar a possibilidade de reutilização de conjuntos de teste de superclasses e a sua adequação.

Durante todas as fases são desenvolvidos Modelos de Teste utilizando os modelos da fase em questão. Além dos modelos de teste de cada fase sāo desenvolvidos também os Modelos de Avaliação do Teste que têm como objetivo a verificação dos requisitos de teste gerados nos Modelos de Teste. As atividades de teste do ProDeS/UML são abordadas no Capítulo 5.

Na Figura 3.1 é mostrada a interação existente entre as fases do processo, os documentos (modelos) produzidos em cada uma delas e a origem das informações para a produção de cada modelo. Como mencionado anteriormente, supõe-se que o usuário define os requisitos do sistema ou que esse documento seja produzido em conjunto pelos usuários e profissionais envolvidos no projeto.

Recomenda-se que um dicionário de dados seja elaborado e mantido durante todo o desenvolvimento do software para definir de forma única os elementos de cada modelo e dessa forma completar a semântica de cada identificador relevante do sistema.

No final de toda fase deve-se checar a consistência e a completitude dos modelos, ou seja, deve-se verificar se não existem contradições entre os modelos e se eles representam toda a funcionalidade esperada do sistema. É importante verificar também se o dicionário de dados está atualizado.

\subsection{O PROCESSO}

\subsubsection{Engenharia de Requisitos}

A Engenharia de Requisitos é a fase na qual são descritas as propriedades gerais do domínio do problema. Há duas perspectivas nesta fase: a perspectiva estrutural capturada no diagrama de classes do domínio e a perspectiva funcional capturada no diagrama de casos de uso (acompanhado das especificações dos casos de uso).

O objetivo da fase de Engenharia de Requisitos é descrever o que o sistema deve fazer e permitir que os desenvolvedores e clientes concordem com essa descrição. Nessa fase o escopo do sistema e o comportamento esperado do mesmo são definidos, isto é, tanto os requisitos funcionais como os requisitos de qualidade devem ser estabelecidos. Uma técnica excelente para garantir o entendimento dos requisitos é a criação de casos de uso, que se tratam de descrições da 
funcionalidade do sistema. Esta seção apresenta os principais conceitos de casos de uso, diagramas de casos de uso e suas especificações.

A fase de engenharia de requisitos utiliza como entrada o documento de requisitos do sistema a partir do qual devem ser identificados os atores e os casos de uso, para que então o diagrama de casos de uso e suas respectivas especificações possam ser criados.

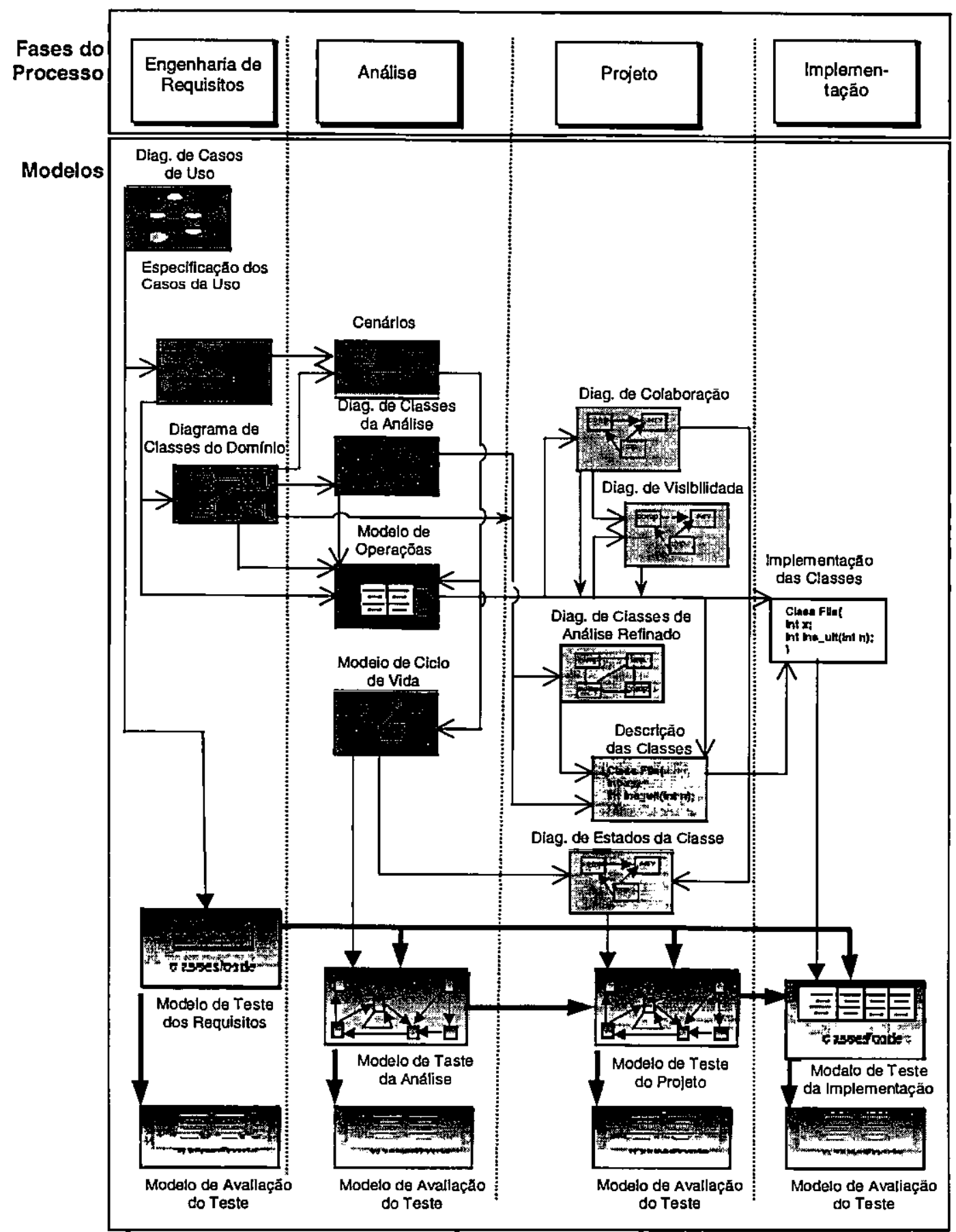

Figura 3.1 - Visão Geral do Processo 
Larman cita duas formas possíveis para a identificação de casos de uso (Larman, 1997):

$>$ Baseado em Ator:

$1^{\circ}$. Passo - identificar os atores relacionados com o sistema ou organização;

$2^{\circ}$. Passo - para cada ator, identificar os processos que eles iniciam ou participam.

$>\quad$ Baseado em Eventos:

$1^{\circ}$. Passo - identificar os eventos externos para os quais o sistema deve responder;

$2^{\circ}$. Passo - relacionar os eventos com atores e casos de uso.

\section{Diagramas de Casos de Uso}

Um diagrama de caso de uso apresenta a funcionalidade do sistema em termos de atores e casos de uso associados. Um ator é uma entidade externa que interage com o sistema, tal como um usuário ou um outro software. Um ator estimula o sistema com eventos de entrada ou recebe alguma saída dele. Um caso de uso é o conjunto de interações entre o sistema e um ou mais atores que alcançam alguns objetivos específicos. Um caso de uso é sempre iniciado por um estímulo de um ator; ocasionalmenté, outros àtores podem participar do caso de uso.

A UML propõe diversos padrões de relacionamentos entre casos de uso ou entre atores e casos de uso.

$>$ Communicates - Participação de um ator em um caso de uso. É um relacionamento que existe somente entre atores e casos de uso.

$>$ Extends - Um relacionamento extends de um caso de uso A para um caso de uso B indica que uma instância de $\mathrm{B}$ pode incluir o comportamento especificado por $\mathrm{A}$.

$>\quad$ Uses - Um relacionamento uses de um caso de uso A para um caso de uso B indica que uma instância de A usa o comportamento especificado por B.

Na UML um ator é representado por uma figura de um homem estilizado com o nome do ator abaixo da figura. Um caso de uso é representado por uma elipse e o nome do caso de uso pode ser colocado dentro da elipse ou abaixo dela. A comunicação entre atores e casos de uso é mostrada utilizando-se urna linha sólida. O relacionamento extends é mostrado por um se gmento de reta de generalização do caso de uso mais abrangente (que estende o comportamento) para o caso de uso base. O relacionamento uses é mostrado por uma linha de generalização do caso de uso cliente (que usa o comportamento) para o caso de uso que está sendo usado. Maiores detalhes sobre a notação UML para os diagramas de casos de uso podem ser obtidas no manual da notação UML (Rational, 1997b).

Na Figura 3.2 é apresentado um exemplo de um diagrama de caso de uso que modela parte da funcionalidade de um sistema de apoio à escrita que auxilia um pesquisador no gerenciamento da sua base de dados bibliográfica. Também são apresentados alguns exemplos de relacionamentos entre casos de uso.

\section{Especificação dos casos de uso}

A estrutura da especificação de um caso de uso segue geralmente um formato padrão, sendo constituída pelo nome do caso de uso, o ator que inicia o caso de uso e uma breve descrição. A UML não especifica um formato rígido, mas é importante que a especificação seja padronizada, organizada e possua um certo nível de detalhes, para propiciar um bom 
entendimento das atividades descritas, produzir uma boa documentação e facilitar o estabelecimento das prioridades de satisfação dos requisitos de teste que deverão ser estabelecidos nesta fase. Este processo utiliza um padrão de especificação de casos de uso expandido, proposto por Larman, que será apresentado posteriormente (Larman, 1997).

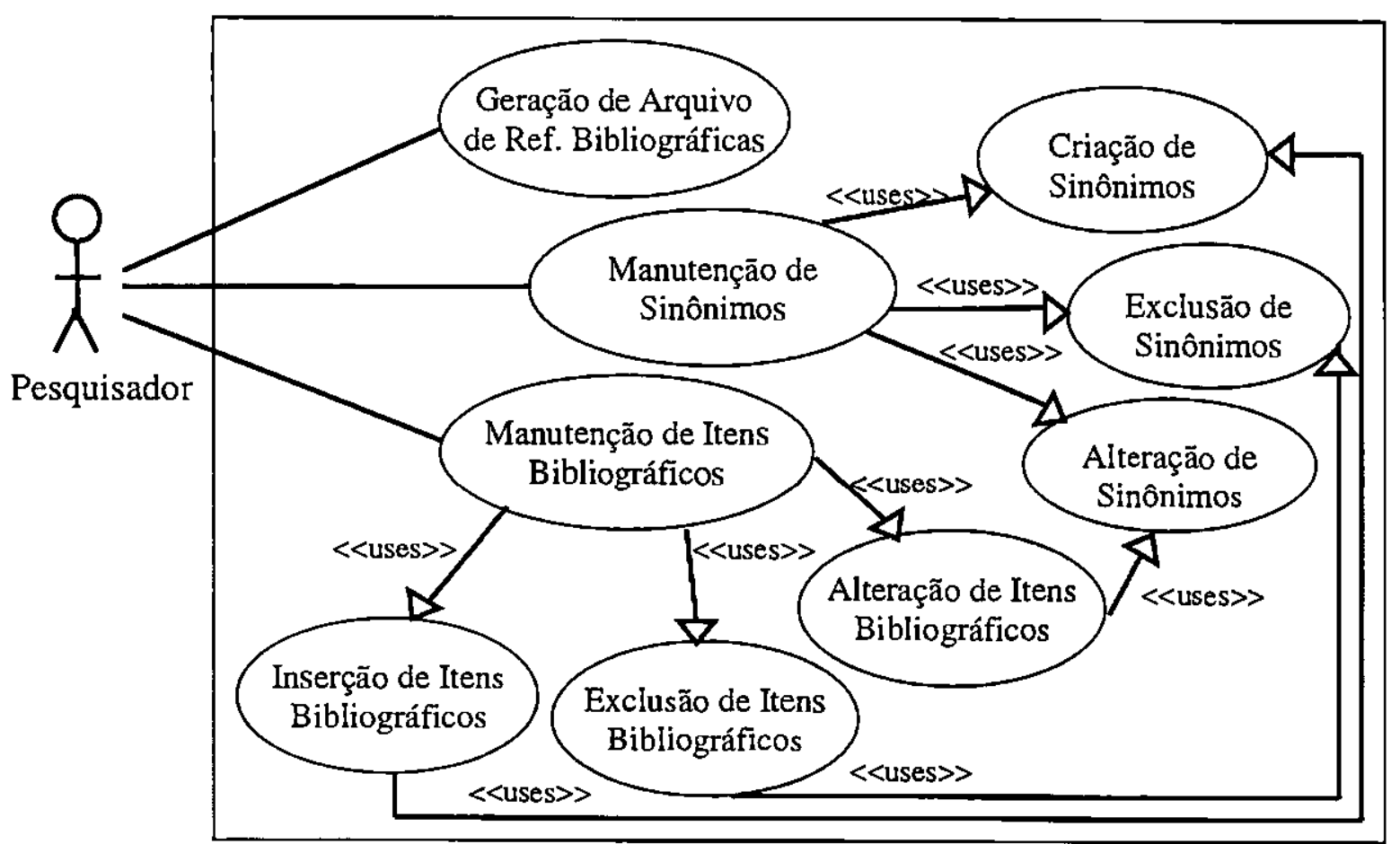

Figura 3.2 - Diagrama de Casos de Uso parcial

Um caso de uso pode ser classificado quanto ao seu detalhamento e quanto à sua importância no contexto do sistema. Considerando o nível de detalhes um caso de uso pode ser:

$>$ Essencial: caso de uso descrito de forma ideal, livre de tecnologia e detalhes de implementação;

$>$ Real: descreve concretamente a atividade, considerando o projeto atual, tecnologias de entrada e saída, etc.

Considerando a importância de um caso de uso para o sistema, ele pode ser classificado como:

$>$ Primário: processo maior ou comum;

$>$ Secundário: processo menor ou de execução esporádica;

$>$ Opcional: processo que pode não ser considerado numa certa versão do sistema.

Geralmente os casos de uso são descritos de forma essencial, sendo que posteriormente eles serão descritos de forma real, já que decisões de projeto deverão ser tomadas e as especificações deverão ser refeitas para especificar. essas decisões. Eventualmente, alguns casos de uso reais poderão ser especificados nesta fase, conforme a necessidade.

Na Figura 3.3 é apresentado o formato expandido de um caso de uso e logo em seguida, na Figura 3.4, é apresentada a especificação do caso de uso Exclusão de Itens Bibliográficos. 


\begin{tabular}{|l|l|}
\hline Caso de Uso: & Nome do caso de uso \\
\hline Ator: & $\begin{array}{l}\text { Lista dos atores (agentes externos) indicando quem inicia o } \\
\text { caso de uso. }\end{array}$ \\
\hline Propósito: & Intenção do caso de uso. \\
\hline Descrição: & Descrição do caso de uso em alto nível. \\
\hline Tipo: & $\begin{array}{l}\text { 1. primário, secundário ou opcional } \\
\text { 2. essencial ou real }\end{array}$ \\
\hline Referências Cruzadas: & $\begin{array}{l}\text { Casos de uso e funções do sistema, relacionados a este caso } \\
\text { de uso. }\end{array}$ \\
\hline
\end{tabular}

Fluxo Típico dos Eventos

\begin{tabular}{|c|c|}
\hline Ação do Ator & Resposta do Sistema \\
\hline Ações numeradas dos atores. & Descrições numeradas das respostas do sistema. \\
\hline
\end{tabular}

\section{Fluxo Alternativo}

Descrição de alternativas que podem ocorrer em determinado item.

Figura 3.3 - Formato da Especificação de' um Caso de Uso
Caso de Uso:
Atores:
Exclusão de Itens Bibliográficos
Propósito:
Pesquisador
Descrição:
Excluir um item bibliográfico da bibliografia.
Tipo:
O pesquisador seleciona o item bibliográfico e este é excluído da bibliografia.
Primário e essencial

\section{Fluxo Típico dos Eventos}

\section{Ação do Ator}

1. O pesquisador recupera o item bibliográfico por meio dos itens de informação: autor, título e sinônimos de autor e título.

3. O pesquisador confirma a exclusão.

\section{Resposta do Sistema}

2. O sistema mostra os itens de informação do item bibliográfico e pede que o pesquisador confirme a exclusão apresentando a seguinte mensagem: "Confirma a exclusão do item bibliográfico?"

4. O item bibliográfico é excluído da bibliografia e a seguinte mensagem é mostrada: "Item bibliográfico excluído."

\section{Fluxo Alternativo}

Linha 2 - O item bibliográfico não foi encontrado na bibliografia, então a mensagem ("Item bibliográfico não encontrado") é mostrada ao pesquisador e a exclusão é cancelada.

Linha 3 - O pesquisador não confirma a exclusão do item bibliográfico.

Linha 4-A exclusão não é efetuada.

Figura 3.4 - Exemplo da Especificação do Caso de Uso Exclusão de Itens Bibliográficos

Um caso de uso pode conter pontos de decisão. Por exemplo, quando um cliente vai efetuar uma compra, ele pode escolher pagar em dinheiro, cheque ou cartão de crédito. Se uma das opções representa o caso típico e as outras opções são raras, não usuais ou excepcionais, então o caso típico deve ser escrito em Fluxo Típico dos Eventos e as outras alternativas devem ser escritas na seção Fluxo Alternativo. No entanto, existem casos em que as alternativas são 
relativamente iguais ou normais. Isso é válido para o exemplo citado acima, neste caso pode ser usada a seguinte estrutura:

1. Indicar ramos para subseções dentro da seção Fluxo Típico dos Eventos;

2. Escrever uma subseção para cada ramo, novamente utilizando Fluxo Típico dos Eventos. A numeração dos eventos deve iniciar em 1 em cada uma das subseções.

3. Se as subseções têm alternativas, escrevê-las na seção Fluxo Alternativo de cada subseção.

Na Figura 3.5 é apresentado o Fluxo Típico dos Eventos para o caso de uso Comprar Itens, que ilustra o problema de alternativas de pagamento, apresentado anteriormente.

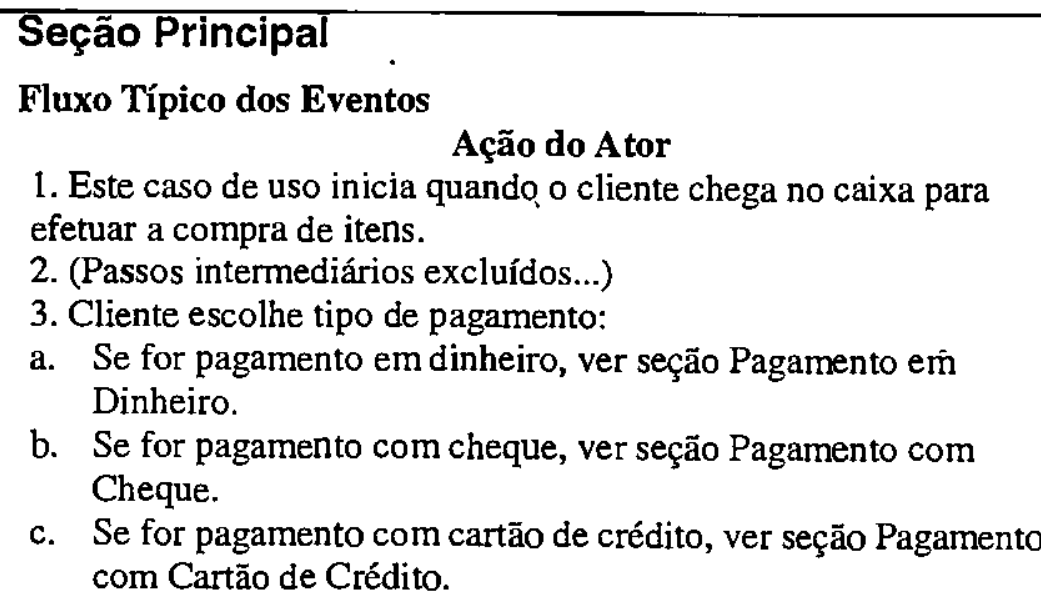

4. A venda é encerrada.

6. O Caixa dá o recibo para o Cliente.

5. Imprime um recibo.

7. O Cliente sai com os itens adquiridos.

\section{Seção Pagamento em Dinheiro}

\section{Fluxo Típico dos Eventos}

\section{Ação do Ator}

1. O Cliente dá o dinheiro, possivelmente a quantia em dinheiro é maior que o valor total da compra.

2. O Caixa registra o pagamento.

4. O Caixa deposita o dinheiro recebido, retira o troco e 3. Mostra o troco que deve ser devolvido ao Cliente.

\section{Resposta do Sistema}

o entrega ao Cliente.

\section{Fluxo Alternativo}

Linha 4: Dinheiro insuficiente na gaveta para fornecer o troco, então o Caixa pede dinheiro para 0 Supervisor de Caixa.

\section{Seção: Pagamento com Cheque}

Cursos Típico e Alternativo para o pagamento com cheque.

\section{Seção: Pagamento com Cartão de Crédito}

Cursos Típico e Alternativo para o pagamento com cartão de crédito. 
Algumas normas podem ser seguidas para padronizar os diagramas de casos de uso e suas especificações, como por exemplo:

$>$ começar os nomes dos casos de uso sempre com um verbo para indicar que se trata de um processo. Exemplo: comprar itens.

$>\quad$ identificar claramente o ator e o evento que iniciam o caso de uso. Exemplo: Este caso de uso inicia-se quando o Cliente chega ao caixa para efetuar uma compra de itens.

\section{Diagrama de Classes do Domínio}

O diagrama de classes do domínio tem por objetivo representar os conceitos existentes no domínio do problema e șuas relações, ignorando questões que se aproximem do projeto ou da implementação. Assim, as classes, atributos e relacionamentos pertencem ao ambiente da aplicação ou então ao próprio sistema.

Um diagrama de classes de domínio minucioso é melhor que um diagrama de classes de domínio generalizado (em alto nível), ou seja, é sempre melhor criar um diagrama com muitos conceitos. Deve-se adicionar ao diagrama conceitos nāo percebidos durante a fase inicial de identificação, pois é comum descobrir conceitos durante a análise dos atributos e/ou associações ou ainda durante a fase de análise. É perfeitamente válido ter conceitos sem atributos ou conceitos que têm uma função puramente comportamental no domínio ao invés de uma função informativa.

Esse diagrama permite representar classes, atributos e relacionamentos entre classes, incluindo agregação e especialização/generalização. A notação usada é a do diagrama de classes da UML. Por modelar o domínio da aplicação, as associações (relacionamentos) não têm direção de navegação e as classes não possuem operações, as operações somente serão incorporadas na fase de projeto.

Nos diagramas de classes da UML uma classe é representada por um retângulo com três compartimentos, conforme indicado na Figura 3.6; o primeiro compartimento é para o nome da classe, o segundo para os seus atributos e o último para as suas operações. As associações são mostradas como linhas que conectam classes. Existe uma variedade de adomos para indicar as propriedades das associações, como nome da associação, cardinalidade, papéis, direcionamento, etc. Nomes de papéis e direcionamento são úteis para deixar claro a ordem de leitura dos relacionamentos, principalmente em auto-relacionamentos.

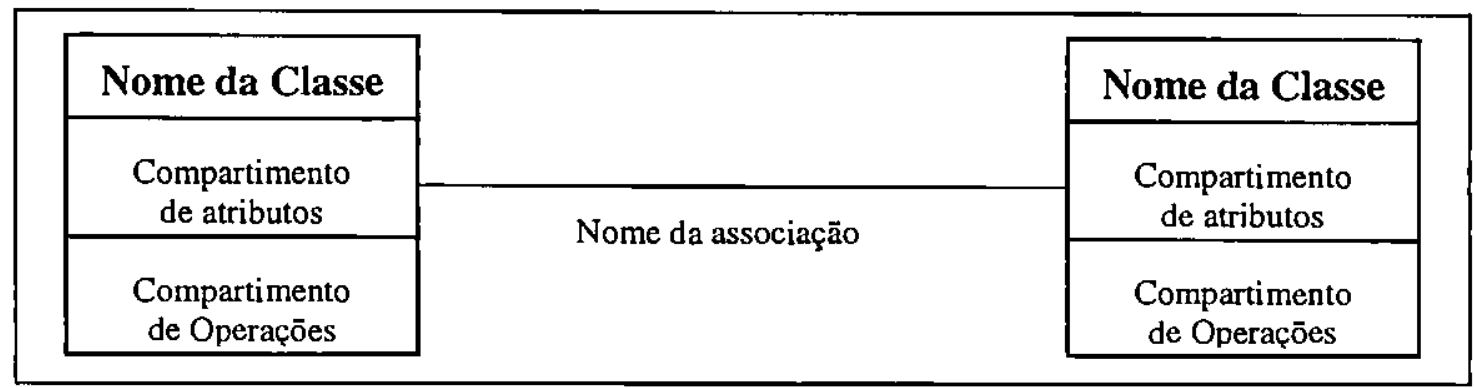

Figura 3.6 - Notação de Classes e Associações

Relacionamentos especiais como agregação, especialização/agregação e dependência podem ser representados nos diagramas de classes da UML. Na Figura 3.7 é apresentada a 
notação dos tipos de relacionamentos existentes nos diagramas de classes da UML. Maiores detalhes a respeito da notação dos diagramas de classes são encontrados em (Rational, 1997b).

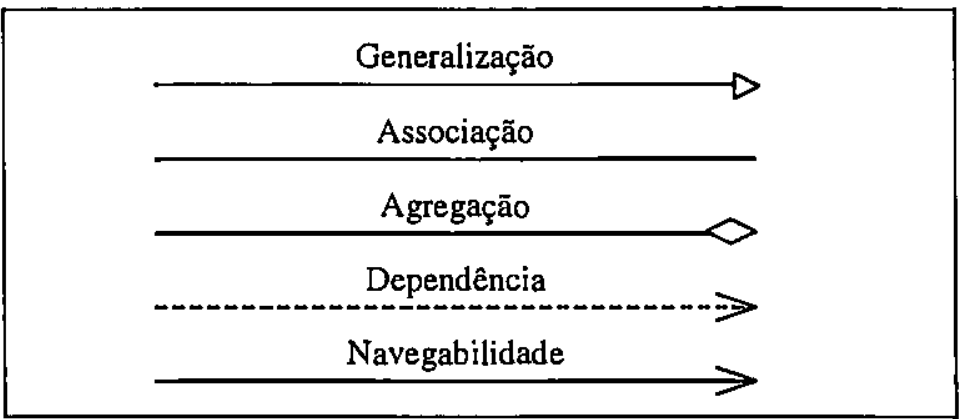

Figura 3.7 - Exemplos de tipos de relacionamentos

Para elaborar o diagrama de classes do domínio pode-se realizar os seguintes passos:

1. se já existir um diagrama de classes de domínio então utilizá-lo como ponto de partida;

2. eliciar os conceitos (examinar as especificações de casos de uso para encontrar as classes candidatas e associações);

3. desenhá-los no diagrama de classes do domínio;

4. adicionar as associações necessárias para registrar os relacionamentos existentes entre os conceitos. Verificar a existência de associações de generalização (é um ou tipo de) e agregação (parte de ou tem um);

5. adicionar cardinalidades às associações;

6. adicionar os atributos necessários para satisfazer os requisitos.

Na Figura 3.8 é apresentado um exemplo parcial do diagrama de classes do domínio do SAPES.

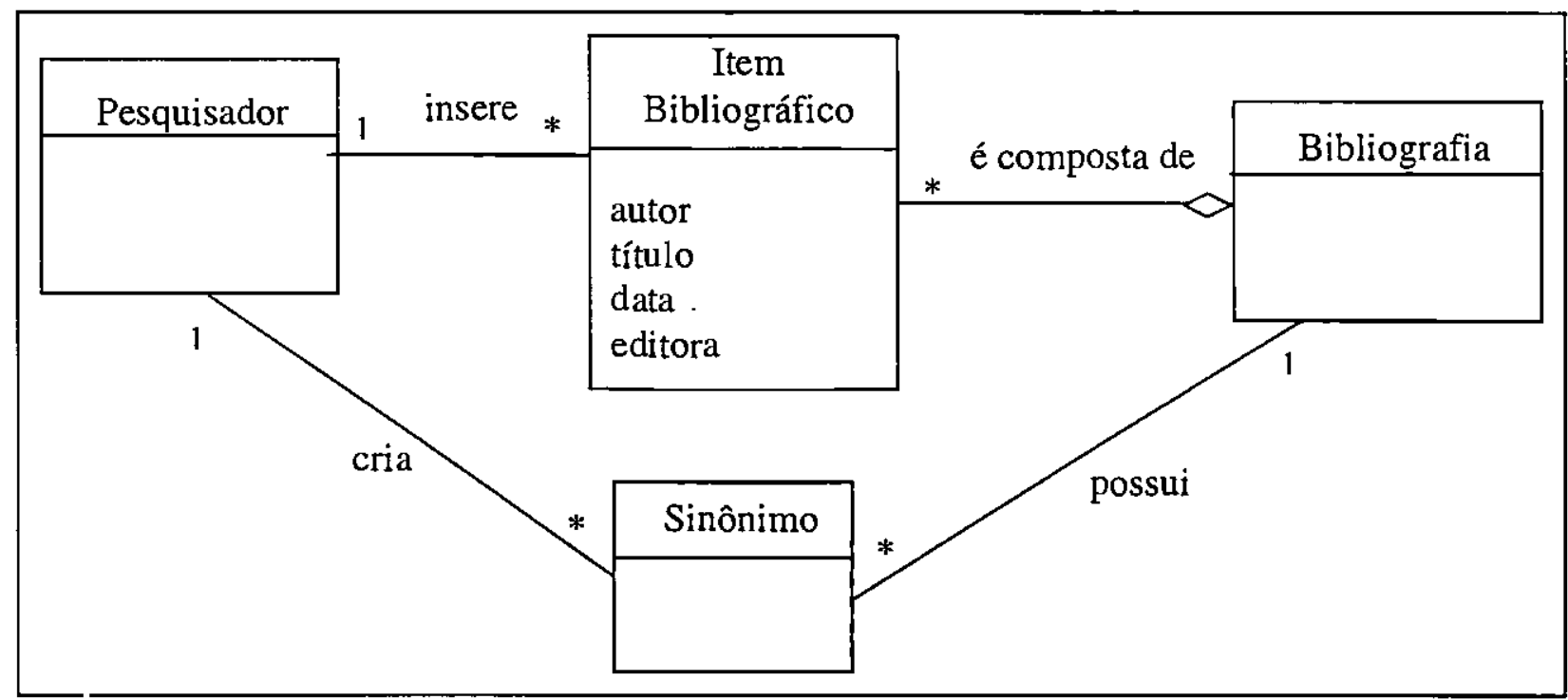

Figura 3.8 - Exemplo de Diagrama de Classes do Domínio 


\subsubsection{Análise}

O objetivo da fase de Análise é especificar o comportamento esperado do sistema. Para isso, nesta fase define-se a interface do sistema com o ambiente, por intermédio das operações que podem ser executadas.

A fase de análise produz os seguintes modelos: diagrama de classes da análise, cenários, modelo de operações e modelo de teste da análise. Os cenários não são obrigatórios, mas eles auxiliam na detecção das operações e eventos de saída do sistema. Os objetos e operações do sistema são definidos sem se preocupar com a maneira como eles serão implementados.

Depois de ter desenvolvido todos os modelos da fase, deve ser feita uma checagem para averiguar a consistência entre os modelos de análise e deles com os modelos da fase anterior.

\section{Diagrama de Classes da Análise}

O diagrama de classes da análíse é criado a partir do diagrama de classes do domínio. Os limites do sistema são definidos excluindo algumas classes e relacionamentos e dando origem aos agentes do ambiente (ou entidades externas) e a classes de interface. Para definir os agentes externos e as classes de interface são utilizados estereótipos, que são mecanismos de extensão da UML utilizados para classificar elementos dos modelos. Os agentes externos são identificados pelo estereótipo <<actor>> ou então pela figura de um homem estilizado. Classes de interface' são definidas pelo estereótipo <<interface $>$. Todas as classes classificadas como ator ou interface não serão implementadas, ou seja, elas estão fora do escopo do sistema. Relacionamentos existentes entre uma classe sem estereótipo e um ator ou uma interface também não fazem parte do escopo, logo não serão implementados. Classes de associação (association classes) provenientes desses relacionamentos também não serão implementadas.

Para criar o diagrama de classes da análise, o diagrama de classes do domínio é estendido de forma a incluir todas as suas classes e relacionamentos, mais novas classes e relacionamentos necessários para a implementação do sistema. Nesse diagrama as classes ainda não têm operações associadas a elas. A notação utilizada neste diagrama é a mesma dos diagramas de classes da UML, já comentada na seção anterior. Um exemplo de diagrama de classes da análise é apresentado na Figura 3.9. Nesta figura aparecem duas classes de associação, elas são classes resultantes de relacionamentos, por isso são conectadas a um relacionamento por meio de uma linha tracejada. As classes de associação possuem todas as características comuns às classes, mas elas são utilizadas principalmente para armazenar atributos de relacionamentos.

\section{Cenários}

Para estabelecer os limites do sistema pode-se usar cenários, que são sequiências típicas de uso do sistema, com o objetivo de determinar os eventos e os dados originados dos usuários (entradas) e as reações do sistema (saídas). Nos cenários o sistema é visto como uma caixa preta, pois só é mostrada a interação entre os agentes (atores) e o sistema, ocultando o comportamento interno do sistema. Os cenários são diagramas de tempo que envolvem o sistema e os agentes, não fazendo parte dos modelos do sistema, isto é, são apenas diagramas auxiliares.

\footnotetext{
${ }^{1}$ Classes de interface $=$ Classes que possuem operações abstratas e que sāo visíveis externamente.
} 
A criação dos cenários depende do diagrama de classes do domínio e das suas especificações. Os casos de uso mostram como um ator interage com o sistema. Durante essa interação, o ator gera algum evento para o sistema e pede alguma resposta. Por exemplo, quando o pesquisador entra com os dados de um item bibliográfico ele espera que o sistema armazene esse item na bibliografia.

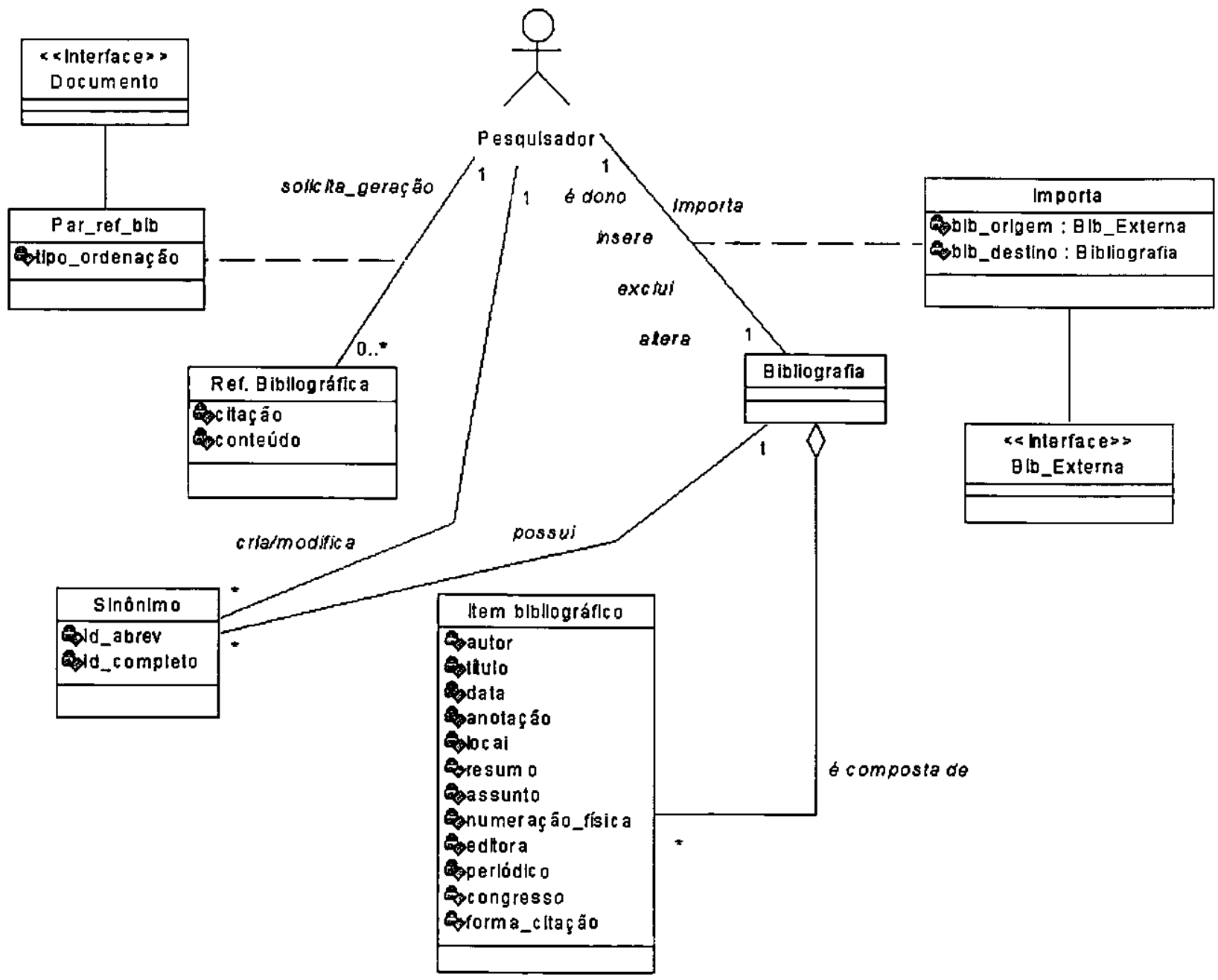

Figura 3.9 - Exemplo de um Diagrama de Classes da Análise

* Os diagramas de seqüência da UML podem ser utilizados para construir cenários, mas nesse caso os objetos do diagrama de sequiência só podem ser os atores do sistema e uma classe que representa o sistema como um todo, pois um cenário mostra a interação entre os atores e o sistema. Um diagrama de seqüência mostra uma interação arranjada em uma sequiência de tempo, mostra os objetos participando na interação pelas suas linhas de vida e as mensagens que eles trocam nessa seqüência de tempo. Um exemplo de cenário utilizando a notação dos diagramas de sequiência é mostrado na Figura 3.10.

Um diagrama de seqüência tem duas dimensões: a dimensão vertical que representa o tempo e a horizontal que representa os objetos. Cada objeto é representado por um retângulo com o nome do objeto/classe sublinhado. Cada objeto possui sua linha de vida, representada por uma linha vertical pontilhada. Uma barra vertical sobre a linha de vida de um objeto indica um período em que o objeto esteve ativado. A comunicação entre os objetos é representada por uma linha de mensagem horizontal entre as linhas de vida dos objetos envolvidos. 


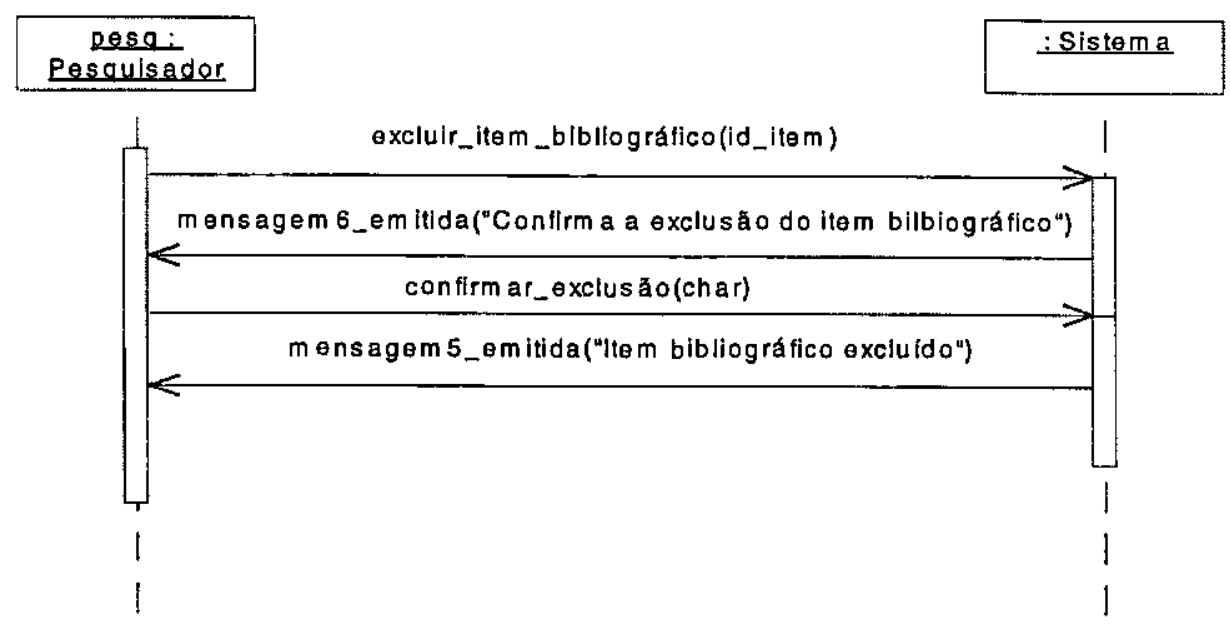

Figura 3.10 - Cenário de exclusão de item bibliográfico confirmada

\section{Modelo de Operações}

Como a UML não oferece recursos para modelagem textual, este processo adota o modelo de operações do Fusion clássico. Ele especifica o comportamento de uma operação individual de forma declarativa em termos de mudança de estado do sistema e geração de eventos de saída. A elaboração do modelo de operações utiliza informações das especificações dos casos de uso e dos cenários e do diagrama de classes da análise. É possível obter, a partir dos cenários, uma listagem das operações e dos eventos de saída relacionados a elas.

Assim como no Fusion clássico, o modelo de operações especifica o comportamento de uma operação do sistema de forma declarativa em termos de mudanças de estado do sistema e geração de eventos de saída. O modelo de operações usa uma notação textual, na forma de um gabarito que pode ser visto na Figura 3.11. Nesse gabarito há entradas para especificar: os dados que são fornecidos junto com os eventos de entrada; os objetos acessados pela operação; os eventos de saída gerados pela operação; as pré e pós-condições que devem ser satisfeitas, comentários ou notas de projeto relevantes, e referências existentes entre a operação e casos de uso ou funções do sistema.

\begin{tabular}{|ll|}
\hline Operação: & nome da operação \\
Descrição: & descrição da operação \\
\hline Lê: & itens de dados \\
Modifica: & itens de dados \\
Envia: & agentes e evento \\
Assume: & condição (pré-condição) \\
Resultado: & estado (pós-condição) \\
Notas: & comentários ou notas de projeto e/ou de algoritmos \\
Ref. Cruzadas: & casos de uso e funções do sistema, relacionados a esta operação \\
\hline
\end{tabular}

Figura 3.11 - Formato do Modelo de Operação

Uma operação do sistema pode:

- Criar uma nova instância de uma classe

- Modificar o valor de um atributo de um objeto existente

- Adicionar ou remóver uma tupla de objetos de um relacionamento

- Enviar um evento de saída para um agente 
A pré-condição especifica as condições para uma operação ser invocada e a pós-condição especifica as mudanças de estado do sistema causadas pela operação e os eventos de saída enviados aos atores. Elas sāo descritas como seqüências de cláusulas descritivas (predicados lógicos) que podem ser falsas ou verdadeiras. O modelo de operaçбes não se refere aos estados intermediários pelos quais o sistema passa enquanto a operação é executada, sendo apenas especificado o estado final. Os estados intermediários dependem de como a operação é executada e por isso devem ser detalhados nas fases de projeto e implementação (Coleman et al., 1994).

A sintaxe das pré- e pós- condições é informal, mas algumas regras de boa formação são requeridas. Os identificadores usados devem existir no modelo de objetos e estarem definidos no dicionário de dados. A operação só deve ser executada se a pré-condição especificada for verdadeira. Nas pós-condições o estilo de redação deve usar o tempo pretérito, pensando no estado do sistema após a execução da operação. Assim, deve-se escrever: $O$ objeto xxx foi criado, $O$ atributo yy recebeu o valor zz, etc. Na Figura 3.12 é apresentado o modelo de operação para a operação excluir_item_bibliográfico do SAPES.

\begin{tabular}{|ll|}
\hline Operação & Excluir_item_bibliográfico \\
Descrição & Elimina um Item Bibliográfico da Bibliografia. \\
\hline Lê: & i: id_item, confirmação, system.acesso \\
Modifica: & Bibliografia, Item Bibliográfico \\
Envia: & Pesquisador: \{mensagem12_emitida\} \\
& Pesquisador:\{mensagem5_emitida\} \\
& Pesquisador:\{mensagem6_emitida\} \\
Pré-condição: & system.acesso=confirmado \\
Pós-condição: & Se i não foi encontrado na Bibliografia então mensagem12_emitida \\
& $\begin{array}{l}\text { ("Item Bibliográfico não encontrado") foi enviado ao Pesquisadore a } \\
\text { exclusão foi cancelada. }\end{array}$ \\
& $\begin{array}{l}\text { Se i foi encontrado em Bibliografia então mensagem6_emitida } \\
\text { ("Confirma a exclusão de Item Bibliográfico?") foi enviado ao }\end{array}$ \\
& $\begin{array}{l}\text { Pesquisador. Se o Pesquisador confirmou a exclusão então i foi } \\
\text { eliminado de Bibliografia e de Item Bibliográfico, e }\end{array}$ \\
& mensagem5_emitida foi enviado ao Pesquisador ("Item Bibliográfico \\
& excluído"). \\
Notas: & \\
Ref. Cruzadas: & Caso de uso n.o 5 - Exclusão de item bibliográfico
\end{tabular}

Figura 3.12 - Modelo de Operação - Excluir Item Bibliográfico

Durante a análise todas as operações devem ser consideradas atômicas. Portanto, a execução de uma não interfere com a outra. Interferências causadas por concorrência devem ser tratadas somente na fase de projeto.

É importante ressaltar que as operações da fase de análise serão chamadas de métodos na fase de implementação, sendo que a única diferença existente é a terminologia. 


\section{Modelo de Ciclo de Vida do Sistema}

O Modelo de Ciclo de Vida descreve o comportamento completo de como o sistema se comunica com o ambiente, desde a sua criação até o seu término. Por meio do Modelo de Ciclo de Vida é possível verificar as seqüências permitidas de execução das operações do sistema. $\mathrm{O}$ Modelo de Ciclo de Vida usa como fontes de informação os Cenários e os Modelos de Operações. Todas as operações que aparecem nesses modelos devem constar no Modelo de Ciclo de Vida.

O Modelo de Ciclo de Vida usa a notação do diagrama de estados da UML. Nele os eventos são as operações do sistema (eventos de entrada) e os estados resultantes representam o estado alcançado pelo sistema após a execução de uma determinada operação.

O diagrama tem um estado inicial mostrado com um círculo preenchido e pode ter mais de um estado final, mostrados por um círculo branco com um círculo preto dentro. Os estados são representados por um retângulo com os cantos arredondados e as transições entre estados por uma seta de um estado para o outro. As transições de estados estão associadas a eventos, neste caso são as operações do sistema. Essas transições são disparadas sempre que a operação for executada, causando uma possível alteração no estado do sistema. Na Figura 3.13 é apresentado o Modelo de Ciclo de Vida do SAPES. O evento $\lambda$ representa um evento que é disparado automaticamente quando a execução da operação anterior é finalizada. [não Ok] e [Ok] indicam pós-condições em relação ao resultado da operação validar_usuário.

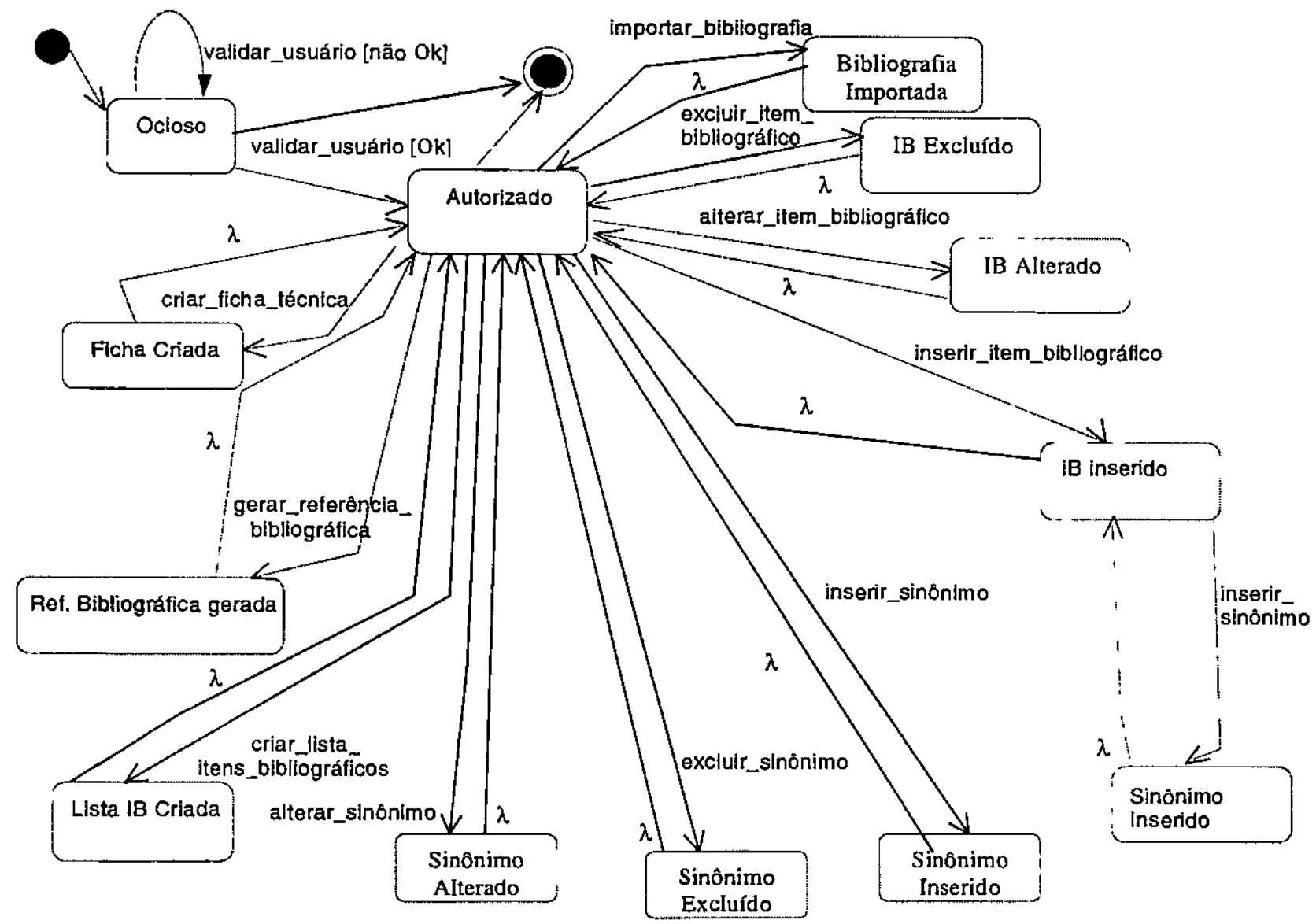

Figura 3.13 - Modelo de Ciclo de Vida do SAPES 


\section{Checagem dos Modelos}

Após ter desenvolvido todos os modelos de análise, alguns critérios podem ser seguidos para checar que a análise está completa:

1. Todas as operações do sistema no modelo de ciclo de vida têm um esquema no modelo de operações:

2. Todas as informações estáticas eliciadas estão representadas no diagrama de classes da análise;

3. Todas as operações que aparecem nos cenários têm um esquema no modelo de operações;

4. Consistência entre casos de uso e modelos de análise: os cenários devem cobrir todos os possíveis usos do sistema e devem ser condizentes com as especificações dos casos de uso. Deve ser feito um teste de mesa dos cenários usando os esquemas do modelo de operações, simulando as mudanças de estado do sistema. Finalmente, deve-se verificar se o resultado obtido é o esperado;

5. Consistência entre modelo de operações e diagrama de classes de análise. Todos os objetos, associações e parâmetros mencionados na especificação das operações devem ser representados no diagrama de classes de análise. Todos os outros conceitos (ex. predicados) devem ser mencionados ao menos uma vez e estar definidos no dicionário de dados;

6. Todos os identificadores em todos os modelos têm entradas no dicionário de dados.

\subsubsection{Projeto}

$\mathrm{Na}$ fase de Projeto especifica-se como uma operação pode ser implementada por intermédio da interação de vários objetos que trocam mensagens entre si. Definem-se uma classe controladora da operação, um conjunto de classes colaboradoras e os métodos relevantes. Estes aparecem na troca de mensagens entre as classes para executar a operação e são associados às classes que recebem as mensagens (servidoras). A partir dos diagramas de colaboração que mostram a interação entre os objetos, define-se a visibilidade que deve existir entre as classes. Relações de herança e objetos de projeto, não existentes no domínio da aplicação, podem ser criados. Com isso define-se como uma classe pode se referir a outras e completam-se os atributos de cada classe. Todas essas informações são reunidas em descrições abstratas de classes.

O propósito principal da fase de projeto é especificar como as funcionalidades do sistema, definidas no modelo de operação, serão implementadas pela interação dos objetos do sistema, para isso, nessa fase, os objetos do sistema passam a ter identificadores, atributos e uma interface (métodos e seus parâmetros). As saídas dessa fase são: diagramas de colaboração, diagrama de visibilidade, diagrama de classes da análise refinado e descrição de classes, que são descritas nesta seção. A seguir são apresentadas alternativas para a determinação de classes controladoras.

\section{Classe Controladora}

Um evento do sistema é um evento de entıada gerado por um ator. Eles são associados a operações do sistema, pois elas respondem aos eventos do sistema. Uma classe controladora é um objeto de interface responsável por tratar um evento do sistema. Uma classe controladora define um método para a operação do sistema. 
Durante a análise do comportamento do sistema, as operações do sistema são descobertas e podem ser associadas ao tipo System para indicar que elas são operações do sistema. Na fase de projeto as operações do sistema devem ser alocadas a uma classe controladora, no entanto, provavelmente não existirá uma classe System a qual elas possam ser associadas. Então, torna-se necessário estabelecer uma classe controladora para as operações do sistema. Larman apresenta quatro alternativas para a escolha da classe controladora (Larman, 1997):

1. Classe que representa o sistema como um todo;

2. Classe que representa o negócio ou organização como um todo;

3. Classe que representa alguma coisa no mundo real que é ativa e está envolvida na tarefa;

4. Classe artificial que trata todos os eventos do sistema de um caso de uso.

A escolha de qual das quatro classes é mais apropriada para ser controladora é influenciada por fatores como coesão e acoplamento. Na Figura 3.14 são apresentadas, de acordo com as opções citadas, possíveis classes controladoras para a operação entrar_item de um sistema de vendas de uma loja.

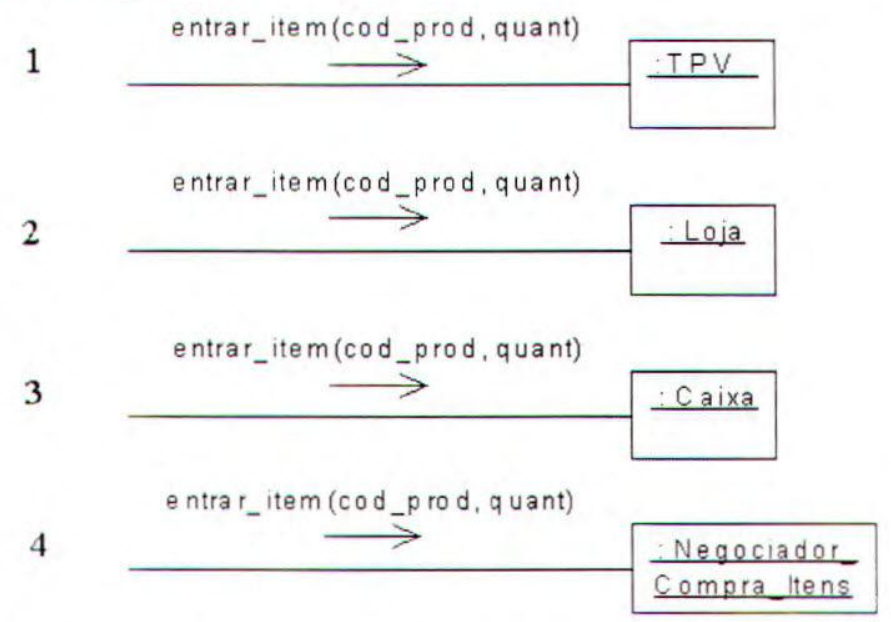

Figura 3.14 - Classes controladoras para um sistema de vendas de uma loja

Uma mesma classe controladora pode ser usada para todos os eventos do sistema de um caso de uso, sendo possível manter informações sobre o estado do caso de uso. Essas informações são úteis para identificar seqüências de saída de eventos do sistema, por exemplo, uma operação efetuar_pagamento deve ser executada antes da operaçãofim_de_venda.

Um problema comum no projeto de controladores é atribuir muita responsabilidade a uma classe controladora. $\mathrm{O}$ ideal seria que a classe controladora delegasse trabalho para outros objetos e coordenasse a atividade. Objetos de interface com o usuário (objetos de janelas, applets, etc.) não devem ter responsabilidade para com os eventos do sistema, esses eventos devem ser controlados por objetos do domínio da aplicação.

As duas primeiras alternativas (classe controladora que representa todo o sistema ou todo o negócio) são boas quando os eventos do sistema são poucos ou quando não é possível redirecionar as mensagens dos eventos do sistema para outros controladores, como por exemplo, um sistema de processamento de mensagens. Essas alternativas garantem baixa coesão e alto acoplamento. 
Quando há muitos eventos do sistema e eles são distribuídos em diferentes processos a melhor opção é a última (classes controladoras para eventos de um mesmo caso de uso), pois com qualquer uma das outras opções a classe controladora ficaria sobrecarregada com a diversidade de eventos do sistema. Essa opção permite saber o estado do processo. Tendo escolhido o tipo de classe controladora que melhor se adequa ao sistema em questão, pode-se passar para a elaboração dos diagramas de colaboração.

\section{Diagramas de Colaboração}

O modelo de operação mostra o funcionamento geral de uma operação. No entanto, não é possível saber por meio deles como as classes interagem entre si para a execução de uma operação. A UML define dois tipos de diagramas de interação: os diagramas de sequiência e os diagramas de colaboração. Os diagramas de colaboração se adequam melhor nesse contexto, pois mostram a interação entre os objetos sem enfatizar o tempo.

Deve-se utilizar as informações contidas no modelo de operação para elaborar um diagrama de colaboração para cada uma das operações existentes no modelo de operação. Os objetos e relacionamentos mencionados nas cláusulas Lê e Modifica do modelo de operação auxiliam a determinar os objetos envolvidos na interação. Um objeto controlador da operação deve ser especificado. Essa operação do sistema deve ser adicionada à interface da classe controladora no diagrama de classes da análise refinado. Os demais objetos que interagem para a execução da operação são colaboradores. A troca de mensagens entre o controlador e os colaboradores dá origem aos métodos, que são associados às classes nesta fase. A seqüência de mensagens entre os objetos de projeto produz o comportamento funcional dos objetos especificado pelo esquema da operação correspondente.

Na Figura 3.15 é mostrado o relacionamento existente entre os elementos dos modelos. Os casos de uso sugerem os eventos do sistema que são mostrados explicitamente nos cenários. Cada uma das operações do sistema que aparece nos cenários é descrita por um modelo de operação. Cada uma das operações representa mensagens que iniciam os diagramas de colaboração.

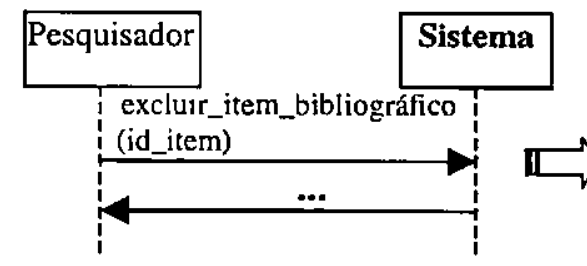

Cenário

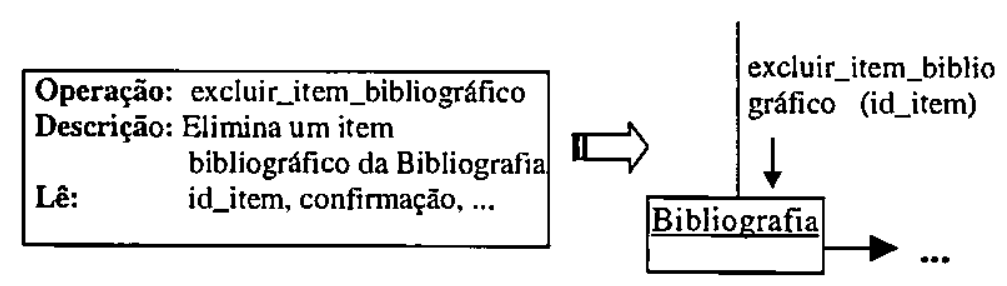

Diagrama de Colaboração

Figura 3.15- Relacionamento entre os elementos dos modelos

Um diagrama de colaboração mostra os objetos que participam da operação, as ligações (links) existentes entre eles e as mensagens enviadas entre os objetos participantes. As ligaçōes são instâncias das associações existentes entre as classes. Os objetos são desenhados como classes, mas seus nomes são sublinhados. As ligaçōes são representadas por linhas, assim como as associações entre classes, mas as ligações não possuem cardinalidade. A uma ligação pode ser associada uma mensagem que, entre outros adornos, possui um número de sequiência, que tem 
como objetivo mostrar a ordem seqüencial das mensagens na execução daquela operação. Um diagrama de colaboração é iniciado por uma operação documentada no modelo de operação.

A UML tem a seguinte sintaxe para as mensagens (os termos entre chaves são opcionais) : N. ${ }^{\circ}$ SEEQÜÊNCIA:[RETORNO:=] MENSAGEM(PARÂMETRO [:TIPO_DO_PARÂMETRO]) [:TIPO_DO_RETORNO]

O diagrama de colaboração mostra os objetos relevantes para a execução de uma operação, incluindo objetos afetados indiretamente ou acessados durante a operação. A colaboração usada para descrever uma operação inclui argumentos e variáveis locais criados durante a execução. Objetos criados durante a execução podem ser designados como \{new\}, objetos destruídos durante a execução podem ser designados como \{destroyed\}, objetos criados e destruídos durante a execução podem ser designados como \{transient\}. A criação de um objeto pode ser acompanhada pela invocação de um método create para atribuir valores iniciais aos atributos do objeto criado. Uma mensagem rotulada por create indica que houve a criação dinâmica de uma instância do objeto.

A UML fornece recursos para enviar mensagens para uma coleção de objetos (instâncias), denominada Multiobjeto; que pode ser mostrada no diagrama de colaboração como uma pilha de classes, conforme apresentado na Figura 3.16. Uma mensagem enviada a um multiobjeto indica que ela foi enviada à própria coleção de objetos. Por exemplo, na Figura 3.15 a mensagem tamanho é enviada para a instância $i$ para consultar o número de elementos de $i$.

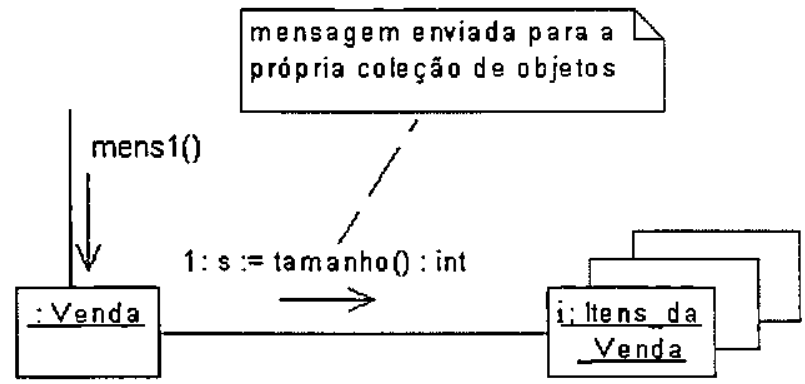

Figura 3.16 - Mensagem para um multiobjeto (Larman, 1997)

Para executar uma operação para cada objeto da coleção deve-se enviar duas mensagens. A primeira deve ser enviada para a coleção, para que esta retorne uma referência a um objeto, e a segunda mensagem deve ser enviada diretamente para o objeto referenciado. Isso constitui uma iteração identificada na mensagem por um * que deve aparecer logo após o número de sequiência da mensagem (Rational, 1997b).

A UML fornece recursos para que um objeto envie mensagens para ele mesmo e para enviar mensagens condicionais. Para enviar mensagens de um objeto para ele próprio, pode-se utilizar estereótipos como $<<$ self $\gg$. Detalhes sobre esses tipos de mensagens e sobre a notação UML como um todo constam no Manual da Notação UML (Rational, 1997b). Na Figura 3.17 é apresentado o diagrama de colaboração para a operação Excluir_item_bibliográfico.

Para checar a consistência de um diagrama de colaboração, deve-se verificar se cada uma das classes do diagrama de classes da análise é usada em ao menos um diagrama de colaboração. Novas classes podem ser introduzidas no projeto, que não fazem parte do diagrama de classes da análise. Elas devem ser acrescentadas ao diagrama de classes da análise refinado. 


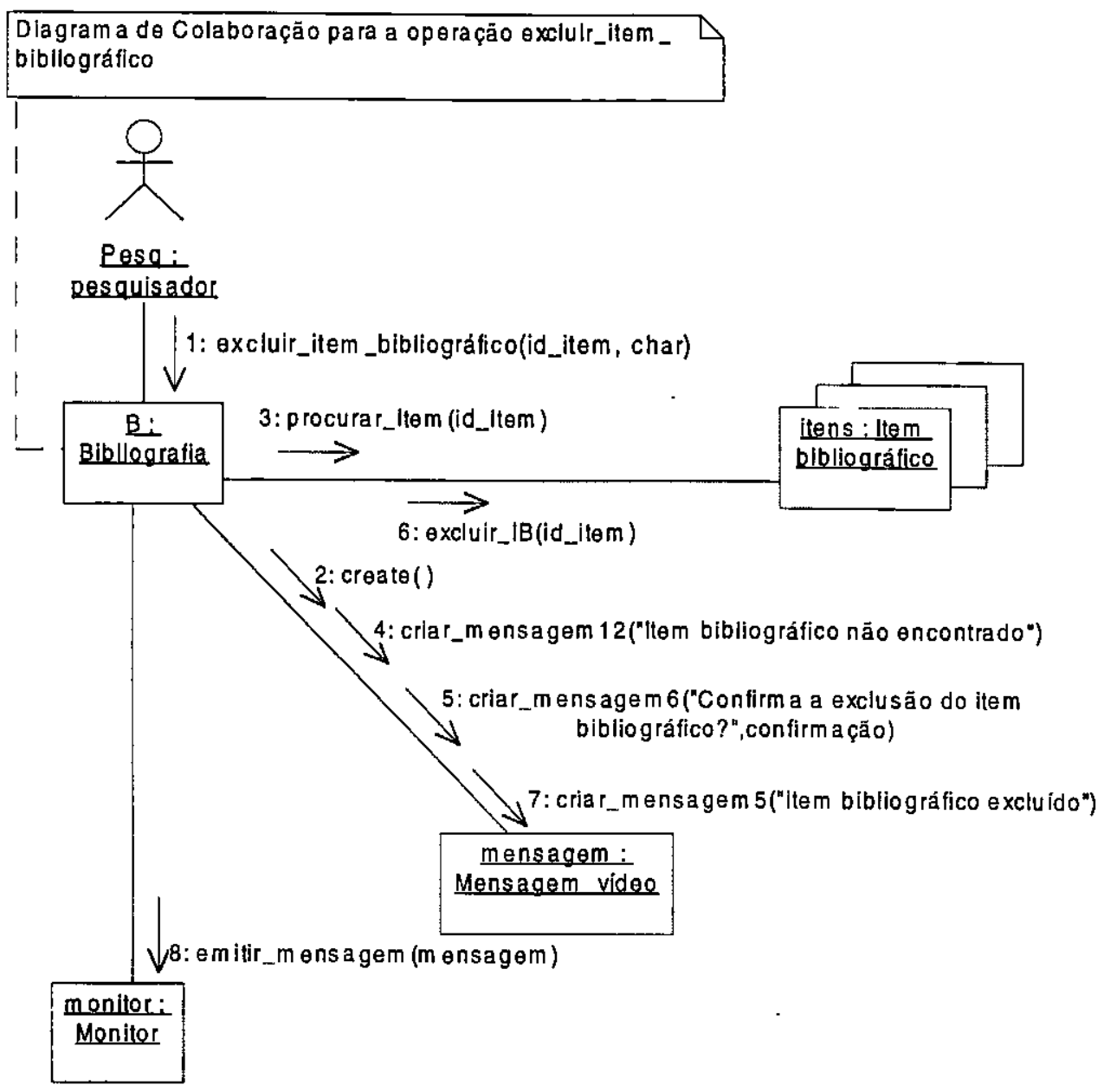

Figura 3.17 - Diagrama de Colaboração para a operação Excluir_item_bibliográfico

O diagrama deve ser complementado em seu significado por uma descrição textual da operação armazenada no dicionário de dados na forma de uma narrativa em português, ou pseudocódigo ou uma especificação formal.

\section{Diagrama de Estados da Classe}

O Diagrama de Estados da Classe descreve o comportamento de uma classe em particular, desde a sua criação até o seu término. Assim como o Modelo de Ciclo de Vida, o diagrama de estados da classe usa a notação do diagrama de estados da UML. A única diferença entre esses dois modelos é o domínio da informação. O primeiro abrange o sistema como um todo e por isso os eventos são as operações. O último limita-se às classes do sistema, tratando do ciclo de vida da classe. Assim, os eventos do diagrama de estados são os métodos da classe em questão. É importante que fique clara a distinção entre o modelo de ciclo de vida do sistema e o diagrama de estados da classe, pois como mencionam Masiero et al em (Masiero et al., 1998) existem problemas quanto à utilização dos conceitos de ciclo de vida do sistema e ciclo de vida do objeto.

Na Figura 3.18 é apresentado o diagrama de estados da classe Item Bibliográfico. Para a construção do diagrama de estados deve-se analisar a sequiência de execução dos métodos da 
classe em todos os diagramas de colaboração. Após a elaboração do diagrama de estados deve-se verificar se todos os métodos da classe constam neste diagrama.

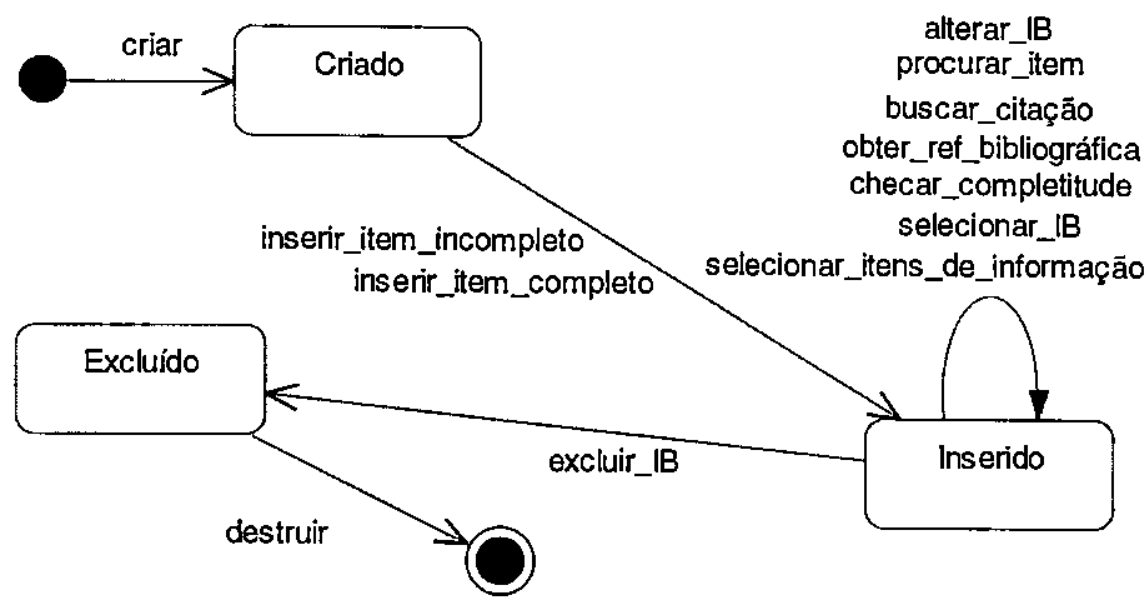

Figura 3.18 - Diagrama de Estados da Classe Item Bibliográfico

\section{Diagrama de Visibilidade}

O Diagrama de Visibilidade permite identificar a necessidade de referências entre classes, a partir da troca de mensagens entre os objetos explicitada nos Diagramas de Colaboração. A identificação e o endereçamento de objetos é chamado de "referenciação", isto é, um objeto servidor deve ser visível por um cliente para que o cliente possa enviar-lhe uma mensagem. No diagrama de visibilidade deve-se reunir, para cada classe de objetos (inclusive os objetos apenas de projeto) os objetos que ela pode referenciar e o tipo apropriado de referência. Essa informação é sintetizada a partir da análise de todos os diagramas de colaboração.

Larman afirma que existem quatro formas de alcançar visibilidade de um objeto A para um objeto B (Larman, 1997):

$>\quad$ visibilidade de atributo: $\mathrm{B}$ é um atributo de A. Essa visibilidade é permanente, pois a visibilidade existe enquanto $\mathrm{A}$ e $\mathrm{B}$ existem;

$>$ visibilidade de parâmetro: $B$ é um parâmetro de um método de A. Essa visibilidade é temporária, pois ela só existe dentro do escopo do método de A;

$>$ visibilidade localmente declarada: B é declarado como um objeto local em um método de A. Essa visibilidade também pode ser considerada temporária;

$>$ visibilidade global: $B$ é globalmente visível. Esse tipo de visibilidade é permanente.

Este processo propõe um diagrama de visibilidade que utiliza a notação dos diagramas de classes da UML, na verdade, o diagrama de visibilidade é uma extensão do diagrama de classes da análise utilizando os relacionamentos de navegabilidade e de dependência. A visibilidade de atributo é representada por uma seta sólida que indica um relacionamento de navegabilidade e as visibilidades de parâmetro, global e localmente definida são representadas por uma seta pontilhada. indicando um relacionamento de dependência, conforme ilustrado na Figura 3.7. A interpretação usual dessas representaçōes é que a visibilidade existe a partir da classe fonte para a classe destino (fim da seta). 
Navegabilidade é uma propriedade de um papel de um relacionamento que indica que é possível navegar unidirecionalmente pela associação a partir do objeto fonte para o objeto destino. O relacionamento de dependência indica que um elemento tem conhecimento de outro(Larman, 1997). Na Figura 3.19 é mostrado um exemplo de Diagrama de Visibilidade. Neste exemplo, a classe Bibliografia tem visibilidade de atributo, estabelecida por relacionamentos de navegabilidade, com as classes Item Bibliográfico e Sinônimo. A visibilidade localmente declarada da classe Bibliografia para as classes Ref. Bibliográfica e Bib_Externa é declarada por meio dos relacionamentos de dependência. $O$ relacionamento de navegabilidade da classe Sinônimo para Bibliografia determina uma visibilidade de atributo de Sinônimo para Bibliografia.

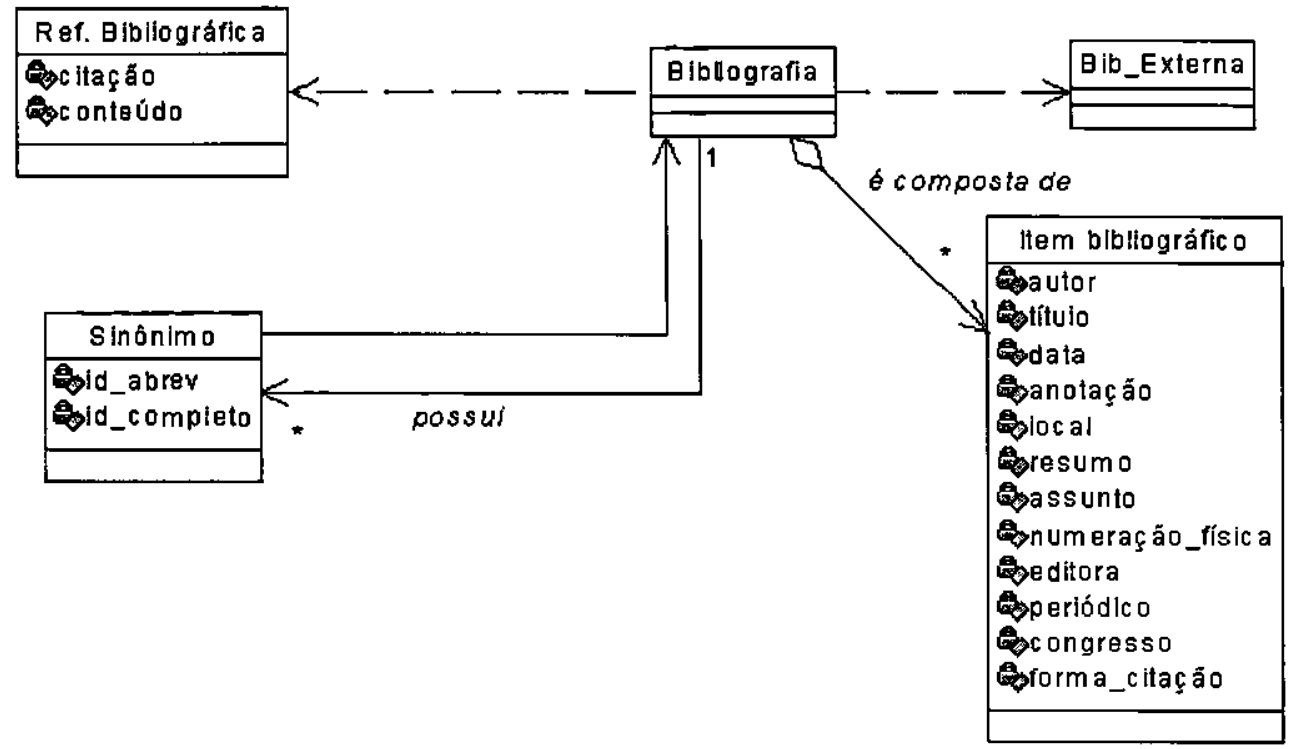

Figura 3.19 - Diagrama de Visibilidade parcial do SAPES consistência:

Depois de completar o diagrama de visibilidade pode-se realizar dois tipos de

$>$ Consistência com o diagrama de classes da análise: para cada relacionamento deve haver um caminho de visibilidade entre as classes correspondentes no projeto.

$>$ Completitude: verificar que todas as mensagens enviadas nos diagramas de colaboração são realizadas no diagrama de visibilidade.

\section{Diagrama de Classes da Análise Refinado}

Pode ser criado o Diagrama de Classes da Análise Refinado, que se trata do Diagrama de Classes da Análise acrescido dos objetos e das relações de generalização/especialização e herança que foram criados na fase de projeto, não existentes no domínio da aplicação. Também são acrescentadas a este diagrama as operaçōes das classes que podem ser identificadas a partir do modelo de operação, elaborados na fase de análise, e dos diagramas de colaboração, elaborados nesta fase. Possivelmente, alguns atributos de projeto são acrescentados às classes.

O Diagrama de Classes da Análise Refinado usa a mesma notação dos outros diagramas de classes deste processo. Ele é usado para complementar as descrições de classes, porque reflete decisões tomadas na fase de projeto. Na Figura 3.20 é apresentado parte do diagrama de classes da análise refinado para o exemplo dado na Figura 3.9. 


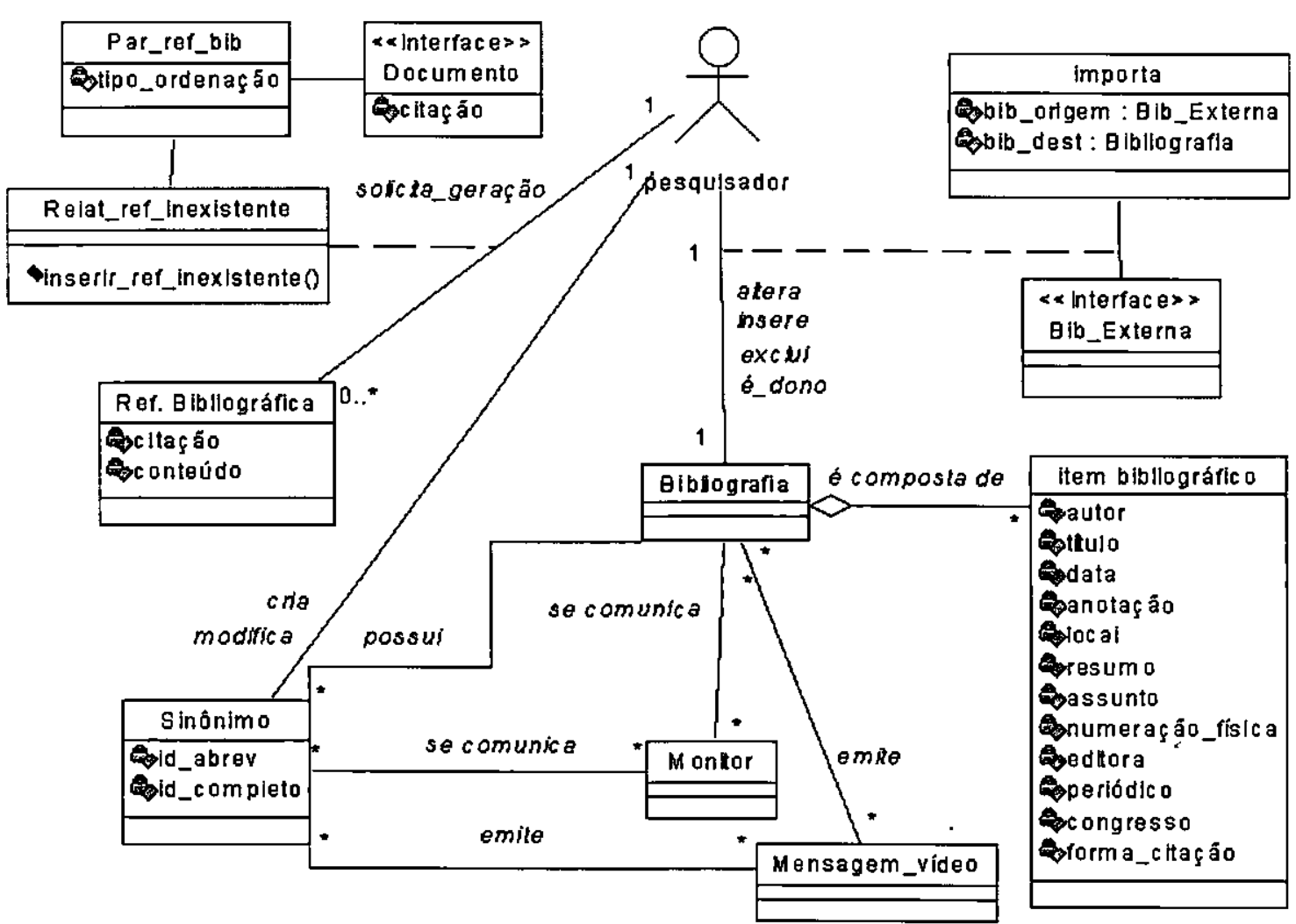

Figura 3.20 - Exemplo de Diagrama de Classes da Análise Refinado

\section{Descrição de Classes}

Cada classe deve ter uma descrição da sua estrutura interna: seus atributos de dados e de objetos, seus métodos (as mensagens para as quais serão fornecidas respostas, conforme definido nos diagramas de colaboração) e sua posição hierárquica, caso exista uma hierarquia de herança. As descrições de classes compõem especificaçōes que servem como base para o início da codificação.

A descrição de classes utilizada por este processo é similar à descrição de classes do Fusion clássico, conforme apresentado na Figura 3.21. Essa descrição, usando uma notação textual abstrata, especifica os atributos de cada objeto e a sua interface externa, isto é seus métodos. Os atributos de dados, atributos de referência a objetos e métodos são definidos para todas as classes do sistema.

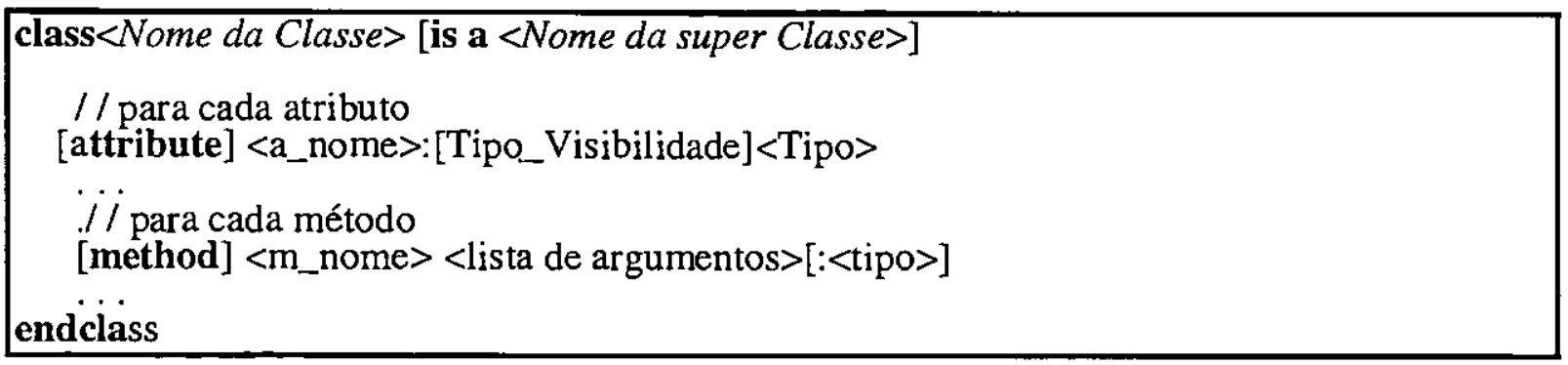


A Descrição de Classes se inicia com a palavra chave class seguida pelo nome da classe. Cada um dos atributos dessa classe é descrito com a palavra chave attribute seguido de nome e tipo. Para os atributos objeto-valorados as palavras reservadas bound ou unbound são usadas para descrever o tipo de visibilidade estipulado no Diagrama de Visibilidade, sendo unbound a opção default. A visibilidade de atributo é designada por unbound, ou seja, a visibilidade não é limitada à execução de algum método. Qualquer outro tipo de visibilidade é designado por bound, indicando um relacionamento de dependência. Se houver um papel no relacionamento de visibilidade, ele pode ser utilizado como base para estabelecer o nome do atributo.

De acordo com a Figura 3.1, as informações para a descrição de classes são reunidas da seguinte forma:

- Atributos de dados, métodos e informaçōes de herança têm origem no Diagrama de Classes da Análise Refinado e no Dicionário de dados;

- Atributos objeto-valorados são derivados do Diagrama de Visibilidade. Um atributo objeto-valorado é aquele que resulta de um relacionamento, como navegabilidade e dependência.

Cada um dos métodos deve ser descrito com a palavra chave method seguida do nome do método, da sua lista de parâmetros e, opcionalmente, do tipo de retorno do método. Descrições referentes aos corpos dos métodos devem ser colocadas no Dicionário de Dados. Na Fi gura 3.22 é mostrada a descrição da classe Sinônimo indicando a origem das informações.

Classe Sinônimo extraída do Diagrama de Classes da Análise Refinado

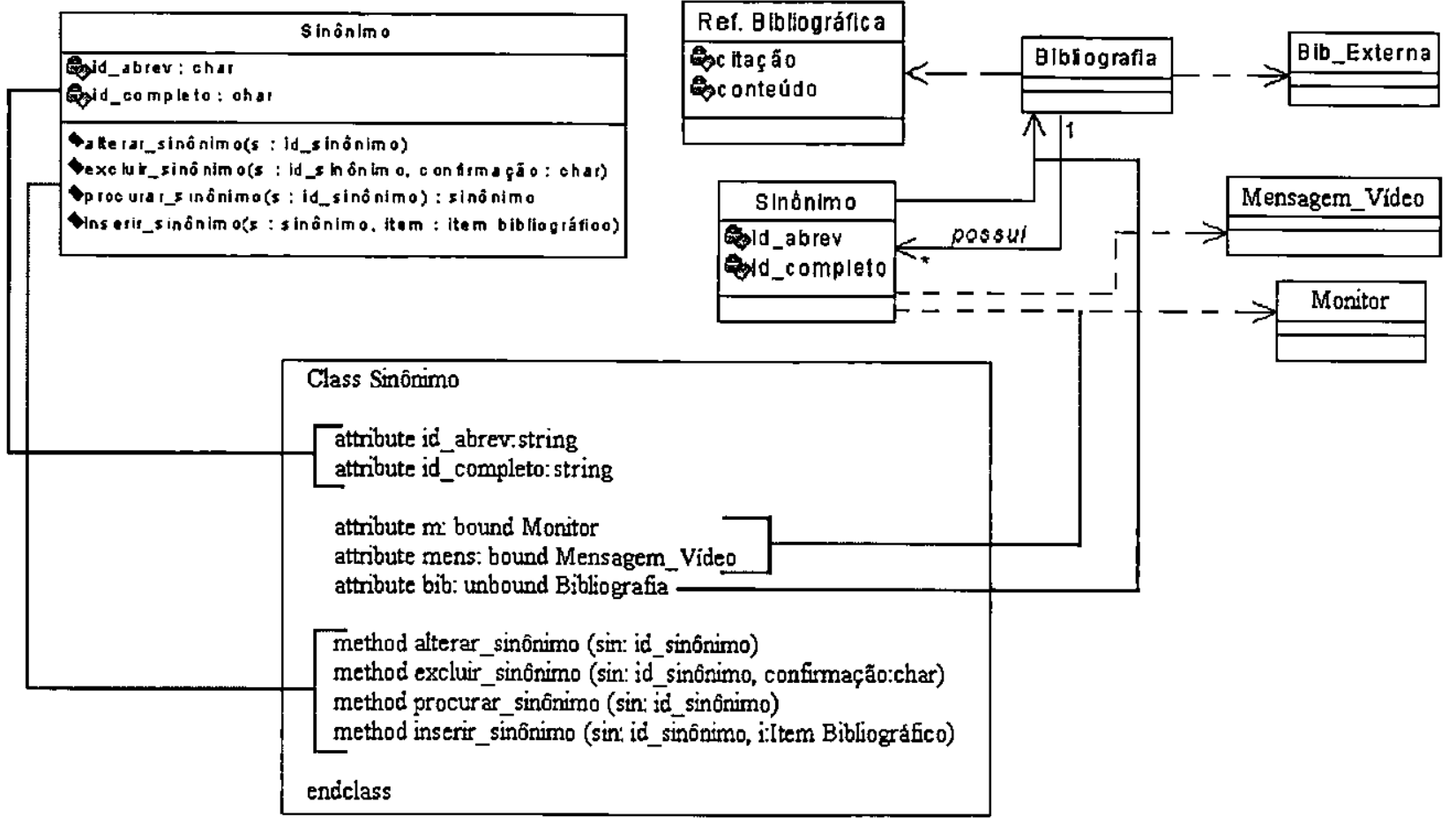

Figura 3.22 - Descrição da Classe Sinônimo indicando a origem das informações

Para checar as descrições de classes, quatro verificações podem ser efetuadas:

$>$ Atributos de dados: verificar que todos os atributos de dados do Diagrama de Classes da Análise aparecem nas descrições de classes;

$>$ Atributos : verificar que todas as referências de visibilidades foram consideradas; 
$>$ Métodos e parâmetros: verificar que todos os métodos dos diagramas de colaboração aparecem nas descrições de classe;

$>$ Herança: verificar que todas as superclasses herdadas estão registradas;

$>$ Com relação a herança, deve-se checar ainda que as descrições de classes contêm todos os métodos comuns preliminarmente definidos e respeita o Diagrama de Classes da Análise Refinado.

\subsubsection{Implementação}

A fase de implementação consiste basicamente numa tarefa de tradução relativamente mecânica. No entanto, muitos dos resultados gerados durante o projeto são incompletos e durante a programação alguns problemas serão descobertos e resolvidos implicando em algumas mudanças no projeto (Larman, 1997).

Uma implementação em uma linguagem de programação $O O$ requer a escrita de código para classes e métodos. As definições de classes já foram feitas na fase de projeto e os métodos são descritos nesta fase.

\section{Corpo dos Métodos}

Os métodos podem ser implementados de diferentes formas, dependendo da linguagem de programação escolhida.

Os diagramas de colaboração contêm grande parte das informações necessárias para a implementação dos métodos, pois eles mostram as mensagens enviadas em reśposta à invocação de um método. A sequiência dessas mensagens deve ser traduzida em um conjunto de declarações na definição do método.

Na Figura 3.23 é apresentada a descrição da classe TPV (Terminal do Posto de Venda) e o diagrama de colaboração para a operação entrar_item de um sistema de venda de uma loja.

A mensagem entrar_item é enviada a uma instância de POST, portanto o método é definido nesta classe. Acompanhando o diagrama de colaboração da Figura 3.23, é apresentada, em Java, a definição de entrar_item .

public void entrar_item(int cod_prod, int quant)

Mensagem 1: em resposta à mensagem entrar_item a primeira declaração é criar condicionalmente uma nova Venda.

\section{if (é_nova_venda ()) $\{v e n d a=$ new Venda ();}

Mensagem 2: uma mensagem especificação é enviada para Catálogo_produto para recuperar a Especificação_produto.

Especificação_produto esp = CatProduto. Especificação (cod_prod);

Mensagem 3: uma mensagem fazer_linha_item é enviada para Venda.

Venda.fazer_linha_item (esp, quant); 


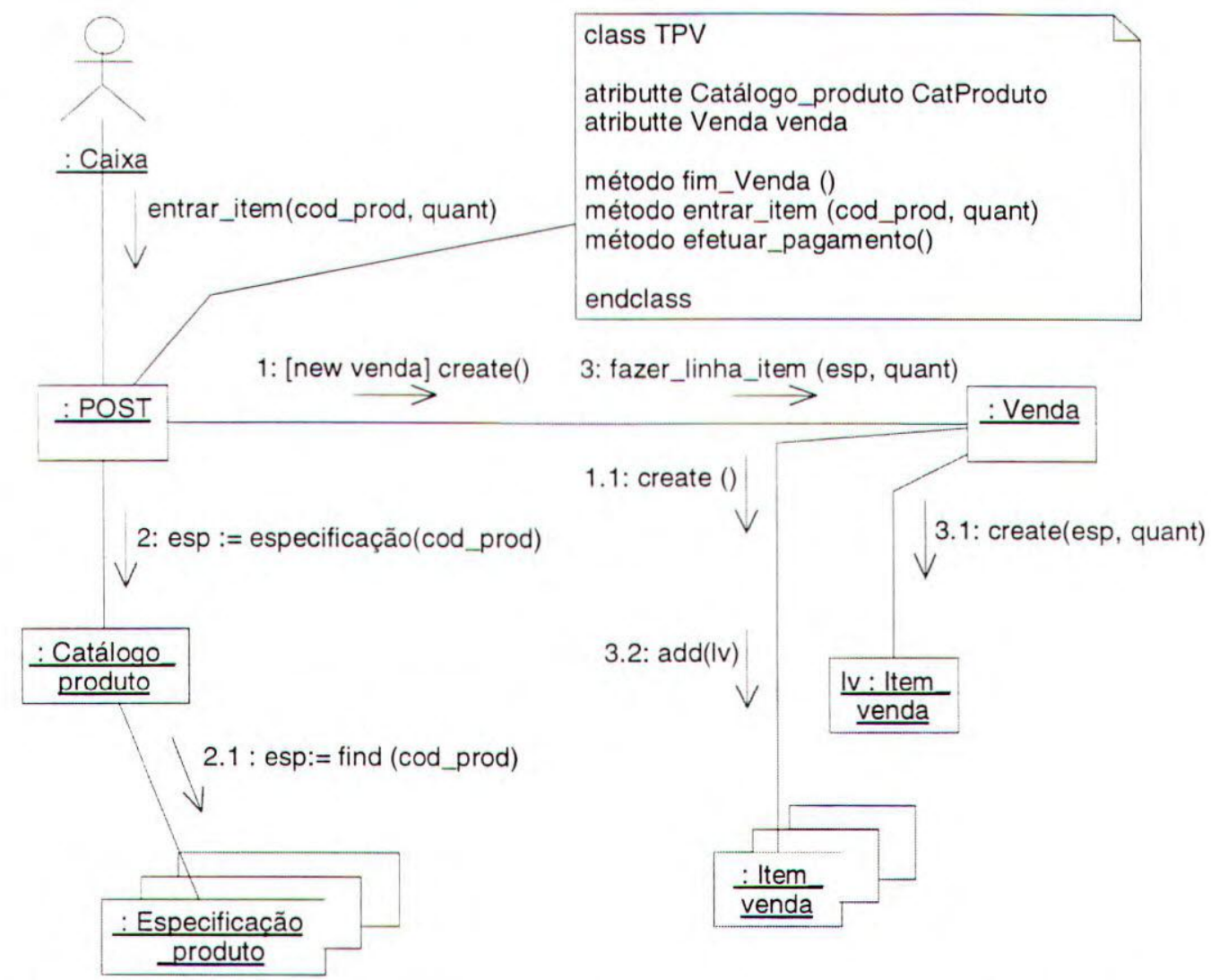

Figura 3.23 - Descrição da Classe TPV e diagrama de colaboração de TPV.entrar_item (Larman, 1997)

A definição do método TPV.entrar_item introduziu um novo método à classe TPV: é_nova_venda que, possivelmente poderia ter sido descoberto na fase de projeto. Este é um exemplo de como, na fase de implementação, mudanças no projeto podem ser necessárias.

é_nova_venda é um método auxiliar que simplesmente verifica se a variável de instância de Venda é nula ( null). Este teste (expressão) poderia ser introduzido no código de entrar_item, mas para facilitar o entendimento do método e manter o contexto da informação tratada, geralmente, expressões que representam uma tomada de decisão são encapsuladas em um novo método.

Na Figura 3.24 é apresentado o corpo do método Venda.fazer_linha_item escrito em Java e parte do diagrama de colaboração da operação entrar_item. A mensagem genérica add foi traduzida como adicionar_item.

Frequentemente é necessário que um objeto mantenha visibilidade para um grupo de outros objetos. Essa necessidade é evidente no valor da cardinalidade dos relacionamentos nos diagramas de classes ou nas mensagens enviadas a multiobjetos nos diagramas de colaboração, porque em linguagens de programação relacionamentos com cardinalidade muitos $(*$ ou +$)$ são frequentemente implementados com a introdução de uma coleção (multiobjeto). A classe do lado 1 do relacionamento define um atributo de referência para uma instância da coleção (lado muitos do relacionamento). 


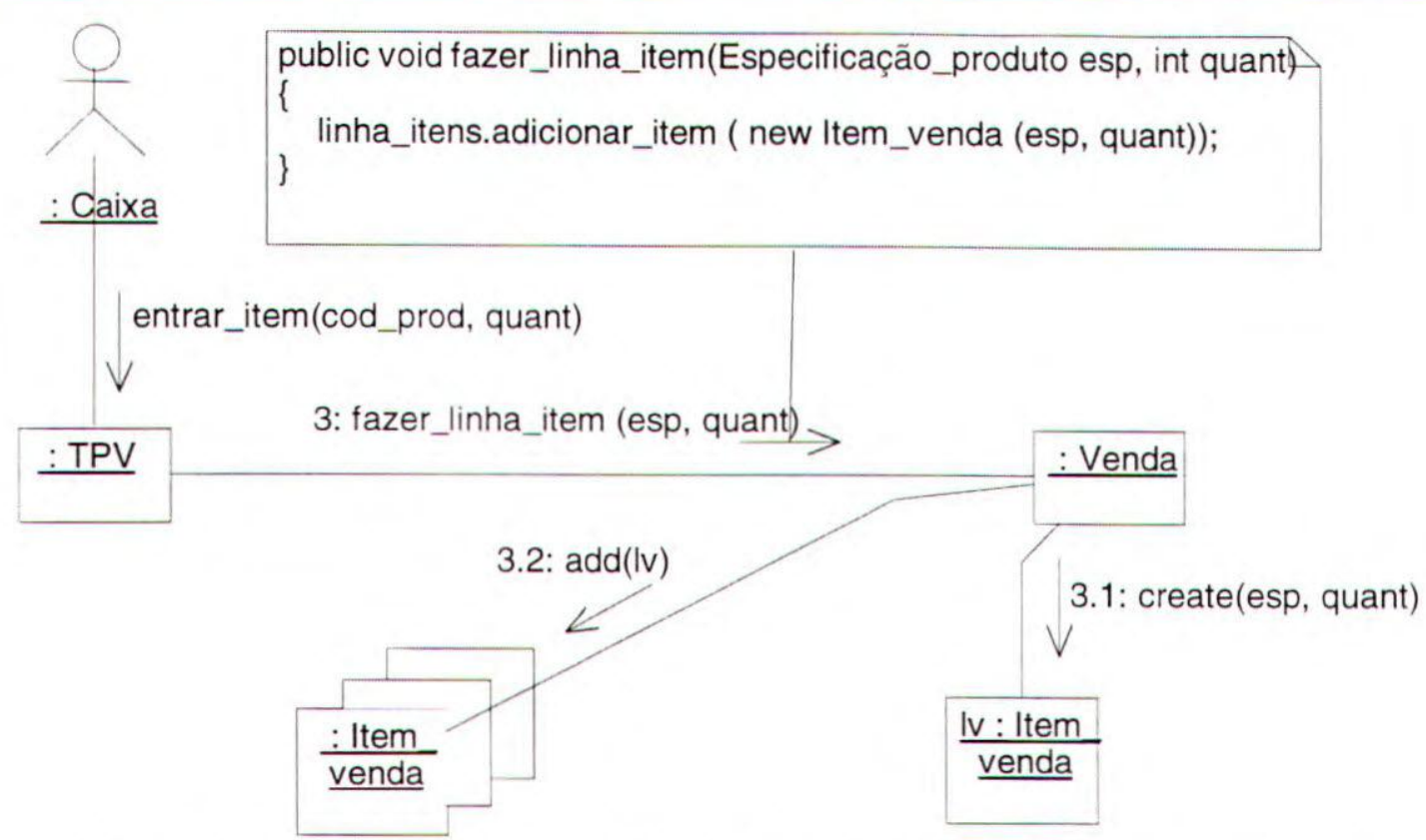

Figura 3.24 - Corpo do método Venda.fazer_linha_item (Larman, 1997)

A escolha do tipo de estrutura de dados a ser utilizado depende dos requisitos, por exemplo, uma busca baseada em chave requer o uso de tabelas de hash e uma lista ordenada requer um vetor.

O corpo do método pode requerer uma variável local objeto-valorada: se for um objeto existente usa-se referência, se for um objeto criado pela operação new e ele sobrevive à invocação do método usa-se uma referência normal (unbound), caso contrário o objeto pode ser criado por valor (bound) com o objetivo de reduzir o gasto com gerenciamento de memória. O método especial create indica o ponto no qual um objeto é iniciado por new.

Algumas informações adicionais sobre o funcionamento esperado dos métodos também podem ser obtidas no dicionário de dados.

O tratamento de erros foi ignorado nos exemplos apresentados, mas aplicações reais devem considerar essa questão já na fase de projeto. Por exemplo, no campo notas do modelo de operação podem existir breves discussões sobre os erros típicos e suas respectivas respostas.

Algumas informações adicionais sobre o funcionamento esperado dos métodos também podem ser obtidas no dicionário de dados.

\section{Atualização das Descrições de Classes}

As descrições de classes devem ser atualizadas depois que todos os métodos forem definidos. Por exemplo, a descrição da classe TPV deve ser atualizada para incluir o método é_nova_venda descoberto na definição do método entrar_item.

Os atributos objeto-valorados devem ser implementados como ponteiros. Coleção de atributos deve usar um dos tipos de estrutura de dados disponível na linguagem de programação. 
Possíveis candidatos são: conjuntos, sacolas, listas, vetores, arrays, etc. Os atributos simples devem ser implementados da melhor forma permitida pela linguagem.

Quanto aos qualificadores de atributos, um objeto unbound deve ser implementado por algum tipo de ponteiro e um objeto bound deve ser eliminado quando o objeto cliente desaparece.

\subsection{COMPARAÇĀo COM O Fusion Clássico}

Nessa subsecção é apresentada uma breve comparação entre o ProDeS/UML e o método Fusion Clássico (Coleman et al., 1994). A Tabela 3.2 mostra todos os modelos que os dois processos de desenvolvimento propõem de acordo com as suas fases. As similaridades e diferenças existentes entre os processos são comentadas a seguir.

Tabela 3.2 - Modelos dos processos de acordo com as fases de desenvolvimento do software

\begin{tabular}{|c|c|c|}
\hline Fase do Processo & Fusion Clássico & ProDes/UML \\
\hline $\begin{array}{l}\text { Fase de } \\
\text { Engenharia de } \\
\text { Requisitos }\end{array}$ & - & $\begin{array}{l}\text { - } \text { Diagrama de Casos de Uso } \\
\text { - Especificação dos Casos de Uso } \\
\text { - Diagrama de Classes do Domínio }\end{array}$ \\
\hline Fase de Análise & $\begin{array}{l}\text { - } \text { Modelo de Objetos } \\
\text { - } \text { Modelo de Objetos do Sistema } \\
\text { - } \text { Cenários } \\
\text { - } \text { Modelo de Ciclo de Vida } \\
\text { - } \text { Modelo de Operações } \\
\end{array}$ & $\begin{array}{l}\text { - Diagrama de Classes da Análise } \\
\text { - Cenários } \\
\text { - Modelo de Operações } \\
\end{array}$ \\
\hline Fase de Projeto & $\begin{array}{l}\text { - Grafo de Interação entre Objetos } \\
\text { - } \quad \text { Diagrama de Visibilidade } \\
\text { - } \quad \text { Descrição de Herança } \\
\text { - }\end{array}$ & $\begin{array}{l}\text { - Diagramas de Colaboração } \\
\text { - Diagrama de Visibilidade } \\
\text { - Diagrama de Classes da Análise } \\
\text { - Refinado } \\
\text { - Descrição de Classes } \\
\end{array}$ \\
\hline $\begin{array}{l}\text { Fase de } \\
\text { Implementação }\end{array}$ & $\begin{array}{l}\text { - Corpo dos Métodos } \\
\text { - Implementaçāo do Ciclo de Vida }\end{array}$ & - Corpo dos Métodos \\
\hline
\end{tabular}

\section{Fase de Engenharia de Requisitos}

O método Fusion não inclui em seu processo de desenvolvimento a fase de engenharia de requisitos. Ele somente propõe que um documento de requisitos seja desenvolvido pelos usuários e/ou engenheiros de software. Já o processo proposto neste trabalho inclui essa fase e, além de recomendar a elaboração de um documento de requisitos, propõe que a partir dele sejam desenvolvidos o diagrama de classes do domínio e o diagrama de casos de uso e suas respectivas especificações. Com isso, o ProDeS/UML espera garantir uma maior qualidade na captura dos requisitos, aumentando consequientemente a qualidade do produto de software.

O diagrama de classes do domínio vem sendo incorporado por outros métodos na tentativa de viabilizar um melhor entendimento dos requisitos sem que haja a preocupação com a modelagem de classes que dizem respeito à implementação do sistema. Similarmente, o diagrama de casos de uso também tem o objetivo de auxiliar na descoberta de todos os requisitos funcionais esperados do sistema, ou seja, todas as possibilidades de uso do sistema. Essa 
descoberta dos requisitos é completada pelas especificaçōes dos casos de uso que explicam o funcionamento de cada um deles.

\section{Fase de Análise}

O Fusion possui o modelo de objetos que contém basicamente as mesmas informações do diagrama de classes do domínio da fase de engenharia de requisitos do ProDeS/UML. O modelo de objetos do sistema e o diagrama de classes da análise também são idênticos embora exista diferença na notação utilizada para determinar o escopo do sistema: o primeiro utiliza uma linha tracejada que exclui objetos e relações do limite do sistema e o segundo classifica alguns objetos por meio do uso de estereótipos, definindo assim objetos que serão implementados ou não.

Ambos os processos utilizam cenários para cobrir todos os possíveis usos do sistema e o modelo de operações para estabelecer o comportamento das operações do sistema. No entanto, o método Fusion utiliza os cenários como diagramas auxiliares que não fazem parte da documentação final do sistema. A única diferença existente entre os dois modelos de operações é que o modelo do ProDeS/UML insere uma cláusula Referência Cruzada que permite mencionar relações existentes entre a operação e casos de uso, funções do sistema, etc.

Os dois processos incluem o modelo de ciclo de vida do sistema que trata do comportamento do sistema ao longo da sua vida. No entanto, a notação deles é diferente, pois o Fusion utiliza um modelo textual baseado em expressões regulares para especificar o comportamento do sistema, ao passo que o ProDeS/UML utiliza um diagrama de estados muito parecido com um statecharts.

\section{Fase de Projeto}

Ao contrário do Fusion, o ProDeS/UML recomenda que seja feita uma análise antes de escolher o tipo de classe controladora, porque nem sempre o mesmo tipo de classe controladora é o melhor para todos os tipos de sistemas, por exemplo, uma classe controladora que representa 0 sistema como um todo é boa para um sistema com poucos eventos, mas não é recomendável para sistemas nos quais o número de eventos é muito grande.

No fase de projeto, tanto os grafos de interação entre objetos e os diagramas de colaboração quanto as descrições de classes dos dois processos de desenvolvimento são equivalentes. Os diagramas de visibilidade têm o mesmo objetivo, ou seja, estabelecer o tipo de referência existente entre as classes de objetos do sistema, no entanto, os tipos de visibilidade utilizados são diferentes. No Fusion, as referências podem ser classificadas segundo quatro aspectos: duração, visibilidade do servidor, dependência do servidor e mutabilidade. Já no ProDeS/UML, as referências são classificadas como visibilidade de atributo, de parâmetro, localmente declarada ou global, se enquadrando basicamente no aspecto de duração do Fusion, já que os outros aspectos classificados pelo Fusion podem ser obtidos por meio dos relacionamentos existentes nos diagramas de classes. O Grafo de Herança do Fusion e o diagrama de classes da análise refinado documentam novos relacionamentos de herança e novas classes criados nesta fase. Além disso, o diagrama de classes da análise refinado mostra todos os métodos das classes. 
Nessa fase o ProDeS/UML acrescenta o diagrama de estados da classe, para o gerenciamento das ativações de métodos. Esse modelo é muito importante para o estabelecimento dos requisitos de teste, como mencionado no próximo capítulo.

\section{Fase de Implementação}

Os dois processos fomecem diretrizes para a composição do corpo dos métodos. O método Fusion fomece dicas para a conversão dos grafos de interação entre objetos no corpo dos métodos considerando algumas características específicas das linguagens de programação C++, Smalltalk e Eiffel. Já o ProDeS/UML indica alguns procedimentos que podem ser seguidos para a tradução dos diagramas de colaboração em corpo de métodos de forma geral, sem considerar alguma linguagem de programação específica.

\subsection{CONSIDERAÇÕes FinaIS}

Neste capítulo foi apresentado o ProDeS/UML, um processo de desenvolvimento de software orientado a objetos baseado no método Fusion e que utiliza a notação UML. Algumas características de outros métodos orientados a objetos também foram incluídas nesse processo, como por exemplo o modelo de casos de uso do Objectory. Foram apresentados os modelos produzidos em cada fase comentando a notação utilizada, fomecendo um exemplo do modelo e algumas diretrizes para a sua construção. A maioria dos modelos é ilustrada com exemplos do SAPES. Em todas as fases recomenda-se que sejam feitas checagens entre modelos para garantir a qualidade da documentação gerada.

Como pôde ser visto na Seção 3.3, na qual é apresentada uma comparação do processo proposto com o método Fusion, ambos são muito semelhantes, especialmente nas fases de análise e projeto. $\mathrm{Na}$ verdade, as principais diferenças entre os dois processos é que o ProDeS/UML não possui notação própria, já que utiliza a notação UML, além de introduzir a fase de engenharia de requisitos com o diagrama de casos de uso e diagrama de classes do domínio e o diagrama de estados da classe na fase de projeto. É possível perceber que o restante dos modelos são equivalentes, embora utilizem notações diferentes e possuam algumas pequenas diferenças. Ambos recomendam que sejam realizadas checagens ao fim de cada fase para avaliar a consistência e a completitude dos modelos produzidos.

No próximo capítulo é apresentado o uso do ProDeS/UML para modelagem do SAPES. São apresentadas também algumas considerações a respeito da notação UML, da ferramenta Rational Rose e do ProDeS/ UML. 


\section{CAPÍTULO IV}

\section{USO E AVALIAÇÃO DO PRODES/UML}

\subsection{CONSIDERAÇÕES INICIAIS}

Neste capítulo é apresentada parte da modelagem do Sistema de Apoio a Escrita (SAPES) com o objetivo de mostrar como aplicar os passos do ProDeS/UML. O SAPES é um sistema que auxilia pesquisadores na elaboração de textos científicos, permitindo manter informações sobre itens bibliográficos e gerar automaticamente um arquivo com as referências bibliográficas das citações presentes em um documento. O Documento de Requisitos do SAPES é apresentado no Anexo A.

Para modelar o SAPES foi utilizada a ferramenta CASE Rational Rose desenvolvida pela Rational Software Corporation, que apóia o desenvolvimento de diagramas que utilizam a notação UML. Na seção 4.2 é apresentada uma visão geral dos requisitos do SAPES. A modelagem é apresentada de acordo com as fases do processo, sendo assim, na seção 4.3 são apresentados os modelos da fase de Engenharia de Requisitos, na seção 4.4 os modelos da Análise, na seção 4.5 encontram-se os modelos da fase de Projeto e na seção 4.6 é mostrada a fase de Implementação. Na seção 4.7 é apresentada uma avaliação da notação UML, da ferramenta Rational Rose e do ProDeS/UML. Finalmente, na seção 4.8 são apresentadas as considerações finais deste capítulo. A modelagem completa e o Dicionário de Dados do SAPES são apresentados no Documento de Trabalho (Colanzi \& Masiero, 1999). Tanto casos de uso como classes, seus atributos e seus relacionamentos, operações do sistema, métodos e invariantes devem constar no Dicionário de Dados. 


\subsection{REQUISITOS DO SISTEMA}

O SAPES tem como objetivo principal auxiliar a pesquisa bibliográfica. Os usuários deste sistema são, principalmente, pesquisadores que durante a sua pesquisa bibliográfica podem ler publicações (por exemplo: artigos, livros e periódicos) e armazená-las no sistema através de itens bibliográficos, construindo, assim, a sua bibliografia pessoal. Esta bibliografia pode ser alterada e consultada conforme a necessidade do pesquisador, além da possibilidade de fornecer diferentes tipos de relatórios. O pesquisador pode também utilizar o sistema durante a redação de textos científicos. A partir do documento produzido pelo pesquisador, o sistema reconhece as citações e gera automaticamente a referência bibliográfica.

O ProDeS/UML recomenda a elaboração de um Documento de Requisitos do Sistema para que a modelagem possa se basear nesse documento. Seguindo essa recomendação, para desenvolver a modelagem do SAPES, é utilizado como base para a modelagem o documento de requisitos apresentado do Anexo A (Turine, 1996).

\subsection{FASE DE ENGENHARIA DE REQUISITOS}

Grande parte das informações do documento de requisitos é utilizada na elaboração do diagrama de casos de uso, que tem como objetivo capturar toda a funcionalidade esperada do sistema. No entanto, nem todos os requisitos são utilizados na construção do Diagrama de Classes do Domínio, já que este somente registra a estrutura na qual o sistema está organizado.

A partir do documento de requisitos apresentado no Anexo A foi elaborado o diagrama de casos de uso apresentado na Figura 4.1. A estruturação do documento de requisitos de acordo com as possibilidades de uso do sistema facilitou a identificação dos principais casos de uso. Por exemplo, a seção Preparação e Manutenção de Itens Bibliográficos do Documento de Requisitos do SAPES diz respeito à inserção, exclusão, alteração e importaçāo de itens bibliográficos e criação e manutenção de sinônimos. Os requisitos dessa seção foram divididos em dois casos de uso: Manutenção de Itens Bibliográficos e Manutenção de Sinônimos, sendo que esses casos de uso representam funções que podem ser decompostas, como por exemplo o caso de uso Manutenção de Sinônimos, que pode ser especializado nos casos de uso Criação de Sinônimos, Alteração de Sinônimos e Exclusão de Sinônimos. Para esta especialização foi utilizado o estereótipo de relacionamentos entre casos de uso <<uses $>>$ que indica que o caso de uso geral inclui o comportamento dos casos de uso especializados.

É importante garantir que todos os casos de uso do Diagrama de Casos de Uso possuam uma especificação. Nas Figuras 4.2 e 4.3 são apresentadas as especificações dos casos de uso Manutenção de Itens Bibliográficos e Inserção de Itens Bibliográficos utilizando o formato de especificação sugerido no capítulo anterior. Destaca-se que o caso de uso Inserção de Item Bibliográfico possui um Fluxo Alternativo dos Eventos, já que podem ocorrer situações em que o Item Bibliográfico já existe ou que ele não foi preenchido completamente. As especificações de todos os casos de uso do SAPES constam em (Colanzi \& Masiero, 1999). 


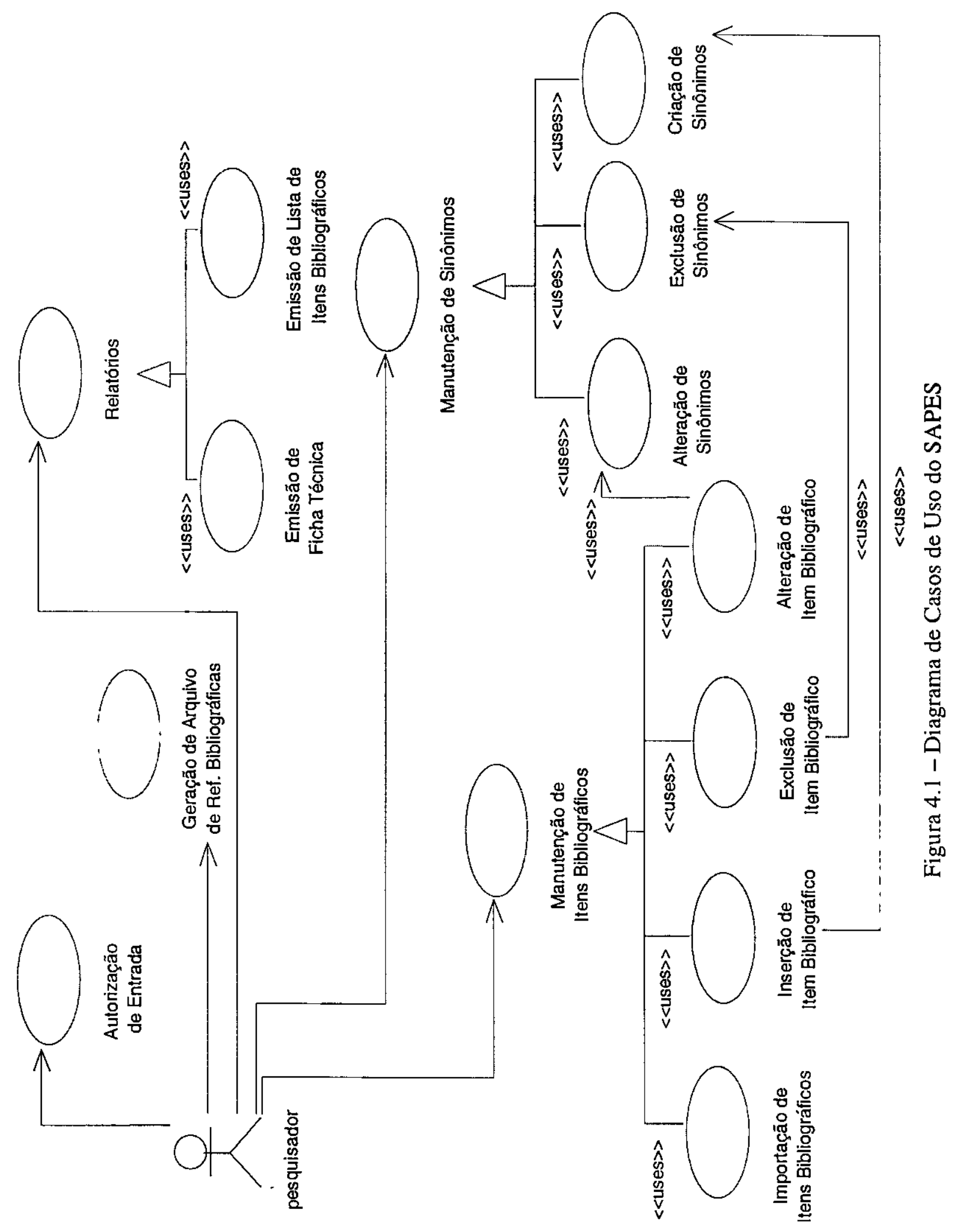




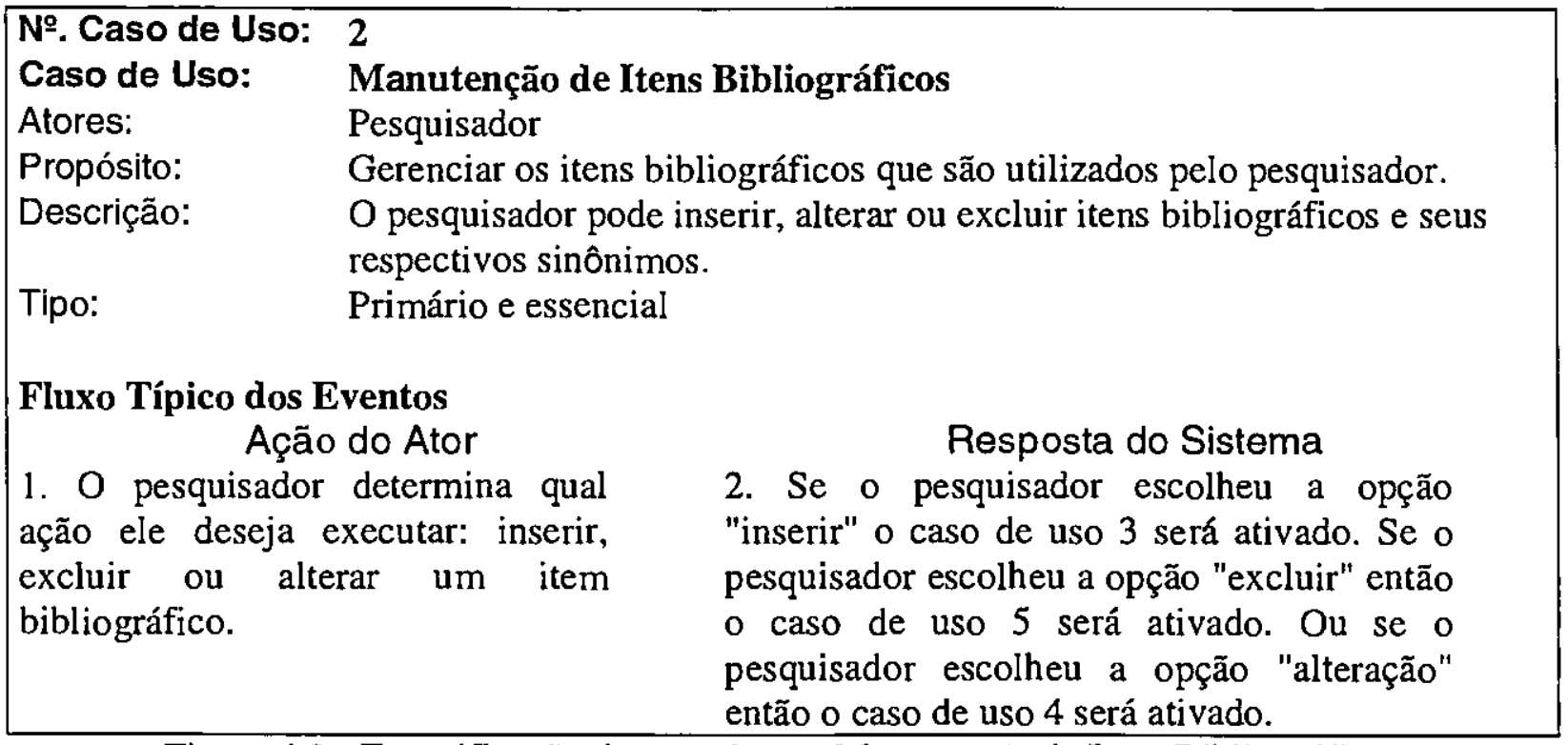

Figura 4.2 - Especificação do caso de uso Manutenção de Itens Bibliográficos

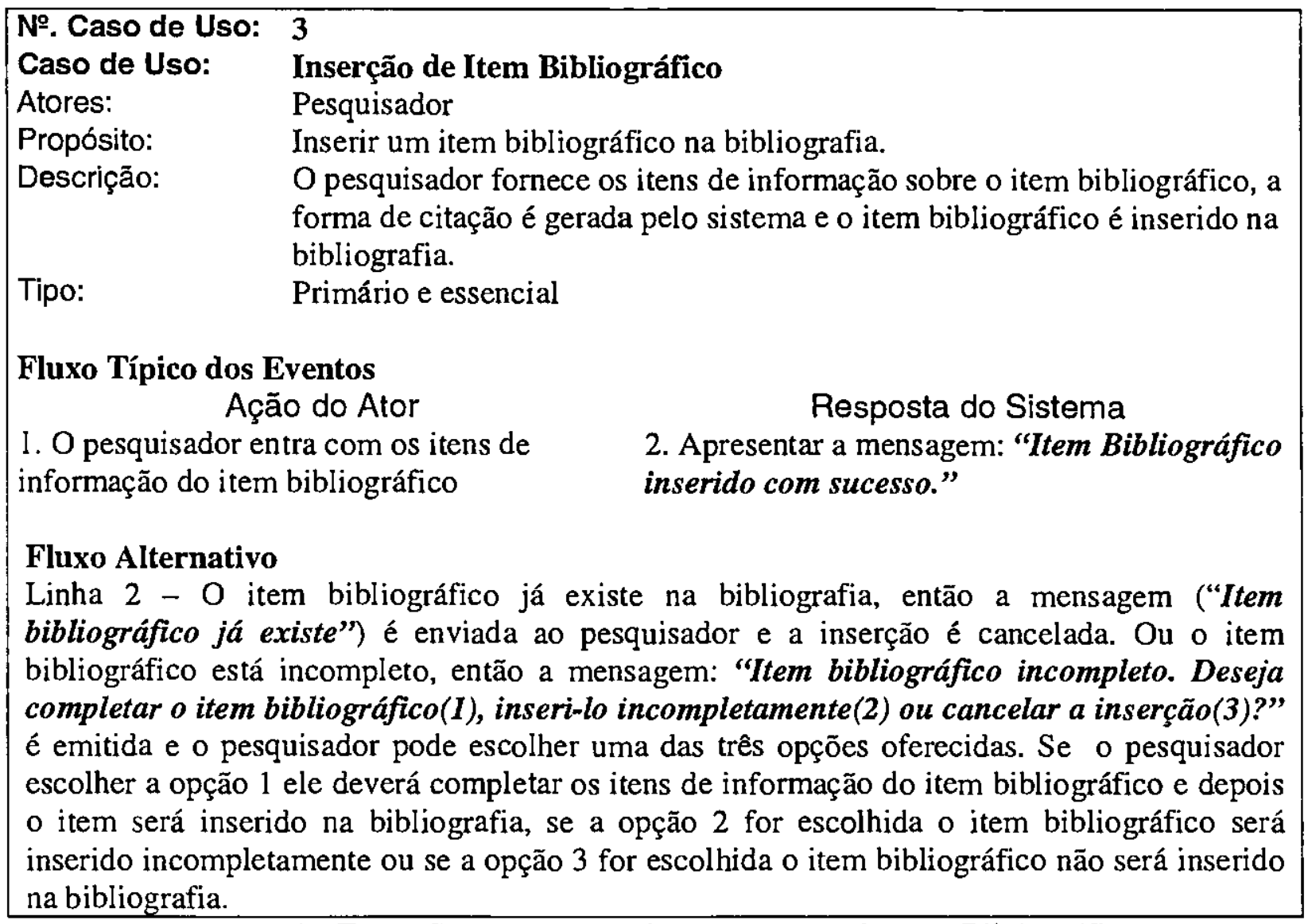

Figura 4.3 - Especificação do caso de uso Inserção de Item Bibliográfico

Na Figura 4.4 é apresentado o Diagrama de Classes do Domínio mostrando os conceitos envolvidos no domínio da aplicação e os relacionamentos existentes entre eles. As classes e os relacionamentos foram criados depois de uma análise do documento de requisitos e das especificaçōes dos casos de uso. Por exemplo, por meio do Documento de Requisitos, 
apresentado no Anexo A, é possível perceber um relacionamento entre as classes Bibliografia e Sinônimo. Tanto no requisito especificado no Documento de Requisitos como na especificação do caso de uso Inserção de Item Bibliográfico nota-se que uma Bibliografia é composta por vários Itens Bibliográficos, caracterizando um relacionamento de agregação. O próximo passo na elaboração do Diagrama de Classes do Domínio foi a atribuição de cardinalidade aos relacionamentos e atributos às classes. Ressalta-se que os atributos autor, editora, periódico e congresso poderiam ter sido normalizados, no entanto, essa normalização não foi realizada nessa modelagem porque não acrescentaria nenhuma complexidade adicional ao trabalho que permitisse ilustrar melhor outros aspectos do ProDeS/UML. Em caso de normalização novas classes apareceriam para alguns atributos, como autor e congresso, e estas estariam ligadas por relacionamentos à classe original Item Bibliográfico.

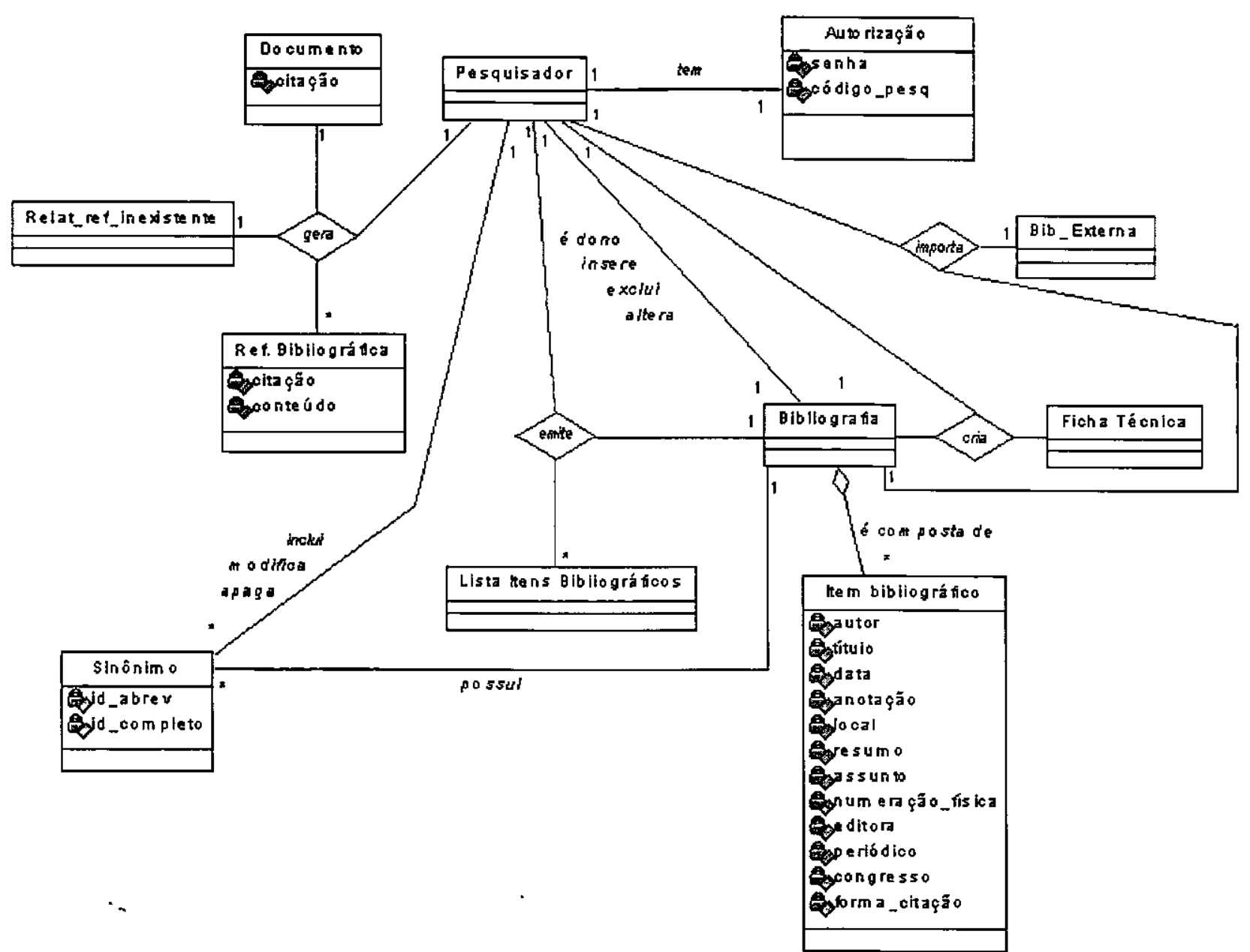

Figura 4.4 - Diagrama de Classes do Domínio do SAPES

Tanto na Figura 4.4 como nas Figuras 4.10, 4.14 e 4.15 o símbolo que aparece antes dos atributos e métodos das classes indica o tipo de visualização permitido (público, privado ou protegido) àquele atributo ou método. Em todas essas figuras os atributos são privados (private) e os métodos são públicos (public). 


\subsection{FASE DE ANÁLISE}

\subsubsection{Cenários}

Utilizando as especificações de casos de uso, foram desenvolvidos todos os cenários de uso possíveis para o SAPES. Na especificação do caso de uso Inserção de Item Bibliográfico existem várias alternativas de inserção, por exemplo, o pesquisador pode ter deixado de preencher algum item de informação (autor, título, data, editora, etc.) do item bibliográfico propositadamente e, nesse caso, o item bibliográfico será inserido incompletamente mediante confirmação, caracterizando o cenário da Figura 4.7. Ou o pesquisador pode simplesmente ter esquecido de preencher algum campo, caracterizando o cenário da Figura 4.8 (Item completado pelo usuário). Nas Figuras 4.5, 4.6, 4.7, 4.8, e 4.9 são apresentados todos os cenários possíveis para a inserção de um item bibliográfico.

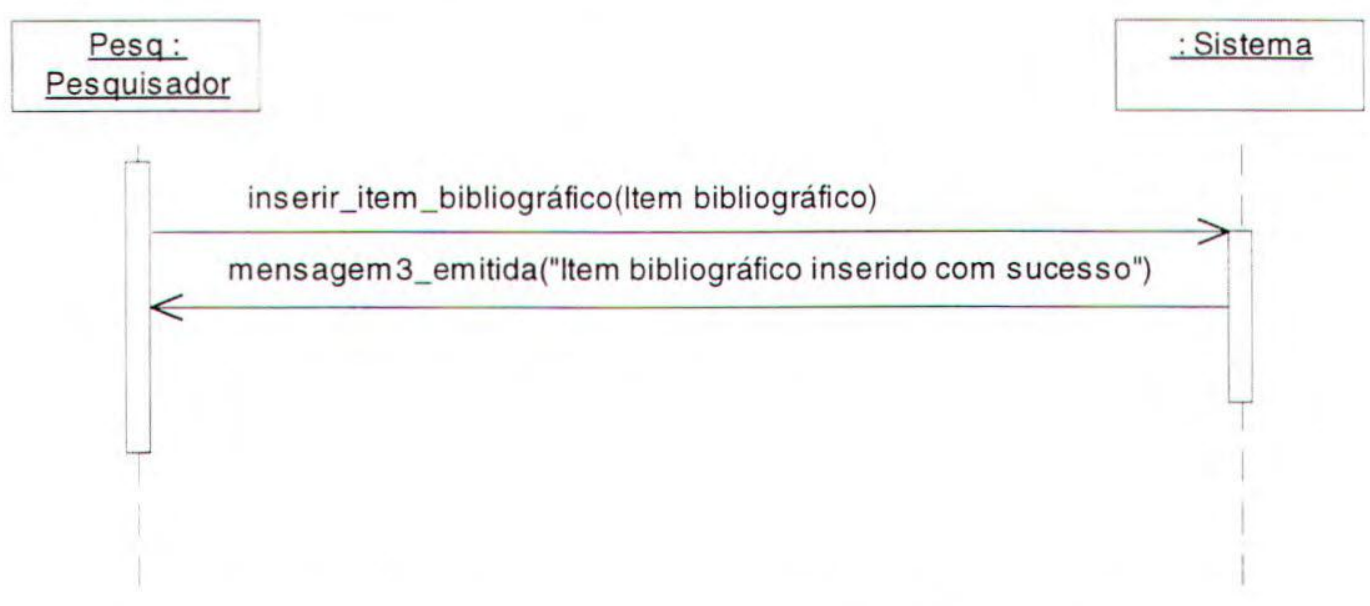

Figura 4.5 - Cenário de inserção de item bibliográfico inserido com sucesso

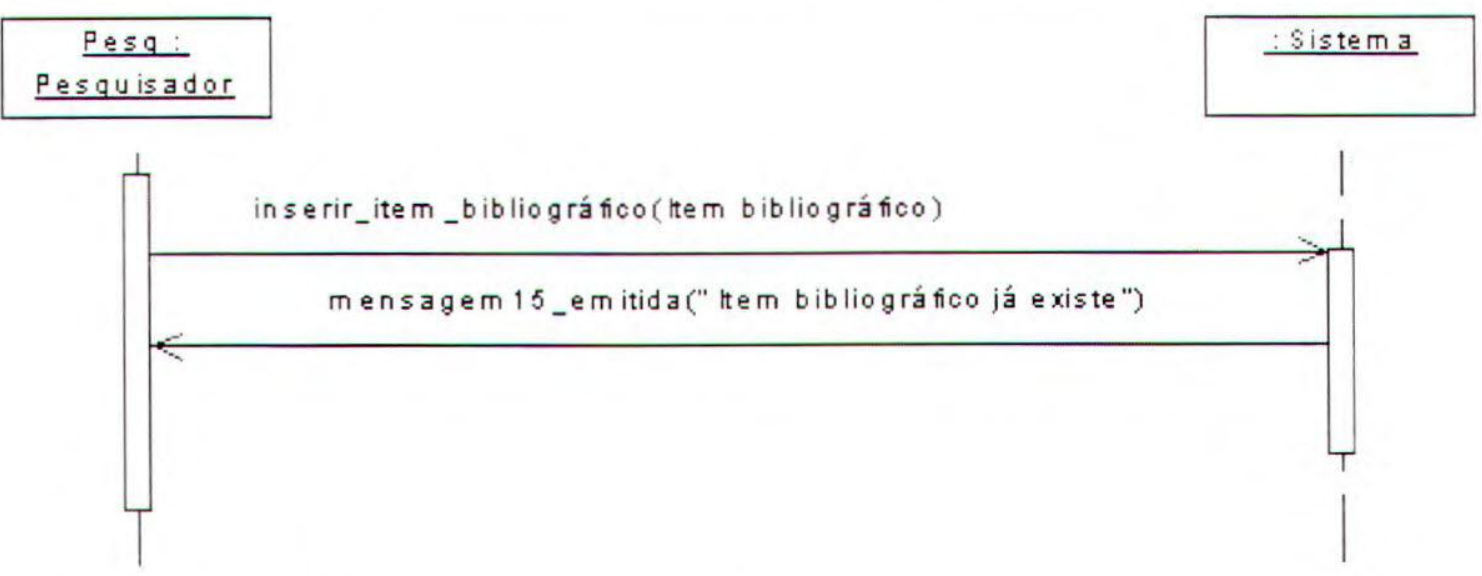

Figura 4.6 - Cenário de inserção de item bibliográfico que já existe 

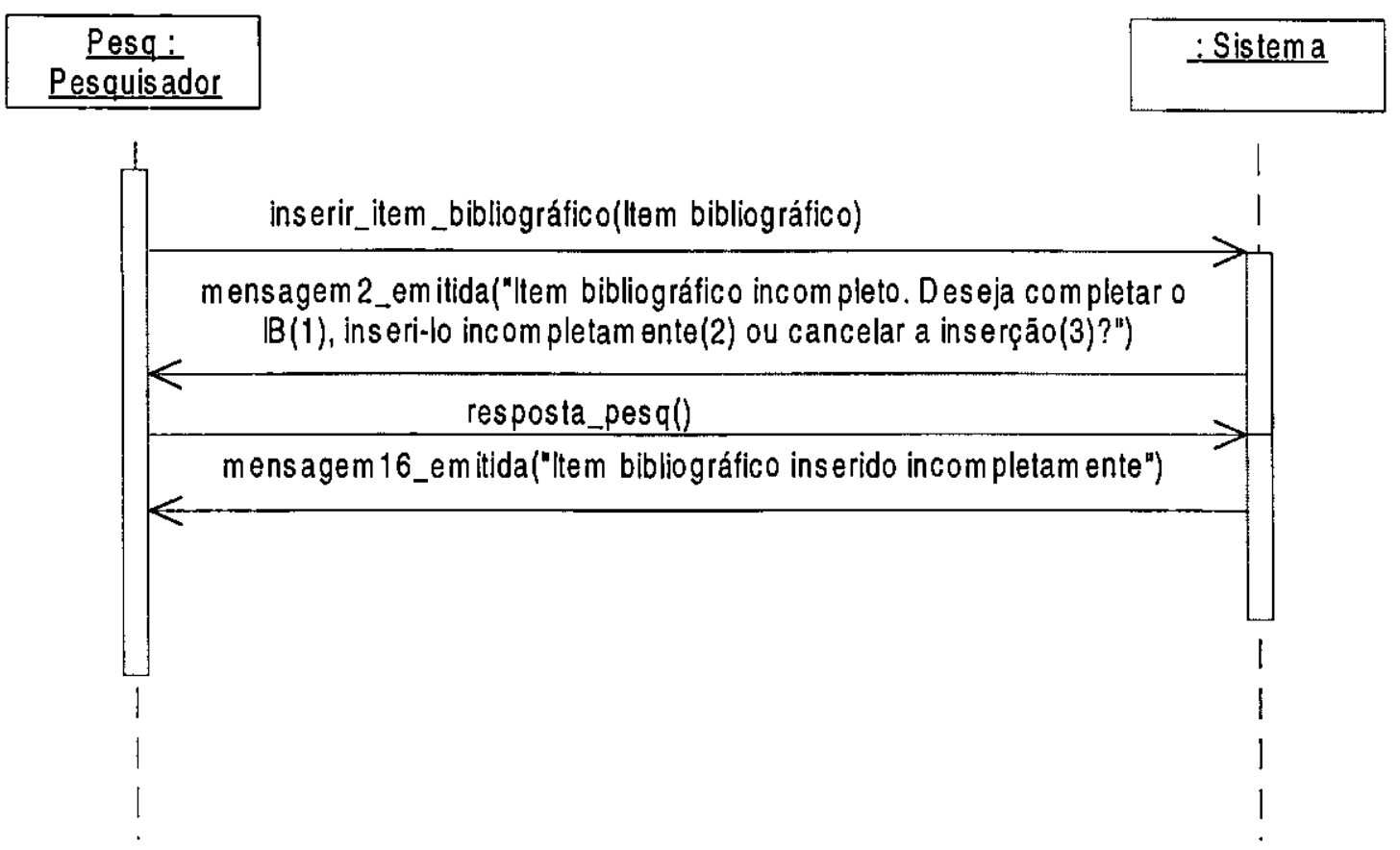

Figura 4.7 - Cenário de inserção de item bibliográfico - Item inserido incompletamente

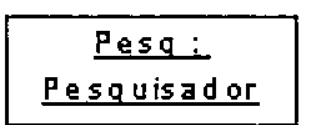

inserir_item_bibliográfico(litem bibliográfico)

mensagem 2_em itida("ltem bibliográfico incom pleto. Deseja completar 0

$\mathbb{B}(1)$, inseri-lo incom pletam ente(2) ou cancelar a inserção(3)?")

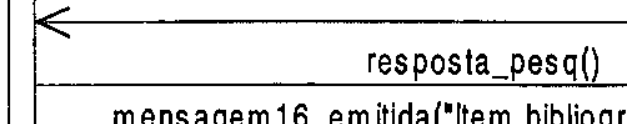

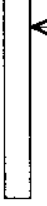

mensagem 16_emitida("ltem bibliográfico inserido incom pletam ente")

$\leftarrow$

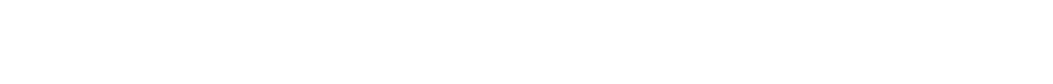




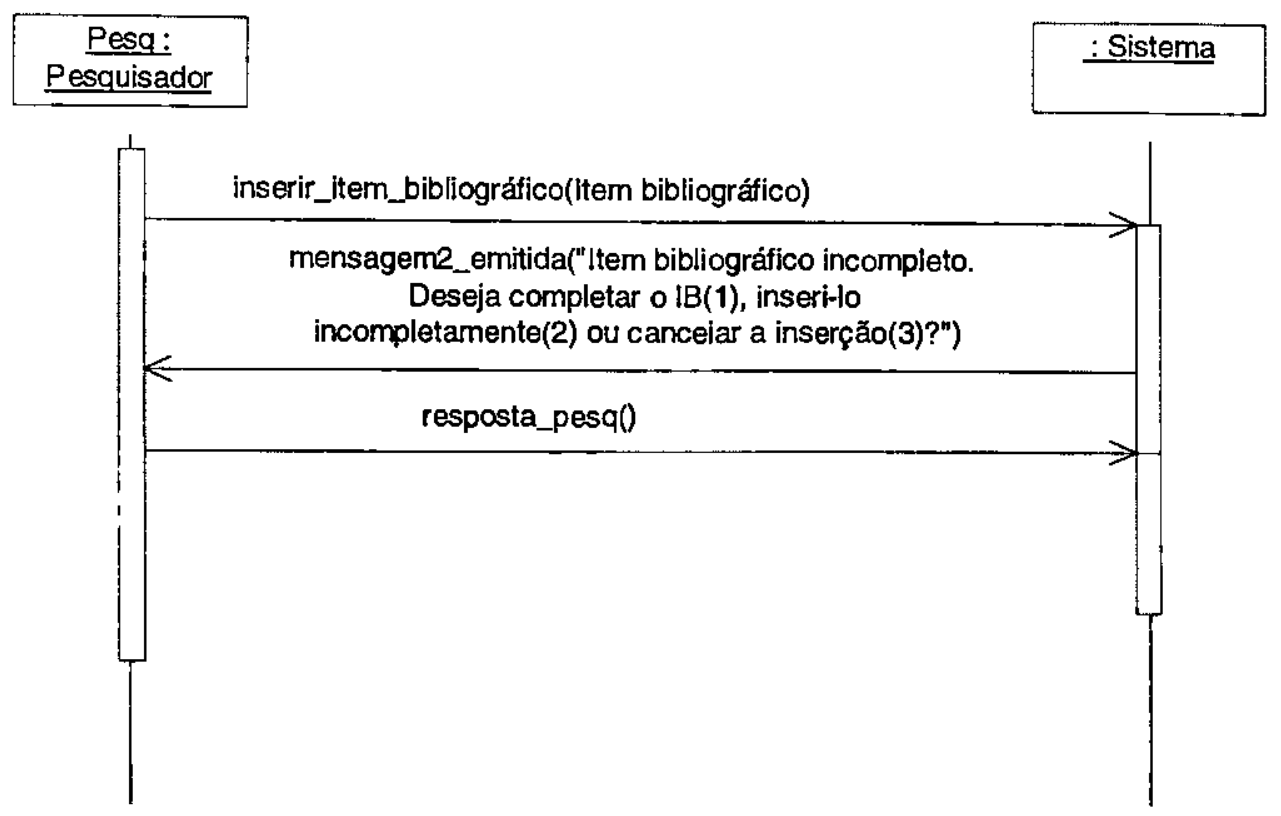

Figura 4.9 - Cenário de inserção de item bibliográfico - inserção cancelada

\subsubsection{Diagrama de Classes da Análise}

Depois de desenvolvidos os cenários deve-se elaborar o Diagrama de Classes da Análise. Conforme pode ser verificado nos cenários o único agente externo que interage com o sistema é o pesquisador. Sendo assim, a classe Pesquisador que já constava no Diagrama de Classes do Domínio pode ser classificada como ator do sistema por meio do estereótipo <<ator $>$ ou da figura de um homem estilizado. As classes Documento e Bib_Externa representam elementos que já existem no ambiente e servem como entradas para a geração do arquivo de referências bibliográficas e para a importação de itens bibliográficos, respectivamente. Dessa forma, essas classes podem ser classificadas como classes de interface utilizando o estereótipo <<interface > Na Figura 4.10 é possível verificar que no Diagrama de Classes da Análise alguns objetos foram classificados com estereótipos de ator ou interface, como mencionado acima, delimitando o escopo do sistema. Aparecem também as classes de associação Par_ft, Par_lib, Par_ref_bib e Importa que possuem atributos de relacionamentos.

\subsubsection{Modelo de Operações}

Para cada uma das operações que aparece nos cenários deve-se elaborar um modelo de operação. As especificações dos casos de uso auxiliam na determinação do comportamento da operação e o Diagrama de Classes da Análise pode ajudar a determinar os objetos, atributos e relacionamentos que são lidos e modificados. Os eventos de saída que aparecem nos cenários se tornarão entradas da cláusula Envia do modelo de operação. Na Figura 4.11 é apresentado o modelo de operação de inserir_item_bibliográfico. Como a Rose não oferece recursos para fazer modelos textuais, os modelos de operação foram feitos no espaço para documentação com exceção das cláusulas Pré e Pós, que constam na especificação da operação e da cláusula Lê, que é coberta pelos argumentos da operação. Na Figura 4.12 é apresentada a janela de especificação de uma operação na Rose. 


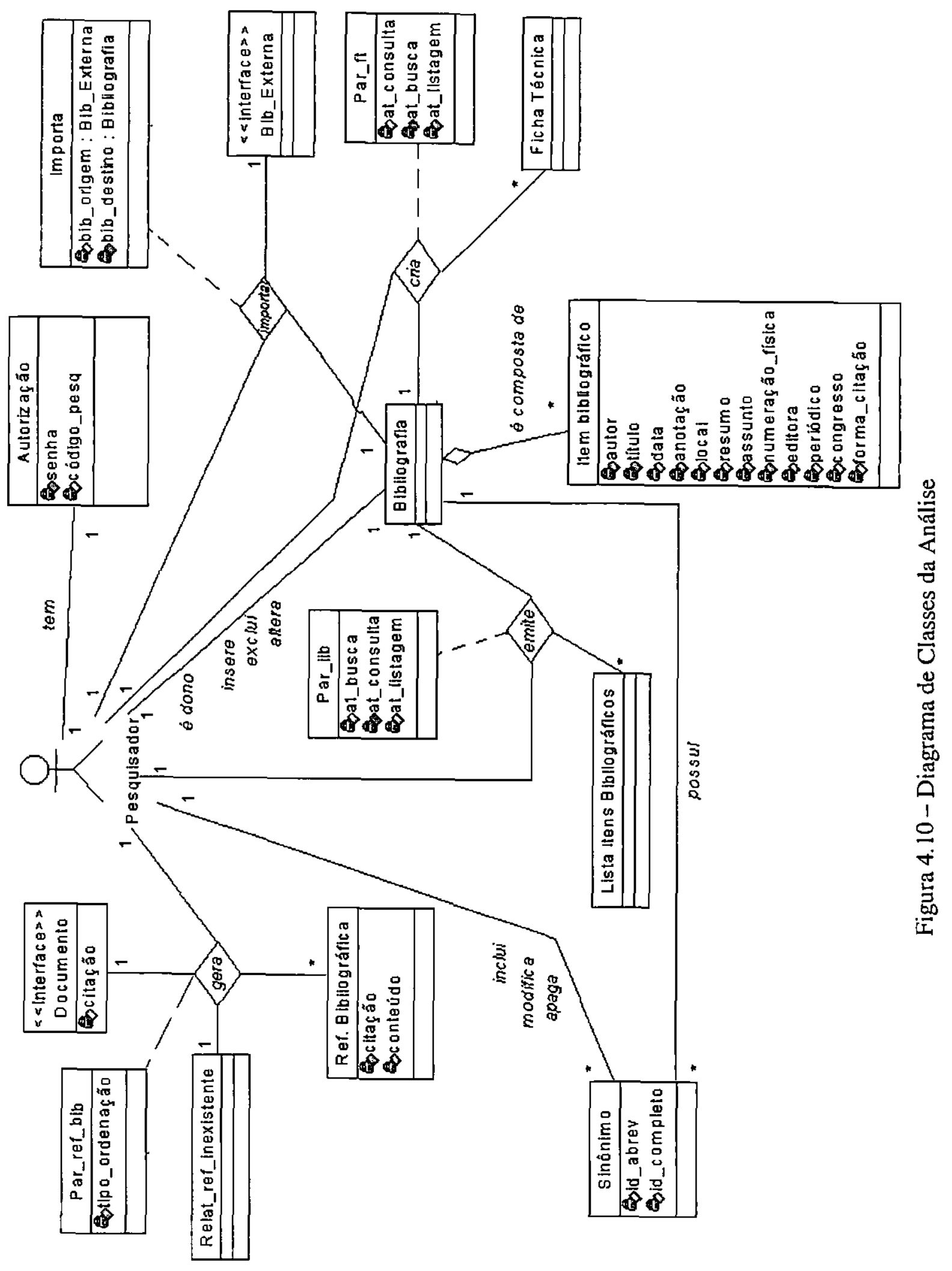




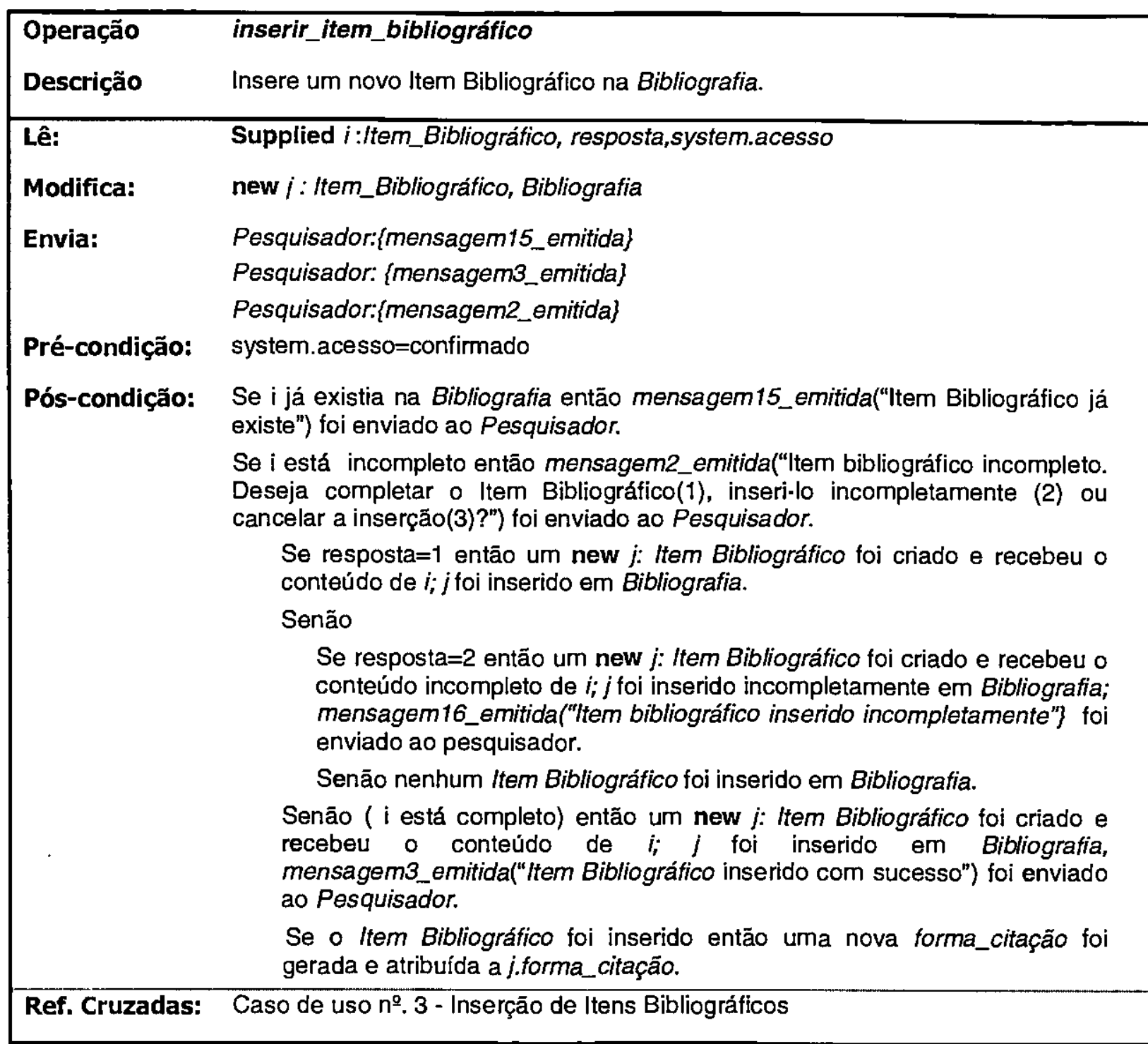

Figura 4.11 - Modelo de Operação para a operação inserir_item_bibliográfico

\subsubsection{Modelo de Ciclo de Vida}

Analisando os Cenários e o Documento de Requisitos do SAPES, o Modelo de Ciclo de Vida do SAPES foi elaborado (Figura 4.13). O evento $\lambda$ representa um evento que é disparado automaticamente quando a execução da operação anterior é finalizada. [não Ok] e [Ok] indicam pós-condições em relação ao resultado da operação validar_usuário.

Ao final desta fase deve-se analisar a completitude e consistência dos modelos gerados. No final da subseção 3.2.2 do Capítulo 3 são apresentados alguns critérios que podem ser seguidos. 


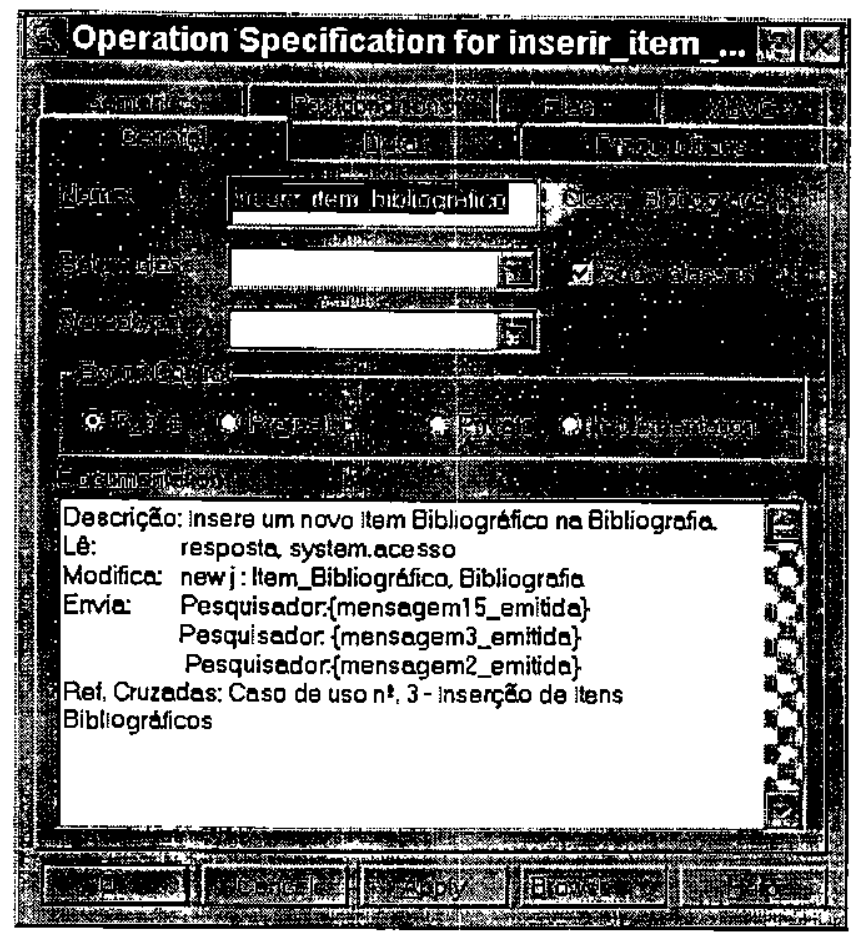

Figura 4.12 - Especificação da operação inserir_item_bibliográfico na ferramenta Rose

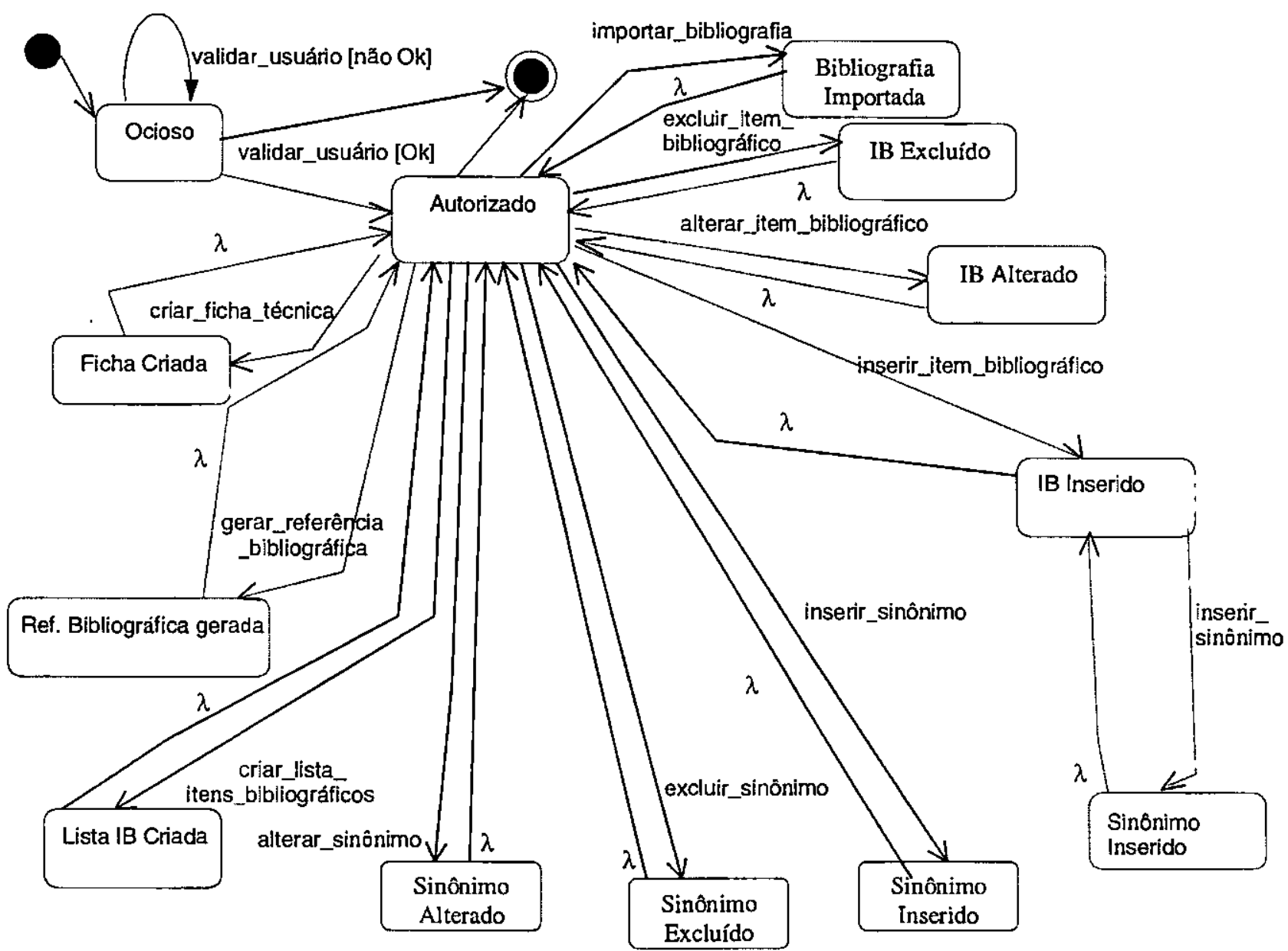

Figura 4.13 - Modelo de Ciclo de Vida 


\subsection{FASE dE PROJETO}

$\mathrm{Na}$ tentativa de não sobrecarregar uma única classe controladora com as operações do sistema decidiu-se estabelecer uma classe controladora para os eventos de cada caso de uso. Dessa forma, a classe Autorização controla os eventos relativos à autorização de acesso ao SAPES, a classe Sinônimo controla eventos relativos à manutenção de sinônimos e Bibliografia trata a Manutenção de Itens Bibliográficos, Geração do Arquivo de Referências Bibliográficas e a Emissão de Relatórios, já que nesses dois últimos casos de uso os dados manipulados estão armazenados em Bibliografia.

\subsubsection{Diagramas de Colaboração}

O Modelo de Operações serve de fonte de informação para a construção dos Diagramas de Colaboração. No Modelo de Operação de inserir_item_bibliográfico, por exemplo, a palavra chave new da sentença new $j$ :Item Bibliográfico indica que um novo objeto da classe Item Bibliográfico deve ser criado. Todas as opções apresentadas na cláusula Pós-condição devem ser satisfeitas no Diagrama de Colaboração por meio de métodos. Assim foi criado um método checar_completitude, que verifica se todos os itens de informação de um Item Bibliográfico foram preenchidos para determinar se o item bibliográfico será inserido completa ou incompletamente. Deve-se garantir que todos os eventos de saída que aparecem na cláusula Envia são enviados às classes. Para enviar mensagens para o Pesquisador foram criadas duas novas classes de projeto: Mensagem_Vídeo, que representa uma mensagem que será enviada ao pesquisador e Monitor, que representa o dispositivo através do qual a mensagem será enviada. $\mathrm{Na}$ Figura 4.14 é apresentado o diagrama de colaboração para a operação inserir_item_bibliográfico. Para diferenciar as operaçōes do SAPES dos métodos que realmente concretizam as operações, convencionou-se que os métodos que representam as operações do sistema devem ter nomes por extenso, ao passo que os outros métodos que realizam a mesma função da operação devem ter nomes abreviados. Por exemplo, a operação inserir_item_bibliográfico controlada pela classe Bibliografia é concretizada por muitos métodos, como pode ser visto na Figura 4.14, dentre eles os métodos inserir_item_completo e inserir_item_incompleto da classe Item_Bibliográfico que fazem a inserção propriamente dita. Analogamente, para excluir ou alterar um item bibliográfico, são executados os métodos Bibliografia.excluir_item_bibliográfico e Bibliografia.alterar_item_bibliográfico que representam operações do SAPES e os métodos Item_Bibliográfico excluir_ib e Item_Bibliográfico.alterar_ib que são os métodos da classe Item_Bibliográfico que realizam a exclusão ou a alteração de um item bibliográfico.

\subsubsection{Diagrama de Estados}

Analisando todos os diagramas de colaboração, foi possível analisar a ordem de execução de todos os métodos da classe Item Bibliográfico e construir o diagrama de estados dessa classe. Esse diagrama é apresentado na Figura 4.15. 


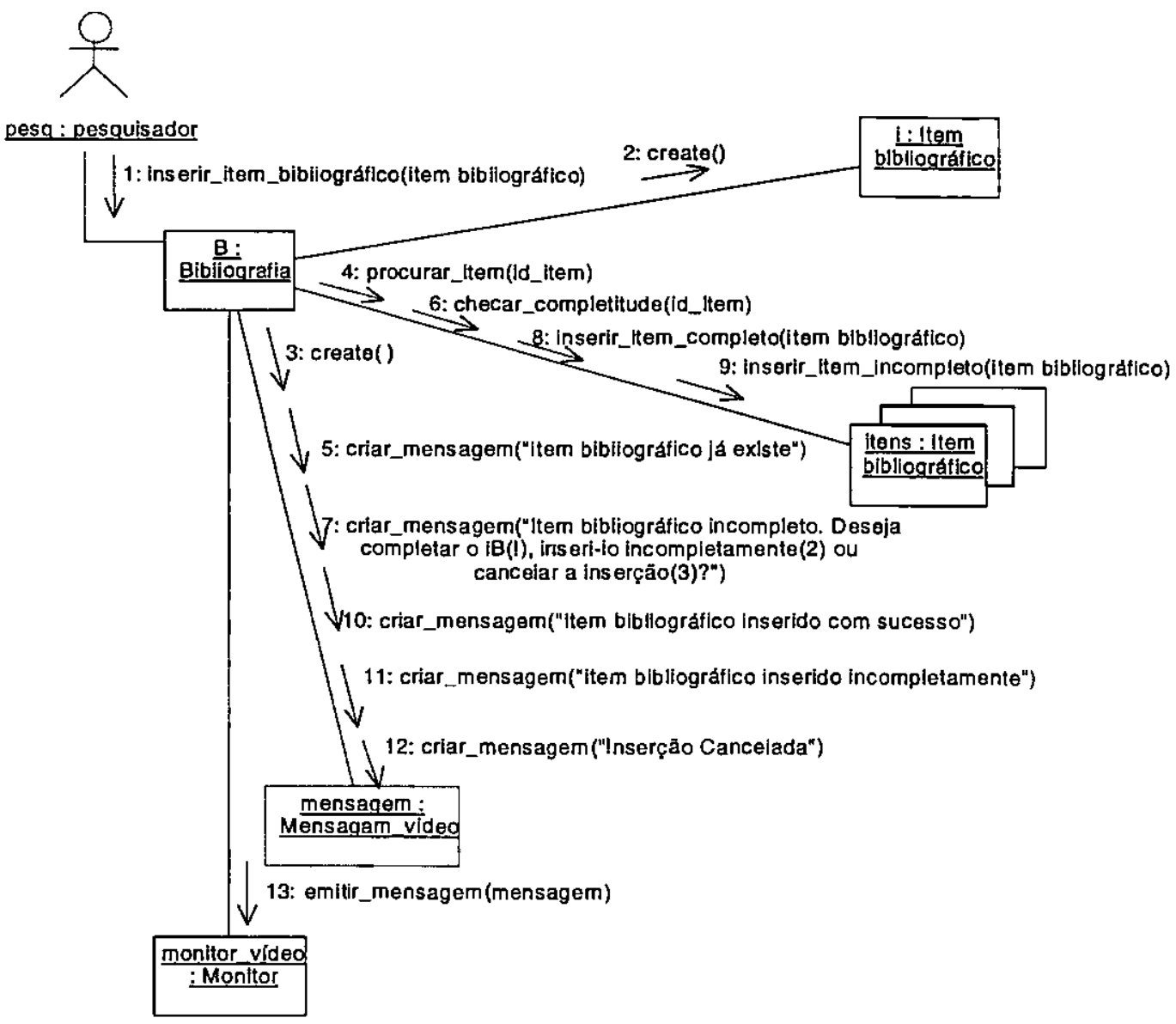

Figura 4.14 - Diagrama de Colaboração para a operação inserir_item_bibliográfico

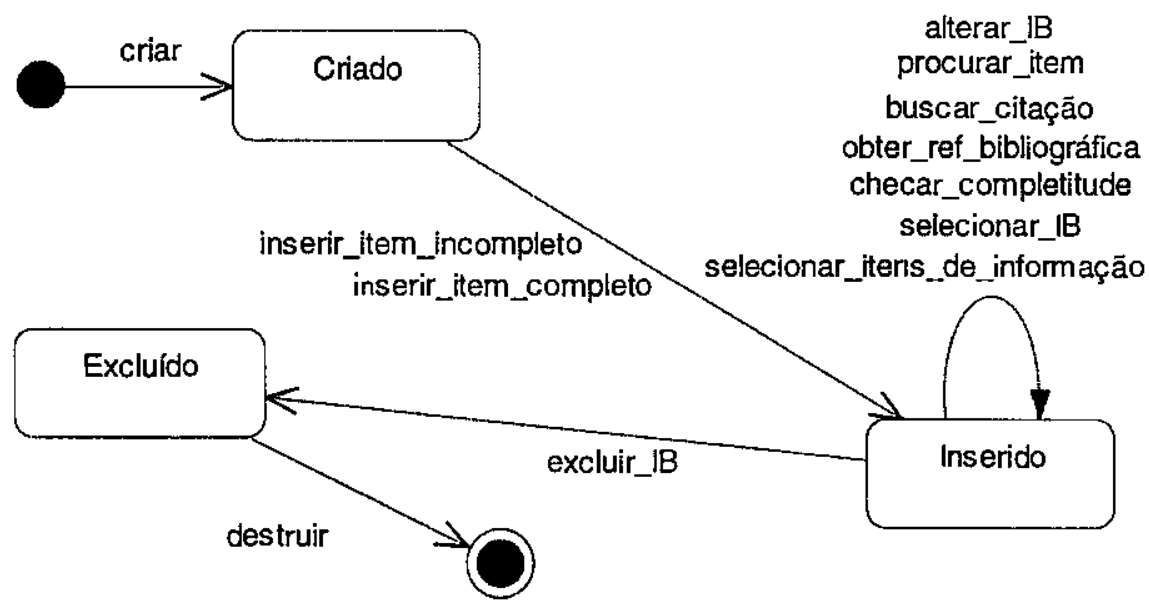

Figura 4.15 - Diagrama de Estados da Classe Item Bibliográfico

\subsubsection{Diagrama de Visibilidade}

De acordo com a Figura 3.1 do Capítulo 3, todos os diagramas de colaboração servem de entrada para o desenvolvimento do diagrama de visibilidade, que especifica as referências existentes entre as classes. Depois de analisar as referências existentes nos Diagramas de Colaboração e de classificá-las de acordo com os tipos de visibilidades apresentados no Capítulo 
3, foi desenvolvido o Diagrama de Visibilidade do SAPES, que é apresentado na Figura 4.16. Por meio dele é possível perceber o tipo de referência existente entre as classes controladoras e as classes colaboradoras. Como pode ser visto na Figura 4.14 a classe Bibliografia tem visibilidade localmente declarada para a classe Mensagem_Vídeo, porque um objeto da classe Mensagem_Vídeo é criado dentro de um método da classe Bibliografia, e tem visibilidade de atributo para a classe Item Bibliográfico. Portanto, a visibilidade de Bibliografia para Item Bibliográfico e para Mensagem_Vídeo deve ser representada por um relacionamento de navegabilidade e por um relacionamento de dependência, respectivamente.

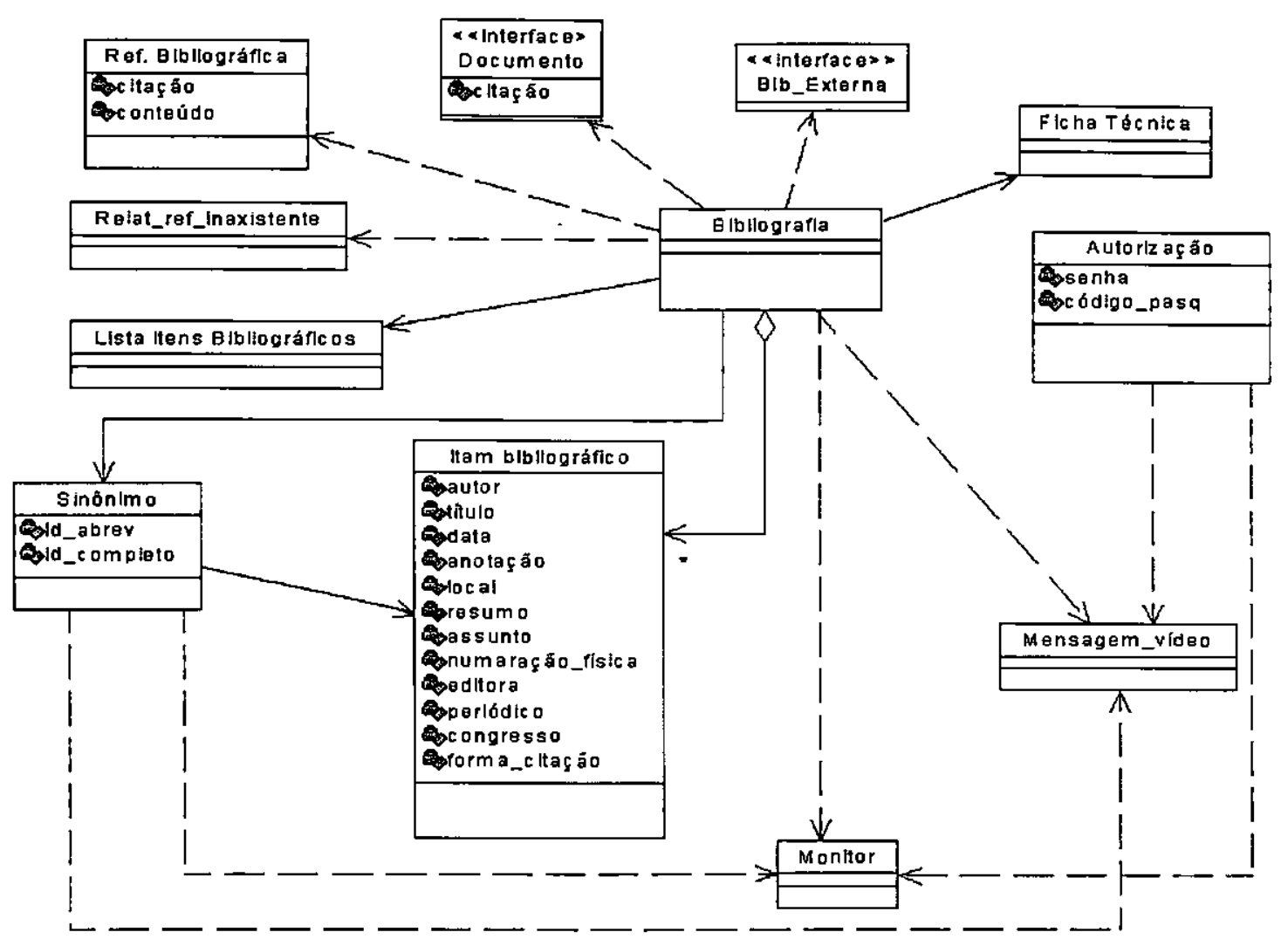

Figura 4.16 - Diagrama de Visibilidade do SAPES

\subsubsection{Diagrama de Classes da Análise Refinado}

O Diagrama de Classes da Análise é atualizado com as classes de projeto, as operações das classes e novas relações de especialização/generalização para formar o diagrama de classes da análise refinado. No caso do SAPES, na fase de projeto foram criadas as classes Monitor e Mensagem_Vídeo e nenhuma relação de herança e nenhum atributo de projeto foi adicionado. Dessa forma, tem-se o Diagrama de Classes da Análise Refinado apresentado na Figura 4.17. Como a Rose foi utilizada para fazer a modelagem, os métodos foram associados às classes automaticamente, facilitando a geração do Diagrama de Classes da Análise Refinado, porém essa informação pode ser sintetizada por meio da análise dos Diagramas de Colaboração. 


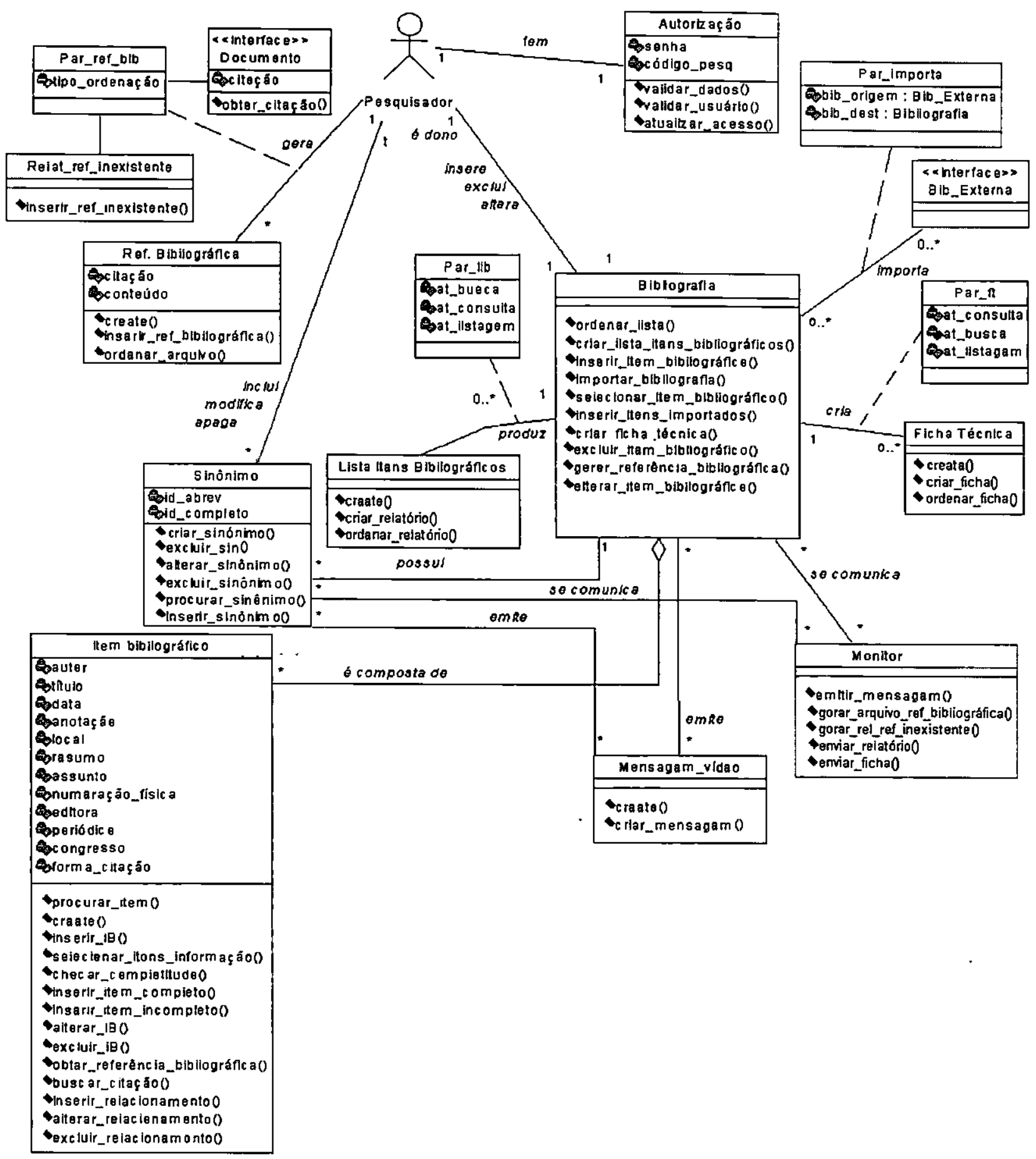

Figura 4.17 - Diagrama de Classes da Análise Refinado do SAPES

\subsubsection{Descrição de Classes}

Nessa subseção são apresentadas as descrições de classes do SAPES, geradas a partir do Diagrama de Classes da Análise Refinado e do Diagrama de Visibilidade. Na Figura 4.18 e 4.19 são apresentadas as descrições das classes Bibliografia e Item Bibliográfico, respectivamente. Todos os atributos e métodos da classe Bibliografia que aparecem no Diagrama de Classes da 
Análise Refinado devem constar na descrição dessa classe. Todas as referências existentes entre a classe Bibliografia e as outras classes do sistema se tornam atributos objeto-valorados e devem ter seus tipos de visibilidade especificados de acordo com as palavras-chave bound e unbound. É possível perceber, na Figura 4.16, que Bibliografia tem relacionamento de dependência para Ref_Bibliográfica, Relat_Ref_Inexistente e Mensagem_Vídeo, etc. Esses relacionamentos de dependência se tornaram atributos objeto-valorados do tipo bound na descrição da classe Bibliografia, ao passo que a classe Sinônimo se tornou um atributo unbound em virtude do relacionamento de navegabilidade existente entre ela e Bibliografia .

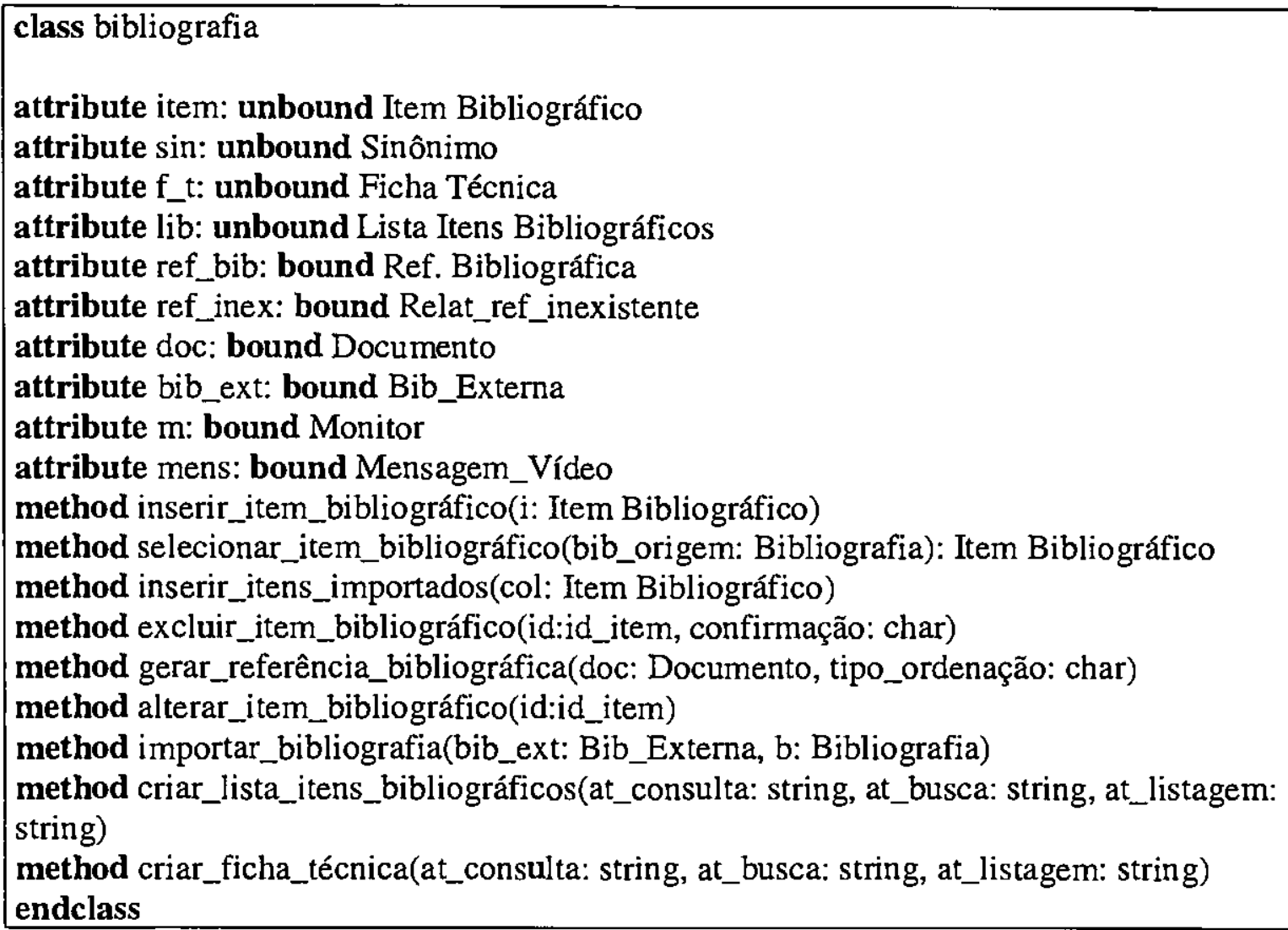

Figura 4.18 - Descrição da Classe Bibliografia

\subsection{FASE DE IMPLEMENTAÇÃO}

$\mathrm{Na}$ fase de Implementação devem ser compostos os corpos dos métodos. Na Figura 4.20 é apresentado, em Java, o corpo do método Bibliografia.inserir_item_bibliográfico. O diagrama de colaboração da operação inserir_item_biblliográfico, da classe Bibliografia, pode ser visto na Figura 4.14.

O método Item Bibliográfico.procurar_item verifica se o item bibliográfico existe na base de dados. O método Item Bibliográfico.checar_completitude verifica se o item que será inserido possui todas as informações necessárias, ou seja, verifica se todos os itens de informação foram preenchidos. Os métodos inserir_item_completo e inserir_item_incompleto da classe Bibliografia executam a inserção propriamente dita do item completo ou incompleto, 
respectivamente. O método Mensagem_Vídeo.criar_mensagem cria uma mensagem que será posteriormente exibida na tela pelo método Monitor.emitir_mensagem.

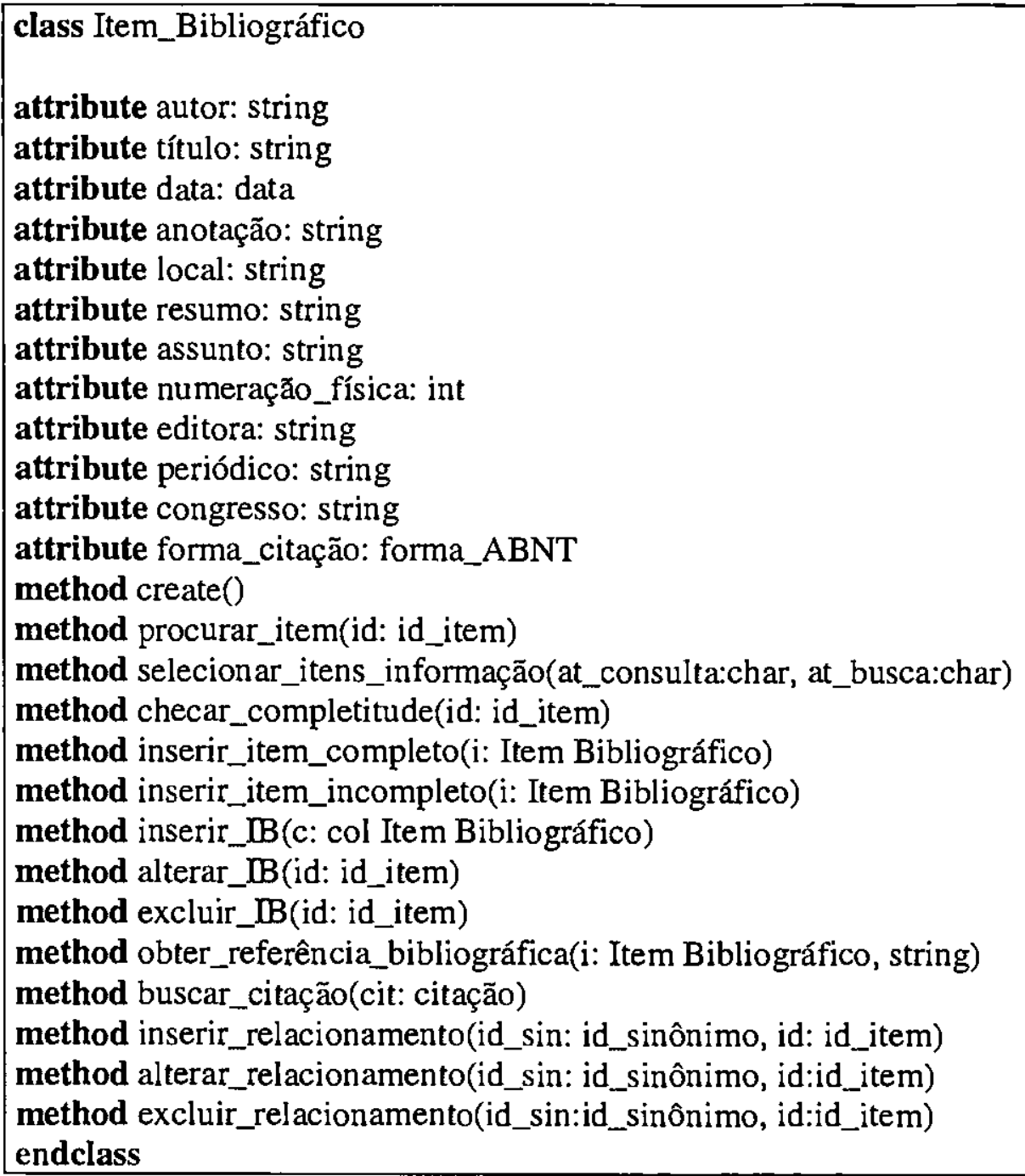

Figura 4.19 - Descrição da Classe Item_bibliográfico

Como o método foi descrito em Java não existe a necessidade de remover os objetos criados dinamicamente, pois a própria linguagem se encarrega dessa tarefa quando termina a execução do método.

Assim que o corpo de todos os métodos for desenvolvido, deve-se atualizar as descrições de classes, pois novos métodos podem ter sido incorporados na fase de implementação. Isso acontece com o método Item Bibliográfico.completar_item, que não havia sido previsto na construção do diagrama de colaboração da operação inserir_item_bibliográfico. Por isso, a descrição da classe Item Bibliográfico deve ser atualizada para incluí-lo, como é mostrado na Figura 4.21. Esse método deve permitir que o pesquisador complete os itens de informação do item bibliográfico que não foram preenchidos previamente para que a inserção possa ser realizada. 


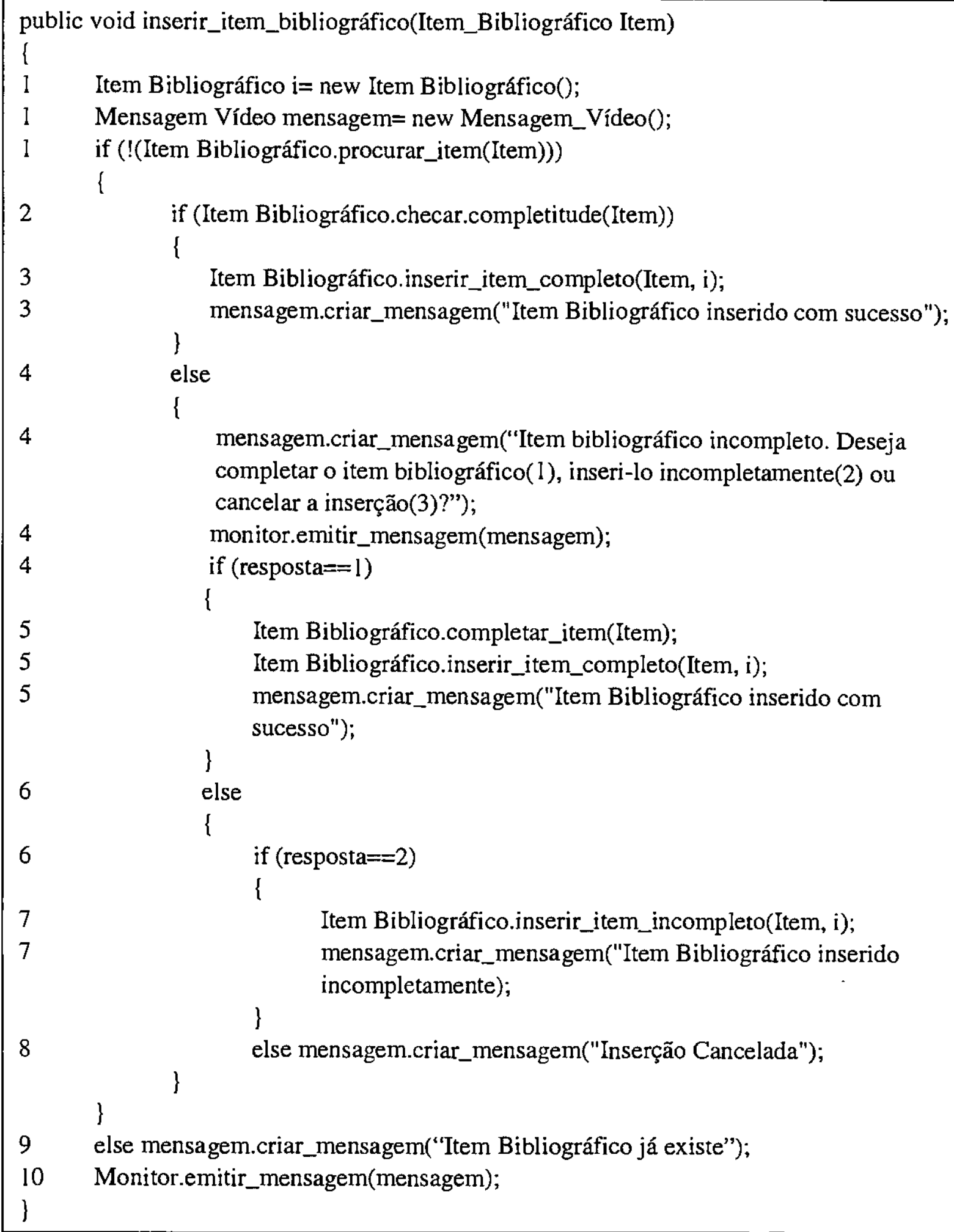

Figura 4.20 - Corpo do Método Bibliografia.inserir_item_bibliográfico 
class Item_Bibliográfico

attribute autor: string

attribute título: string

attribute data: data

attribute anotação: string

attribute local: string

attribute resumo: string

attribute assunto: string

attribute numeração_física: int

attribute editora: string

attribute periódico: string

attribute congresso: string

attribute forma_citação: forma_ABNT

method create()

method procurar_item(id: id_item)

method selecionar_itens_informação(at_consulta:char, at_busca:char)

method checar_completitude(id: id_item)

method inserir_item_completo(i: Item Bibliográfico)

method inserir_item_incompleto(i: Item Bibliográfico)

method inserir_IB(c: col Item Bibliográfico)

method alterar_IB(id: id_item)

method excluir_IB(id: id_item)

method obter_referência_bibliográfica(i: Item Bibliográfico, string)

method buscar_citação(cit: citação)

method inserir_relacionamento(id_sin: id_sinônimo, id: id_item)

method alterar_relacionamento(id_sin: id_sinônimo,id:id_item)

method excluir_relacionamento(id_sin:id_sinônimo, id:id_item)

method completar_item(i: Item Bibliográfico)

endclass

Figura 4.21 - Descrição atualizada da Classe Item_bibliográfico

\subsection{Avalıação}

Após a utilização da notação UML, do ProDeS/UML e da Rational Rose, algumas observações podem ser feitas. Essas observações são apresentadas nas próximas seções.

\subsubsection{Notação UML}

É possível representar toda a informação do Modelo de Objetos do Fusion utilizando os Diagramas de Classes, até porque eles são mais abrangentes. Existem alguns problemas quanto à interpretação semântica da relação de agregação, já que a UML possibilita mais de um tipo de representação. No Fusion a semântica dos relacionamentos mostrados na Figura 4.22 é a seguinte: a área de carregamento (Área_Carreg) contém tambores que serão guardados em um armazém e fazem parte da Lista_Alocação, ou seja, todos os objetos tambor que tem relacionamento com Armazém devem fazer parte de Lista_Alocação. Em UML esse mesmo modelo de objetos poderia ser representado de três formas, duas delas são mostradas na Figura 
4.23. Analogamente, a Figura 4.23 (b) representa a mesma modelagem da Figura 4.22 , o que não fica claro é se a Figura 4.23 (a) tem o mesmo significado semântico que a Figura 4.22, ou seja, todos os objetos Tambor relacionados com Armazém têm necessariamente que fazer parte de Lista_Alocação? Uma modelagem equivalente à modelagem do Fusion é apresentada na Figura 4.24, nessa modelagem Lista_Alocação agrega a classe Tambor_Armazém, uma classe de associação que representa todos os Tambores que estão relacionados com algum Armazém.

É perfeitamente possível representar cenários com a notação dos diagramas de sequiência, basta mudar o enfoque de interação entre os objetos do sistema para a interação entre um ator e o sistema. O sistema é visto como uma caixa preta.

Como na UML operação tem o mesmo sentido de método, para modelar o modelo de ciclo de vida do Fusion utilizando o diagrama de estados da UML é preciso que haja uma mudança no nível de abstração, de forma que as transições do diagrama estejam associadas a operações em vez de métodos. Para a modelagem dos diagramas de estados da classe o nível de abstração permanece o mesmo. Como não existem modelos textuais e não existe na UML nenhum diagrama equivalente ao modelo de operações, as suas informações devem ser registradas nas especificações das operações caso alguma ferramenta CASE esteja sendo utilizada.

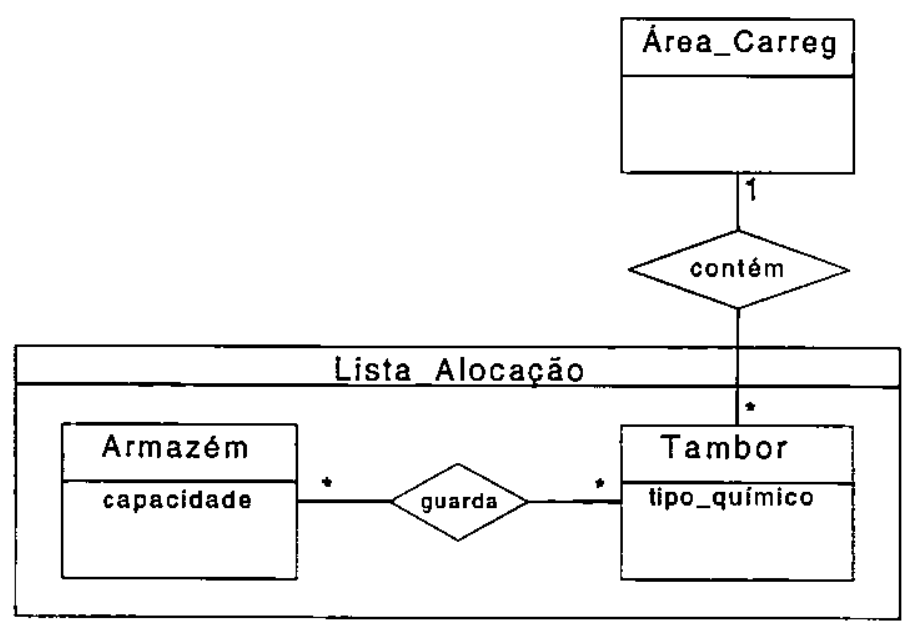

Figura 4.22 - Modelo de Objetos parcial de um depósito de tambores modelado em Fusion

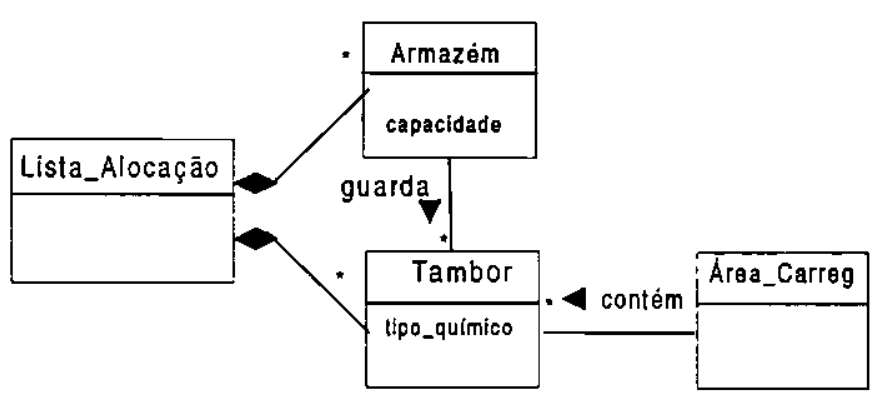

(a)

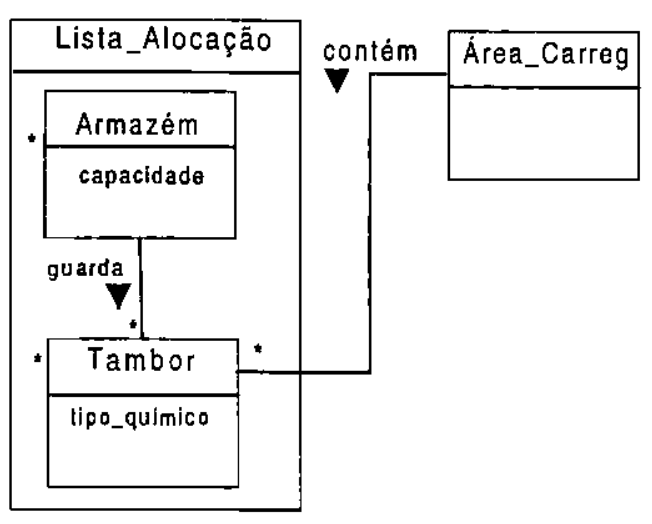

(b)

Figura 4.23 - Modelo de Objetos parcial de um depósito de tambores modelado em UML 


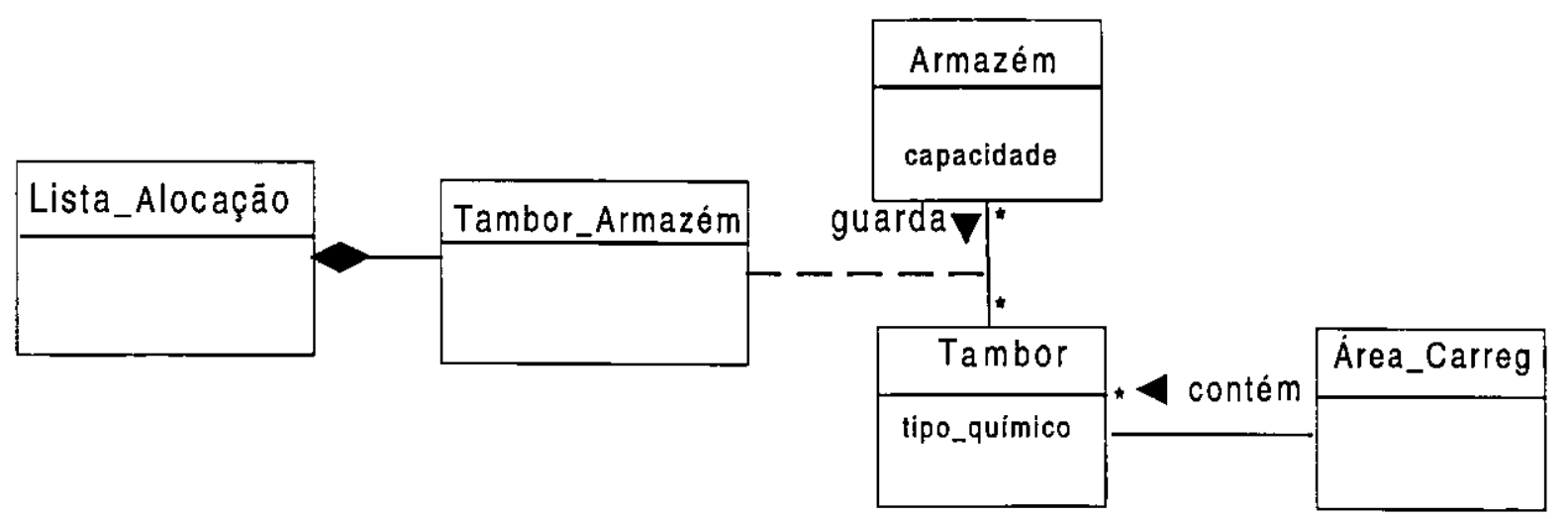

Figura 4.24 - Outra modelagem do depósito de tambores usando uma classe de associação da UML

Não é possível representar todos os tipos de visibilidade do Grafo de Visibilidade do Fusion em algum diagrama da UML, mas dependência (duração da referência) pode ser modelada por meio de relacionamentos de navegabilidade e dependência nos diagramas de classes.

\subsubsection{Ferramenta Rational Rose}

A ferramenta CASE utilizada para apoiar o ProDeS/UML foi a Rational Rose 98, da Rational Software Corporation, uma versão que gera o cabeçalho dos métodos em Java. Essa ferramenta permite construir todos os modelos da UML, mas alguns desses modelos ainda não têm todos os seus recursos implementados, como por exemplo, o Diagrama de Classes, que ainda não tem disponível o relacionamento temário, a associação unidirecional e o direcionamento da associação. Uma solução encontrada para modelar o relacionamento ternário foi a criação de uma classe de associação para representá-lo, conforme mostrado na Figura 4.19.

Apesar da UML não possuir modelos textuais, na janela de especificação de uma operação na Rose é possível adicionar as pré e pós-condições e os argumentos de entrada da operação, que representam respectivamente a mesma informação das cláusulas Pré-Condição, Pós-Condição e Lê do Modelo de Operações. As outras informações do Modelo de Operações devem ser adicionadas no campo de especificação da operação, sobre o qual nenhum controle de consistência é realizado.

Apesar da descrição de classes ser um modelo textual, a Rose adiciona no Diagrama de Classes todos os métodos e atributos dentro de cada classe, além de acrescentar a visibilidade (público, privado ou protegido) do método ou atributo.

A Rose somente permite construir um Diagrama de Estados se ele estiver associado a uma classe, assim um problema existente para a utilização da Rose no ProDeS/UML é a criação do Modelo de Ciclo de Vida, que não se refere a uma classe em particular, mas a todas as operações do sistema. Larman apresenta algumas opções para o controle das operações do sistema (Larman, 1997). Considerando as sugestões de Larman, uma possível solução para esse problema seria criar uma classe de interface, que representa a classe controladora de todas as operações do sistema e tem como diagrama de estados o Modelo de Ciclo de Vida do sistema. 
Na elaboração dos diagramas de colaboração não é possível numerar as mensagens, já que a numeração é gerada automaticamente. Uma vez criado o diagrama, é preciso convertê-lo em um diagrama de sequiência caso seja preciso alterar a ordem das mensagens, e então converter o diagrama novamente em diagrama de colaboração.

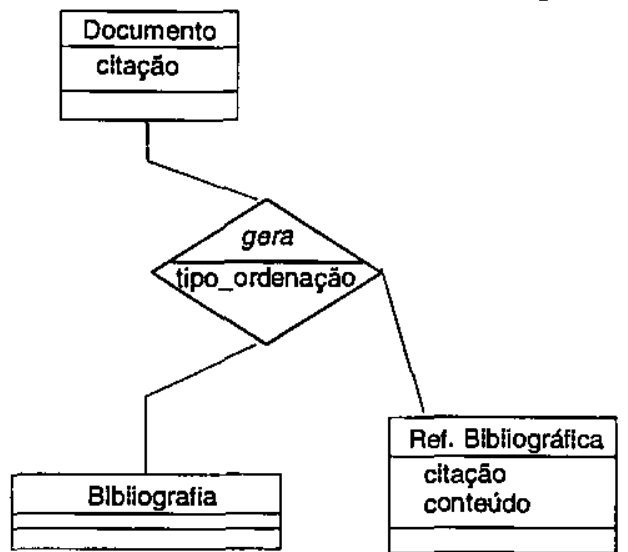

(a)

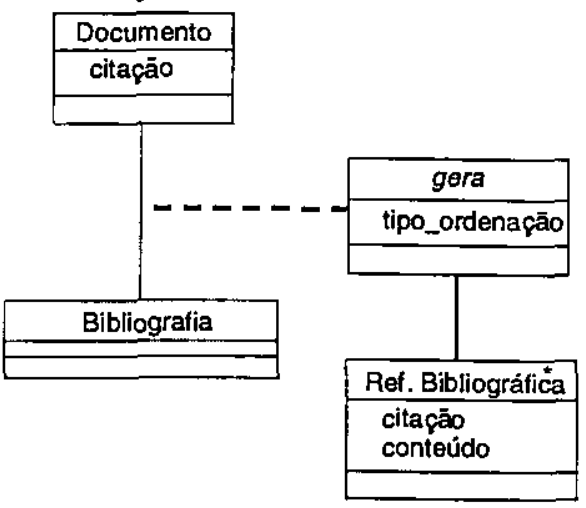

(b)

Figura 4.25 - (a) Relacionamento ternário (b) Classe de associação para representar um relacionamento ternário

\subsubsection{ProDeS/UML}

O ProDeS/UML foi utilizado somente para modelar o SAPES, logo seria necessário realizar outros estudos de caso para poder avaliar a sua eficiência, os pontos que precisam ser melhorados e a qualidade do produto obtido por meio do seu emprego. Ainda assim, pode-se inferir que o produto final estará em conformidade com os requisitos desde que todos os passos indicados pelo ProDeS/UML sejam seguidos, pois, afinal, ele inclui o planejamento dos requisitos de teste e possui basicamente a mesma seqüência de passos do método Fusion, que é um método cuja eficiência já foi comprovada.

A Tabela 4. I é uma tabela comparativa na qual apresentam-se características de alguns processos orientados a objetos, dentre eles o ProDeS/UML. Como mencionado anteriormente, além de utilizar a notação UML, uma das características marcantes do ProDeS/UML é o gerenciamento da atividade de teste introduzida por uma abordagem de teste que fornece diretrizes para a geração de requisitos de teste.

Tabela 4. I - Tabela Comparativa de alguns processos orientados a objetos

\begin{tabular}{|c|c|c|c|c|c|}
\hline $\begin{array}{l}\text { Processos } \\
\text { Características }\end{array}$ & ProDeS/UML & Fusion & $\begin{array}{l}\text { Unified } \\
\text { Process }\end{array}$ & Teamfusion & Objectory \\
\hline Iterativo & $\checkmark$ & $\checkmark$ & $\checkmark$ & $\checkmark$ & $\checkmark$ \\
\hline Enfase em teste & $\checkmark$ & & $\checkmark$ & & $\checkmark$ \\
\hline $\begin{array}{l}\text { Revisão des } \\
\text { Modelos }\end{array}$ & $\checkmark$ & $\checkmark$ & & $\checkmark$ & \\
\hline $\begin{array}{l}\text { Usa a notação da } \\
\text { UML }\end{array}$ & $\checkmark$ & & $\checkmark$ & $\checkmark$ & \\
\hline
\end{tabular}


Todos os processos apresentados incluem as fases de Análise, Projeto e Implementação. Alguns deles são mais abrangentes, incluindo a fase de Engenharia de Requisitos e/ou de Arquitetura, como por exemplo, o TeamFusion, que abrange essas duas fases.

Assim como o ProDeS/UML, o uso do Unified Process pode ser apoiado pela ferramenta Rational Rose. O método Fusion também possui uma ferramenta de apoio, a FusionCase.

O ProDeS/UML, o método Fusion e o TeamFusion introduzem checagens ao final de cada fase para verificar a consistência entre os modelos de uma fase em relação aos da fase anterior. Com isso, espera-se garantir a qualidade dos modelos gerados e consequentemente do produto final.

\subsection{CONSIDERAÇÕES FINAIS}

Neste capítulo foram apresentados exemplos mostrando como o ProDeS/UML é utilizado no desenvolvimento de um sistema. O tema utilizado para exemplificar foi a inserção de item bibliográfico do SAPES e, conseqüentemente, foram mostrados todos os modelos relacionados a esse tema. Para melhorar o entendimento do uso do processo foi mencionada a origem da informação na elaboração de cada diagrama.

A modelagem completa do SAPES gerada na Rose foi registrada em um Documento de Trabalho (Colanzi \& Masiero, 1999).

No próximo capítulo é apresentada a abordagem de teste proposta para ser usada em conjunto com o ProDeS/UML. Assim como neste capítulo, no Capítulo 5 é apresentado um exemplo de uso dessa abordagem de teste para uma parte do SAPES. 


\section{CAPÍTULO V}

\section{ABORDAGEM DE TESTE}

\subsection{CONSIDERAÇÕES INICIAIS}

O ProDeS/UML distribui a atividade de teste ao Iongo do processo de desenvolvimento do software. Isto é feito por meio da introdução de uma abordagem de teste que fornece diretrizes para a geração de modelos de teste a cada fase do desenvolvimento. Esses modelos de teste incluem os requisitos de teste extraídos dos modelos de especificação do software. A abordagem de teste recomenda que sejam feitas revisões nos modelos de teste para tentar garantir que os requisitos de teste satisfazem os critérios de teste utilizados para a sua geração.

Este capítulo está organizado da seguinte maneira: na seção 5.2 é apresentada a abordagem de teste do ProDeS/UML, na seção 5.3 é ilustrado o uso da abordagem de teste e na seção 5.4 são apresentadas as considerações finais do capítulo.

\subsection{ABORDAGEM DE TESTE}

Tradicionalmente, as atividades de teste são divididas em três fases: teste de unidade, de integração e de sistema. $O$ teste de unidade concentra esforços para identificar erros na menor unidade do projeto de software: o módulo. O teste de integração é uma atividade sistemática aplicada durante a integração da estrutura do programa visando a descobrir erros associados às interfaces entre os módulos. O teste de sistema, realizado após a integração do sistema, visa a identificar erros de funções e características de desempenho que não estejam de acordo com a especificação. Após essas fases ocorre o teste de aceitação conduzido com o usuário final. Na 
abordagem orientada a objetos, em função da introdução do conceito de classe, caracteriza-se adicionalmente o Teste de Classe, que tem por objetivos descobrir erros de integração entre os métodos dentro do escopo da classe em teste, e o Teste de Integração para software orientado a objetos tem o objetivo de encontrar erros na integração de classes do sistema. Assim, o teste orientado a objetos é organizado em quatro fases, além do teste de aceitação, a saber:

$>$ Teste de unidade $=$ testa os métodos individualmente,

$>$ Teste de classe $=$ testa a interação entre métodos de uma classe,

$>$ Teste de integração = testa a interação entre classes do sistema,

$>$ Teste de sistema $=$ testa a funcionalidade do sistema como um todo.

Como o teste de métodos tem a mesma abrangência do teste de módulos, pode-se empregar, nessa fase de teste, os critérios de teste de unidade de software procedimental no teste de software OO. O teste de classe é introduzido como sendo um subconjunto do teste de integração, e devem ser testadas todas as interações existentes entre os métodos da classe em questão. A grande maioria dos trabalhos propostos na atualidade visa ao teste de classe (Binder, 1995; Binder, 1996b; Doong \& Frankl, 1991; D’Souza \& Leblanc, 1994; Harrold \& Rothermel, I994; Murphy et al., I994; Smith \& Robson, 1992; Vieira \& Travassos, I998).

Para empregar as técnicas de teste de integração existentes no teste de software OO devese considerar que não existe um módulo de controle de invocação de métodos, ou seja, um objeto pode interagir diretamente com outro sem necessariamente ter que passar por um objeto intermediário (de controle). Sendo assim, os critérios de teste de integração para software procedimental devem ser adaptados para testar a integração das classes de um software OO, pois eles consideram a existência de um módulo que controla a invocação de módulos (Berard, 1992).

Como o domínio da informação a ser testada no teste de sistema é o mesmo, ou seja, o funcionamento do sistema como um todo, é possível utilizar as técnicas empregadas no teste de sistema de software procedimental no teste de software $\mathrm{OO}$, com as devidas adequaçōes.

Pode-se considerar ainda o teste de validação, que é realizado entre o teste de integração e o teste de sistema. O teste de validação é realizado com o intuito de mostrar que o software está em conformidade com os requisitos. Os casos de teste são gerados a partir do documento de requisitos do sistema utilizando critérios de teste caixa preta. Tanto o plano como o procedimento de teste são projetados para garantir que todos os requisitos funcionais são satisfeitos, que os requisitos de desempenho são alcançados, que todos os elementos da configuração do software foram propriamente desenvolvidos e que a documentação está correta (Pressman, 1992). Sempre que se detecta um problema em relação à especificação do software (erro de conformidade com os requisitos) ele deve ser adicionado à lista de deficiências do software.

De uma maneira geral, o teste de software, que é uma das atividades de garantia de qualidade de software, envolve as seguintes atividades: planejamento, projeto de casos de teste, execução dos casos de teste e análise (avaliação) dos resultados dos testes. A ausência de planejamento das atividades de desenvolvimento é uma das origens da crise de software (Pressman, 1992). O planejamento da atividade de teste deve resultar num Plano de Teste, no qual são estimados recursos e são definidas estratégias, métodos e técnicas de teste, caracterizando-se um critério de aceitação do software em desenvolvimento. A falta de tempo e de recursos, e a indisponibilidade de ferramentas adequadas são os principais problemas 
enfrentados pelas equipes de teste. Uma questão usualmente presente na elaboração do plano de teste é saber quando as atividades de teste devem ser encerradas, ou seja, estabelecer um critério de parada (Maldonado, 1991).

Quanto ao projeto de casos de teste, o ideal seria gerar casos de teste para testar exaustivamente o software, mas isso é impraticável devido a restriçōes de tempo e custo. Logo, os critérios de teste existentes têm como objetivo detectar o maior número de erros no software, sem contudo garantir que o software esteja correto. A análise dos resultados dos testes consiste em confrontar os resultados obtidos em relação aos esperados para cada caso de teste e, possivelmente, avaliar a cobertura do conjunto de teste gerado.

Os modelos de desenvolvimento de software são uma fonte muito rica de informações para o planejamento e posterior construção de casos de teste. Assim, é possível especificar requisitos de teste ao tongo do ciclo de vida do software a partir das informações presentes nos modelos obtidos durante o desenvolvimento. Pode-se projetar diferentes tipos de teste de acordo com a abrangência das informações que constam nos modelos de cada fase. Roper apresenta um ciclo de vida ideal de desenvolvimento de sistemas, no qual em paralelo às fases do ciclo de vida são projetados os testes (Figura 5.1) (Roper, 1994). Considerando as fases de teste de software OO e similarmente ao ciclo de vida apresentado por Roper, a abordagem de teste proposta neste trabalho considera o desenvolvimento de modelos de teste com diferentes perspectivas, baseando-se no processo de desenvolvimento de software proposto neste trabalho.

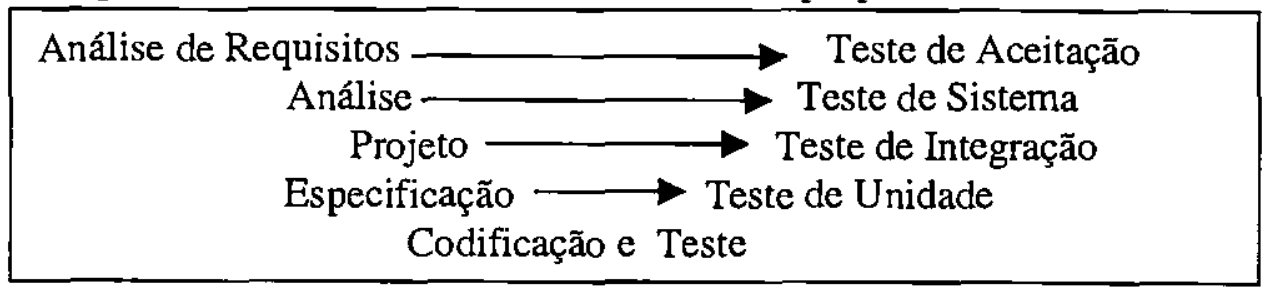

Figura 5.1 - Ciclo de Vida de Desenvolvimento de Sistema Ideal (Roper, 1994)

Na Figura 5.2 são apresentados os modelos de teste gerados por esta abordagem em cada uma das fases do desenvolvimento do software. Na Tabela 5.1 são mostrados os modelos que servem como fonte de informação para cada modelo de teste e qual é a atividade envolvida no desenvolvimento do modelo de teste. Ressalta-se que nem todos os modelos do ProDeS/UML foram utilizados para a derivação de requisitos de teste nesta abordagem de teste.

O Modelo de Avaliação do Teste engloba atividades de garantia de qualidade da atividade de teste. Nesse modelo a atividade de teste é avaliada sob duas perspectivas: resultados obtidos do teste em relação ao oráculo e consistência do projeto de teste com os modelos que serviram como fonte para a geração do teste. Dessa forma, as informações contidas neste modelo registram a condução de inspeções dos modelos de teste gerados ao longo do desenvolvimento e os resultados obtidos da execução dos conjuntos de casos de teste, confrontando-os com os resultados esperados. É importante salientar que os conjuntos de casos de teste podem ser executados em qualquer fase do desenvolvimento do software, desde que se tenha uma especificação executável. Se nenhum dos conjuntos de casos de teste tiver sido executado, todos eles deverão ser executados na fase de Implementação, assim que a codificação tiver sido concluída. $\mathrm{O}$ armazenamento dos modelos de teste que compöem os conjuntos de casos de teste e os resultados obtidos quando da sua execução facilitam o teste de regressão numa eventual manutenção. 


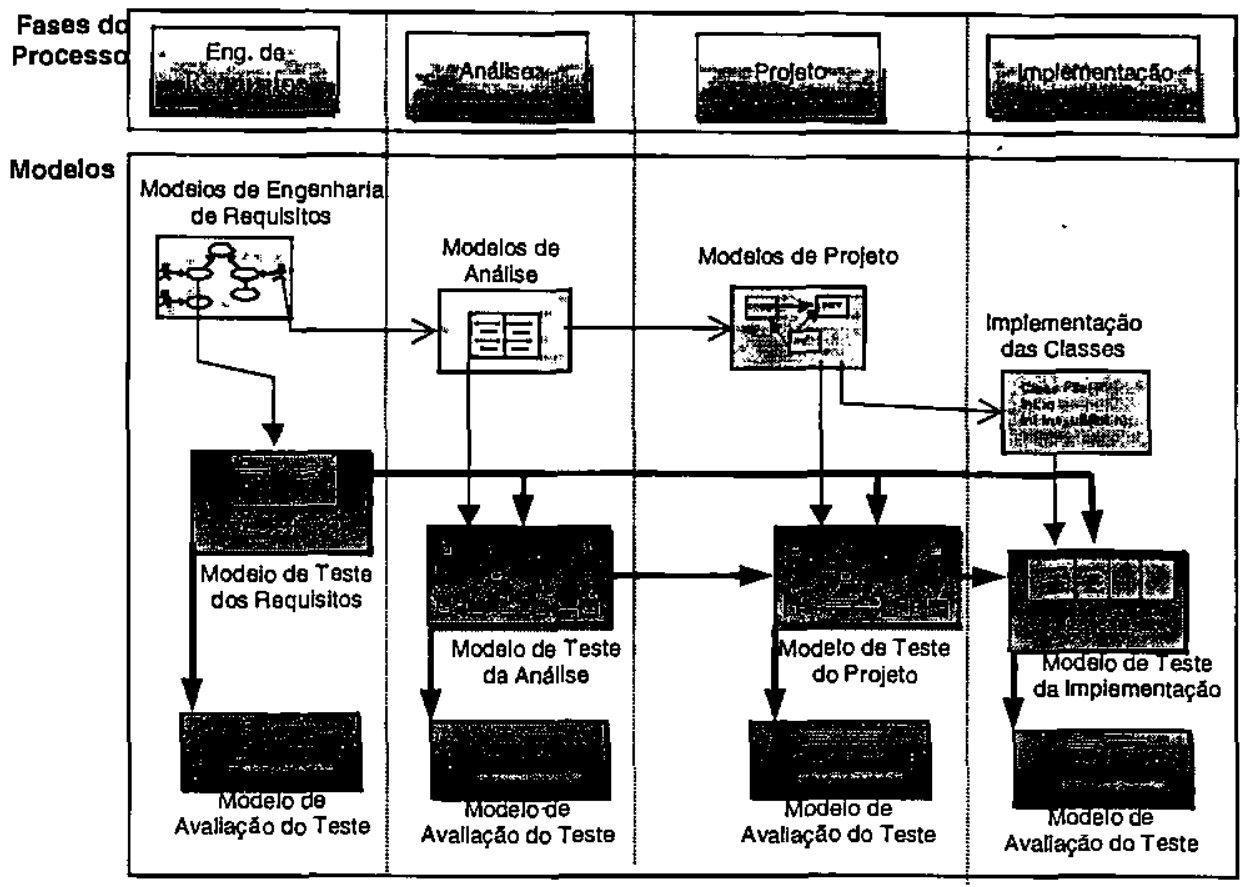

Figura 5.2 - Modelos de Teste gerados pela Abordagem de Teste

Tabela 5.1 - Tipos e Modelos de Teste desenvolvidos durante o ciclo de vida do software

\begin{tabular}{|c|c|c|}
\hline Fase/ Produto & Modelo de Teste & Atividade de Teste \\
\hline $\begin{array}{l}\text { Engenharia de Requisitos } \\
\text { - Especificação dos casos de } \\
\text { uso }\end{array}$ & $\begin{array}{l}\text { Modelo de Teste dos } \\
\text { Requisitos }\end{array}$ & Projeto do Teste de Sistema \\
\hline $\begin{array}{l}\text { Análise } \\
\text { - Modelo de Ciclo de Vida }\end{array}$ & $\begin{array}{l}\text { Modelo de Teste da } \\
\text { Análise }\end{array}$ & Projeto do Teste de Integração \\
\hline $\begin{array}{l}\text { Projeto } \\
\text { - Diagramas de Estados das } \\
\text { Classes } \\
\text { - Diagramas de Colaboração }\end{array}$ & $\begin{array}{l}\text { Modelo de Teste do } \\
\text { Projeto } \\
\text { Modelo de Teste do } \\
\text { Projeto }\end{array}$ & $\begin{array}{l}\text { Projeto do Teste de Classe baseado } \\
\text { em especificação } \\
\text { Projeto do Teste de Integração }\end{array}$ \\
\hline $\begin{array}{l}\text { Implementação } \\
\text { - Corpo dos métodos ou } \\
\text { código }\end{array}$ & $\begin{array}{l}\text { Modelo de Teste da } \\
\text { Implementação }\end{array}$ & $\begin{array}{l}\text { Projeto do Teste de Unidade/Classe } \\
\text { baseado em implementação }\end{array}$ \\
\hline
\end{tabular}

Considerando as atividades envolvidas no teste de software, a abordagem de teste proposta neste trabalho tem como principal objetivo fornecer algumas diretrizes para planejar o teste de software OO. Para isso são discutidos os critérios de teste passíveis de aplicação em determinada fase do desenvolvimento do software, considerando as informações disponíveis naquela fase. Avalia-se a adequação da utilização desses critérios e, para alguns deles, são fornecidas algumas diretrizes para o projeto de casos de teste. No contexto deste trabalho, os critérios de teste escolhidos são geralmente os que exigem os requisitos mínimos de teste e que são mais facilmente aplicáveis, visto que os modelos de teste serão gerados manualmente. Para cada fase é apresentado um exemplo de modelo de teste para o SAPES utilizando um critério escolhido. 


\subsubsection{Fase de Engenharia de Requisitos}

\subsubsection{Modelo de Teste dos Requisitos}

O Modelo de Teste dos Requisitos é desenvolvido na fase de engenharia de requisitos, na qual os modelos disponíveis são os diagramas de casos de uso e o modelo de objetos do domínio.

Assim como no teste de software procedimental, a maioria das técnicas de teste de software $\mathrm{OO}$ utiliza os critérios da técnica de teste funcional. Como os diagramas de casos de uso modelam a funcionalidade do sistema como um todo, os critérios da técnica funcional se adequam perfeitamente, pois esses visam a testar a funcionalidade do sistema independentemente de uma particular implementação. O Unified Process (Jacobson et al., 1999) mostra exemplos de casos de teste para o sistema gerados a partir dos casos de uso, no entanto, nenhum critério de teste é mencionado. Os critérios de teste aplicáveis nessa fase são: Grafo de Causa-Efeito, Análise do Valor Limite e Particionamento em Classes de Equivalência. Ambos os critérios têm como fonte de informação os diagramas de casos de uso. Recomenda-se que os três critérios citados sejam utilizados em conjunto.

Para aplicar os critérios Particionamento em Classes de Equivalência e Análise do Valor Limite deve-se analisar as condições de entrada de dados das especificações dos casos de uso para definir as classes de equivalência do sistema. Em seguida deve-se aplicar o critério de análise do valor limite, gerando para cada classe de equivalência casos de teste que estejam nos limites dessas classes. Por exemplo, na inserção de item bibliográfico no SAPES, deve-se gerar um caso de teste para inserir um item bibliográfico não existente na bibliografia e outro para inserir um item que já existe. Deve-se testar também os casos em que o pesquisador tenta inserir um item bibliográfico que possui algum item de informação incompleto e nesse caso o pesquisador pode efetuar a inserção incompleta do item, completar os itens de informação que estiverem incompletos ou cancelar a inserção, de acordo com a descrição do caso de uso apresentado na Figura 4.3 do Capítulo 4.

O Modelo de Teste dos Requisitos se constitui então da tabela com as classes de equivalências de cada caso de uso e da tabela com os casos de teste relacionados às classes de equivalência, conforme apresentado nas Tabelas 5.2 e 5.3, respectivamente. Na Tabela 5.4 são apresentadas as classes de equivalência para a inserção do item bibliográfico do SAPES e na Tabela 5.5 é mostrado um exemplo parcial do Modelo de Teste dos Requisitos para o caso de uso Inserção de Item Bibliográfico do SAPES.

Tabela 5.2 - Modelo da Tabela de Classes de Equivalência (Maldonado et al., 1998)

\begin{tabular}{|l|l|l|}
\hline Restrições de Entrada & \multicolumn{1}{|c|}{ Classes Válidas } & \multicolumn{2}{c|}{ Classes Inválidas } \\
\hline $\begin{array}{l}\text { Conteúdo da senha do } \\
\text { usuário }\end{array}$ & $\begin{array}{l}\text { Sequiência de caracteres } \\
\text { alfanuméricos }\end{array}$ & $\begin{array}{l}\text { Sequência de caracteres } \\
\text { numéricos }\end{array}$ \\
\hline$\ldots$ & $\ldots$ & $\ldots$ \\
\hline
\end{tabular}


Tabela 5.3-Modelo de Teste dos Requisitos Genérico

\begin{tabular}{|c|c|c|}
\hline \multicolumn{2}{|l|}{ Caso de Uso: 1} & Classe de Equivalência \\
\hline \begin{tabular}{|l|} 
Entrada \\
\end{tabular} & Saída Esperada & \\
\hline $\mathrm{A}$ & $\mathrm{Z}$ & 1 \\
\hline $\mathrm{E}$ & $\mathrm{H}$ & 2 \\
\hline & & $\ldots$ \\
\hline \multicolumn{3}{|l|}{ Caso de Uso: 2} \\
\hline \begin{tabular}{|l} 
Entrada \\
\end{tabular} & Sá́da Esperada & \\
\hline \begin{tabular}{|l|l}
$B$ \\
\end{tabular} & \begin{tabular}{|l|l|}
$\mathrm{Y}$ \\
\end{tabular} & $1,2,3$ \\
\hline & $\begin{array}{ll}2 \ldots & \vdots \\
\end{array}$ & $\ldots$ \\
\hline \multicolumn{3}{|l|}{ Caso de Uso: 3} \\
\hline \begin{tabular}{|l|} 
Entrada \\
\end{tabular} & \begin{tabular}{|l} 
Saída Esperada \\
\end{tabular} & \\
\hline $\mathrm{C}$ & $\mathrm{X}$ & 2 \\
\hline D & $\mathrm{J}$ & 1,3 \\
\hline $\mathrm{F}$ & G & $1,2,3$ \\
\hline$\ldots$ & $\ldots$ & $\ldots$ \\
\hline
\end{tabular}

Tabela 5.4 - Classes de Equivalência para a inserção de item bibliográfico do SAPES

\begin{tabular}{|c|c|c|}
\hline Restrições de Entrada & Classes Válidas & Classes Inválidas \\
\hline $\begin{array}{lll}\text { Existência } & \text { do } & \text { Item } \\
\text { Bibliográfico } & & \\
\end{array}$ & Não existente(1) & Existente(2) \\
\hline $\begin{array}{lll}\begin{array}{l}\text { Completitude } \\
\text { Bibliográfico }\end{array} & \text { do } & \text { Item } \\
\end{array}$ & $\begin{array}{l}\text { Completo(3) } \\
\text { Incompleto(4) }\end{array}$ & $\begin{array}{l}\text { Incompleto com atributos } \\
\text { e/ou título não fornecidos(5) }\end{array}$ \\
\hline
\end{tabular}

Tabela 5.5 - Exemplo Parcial do Modelo de Teste dos Requisitos para o SAPES

\begin{tabular}{|c|c|c|c|}
\hline \multicolumn{3}{|c|}{ Caso de Uso: Inserção de Item Bibliográfico } & \multirow[b]{2}{*}{$\begin{array}{c}\text { Classe de } \\
\text { Equivalência }\end{array}$} \\
\hline $\begin{array}{l}\text { Caso de } \\
\text { Teste }\end{array}$ & Entrada & Saída Esperada & \\
\hline 1 & $\begin{array}{l}\text { item não existente } \\
\text { completo }\end{array}$ & \begin{tabular}{|llll}
$\begin{array}{l}\text { Mensagem("Item } \\
\text { sucesso") }\end{array}$ & Bibliográfico inserido com \\
\end{tabular} & 1,3 \\
\hline 2 & $\begin{array}{l}\text { Item não existente } \\
\text { incompleto }\end{array}$ & $\begin{array}{l}\text { Mensagem("Item Bibliográfico incompleto. Deseja } \\
\text { (1) completa-lo, (2)inseri-lo incompletamente ou (3) } \\
\text { cancelar a inserção?") }\end{array}$ & 1,4 \\
\hline 2 & \begin{tabular}{|ll} 
item & existente \\
incompleto & \\
\end{tabular} & Mensagem("Item Bibliográfico já existe") & 2 \\
\hline 3 & $\begin{array}{l}\text { item com atributo } \\
\text { autor não fornecido }\end{array}$ & $\begin{array}{l}\text { Mensagem("Item Bibliográfico incompleto. Deseja } \\
\text { (1) completa-lo ou (2) cancelar a inserção?"). }\end{array}$ & 5 \\
\hline
\end{tabular}

Durante o projeto do sistema muitas vezes, por questões de tempo, decide-se por implementar somente os casos de uso primários, visto que esses são os de maior importância e utilização no sistema e posteriormente são implementados os casos de uso secundários e opcionais. Sendo assim, um ponto a considerar é a cobertura do Modelo de Teste dos Requisitos em relação aos tipos de casos de uso. Se os casos de uso secundários e opcionais não forem implementados, em princípio, não seria necessário o projeto dos casos de teste para tais casos de uso nesse momento. Portanto, cabe ao projetista de teste decidir se todos os casos de teste serão desenvolvidos independentemente da implementação das funcionalidades do sistema ou se somente serão desenvolvidos casos de teste para os casos de uso que forem implementados. A primeira alternativa despende mais tempo e esforço para o projeto do Modelo de Teste dos Requisitos, portanto, se o tempo para a entrega do software for restrito talvez seja melhor optar 
por desenvolver somente casos de teste para as funcionalidades que serão implementadas na primeira instância do sistema.

\subsubsection{Modelo de Avaliação do Teste}

No Modelo de Avaliação do Teste tem-se o objetivo de analisar a consistência entre o Modelo de Teste da fase em questão com os modelos que serviram como fonte para a geração dos testes. Dessa forma, na fase de Engenharia de Requisitos deve-se verificar primeiramente se foram gerados testes para todos os casos de uso. Para revịsar os testes gerados pelo critério Particionamento em Classes de Equivalência deve-se verificar se foi gerado um caso de teste para cada classe de equivalência inválida e ao menos um caso de teste que cubra todas as classes de equivalência válidas. Para o critério Análise do Valor Limite deve-se verificar se existem casos de teste para os valores limites e suas proximidades. E para os Grafos de Causa-Efeito deve-se averiguar se todas as condições de entrada especificadas nos casos de uso estão no grafo, além disso, se cada ação foi associada à sua respectiva causa(condição de entrada). Se a tabela de decisão do Grafo de Causa-Efeito estiver sendo gerada manualmente é importante conferir a consistência entre eles.

Já que a técnica de teste funcional não permite formas de quantificação da atividade de teste, uma forma de avaliar a massa de teste gerada nesta fase é verificar se tanto o fluxo típico como o fluxo alternativo dos eventos de cada caso de uso são executados pelo menos uma vez.

Ressalta-se que as mudanças feitas na especificação do software devem refletir mudanças nos requisitos de testes, logo, todos os modelos de teste devem ser revisados sempre que houver uma mudança na modelagem do sistema.

\subsubsection{Fase de Análise}

\subsubsection{Modelo de Teste da Análise}

$\mathrm{Na}$ fase de análise é possível projetar casos de teste de integração pois os limites do sistema são definidos determinando-se quais classes de objetos e quais relacionamentos serão implementados. Como ainda não existem informações a respeito dos métodos de cada classe ainda não é possível derivar casos de teste de classe.

Critérios de teste de classe, como o teste baseado em estados (Binder, 1995) e a técnica de teste modal (Binder, 1996b), podem ser adaptados para gerar casos de teste de integração, desde que sejam consideradas as operações do sistema como os eventos que disparam as transições da máquina de estados que representa o comportamento do sistema e a partir da qual seriam originados os casos de teste. No caso do ProDeS/UML, a máquina de estados que usada como fonte para a geração do Modelo de Teste da Análise é o Modelo de Ciclo de Vida. O critério W (Chow, 1978), usado para testar software cujo comportamento é modelado por uma máquina de estados finitos, também pode ser utilizado seguindo a mesma linha de raciocínio apresentada para os critérios de teste de classe.

Se o Critério de Teste Baseado em Estados, de Binder, for utilizado para gerar as seqüências de teste, o Modelo de Teste da Análise seria constituído da árvore de teste gerada para o modelo de ciclo de vida do sistema e de uma tabela com as sequiências de teste derivadas da 
árvore de teste e os resultados esperados da execução de cada uma delas, conforme ilustrado na Tabela 5.6. As sequiências de teste são todos os ramos parciais e completos da árvore de teste (Binder, 1995). Essas sequiências de teste serão constituídas por várias combinações das operações do sistema. Dessa forma, além de verificar como o sistema se comporta diante da execução de uma determinada sequiência de execução de operações, ainda é possível verificar a integração entre as classes que estão envolvidas na execução de uma operação do sistema. Geralmente, uma operação do sistema é composta por vários métodos, sendo assim, as sequiências de teste geradas nesta fase deverão ser atualizadas na fase de projeto, de forma que a sequiência de teste seja composta por métodos que, juntos, realizam a operação.

Tabela 5.6 - Estrutura do Modelo de Teste da Análise

\begin{tabular}{|c|c|c|}
\hline $\begin{array}{c}\text { Caso de } \\
\text { Teste }\end{array}$ & $\begin{array}{c}\text { Seqüências de Teste da } \\
\text { Árvore de Transiçăo: }\end{array}$ & \multicolumn{1}{|c|}{ Resultados Esperados } \\
\hline $\begin{array}{c}\mathrm{N}^{\circ} \text {. do caso } \\
\text { de teste }\end{array}$ & $\begin{array}{l}\text { Sequiência de métodos da árvore } \\
\text { de transição }\end{array}$ & $\begin{array}{l}\text { Resultado esperado após a execução da seqüência de } \\
\text { teste, por exemplo, uma mensagem emitida, a } \\
\text { situação do banco de dados, etc. }\end{array}$ \\
\hline
\end{tabular}

O modelo de ciclo de vida do SAPES é mostrado na Figura 5.3, na Figura 5.4 é mostrada a árvore de teste e na Tabela 5.7 é mostrado o Modelo de Teste da Análise com as seqüências de teste derivadas da árvore de teste da Figura 5.4. O evento $\lambda$ representa um evento que é disparado automaticamente quando termina a execução da operação associada ao estado, sendo assim, ele não precisa ser adicionado às sequiências de teste, pois uma vez terminada a execução da operação ele é automaticamente executado.

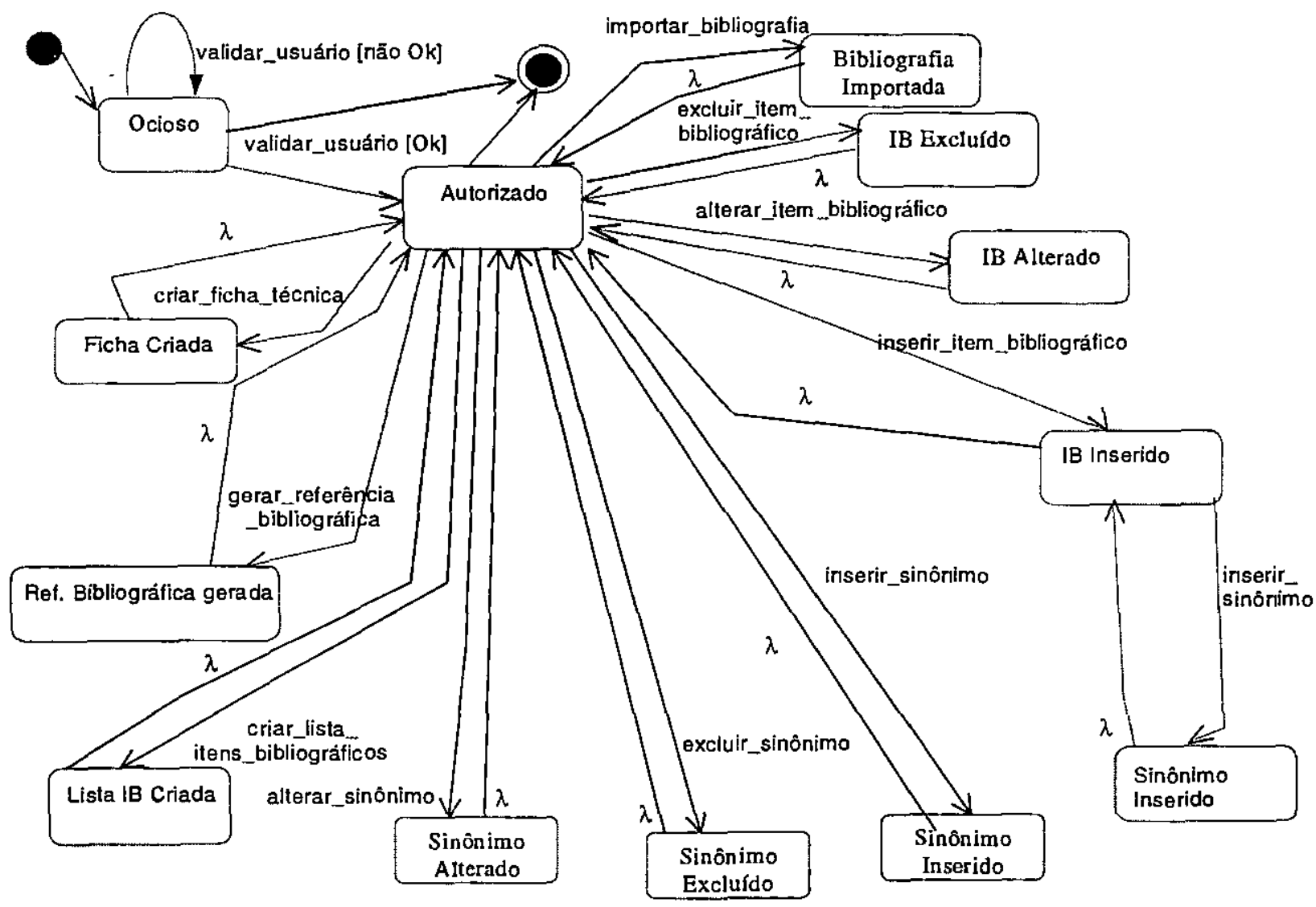

Figura 5.3 - Modelo de Ciclo de Vida 


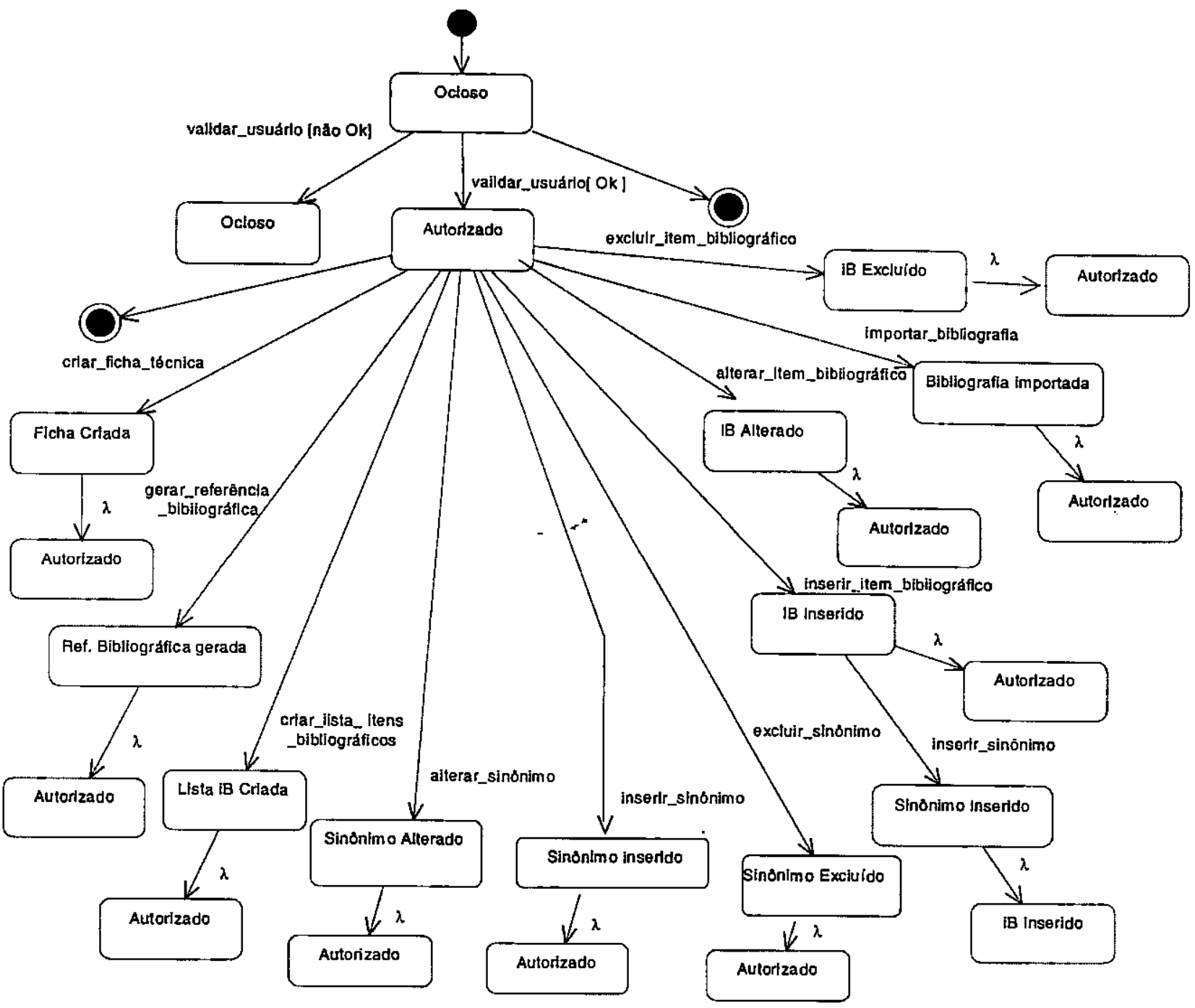

Figura 5.4 - Árvore de Teste

Binder se baseia no critério W (Chow, 1978) para afirmar que o seu critério baseado em estados cobre as mesmas classes de erros cobertas pelo critério de Chow. No entanto, ele não utiliza o mesmo procedimento de derivação de sequiências de teste usado por Chow, pois o conjunto de caracterização utilizado no critério W não é utilizado no critério de Binder durante a geração dos casos de teste. Não é adequado afirmar que o critério baseado em estados de Binder consegue cobrir todas as classes de erros cobertas pelo método $\mathrm{W}$. Na verdade o critério de Binder tem basicamente a mesma cobertura do critério Transition Tour (Naito \& Tsunoyama, 1981), que cobre todas as transições da árvore de teste. Chow afirma que esse critério não cobre erros de transferência (Chow, 1978). Ainda assim, o critério de Binder pode ser utilizado para gerar as sequiências de teste, pois ele consegue detectar erros de especificação do software, mas, para conseguir uma maior cobertura de erros seria melhor utilizar o critério W.

A notação utilizada para representar os resultados esperados é a mesma utilizada pelo Fusion para as expressōes regulares do Modelo de Ciclo de Vida, na qual a I b representa a exclusão mútua entre a e b, e a . b significa que b é executado depois de a. De acordo com os resultados esperados pode ser necessário gerar mais de um caso de teste para cada seqüência de teste. Por exemplo, o Caso de Teste 1 da Tabela 5.5 precisa ser expandido em um caso de teste 
com código e senha válidos e outro com código e/ou senha inválidos. É possível perceber que há um certo relacionamento entre as sequiências de teste e as classes de equivalência classificadas na fase de engenharia de requisitos. Isto é, para cada classe de equivalência deverá haver um caso de teste gerado a partir das seqüências de teste.

Tabela 5.7 - Modelo de Teste da Análise

\begin{tabular}{|c|c|c|}
\hline $\begin{array}{l}\text { Caso de } \\
\text { Teste }\end{array}$ & $\begin{array}{c}\text { Seqüências de Teste da Árvore } \\
\text { de Transição: }\end{array}$ & Resultados Esperados \\
\hline 1 & Validar_usuário [não Ok] & mensagem "Acesso Negado" \\
\hline 2 & Validar_usuário [OK] & Acesso permitido \\
\hline 3 & $\begin{array}{l}\text { Validar_usuário [Ok], } \\
\text { criar_ficha_técnica } \\
\end{array}$ & Acesso permitido . ficha técnica foi criada \\
\hline 4 & $\begin{array}{l}\text { Validar_usuário [Ok], } \\
\text { gerar_referência_bibliográfica }\end{array}$ & $\begin{array}{l}\text { Acesso permitido . arquivo com referências } \\
\text { bibliográficas gerado }\end{array}$ \\
\hline 5 & $\begin{array}{l}\text { Validar_usuário [Ok], } \\
\text { criar_lista_itens_bibliográficos }\end{array}$ & $\begin{array}{l}\text { Acesso permitido . lista de itens bibliográficos } \\
\text { foi criada }\end{array}$ \\
\hline 6 & Validar_usuário [Ok], alterar_sinônimo & $\begin{array}{l}\text { Acesso permitido . sinônimo foi alterado com } \\
\text { novos dados fornecidos }\end{array}$ \\
\hline 7 & Validar_usuário [Ok], inserir_sinônimo & $\begin{array}{l}\text { Acesso permitido . sinônimo foi inserido de } \\
\text { acordo com os dados fornecidos }\end{array}$ \\
\hline 8 & Validar_usuário [Ok], excluir_sinônimo & Acesso permitido . sinônimo foi excluído \\
\hline 9 & \begin{tabular}{|l|} 
Validar_usuário [Ok], \\
inserir_item_bibliográfico
\end{tabular} & Acesso permitido . item bibliográfico inserido \\
\hline 10 & $\begin{array}{l}\text { validar_usuário [Ok], } \\
\text { inserir_item_bibliográfico, } \\
\text { inserir_sinônimo }\end{array}$ & $\begin{array}{l}\text { Acesso permitido. Item bibliográfico inserido. } \\
\text { Sinônimo inserido }\end{array}$ \\
\hline 11 & \begin{tabular}{|l|} 
validar_usuário [Ok], \\
importar_bibliografia \\
\end{tabular} & $\begin{array}{c}\text { Acesso permitido . itens bibliográficos } \\
\text { importados }\end{array}$ \\
\hline 12 & $\begin{array}{l}\text { validar_usuário } \\
\text { [Ok],excluir_item_bibliográfico }\end{array}$ & Acesso permitido . item bibliográfico excluído \\
\hline 13 & $\begin{array}{l}\text { Validar_usuário [Ok], } \\
\text { alterar_item_bibliográfico }\end{array}$ & Acesso permitido . item bibliográfico alterado \\
\hline 14 & Validar_usuário [Ok], (sair) ${ }^{\prime}$ & Acesso permitido . fim da sessão do pesquisador \\
\hline 15 & Validar_usuário [não Ok], (sair) & $\begin{array}{c}\text { mensagem " Acesso Negado". Usuário termina o } \\
\text { uso do sistema }\end{array}$ \\
\hline
\end{tabular}

As seqüências de teste de integração são cornpostas por operações do sistema. Recomenda-se que o Modelo de Teste da Análise seja expandido na fase de Projeto. Fase na qual as seqüências de teste compostas por operaçōes serão decompostas em seqüências de métodos das classes envolvidas na operação do sistema.

\subsubsection{Modelo de Avaliação do Teste}

Na fase de Análise são desenvolvidos os cenários de uso do sistema. Caso algum cenário não tenha sido descrito nas especificações dos casos de uso, deve-se completar todos os modelos da fase de Engenharia de Requisitos. Isto implica no compiemento do Modelo de Teste dos Requisitos.

\footnotetext{
${ }^{1}$ O evento (sair) representa uma açāo do pesquisador indicando que deseja encerrar a sessão de uso do SAPES.
} 
$\mathrm{Na}$ fase de análise pode-se utilizar os cenários para verificar a completitude do Modelo de Teste dos Requisitos. Se existirem informações presentes nos cenários que não são cobertas pelo Modelo de Teste dos Requisitos deve-se então gerar casos de teste que exercitem a funcionalidade não coberta.

Deve-se verificar também se todas as sequiências de mensagens da árvore de teste foram inseridas no Modelo de Teste da Análise, conforme o procedimento indicado pelo critério de teste escolhido. Por exemplo, se for adotado o critério $\mathrm{W}$, as sequiências de teste do Modelo de Teste da Análise devem ser compostas pelos caminhos parciais e totais da árvore concatenadas ao conjunto de caracterização. Caso seja adotado o critério de teste baseado em estados de Binder as sequiências de teste são somente os caminhos parciais e totais da árvore de teste.

Tanto na fase de análise como nas fases posteriores do ciclo de vida deve-se verificar se algum caso de uso essencial foi descrito de forma real, ou seja, considerando detalhes relativos ao projeto/implementação. Considerando as especificações de casos de uso reais deve-se refinar os casos de teste desenvol vidos no Modelo de.Teste dos Requisitos para que esses cubram todos os requisitos descritos no caso de uso real.

\subsubsection{Fase de Projeto}

\subsubsection{Modelo de Teste do Projeto}

\section{Teste de Classe.}

Existe a necessidade de avaliar o funcionamento de cada classe antes de integrá-la às demais e existe uma diversidade de critérios de teste de classe, sendo que quase todos avaliam o aspecto comportamental da classe, ou seja, visam a testar se a classe se comporta de acordo com o esperado; dentre esses critérios estão o critério baseado em estados (Binder, 1995), o critério de teste modal (Binder, 1996b) e os cenários de teste (Vieira \& Travassos, 1998). Geralmente, os critérios de teste tradicionais são adaptados ao teste de classe, sendo que algumas das propostas, além de estipular o critério de teste, propõem uma ferramenta que viabiliza o seu uso (Doong \& Frankl. 1991; Smith \& Robson, 1992).

Os cenários de teste podem ser utilizados perfeitamente para sistemas cujas máquinas de estados finitos possuem as propriedades exigidas pelo método $\mathrm{W}$. O uso de uma ferramenta, como por exemplo a MGASET, facilita enormemente esta tarefa. No entanto, se as MEFs não satisfizerem tais propriedades, uma alternativa seria a utilização do critério de teste modal. Para empregar esse critério deve-se avaliar o comportamento da classe e classificá-lo de acordo com a proposta da técnica (classe modal, não-modal, unimodal ou quasimodal) e então seguir os passos do projeto de teste do tipo de classe (Binder, 1996b). Deve-se notar que empre gando o critério de teste modal as sequiências de mensagens ilegais só poderão ser aplicadas se houver algum driver de teste ou se o programa for executado por linhas de comando, já que programas com interface gráfica só disponibilizam a execução de mensagens legais se a interface estiver correta.

Uma outra alternativa seria utilizar ferramentas de teste de classe, como as propostas por Doong e Smith (Doong \& Frankl, 1991; Smith \& Robson, 1992). A utilização de ferramentas é uma boa alternativa por possuir drivers de teste que permitem executar sequiências de teste que geralmente não poderiam ser executadas pelo testador a partir da interface do software. 
Se nem todas as classes do sistema satisfazem às propriedades exigidas pelo critério $\mathrm{W}$, uma outra alternativa seria utilizar o critério $W$ para testar as classes que satisfazem as propriedades exigidas por este critério e utilizar o critério baseado em estados de Binder ou o critério de teste modal para testar as demais classes.

Depois de escolhido o critério de teste e projetados os casos de teste, deve-se avaliar a necessidade de execução dos testes de acordo com a técnica de teste incremental hierárquica que visa a redução do esforço do teste se houver herança de métodos já testados em outras circunstâncias (Harrold et al., 1992).

Como o objetivo da abordagem de teste proposta neste trabalho é indicar o uso de critérios que satisfazem os requisitos mínimos de teste, o critério utilizado nesta fase para projetar o teste de classe poderia ser o critério de teste baseado em estados de Binder. Para ilustrar, na Figura 5.5 é apresentado o diagrama de estados para a classe Item Bibliográfico e na Figura 5.6 o diagrama de estados e a árvore de teste da classe Autorizaçāo; na Figura 5.7 é mostrada a árvore de teste para o diagramas de estados da classe Item Bibliográfico; e nas Tabelas 5.8 e 5.9 são mostradas as seqüências de teste extraídas das árvores de teste.

Considerando as diretrizes da técnica incremental hierárquica proposta por Harrold é preciso avaliar a necessidade de execução dos casos de teste de acordo com as relações de herança (Harrold et al., 1992). Nesse caso, todas as seqüuências de teste devem ser executadas, pois năo existe nenhum mecanismo de herança relacionado às classes Item Bibliográfico e Autorização.

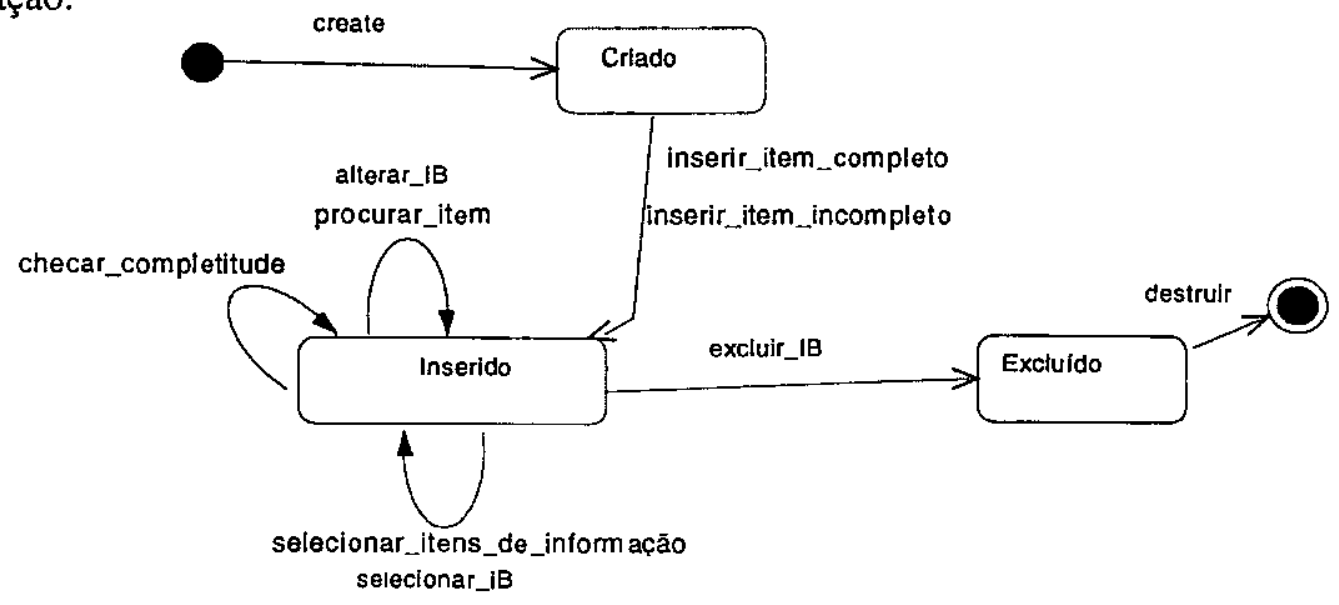

Figura 5.5 - Diagrama de estados para a classe Item Bibliográfico
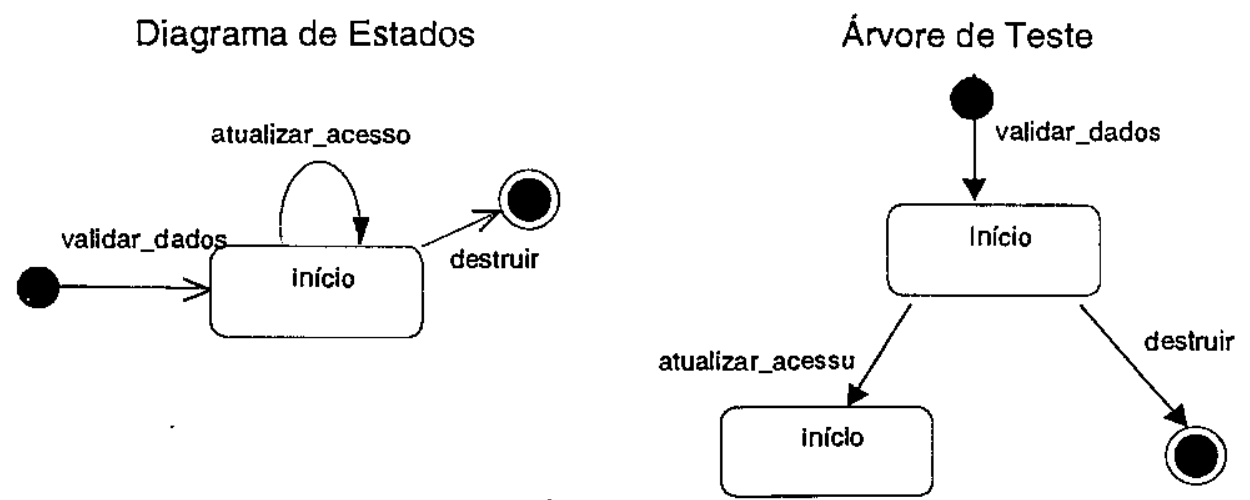

Figura 5.6 - Diagràma de Estados e Árvore de teste para a classe Autorização 
Tabela 5.8 - Modelo de Teste do Projeto - Seqüências de Teste para a Classe Autorização

\begin{tabular}{|c|c|c|}
\hline $\begin{array}{c}\text { Caso de } \\
\text { Teste }\end{array}$ & $\begin{array}{c}\text { Seqüências de Teste da } \\
\text { Árvore de Teste }\end{array}$ & Resultados Esperados \\
\hline 1 & Validar_dados & Mensagem (“Acesso Negado") l acesso permitido \\
\hline 2 & Validar_dados, atualizar_acesso & acesso permitido \\
\hline 3 & Validar_dados, destruir & $\begin{array}{c}\text { Mensagem ("Acesso Negado") . fim da execução do } \\
\text { SAPES }\end{array}$ \\
\hline 4 & $\begin{array}{c}\text { Validar_dados, atualizar_acesso, } \\
\text { destruir }\end{array}$ & \begin{tabular}{c} 
acesso permitido . fim da execução do SAPES \\
\hline
\end{tabular}
\end{tabular}

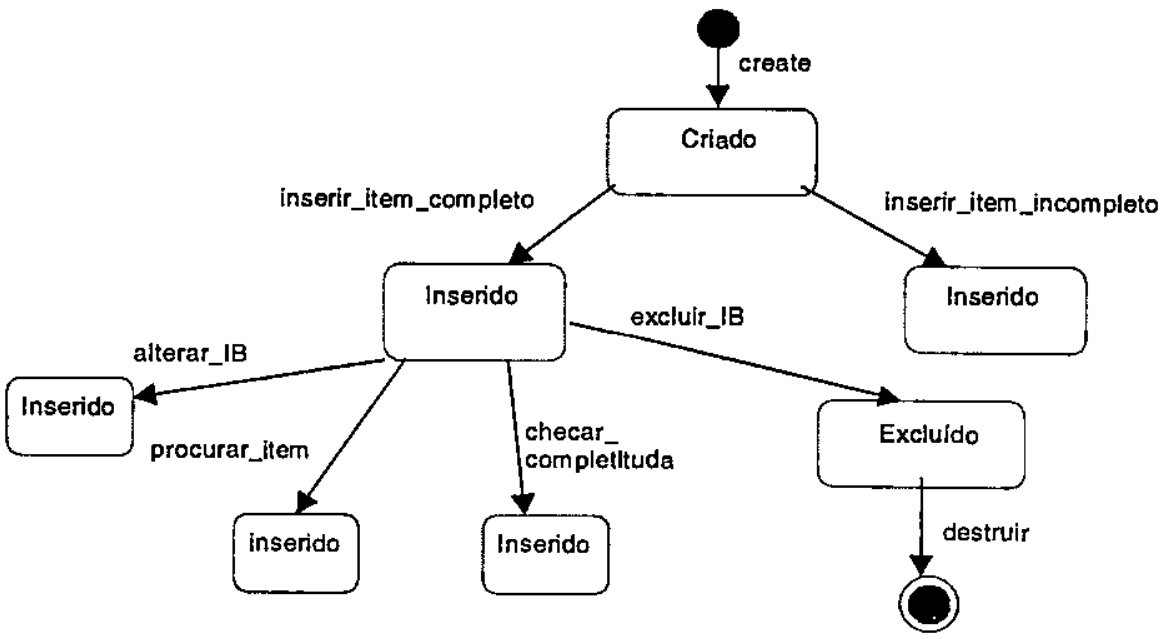

Figura 5.7 - Árvore de Teste para a classe Item Bibliográfico

Tabela 5.9 - Modelo de Teste do Projeto - Sequiências de Teste para a Classe Item Bibliográfico

\begin{tabular}{|c|c|c|}
\hline $\begin{array}{l}\text { Caso de } \\
\text { Teste }\end{array}$ & $\begin{array}{l}\text { Seqüências de Teste } \\
\text { da Árvore de Teste }\end{array}$ & Resultados Esperados \\
\hline l & Create & Objeto item bibliográfico criado \\
\hline 2 & completo & $\begin{array}{l}\begin{array}{l}\text { Objeto item bibliográfico criado } \\
\text { bibliográfico inserido com sucesso") }\end{array} \\
\end{array}$ \\
\hline 3 & $\begin{array}{l}\text { Create, } \\
\text { inserir_item_completo, } \\
\text { alterar_IB }\end{array}$ & 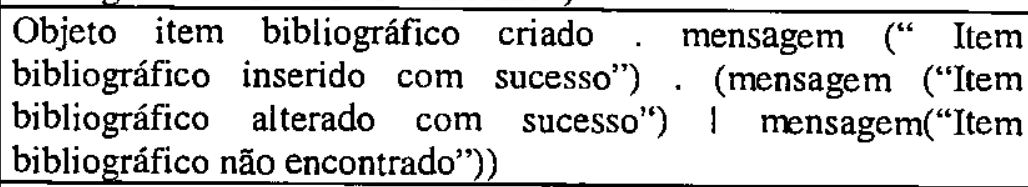 \\
\hline 4 & to, & $\begin{array}{l}\text { Objeto item bibliográfico criado } \quad \text { mensagem (" Item } \\
\text { bibliográfico inserido com sucesso") } \\
\text { bibliográfico já existe")| item bibliográfico não encontrado) }\end{array}$ \\
\hline 5 & to, & $\begin{array}{l}\text { Objeto item bibliográfico criado . mensagem (" Item } \\
\text { bibliográfico inserido com sucesso"). resposta positiva ou } \\
\text { negativa em relação à completitude do item }\end{array}$ \\
\hline 6 & _item_completo, & $\begin{array}{l}\text { Objeto item bibliográfico criado } \\
\text { bibilográfico inserido com sucesso") . (mensagem ("Confirma a } \\
\text { exclusão do item bibliográfico?") I mensagem("Item } \\
\text { bibliográfico não encontrado")) }\end{array}$ \\
\hline 7 & $\because$ item con & $\begin{array}{l}\text { Objeto item bibliográfico criado , } \\
\text { bibliográfico inserido com sucesso") } \\
\text { bibliográfico excluído")) . objeto item bibiográfico destruído }\end{array}$ \\
\hline 8 & incompleto & $\begin{array}{l}\text { Objeto item bibliográfico criado . mensagem("Item Bibliográfico } \\
\text { incompleto. Deseja (1) completa-lo. (2)inseri-lo incompletamente } \\
\text { ou (3) cancelar a inserção?") }\end{array}$ \\
\hline
\end{tabular}




\section{Teste de Integração}

Nesta abordagem de teste propõe-se que as sequiências de teste geradas na fase de análise sejam expandidas utilizando as informações contidas nos diagramas de estados das classes. As sequiências da fase de análise representam diversas seqüências de ativação de operações do sistema, porém essas operações são decompostas em métodos na fase de projeto, permitindo complementar as seqüências de teste geradas na fase anterior. Para isso é preciso analisar os diagramas de estados das classes envolvidas nas operações da sequiência de teste. Informações como qual é a classe controladora de uma operação e quais são as classes envolvidas na operação podem ser extraídas dos diagramas de colaboração.

A sequência de teste número 13 do Modelo de Teste da Análise é: validar_usuário, alterar_item_bibliográfico. Pelos diagramas de colaboração é possível perceber que as classes controladoras dessas operações são Autorização e Bibliografia, e que muitos métodos de várias classes são disparados para executar as duas operaçōes. Portanto, para executar essa sequiência de teste, é preciso analisar todas as classes envolvidas na realização da operação e garantir que todos os métodos envolvidos nessa operação sejam executados. No entanto, para executar algum método de uma classe é preciso analisar os pré-requisitos para a execução desse método, ou seja, para que a classe aceite a invocação de determinado método é necessário que ela esteja em um estado no qual esse método representa uma transição aceitável.

Por exemplo, na operação alterar_item_bibliográfico, o método que efetua a alteração propriamente dita é o método alterar_IB da classe Item Bibliográfico, mas para que esse método seja executado é preciso que anteriormente um objeto da classe item bibliográfico tenha sido instanciado e que um dos métodos inserir_item_completo ou inserir_item_incompleto tenha sido executado para efetuar a inserção dos dados do item bibliográfico que agora pretende-se alterar. Sendo assim, para executar a seqüência de teste de integração <validar_usuário, alterar_item_bibliográfico $>$, é necessário analisar os diagramas de estados das classes envolvidas nessas operações. Analisando a classe Item Bibliográfico percebe-se que para a alteração de item bibliográfico é necessário que o item bibliográfico a ser alterado esteja no estado Inserido, permitindo a execução do método alterar_IB. A operação validar_usuário é decomposta nos métodos validar_dados e atualizar_acesso, como validar_dados é um método acessível a partir do estado inicial do diagrama de estados de Autorização, não existe nenhum pré-requisito para a execução de validar_usuário. Quando essa análise é terminada, tem-se uma seqüência de teste de integração que pode ser executada, que no exemplo dado seria: Autorização.validar_usuário, Item_bibliográfico.inserir_item_completo, Bibliografia..al terar_item_bibliográfico.

Na Tabela 5.10 é mostrada a estrutura do Modelo de Teste dos Requisitos para teste de integração e na Tabela 5.11 é mostrado o Modelo de Teste dos Requisitos para o teste de integração do SAPES, enfocando somente as seqüências de teste relacionadas à manutenção de itens bibliográficos.

Tabela 5.10 - Estrutura do Modelo de Teste do Projeto - Teste de Integração

\begin{tabular}{|c|l|l|}
\hline $\begin{array}{c}\text { Caso de } \\
\text { Teste }\end{array}$ & \multicolumn{1}{|c|}{$\begin{array}{c}\text { Seqüências de Teste da } \\
\text { Árvore de Teste }\end{array}$} & \multicolumn{1}{|c|}{ Resultados Esperados } \\
\hline $\begin{array}{c}\mathrm{N}^{\circ} \text {. do caso } \\
\text { de teste }\end{array}$ & $\begin{array}{l}\text { ClasseA.métodol, } \\
\text { ClasseB.método1, ClasseC. } \\
\text { Método3 }\end{array}$ & $\begin{array}{l}\text { Resultado esperado após a execução da seqüência } \\
\text { de teste, por exemplo, uma mensagem emitida, a } \\
\text { situação do banco de dados, etc. }\end{array}$ \\
\hline
\end{tabular}


Tabela 5.11 - Modelo de Teste do Projeto - Teste de Integração

\begin{tabular}{|c|l|c|}
\hline $\begin{array}{c}\text { Caso de } \\
\text { Teste }\end{array}$ & \multicolumn{1}{|c|}{ Seqüências de Teste da Árvore de Teste } & Resultados Esperados \\
\hline 1 & Autorização.validar_usuário [não Ok] & mensagem “ Acesso Negado" \\
\hline 2 & Autorização.validar_usuário [Ok] & Acesso permitido \\
\hline 9 & $\begin{array}{l}\text { Autorização.validar_usuário [Ok], } \\
\text { Bibliografia.inserir_item_bibliográfico }\end{array}$ & $\begin{array}{c}\text { Acesso permitido . item } \\
\text { bibliográfico inserido }\end{array}$ \\
\hline 10 & $\begin{array}{l}\text { Autorização.validar_usuário [Ok], } \\
\text { Bibliografia.inserir_item_bibliográfico, } \\
\text { Sinônimo.inserir_sinônimo }\end{array}$ & $\begin{array}{c}\text { Acesso permitido. Item bibliográfico } \\
\text { inserido. Sinônimo inserido }\end{array}$ \\
\hline 12 & $\begin{array}{l}\text { Autorização.validar_usuário } \\
\text { [Ok],Item_Bibliográfico.inserir_item_completo, } \\
\text { Bibliografia.excluir_item_bibliográfico }\end{array}$ & $\begin{array}{c}\text { Acesso permitido . item } \\
\text { bibliográfico inserido . item } \\
\text { bibliográfico excluído }\end{array}$ \\
\hline 13 & $\begin{array}{l}\text { Autorização.validar_usuário [Ok], } \\
\text { Item_Bibliográfico.inserir_item_completo, } \\
\text { Bibliografia.alterar_item_bibliográfico }\end{array}$ & $\begin{array}{c}\text { Acesso permitido . item } \\
\text { bibliográfico inserido . item } \\
\text { bibliográfico alterado }\end{array}$ \\
\hline
\end{tabular}

Alguns autores têm proposto critérios de teste de integração para software $O O$, dentre eles os Cenários de Teste (Vieira \& Travassos, 1998) e o critério MM-Path (Method/Message Path) (Jorgensen \& Erickson, 1994). Esses critérios podem ser aplicados no teste de integração e, para tanto, são discutidas abaixo algumas diretrizes para a sua aplicação.

Os cenários de teste utilizam como fonte de informação os diagramas de classes, os cenários e os diagramas de interação entre objetos, sendo que nesse processo de desenvolvimento os diagramas de interação entre objetos equivalem aos diagramas de colaboração. Para utilizá-los é preciso desenvolver uma árvore de teste para cada diagrama de colaboração. Essa árvore tem como nó inicial o ator que dispara a operação. Os outros nós são compostos pelos nomes dos objetos e seus respectivos estados depois da ativação do método associado à transição que leva até o nó. $O$ ator que inicia a operação e os métodos que são ativados são retirados do diagrama de colaboração e o estado do objeto depois da ativação do método é fornecido pelo diagrama de estados. Depois de geradas as árvores de teste deve-se extrair as sequiencias de teste. Sendo assim, o Modelo de Teste dos Requisitos seria formado pelas árvores de teste e pelas seqüências de execução de métodos.

O critério MM-Path só pode ser empregado na fase de implementação, pois para utilizá-lo é necessário gerar para cada operação do sistema um grafo mostrando a troca de mensagens entre os métodos das classes envolvidas na operação. Para isso é preciso utilizar as informações constantes nos modelos de operações e nos corpos dos métodos ou no código.

Lembrando que os métodos podem ser considerados como módulos, os critérios Potenciais Usos de Integração (Vilela, 1998) podem ser utilizados tanto para o teste de classes como para o teste de integração. Para o teste de integração deve-se gerar casos de teste para todos os pares de métodos que interagem na execução de alguma operação do sistema.

Os cenários de teste constituem uma bou alternativa para o teste de integração de sistemas complexos desde que a ferramenta desenvolvida para a geração e visualização dos cenários esteja sendo utilizada, pois o volume de informação a ser gerado é grande demais para ser gerenciado manualmente. 


\subsubsection{Modelo de Avaliação do Teste}

A revisão do projeto do teste de classes pode seguir as mesmas recomendações feitas para o Modelo de Teste da Análise, pois as técnicas empregadas são as mesmas.

Uma vez que o projeto de teste de integração foi iniciado na fase anterior, espera-se que ele já tenha sido revisado. Assim, na fase de projeto basta verificar se as sequiências de invocação de métodos podem ser executadas analisando os diagramas de estados das classes.

\subsubsection{Fase de Implementação}

\subsubsection{Modelo de Teste da Implementação}

Pressman afirma que o ideal é aplicar tanto o teste de caixa branca como o teste de caixa preta para que se valide a interface com o software e se garanta seletivamente que 0 funcionamento interno do software esteja correto (Pressman, 1992). Seguindo essa linha de pensamento e considerando que a maioria dos critérios utilizados nos modelos de teste das fases anteriores são da técnica funcional, algum critério da técnica estrutural deve ser utilizado neste momento para projetar/avaliar os casos de teste para a unidade. Sendo assim, os únicos critérios propostos para serem utilizados neste modelo são os critérios de teste de caixa branca.

Como os métodos geralmente constituem pequenos módulos, um critério de fácil aplicação e que constitui um dos requisitos mínimos de teste é o critério Todos-Ramos, pois ele requer que toda transferência de controle entre blocos de comandos seja exeŕcitada pelo menos uma vez (referência). Como esse critério constitui um dos requisitos mínimos de teste é provável que algum outro critério de teste que tenha sido empregado numa fase anterior, tenha verificado os mesmos tipos de erros verificados pelo critério Todos-Ramos; no entanto, seria preciso realizar experimentos para averiguar a veracidade dessa afirmação. A aplicação do Critério Todos-Ramos consiste em elaborar o grafo de fluxo de controle do método e especificar um caso de teste para cada caminho (ramo) do grafo. O Modelo de Teste da Implementação, mostrado na Tabela 5.12, é composto pelo número do caso de teste e pelo caso de teste que deve ser relacionado ao caminho do grafo que será exercitado. Na Figura 5.8 é apresentado o método procurar_item da classe Bibliografia e o seu grafo de fluxo de controle; procurar_item tem como. objetivo verificar se um item bibliográfico existe ou não na bibliografia, caso ele exista este método retorna true, caso contrário, retorna false.
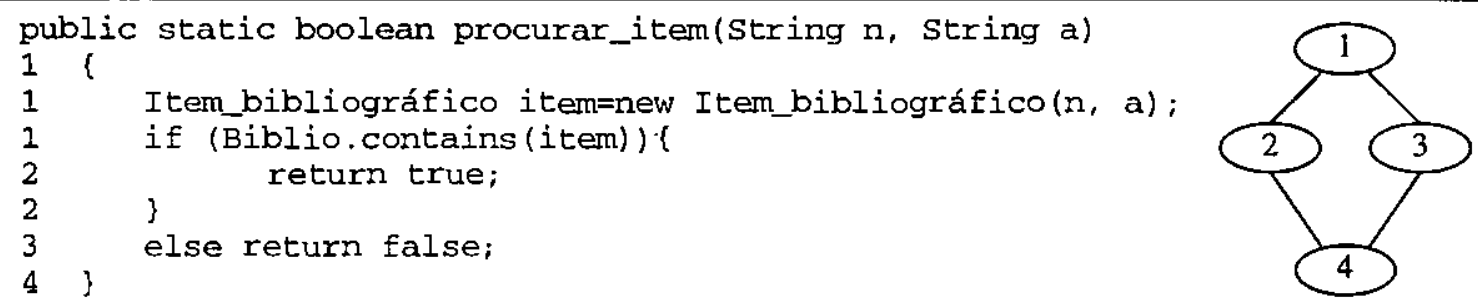

Figura 5.8-Método procurar_item e seu grafo de fluxo de controle

Deve-se gerar um caso de teste que passe pelo caminho 1-2-1 e outro que passe pelo caminho 1 -3-4, conforme mostrado na Tabela 5.12. Ressalta-se que os casos de teste do Modelo de Teste dos Requisitos apresentados na Tabela 5.5 já cobrem os caminhos do grafo de fluxo de 
controle de procurar_item.

Tabela 5.12 - Modelo de Teste da Implementação

\begin{tabular}{|c|l|c|}
\hline $\begin{array}{c}N^{\circ} \text {. Caso } \\
\text { de Teste }\end{array}$ & \multicolumn{1}{|c|}{ Caso de Teste } & $\begin{array}{c}\text { Caminho do Grafo de } \\
\text { Fluxo de Controle }\end{array}$ \\
\hline 1 & Item bibliográfico existente na Bibliografia & $1-2-4$ \\
\hline 2 & Item bibliográfico que não existe na Bibliografia & $1-3-4$ \\
\hline
\end{tabular}

De acordo com o tempo disponível para a atividade de teste do software e/ou da complexidade dos métodos pode-se aplicar outros critérios de teste de fluxo de controlẹ ou de fluxo de dados, como por exemplo, os critérios de Rapps e Weyuker (Rapps \& Weyuker; 1982; Rapps \& Weyuker, 1985) e os Critérios Potenciais-Usos (Maldonado, 1991).

A maioria dos critérios para testar classes tem como objetivo testar o comportamento da classe sem se preocupar com a sua estrutura interna. Uma boa alternativa, mas que exigiria um pouco mais de tempo, seria utilizar algum critério de teste estrutural para gerar os testes da classe com o objetivo de complementar o conjunto de teste baseado em especificação. Nesse sentido poderiam ser empregados o teste de fluxo de dados para classes proposto por Harrold (Harrold \& Rothermel, 1994), a Mode Machine da Estratégia Free (Binder, 1996a) ou o Critério PotenciaisUsos de integração para testar as classes (Vilela, 1998).

Para utilizar o teste de fluxo de dados para classes proposto por Harrold é preciso construir o grafo de chamada da classe e substituir cada nó pelos grafos de fluxo de controle dos métodos. A partir da árvore resultante deve-se definir os pares def-use intra-método, intermétodo e intra-classe, de acordo com as definições dadas em (Harrold \& Rothermel, 1994).

Para utilizar a Mode Machine da Estratégia FREE (Binder, 1996a) no teste das classe é preciso desenvolver um grafo de fluxo de controle para cada método da classe e trocar cada transição do diagrama de estados da classe pelo grafo de fluxo do método que é ativado por essa transição. Os casos de teste serão todos os caminhos da árvore de fluxo de controle resultante.

Depois de projetar os casos de teste deve-se executar os testes de classe e de unidade e verificar se os resultados obtidos estão de acordo com os resultados esperados.

\subsubsection{Modelo de Avaliação do Teste}

Considerando o critério Todos-Ramos, deve-se verificar se o grafo de fluxo de controle foi gerado de acordo com o código do método e depois garantir que existe um caso de teste, no Modelo de Teste da Implementação, para caminho do grafo.

\subsection{USO dA ABORDAGEM DE TESTE}

Nesta seção é apresentado um exemplo da aplicação da abordagem de teste para parte do SAPES. Como não havia ferramenta disponível que viabilizasse o teste de especificações, por exemplo, o teste de diagramas de estados, os testes só puderam ser executados após a implementação do sistema. $\mathrm{Na}$ subseção 5.3.1 são apresentadas as características da implementação que foi testada, e na subseção 5.3.2 são apresentados os modelos de teste utilizados para testar parte da funcionalidade do SAPES. 


\subsubsection{Implementação}

Parte do SAPES foi implementada em Visual $\mathrm{J}++$. Na Figura 5.9 são mostradas as classes e os métodos das classes que foram implementados; o número de linhas de código é da ordem de 2000 linhas. Do caso de uso Manutenção de Item Bibliográfico, a única função que não foi implementada é a importação de itens bibliográficos. A geração automática da forma de citação do item bibliográfico seguindo as normas da $\mathrm{ABNT}$ conforme recomendado no documento de requisitos, também não foi implementada. Assim, o pesquisador precisa informar a forma de citação do item bibliográfico que se deseja inserir. O caso de uso Manutenção de Sinônimos foi implementado completamente. A Ficha Técnica é gerada somente para exibição na tela. Os casos de uso de Geração do Arquivo de Referências Bibliográficas e da Geração da Lista de Itens Bibliográficos não foram implementados. O método validar_usuário da classe Autorização foi implementado para verificar se os dados entrados pelo pesquisador (nome e senha) são válidos, no entanto não foram implementados os métodos de inserção e exclusão de pesquisador e de alteração de senha. Estes métodos implementariam os relacionamentos insere, exclui e altera entre a classe Pesquisador e Autorização.

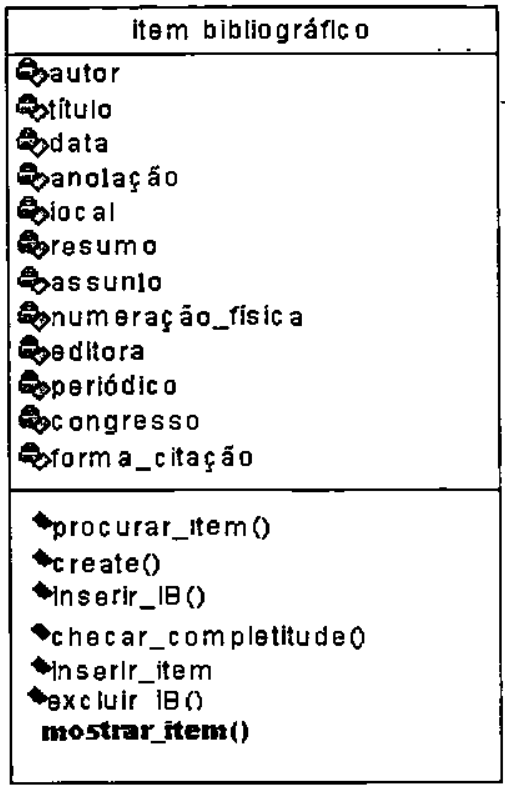
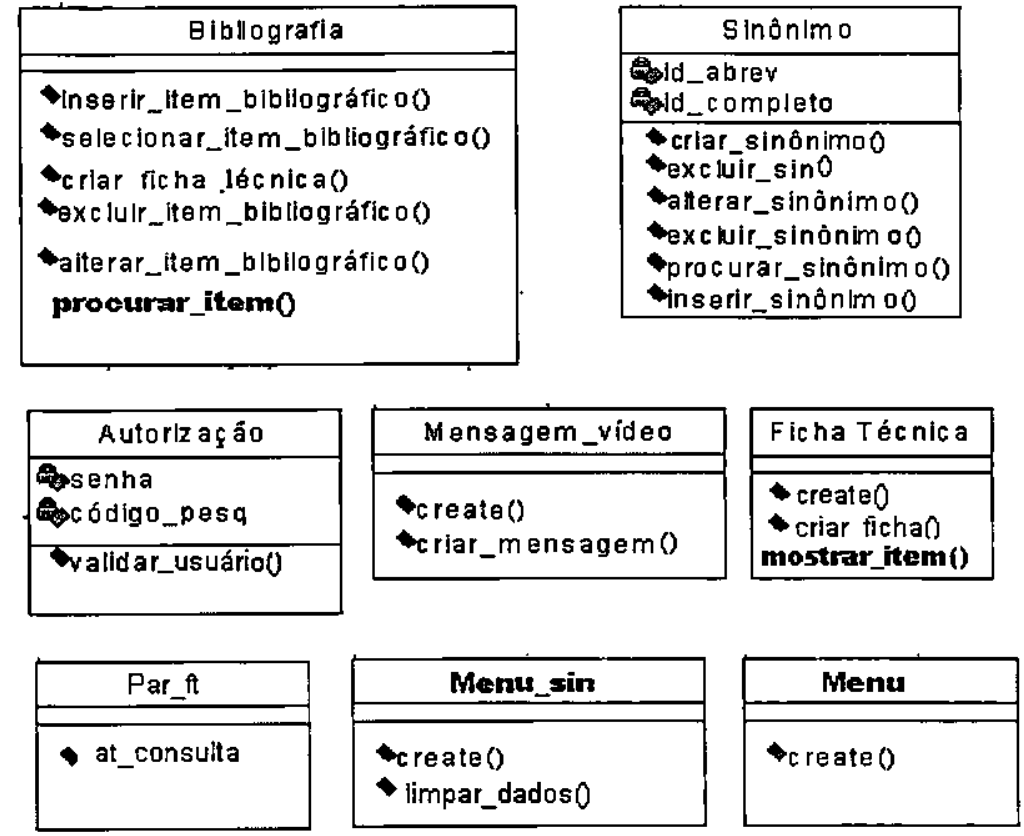
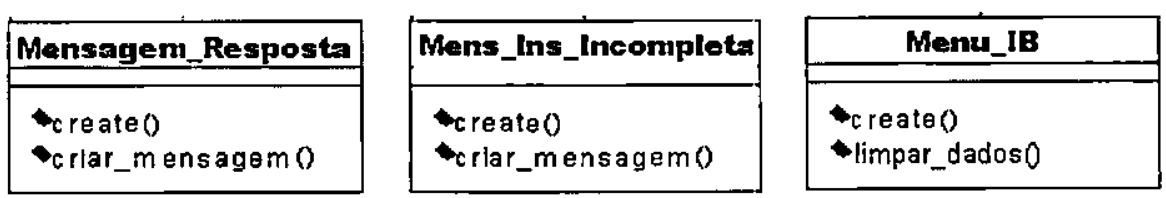

Figura 5.9 - Classes e métodos do SAPES implementados em Java

No momento da implementação percebeu-se a necessidade de criação de alguns métodos e classes que são identificados em negrito na Figura 5.9. As classes Mens_Ins_Incompleta e Mensagem_Resposta foram criadas para exibir na tela uma mensagem referente à inserção e exclusāo do item bibliográfico, respectivamente, e em seguida retornar a resposta dada pelo pesquisador. As classes Menu, Menu_sin e Menu_IB são classes que representam os mellus do sistema. O método create que aparece na maioria das classes representa o método construtor da classe. Foram implementados os métodos construtor e destrutor de todas as classes, embora não apareçam na Figura 5.9. 
A implementação é uma Applet, ou seja, é uma mini-aplicação executada por um navegador (browser). Os dados manipulados pela parte implementada do SAPES estão sendo armazenados na memória. Quando o sistema for implementado por completo, deve-se armazenar os dados em algum banco de dados.

\subsubsection{Exemplo de Uso para o SAPES}

O objetivo desta seção é ilustrar como devem ser os modelos de teste gerados ao longo do desenvolvimento do sistema e como devem ser realizados os testes. Para isso é mostrado um exemplo de uso da abordagem de teste considerando somente o caso de uso Manutenção de Itens Bibliográficos do SAPES. Em cada uma das fases um critério de teste é escolhido e aplicado, ressaltando-se que outros critérios de teste podem ser utilizados no lugar dos que foram utilizados ou em complemento a eles. Os testes das classes de interface foram omitidos.

\subsubsection{Fase de Engenharia de Requisitos}

Para derivar os requisitos de teste desta fase adotou-se o critério de teste funcional Particionamento em Classes de Equivalência. Nas Figuras 5.10, 5.12, 5.13 e 5.14 são mostrados, respectivamente os Modelos de Teste dos Requisitos para a autorização de entrada, a inserção, a exclusão e alteração de itens bibliográficos.

Testes relacionados ao tamanho e à máscara do atributo, por exemplo, um atributo que deve ser composto por no máximo 10 caracteres numéricos, não foram desenvolvidos já que isso é verificado pela interface do sistema. No exemplo apresentado, verifica-se somente se o conteúdo do atributo senha é válido para determinado código de usuário. Outras classes de equivalência surgiriam se existissem outras restrições para a senha, como por exemplo, as classes de equivalência apresentadas na Figura 5.11 para uma senha que deve começar com um caractere alfabético e cujo tamanho pode variar entre 1 e 8.

\begin{tabular}{|c|c|c|c|c|c|}
\hline \multicolumn{6}{|c|}{ Caso de Uso: Autorização de Entrada } \\
\hline \multicolumn{6}{|c|}{ Classes de Equivalência } \\
\hline \multicolumn{2}{|c|}{ Restrições de Entrada } & \multicolumn{2}{|r|}{ Classes Válidas } & \multicolumn{2}{|c|}{ Classes Inválidas } \\
\hline \multicolumn{2}{|c|}{$\begin{array}{l}\text { Conteúdo de } \\
\text { usuário }\end{array}$} & \multicolumn{2}{|c|}{\begin{tabular}{|lrr} 
Senha válida para & um \\
determinado código & do \\
usuário (1) & & \\
\end{tabular}} & \multicolumn{2}{|c|}{$\begin{array}{l}\text { Senha inválida para um } \\
\text { determinado código do usuário } \\
\text { (2) }\end{array}$} \\
\hline \multicolumn{6}{|c|}{ Requisitos de Teste } \\
\hline $\begin{array}{l}\text { Caso de } \\
\text { Teste }\end{array}$ & \multicolumn{2}{|l|}{ Entrada } & \multicolumn{2}{|l|}{ Saída Esperada } & \begin{tabular}{|l|} 
Classe de \\
Equivalência
\end{tabular} \\
\hline 1 & \multicolumn{2}{|c|}{$\begin{array}{l}\text { código de usuário cadastrado } \\
\text { e senha válida }\end{array}$} & \multicolumn{2}{|c|}{$\begin{array}{l}\text { Abertura do menu principal que possibilita o } \\
\text { acesso às informaços do sistema. }\end{array}$} & 1 \\
\hline 2 & \multicolumn{2}{|c|}{$\begin{array}{l}\text { código de usuário cadastrado } \\
\text { e senha inválida }\end{array}$} & \multicolumn{2}{|c|}{ Mensagem avisando que a senha não confere. } & 2 \\
\hline
\end{tabular}

Figura 5.10. - Modelo de Teste dos Requisitos para a Autorização de Entrada no SAPES 


\begin{tabular}{|l|l|l|}
\hline \multicolumn{3}{|c|}{ Classes de Equivalência } \\
\hline Restrições de Entrada & \multicolumn{1}{|c|}{ Classes Válidas } & \multicolumn{1}{c|}{ Classes Inválidas } \\
\hline $1^{\circ}$ caractere & $\begin{array}{l}\text { Caractere alfabético }<\text { a-z }> \\
<\mathrm{A}-\mathrm{Z}>(3)\end{array}$ & $\begin{array}{l}\text { Caractere numérico }<0-9>(4) \\
\text { Caractere especial }<\sim, !, \#, @, \ldots>(5)\end{array}$ \\
\hline Tamanho & $1 \leqslant$ tamanho $\leqslant 8(6)$ & $\begin{array}{l}\text { tamanho }=0(7) \\
\text { tamanho }>9(8)\end{array}$ \\
\hline
\end{tabular}

Figura 5.11 - Outras classes de equivalência para senha

\begin{tabular}{|c|c|c|c|c|c|}
\hline \multicolumn{6}{|c|}{ Caso de Uso: Inserção de Item Bibliográfico } \\
\hline \multicolumn{6}{|c|}{ Classes de Equivalência } \\
\hline \multicolumn{2}{|c|}{ Restrições de Entrada } & \multicolumn{2}{|r|}{ Classes Válidas } & \multicolumn{2}{|c|}{ Classes Inválidas } \\
\hline \multicolumn{2}{|c|}{\begin{tabular}{lll|} 
Existência do & Item \\
Bibliográfico & & \\
\end{tabular}} & \multicolumn{2}{|c|}{ Não existente(1) } & \multicolumn{2}{|l|}{ Existente(2) } \\
\hline \multicolumn{2}{|c|}{$\begin{array}{l}\text { Completitude do Item } \\
\text { Bibliográfico }\end{array}$} & \multicolumn{2}{|c|}{$\begin{array}{l}\text { Completo(3) } \\
\text { Incompleto(4) }\end{array}$} & \multicolumn{2}{|c|}{$\begin{array}{l}\text { Incompleto com atributos autor } \\
\text { e/ou título não fornecidos(5) }\end{array}$} \\
\hline \multicolumn{6}{|c|}{ Requisitos de Teste } \\
\hline $\begin{array}{l}\text { Caso de } \\
\text { Teste } \\
\end{array}$ & \multicolumn{2}{|l|}{ Entrada } & \multicolumn{2}{|l|}{ Saída Esperada } & $\begin{array}{c}\text { Classe de } \\
\text { Equivalência }\end{array}$ \\
\hline 3 & \multicolumn{2}{|c|}{ item não existente completo } & \multicolumn{2}{|c|}{$\begin{array}{l}\text { Mensagem("Item Bibliográfico inserido } \\
\text { com sucesso") }\end{array}$} & 1,3 \\
\hline 4 & \multicolumn{2}{|c|}{$\begin{array}{l}\text { Item não existente } \\
\text { incompleto }\end{array}$} & \multicolumn{2}{|c|}{$\begin{array}{l}\text { Mensagem("Item } \\
\text { incompleto. Deseja (1) completá-lo, } \\
\text { (2)inseri-lo incompletamente ou (3) } \\
\text { cancelar a inserção?") }\end{array}$} & 1,4 \\
\hline 5 & \multicolumn{2}{|c|}{ item existente incompleto } & \multicolumn{2}{|c|}{ Mensagem("Item Bibliográfico já existe") } & 2 \\
\hline 6 & \multicolumn{2}{|c|}{$\begin{array}{l}\text { item com atributo autor não } \\
\text { fornecido }\end{array}$} & \multicolumn{2}{|c|}{$\begin{array}{l}\text { Mensagem("Item Bibliográfico } \\
\text { incompleto. Deseja (1) completá-lo ou (2) } \\
\text { cancelar a inserção?") }\end{array}$} & 5 \\
\hline 7 & \multicolumn{2}{|c|}{$\begin{array}{l}\text { item com atributo título não } \\
\text { fornecido }\end{array}$} & \multicolumn{2}{|c|}{$\begin{array}{l}\text { Mensagem("Item Bibliográfico } \\
\text { incompleto. Deseja (1) completá-lo ou (2) } \\
\text { cancelar a inserção?") }\end{array}$} & 5 \\
\hline
\end{tabular}

Figura 5.12 - Modelo de Teste dos Requisitos para a Inserção de Item Bibliográfico

Uma vez concluída a geração dos Modelos de Teste dos Requisitos, devem-se realizar as atividades sugeridas pelo Modelo de Avaliação do Teste. Considerando o critério de teste adotado, foram gerados um caso de teste para cada classe inválida e um caso de teste para cobrir todas as classes válidas. Verifica-se também que tanto o fluxo típico como o fluxo alternativo dos eventos dos casos de uso testados serão executados.

Para executar os testes, cada um dos casos de teste definidos no Modelo de Teste dos Requisitos deve ser refínado de forma a definir os dados de entrada. Por exemplo, o Caso de Teste 2 da Autorização de Entrada deve ser refinado em um código de usuário que tenha sido cadastrado e uma senha inválida para aquele usuário. Os dados de teste poderiam ser, por exemplo, código de usuário: Andrea e senha: 123456, que é uma senha inválida para este código de usuário. O exemplo da entrada destes dados de teste é apresentado na Figura 5.15, cuja saída pode ser vista no rodapé da tela (Senha não confere). O Caso de Teste 4 poderia ser executado e para os dados de teste apresentados na Figura 5.16. Como resposta a essa entrada o SAPES 
mostra a janela apresentada na Figura 5.17 possibilitando escolher entre completar o item bibliográfico, inserir o item bibliográfico incompletamente ou cancelar a inserção. A segunda opção foi escolhida e o item bibliográfico foi inserido incompletamente.

\begin{tabular}{|c|c|c|c|c|c|}
\hline \multicolumn{6}{|c|}{ Caso de Uso: Exclusão de Item Bibliográfico } \\
\hline \multicolumn{6}{|c|}{ Classes de Equivalência } \\
\hline \multicolumn{2}{|c|}{ Restrições de Entrada } & \multicolumn{2}{|r|}{ Classes Válidas } & \multicolumn{2}{|c|}{ Classes Inválidas } \\
\hline \multicolumn{2}{|c|}{$\begin{array}{lll}\begin{array}{l}\text { Existência } \\
\text { bibliográfico }\end{array} & \text { do } & \text { Item } \\
\end{array}$} & \multicolumn{2}{|r|}{\begin{tabular}{|ll} 
Item & bibliográfico \\
existente $(1)$ & \\
\end{tabular}} & \multicolumn{2}{|c|}{$\begin{array}{l}\text { Item bibliográfico não } \\
\text { existente(2) }\end{array}$} \\
\hline \multicolumn{6}{|c|}{ Requisitos de Teste } \\
\hline $\begin{array}{l}\text { Caso de } \\
\text { Teste } \\
\end{array}$ & Entrada & & Saída Esperada & & $\begin{array}{ll}\text { Classe de } \\
\text { Equivalência } \\
\end{array}$ \\
\hline 8 & $\begin{array}{l}\text { itens de informação } \\
\text { um item bibliográfi } \\
\text { existente }\end{array}$ & & $\begin{array}{l}\text { Os itens de informação do it } \\
\text { são mostrados e é pedida a } \\
\text { exclusão e mediante conf } \\
\text { bibliográfico deve ser excluíc } \\
\text { a exclusão é cancelada. }\end{array}$ & $\begin{array}{l}\text { item bibliográfico } \\
\text { a confirmação de } \\
\text { firmação o item } \\
\text { do, caso contrário }\end{array}$ & 1 \\
\hline 9 & $\begin{array}{l}\text { itens de informação } \\
\text { um item bibliográf } \\
\text { que não existe }\end{array}$ & & $\begin{array}{l}\text { É exibida a mensagem "Item } \\
\text { encontrado" }\end{array}$ & bibliográfico não & 2 \\
\hline
\end{tabular}

Figura 5.13 - Modelo de Teste dos Requisitos para a Exclusão de Item Bibliográfico

\begin{tabular}{|c|c|c|c|c|c|}
\hline \multicolumn{6}{|c|}{ Caso de Uso: Alteração de Item Bibliográfico } \\
\hline \multicolumn{6}{|c|}{ Classes de Equivalência } \\
\hline \multicolumn{2}{|c|}{ Restrições de Entrada } & \multicolumn{2}{|r|}{ Classes Válidas } & \multicolumn{2}{|c|}{ Classes Inválidas } \\
\hline \multicolumn{2}{|c|}{$\begin{array}{l}\begin{array}{l}\text { Existência } \\
\text { bibliográfico }\end{array} \\
\text { do }\end{array}$} & \multicolumn{2}{|c|}{$\begin{array}{ll}\text { Item } & \text { bibliográfico } \\
\text { existente(1) } & \end{array}$} & \multicolumn{2}{|c|}{\begin{tabular}{|ll} 
Item bibliográfico não \\
existente(2)
\end{tabular}} \\
\hline \multicolumn{6}{|c|}{ Requisitos de Teste } \\
\hline $\begin{array}{l}\text { Caso de } \\
\text { Teste }\end{array}$ & \multicolumn{2}{|l|}{ Entrada } & \multicolumn{2}{|l|}{ Saída Esperada } & $\begin{array}{l}\text { Classe de } \\
\text { Equivalência }\end{array}$ \\
\hline 10 & \multicolumn{2}{|c|}{$\begin{array}{l}\text { itens de informação de um } \\
\text { item bibliográfico existente }\end{array}$} & \multicolumn{2}{|c|}{$\begin{array}{l}\text { Os itens de informação do item } \\
\text { bibliográfico são mostrados e, assim que } \\
\text { o pesquisador entrar com os itens que } \\
\text { devem ser alterados, a alteração é } \\
\text { efetuada e a mensagem "Item } \\
\text { bibliográfico alterado com sucesso" é } \\
\text { emitida. }\end{array}$} & 1 \\
\hline 11 & \multicolumn{2}{|c|}{$\begin{array}{l}\text { itens de informação de um } \\
\text { item bibliográfico que não } \\
\text { existe }\end{array}$} & \multicolumn{2}{|c|}{$\begin{array}{l}\text { É exibida a mensagem "Item } \\
\text { bibliográfico não encontrado" }\end{array}$} & 2 \\
\hline
\end{tabular}

Figura 5.14 - Modelo de Teste dos Requisitos para a Alteração de Item Bibliográfico 


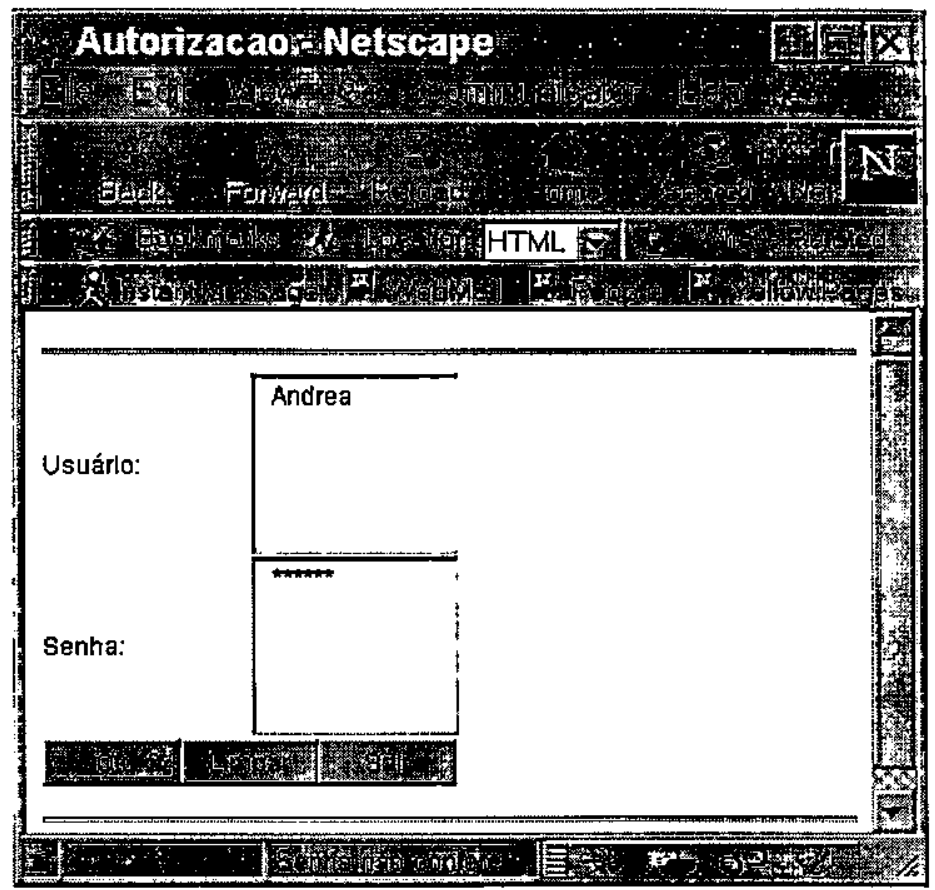

Figura 5.15 - Tela do SAPES para a Autorização do usuário

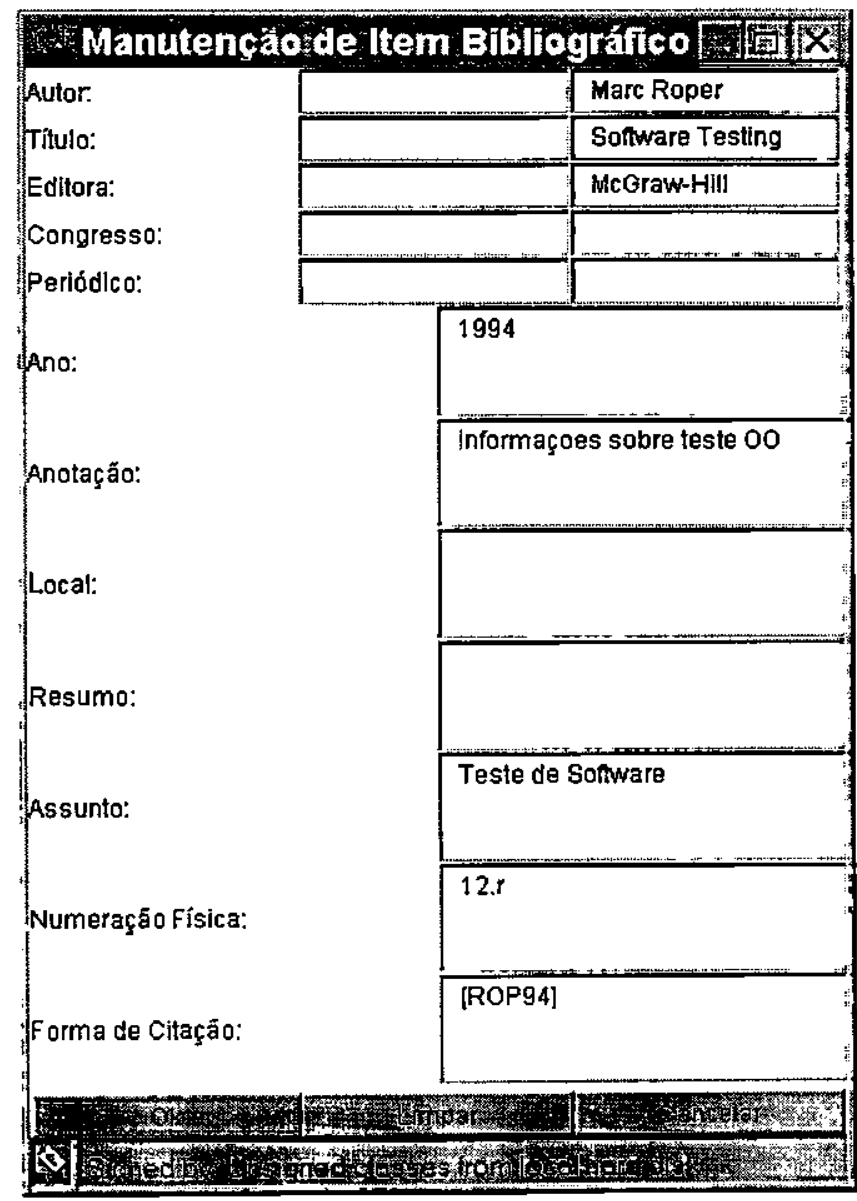

Figura 5.16 - Tela do SAPES para Inserção de Item Bibliográfico 


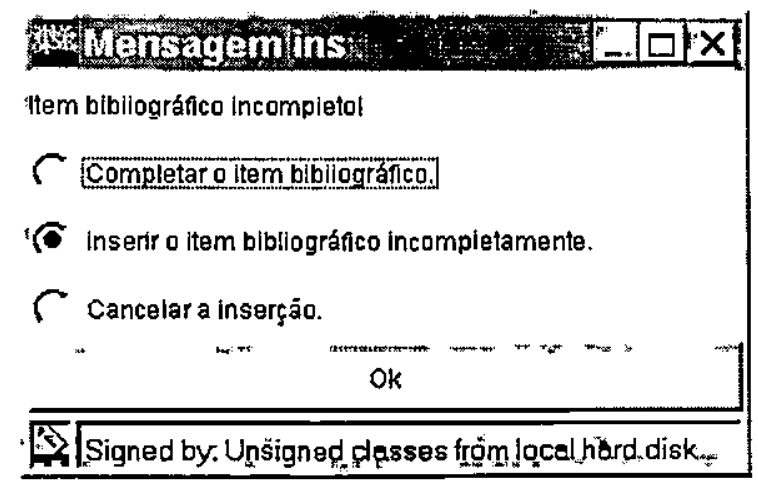

Figura 5.17 - Tela do SAPES para a escolha do tipo de inserção

Todos os requisitos de teste estipulados nos Modelos de Teste dos Requisitos foram executados utilizando a implementação parcial do SAPES. Os Casos de Teste 6 e 7 da Inserção de Item Bibliográfico, que consiste em entrar com um item bibliográfico cujo atributo autor/título não foi preenchido, detectaram erro, pois em vez de ser emitida uma mensagem avisando que 0 item está incompleto, a inserção foi feita como se o item estivesse completo. Analisando o código percebeu-se que o erro encontrado estava no método checar_completitude da classe Item_Bibliográfico.

\subsubsection{Fase de Análise}

$\mathrm{Na}$ fase de Análise ilustra-se o uso do critério baseado em estados de Binder. Conforme mencionado anteriormente, o critério de Binder não cobre erros de transferência. De acordo com o tempo disponível para a atividade de teste, o ideal seria aplicar algum critério com maior cobertura, como por exemplo os critérios W e Wp, descritos por Nakazato et al. em (Nakazato et al., 1994). O critério Wp é derivado do método $\mathrm{W}$ e sua principal vantagem sobre o método $\mathrm{W}$ é a redução no comprimento do conjunto de teste, pois somente um subconjunto do conjunto de caracterização é utilizado em certos casos. No caso da modelagem do SAPES, não seria possível utilizar os critérios $\mathrm{W}$ e Wp, pois as MEFs do SAPES não possuem todas as características exigidas por estes critérios, por exemplo, as MEFs não são completamente especificadas. Para garantir uma cobertura maior do que a do critério de Binder seria preciso utilizar nesta fase algum outro critério de teste.

Na Figura 5.18 é mostrado o Modelo de Ciclo de Vida do SAPES parcial, enfatizando a manutenção de itens bibliográficos. Na Figura 5.19 é mostrada a árvore de teste para a MEF do Figura 5.18 e na Tabela 5.13 é mostrado o Modelo de Teste da Análise gerado para a árvore de teste da Figura 5.19 utilizando o critério baseado em estados de Binder.

Utilizando o critério baseado em estados de Binder, após a geração do Modelo de Teste da Análise deve-se verificar se todas as seqüências parciais e totais da árvore de teste correspondem a um caso de teste. O Modelo de Teste da Análise deve ser refinado na próxima fase de forma a converter as seqüências de execução de operações em seqüências de execução de métodos. 


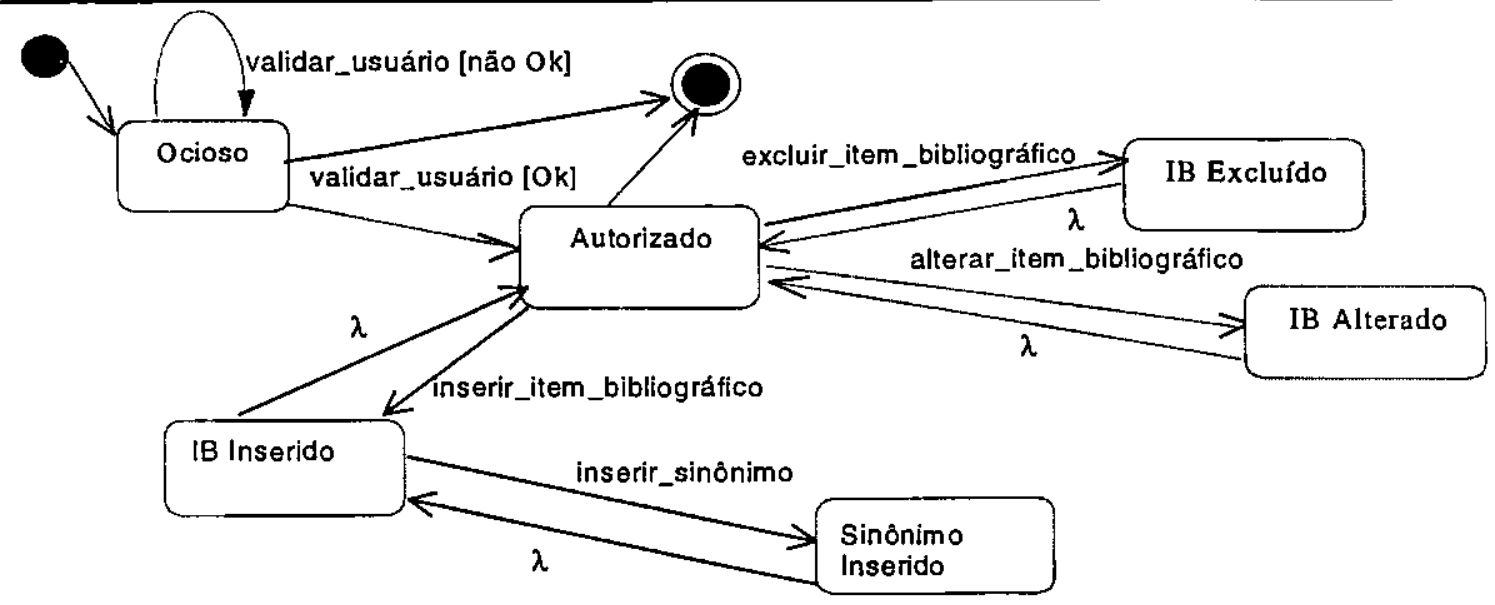

Figura 5.18 - Modelo de Ciclo de Vida do SAPES - Ênfase na Manutenção de Itens Bibliográficos

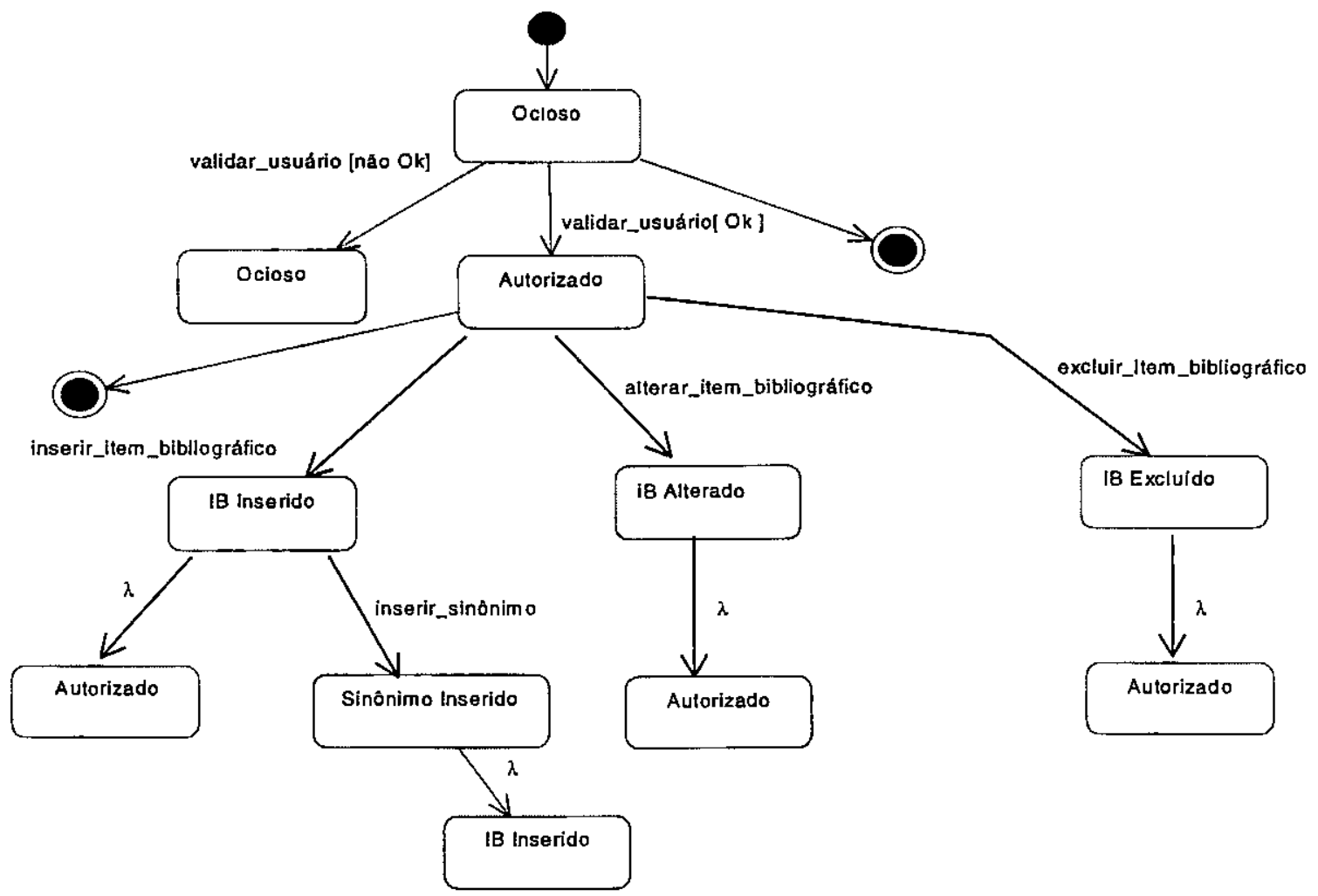

Figura 5.19- Árvore de Teste

\subsubsection{Fase de Projeto}

Na Tabela 5.14 é apresentado o Modelo de Teste do Projeto para o teste de integração, que representa a expansão do Modelo de Teste da Análise apresentado na Tabela 5.13. Foi adicionada a este modelo uma coluna referente aos casos de teste da fase anterior que já cobriram a sequiência que constitui o caso de teste. Como as sequiências dos Casos de Teste 12, 13 e 14 já foram executadas, é necessário executar somente os Casos de Teste 15,16 e 17. Na Tabela 5.15 são mostrados os resultados obtidos em relação à execução dos Casos de Teste 15, 16 e 17. No entanto, nenhum erro foi detectado. Nesta tabela apresenta-se também o caminho percorrido em cada método executado pelo caso de teste. O código e o grafo de fluxo de controle dos métodos 
testados são mostrados no Anexo B. A classe Manut_IB é uma classe de interface que gerencia a execução de uma operação do sistema caso um botão seja pressionado. O método inserir_item da classe Item_Bibliográfico insere itens bibliográficos completos ou incompletos, logo os métodos inserir_item_completo e inserir_item_incompleto tiveram suas funcionalidades implementadas em um único método.

Tabela 5.13 - Modelo de Teste da Análise

\begin{tabular}{|c|c|c|}
\hline $\begin{array}{c}\text { Caso de } \\
\text { Teste }\end{array}$ & $\begin{array}{c}\text { Seqüências de Teste da Árvore de } \\
\text { Teste }\end{array}$ & Resultados Esperados \\
\hline 12 & Validar_usuário [não Ok] & Mensagem "Acesso Negado" \\
\hline 13 & Validar_usuário [Ok] & Acesso permitido \\
\hline 14 & Validar_usuário [Ok], inserir_item_bibliográfico & $\begin{array}{c}\text { Acesso permitido . item bibliográfico } \\
\text { inserido }\end{array}$ \\
\hline 15 & $\begin{array}{l}\text { Validar_usuário [Ok], inserir_item_bibliográfico, } \\
\text { inserir_sinônimo }\end{array}$ & $\begin{array}{l}\text { Acesso permitido. Item bibliográfico } \\
\text { inserido. Sinônimo inserido }\end{array}$ \\
\hline 16 & Validar_usuário [Ok], excluir_item_bibliográfico & $\begin{array}{c}\text { Acesso permitido . item bibliográfico } \\
\text { excluído }\end{array}$ \\
\hline 17 & Validar_usuário [Ok], alterar_item_bibliográfico & $\begin{array}{l}\text { Acesso permitido . item bibliográfico } \\
\text { alterado }\end{array}$ \\
\hline
\end{tabular}

Tabela 5.14 - Modelo de Teste do Projeto - Teste de Integração

\begin{tabular}{|c|c|c|c|c|}
\hline $\begin{array}{l}\text { Caso de } \\
\text { Teste } \\
\text { (CT) }\end{array}$ & $\begin{array}{l}\text { Seqüências de Teste da } \\
\text { Árvore de Teste }\end{array}$ & $\begin{array}{l}\text { Resultados } \\
\text { Esperados }\end{array}$ & $\begin{array}{c}\text { Caminho da árvore de } \\
\text { teste }\end{array}$ & $\begin{array}{l}C T \text { que } \\
\text { executa a } \\
\text { seqüência }\end{array}$ \\
\hline 12 & $\begin{array}{l}\text { Autorização.validar_usuário } \\
\text { [não Ok] }\end{array}$ & $\begin{array}{c}\text { mensagem " Acesso } \\
\text { Negado" }\end{array}$ & validar_usuário [não Ok] & 2 \\
\hline 13 & Autorização.validar_usuário [OK] & Acesso permitido & validar_usuário [Ok] & 1 \\
\hline 14 & $\begin{array}{l}\text { Autorização.validar_usuário [Ok], } \\
\text { Bibliografia.inserir_item_ } \\
\text { bibliográfico }\end{array}$ & $\begin{array}{c}\text { Acesso permitido } \\
\text { item bibliográfico } \\
\text { inserido } \\
\end{array}$ & $\begin{array}{c}\text { validar_usuário [Ok], } \\
\text { inserir_item_bibliográfico }\end{array}$ & 4 \\
\hline 15 & $\begin{array}{l}\text { Autorização.validar_usuário [Ok], } \\
\text { Bibliografia.inserir_item_ } \\
\text { bibliográfico, } \\
\text { Sinônimo.inserir_sinônimo }\end{array}$ & $\begin{array}{c}\text { Acesso permitido. } \\
\text { Item bibliográfico } \\
\text { inserido. Sinônimo } \\
\text { inserido } \\
\end{array}$ & $\begin{array}{l}\text { validar_usuário [OK], } \\
\text { inserir_item_bibliográfico, } \\
\text { inserir_sinônimo }\end{array}$ & \\
\hline 16 & $\begin{array}{l}\text { Autorização.validar_usuário } \\
\text { [Ok],Item_Bibliográfico.inserir_} \\
\text { item_completo,Bibliografia.excluir_i } \\
\text { tem_bibliográfico }\end{array}$ & $\begin{array}{l}\text { Acesso permitido } \\
\text { item bibliográfico } \\
\text { inserido. item } \\
\text { bibliográfico } \\
\text { excluído } \\
\end{array}$ & $\begin{array}{l}\text { validar_usuário [Ok], } \\
\text { excluir_item_bibliográfico }\end{array}$ & \\
\hline 17 & $\begin{array}{l}\text { Autorização.validar_usuário [Ok], } \\
\text { Item_Bibliográfico.inserir_item_- } \\
\text { completo,Bibliografia.alterar_item_b } \\
\text { ibliográfico }\end{array}$ & $\begin{array}{l}\text { Acesso permitido } \\
\text { item bibliográfico } \\
\text { inserido . item } \\
\text { bibliográfico } \\
\text { alterado }\end{array}$ & $\begin{array}{l}\text { validar_usuário [Ok], } \\
\text { alterar_item_bibliográfico }\end{array}$ & \\
\hline
\end{tabular}

Para o teste de classe adota-se também o critério baseado em estados de Binder. Neste trabalho é ilustrado o teste da classe Item_Bibliográfico, cujos diagramas de estados e árvore de teste são mostrados, respectivamente, nas Figuras 5.5 e 5.7. O Modelo de Teste do Projeto para a classe Item_Bibliográfico é mostrado na Tabela 5.16. Como pode-se observar, todas as sequiências.de teste da classe Item_Bibliográfico já foram executadas no teste de integração. No 
Caso de Teste 16, por exemplo, a sequiência do Caso de Teste 23 já é executada ${ }^{2}$. Neste caso não é necessária a execução dos casos de teste da classe Item_Bibliográfico, já que eles foram cobertos pelo teste de integração.

Tabela 5.15 - Resultados dos Casos de teste do Modelo de Teste de Projeto - Teste de Integração

\begin{tabular}{|c|c|c|c|}
\hline $\begin{array}{c}\text { Caso de } \\
\text { Teste }\end{array}$ & $\begin{array}{l}\text { Resultado Obtido } \\
\times \text { Esperado }\end{array}$ & Classe.Método executado & $\begin{array}{l}\text { Caminho } \\
\text { percorrido }\end{array}$ \\
\hline 15 & $\mathrm{Ok}$ & $\begin{array}{l}\text { Autorizaçảo.validar_usuário } \\
\text { Manut_IB.inserir_item_bibliográfico } \\
\text { Bibliografia.procurar_item } \\
\text { Sinônimo.procurar_sinônimo } \\
\text { Sinônimo.inserir_sinônimo } \\
\text { Item_Bibliográfico.checar_completitude } \\
\text { Item_Bibliográfico.inserir_item }\end{array}$ & $\begin{array}{l}1-2-4 \\
1-2-4-5-7 \\
1-3-4 \\
1-3-4 \\
1 \\
1-2-3-5-6-7 \\
1-2-4\end{array}$ \\
\hline 16 & $\overline{\mathrm{Ok}}$ & $\begin{array}{l}\text { Autorização.validar_usuário } \\
\text { Manut_IB.inserir_item_bibliográfico } \\
\text { Bibliografia.procurar_item } \\
\text { Item_Bibliográfico.checar_completitude } \\
\text { Bibliografia.inserir_item_bibliográfico } \\
\text { Manut_IB.excluir_item_bibliográfico } \\
\text { Bibliografia.procurar_item } \\
\text { Item_bibliográfico.excluir_ib }\end{array}$ & $\begin{array}{l}1-2-4 \\
1-2-4-5-7 \\
1-3-4 \\
1-2-3-5-6-7 \\
1-2-4 \\
1-2-4 \\
1-2-4 \\
1 \\
\end{array}$ \\
\hline 17 & Ok & $\begin{array}{l}\text { Autorização.validar_usuário } \\
\text { Manut_IB.inserir_item_bibliográfico } \\
\text { Bibliografia.procurar_item } \\
\text { Item_Bibliográfico.checar_completitude } \\
\text { Bibliografia.inserir_item_bibliográfico } \\
\text { Manut_IB.alterar_item_bibliográfico } \\
\text { Bibliografia.procurar_item } \\
\text { Item_Bibliográfico.alterar_item_bibliográfico }\end{array}$ & $\begin{array}{l}1-2-4 \\
1-2-4-5-7 \\
1-3-4 \\
1-2-3-5-6-7 \\
1-2-4 \\
1-2-3-4-6 \\
1-2-4 \\
1 \\
\end{array}$ \\
\hline
\end{tabular}

Analisando-se o diagrama de estados de Item Bibliográfico (Figura 5.5) percebe-se que uma sequiência permitida é create, inserir_item_incompleto, alterar_IB. No entanto, aplicando o critério de estados de Binder, essa sequiência não é requerida, ou seja, não corresponde a um caso de teste.

\subsubsection{Fase de Implementação}

Para a geração do Modelo de Teste da Implementação utilizou-se o critério de teste estrutural Todos-Ramos, que exige que todos os caminhos do grafo de fluxo de controle do método sejam executados. Nas Tabelas 5.17, 5.18 e 5.19 são mostrados os Modelos de Teste da Implementação para os métodos Bibliografia.procurar_item, Autorização.validar_usuário e Item_Bibliográfico.checar_completitude, respectivamente. Depois de executar os Modelos de Teste das outras fases pôde-se perceber que todos os casos de teste de implementação gerados para o critério Todos-Ramos foram cobertos pelos casos de teste do critério Particionamento em Classes de Equivalência, sendo assim, foram acrescentados aos Modelos de Teste da Implementação uma coluna que indica qual caso de teste do Modelo de Teste dos Requisitos cobriu aquele caminho.

\footnotetext{
${ }^{2}$ O método construtor (create) da classe Item Bibliográfico nāo aparece na seqüência de teste de integraçāo, mas ele é implicitamente executado para viabilizar a inserção de um item bibliográfico.
} 
Tabela 5.16 - Modelo de Teste do Projeto - Seqüências de Teste para a Classe Item Bibliográfico

\begin{tabular}{|c|c|c|c|}
\hline $\begin{array}{l}\text { Caso } \\
\text { de } \\
\text { Teste }\end{array}$ & $\begin{array}{l}\text { Seqüências de } \\
\text { Teste da Árvore } \\
\text { de Teste }\end{array}$ & Resultados Esperados & $\begin{array}{l}\text { CT que } \\
\text { executa a } \\
\text { seqüência }\end{array}$ \\
\hline 18 & Create & Objeto item bibliográfico criado & 4 \\
\hline 19 & $\begin{array}{l}\text { Create, } \\
\text { inserir_item_completo }\end{array}$ & $\begin{array}{l}\text { Objeto item bibliográfico criado . mensagem (" Item } \\
\text { bibliográfico inserido com sucesso") }\end{array}$ & 4 \\
\hline 20 & $\begin{array}{l}\text { Create, } \\
\text { inserir_item_completo, } \\
\text { alterar_IB }{ }^{3}\end{array}$ & $\begin{array}{l}\text { Objeto item bibliográfico criado . mensagem (" Item } \\
\text { bibliográfico inserido com sucesso"). (mensagem ("Item } \\
\text { bibliográfico alterado com sucesso") I mensagem("Item } \\
\text { bibliográfico não encontrado")) }\end{array}$ & 18 \\
\hline 21 & $\begin{array}{l}\text { Create, } \\
\text { inserir_item_completo, } \\
\text { procurar_item }\end{array}$ & $\begin{array}{l}\text { Objeto item bibliográfico criado . mensagem (" Item } \\
\text { bibliográfico inserido com sucesso"). (mensagem("Item } \\
\text { bibliográfico já existe") I item bibliográfico nāo encontrado) }\end{array}$ & 4 \\
\hline 22 & $\begin{array}{l}\text { Create, } \\
\text { inserir_item_completo, } \\
\text { checar_completitude }\end{array}$ & $\begin{array}{l}\text { Objeto item bibliográfico criado . mensagem (" Item } \\
\text { bibliográfico inserido com sucesso"). resposta positiva ou } \\
\text { negativa em relação à completitude do item }\end{array}$ & 4 \\
\hline 23 & $\begin{array}{l}\text { Create, } \\
\text { inserir_item_completo, } \\
\text { excluir_IB }\end{array}$ & $\begin{array}{l}\text { Objeto item bibliográfico criado - mensagem (" Item } \\
\text { bibliográfico inserido com sucesso") (mensagem } \\
\text { ("Confirma a exclusão do item bibliográfico?") | } \\
\text { mensagem("Item bibliográfico não encontrado")) }\end{array}$ & 17 \\
\hline 24 & $\begin{array}{l}\text { Create, } \\
\text { inserir_item_completo, } \\
\text { excluir_IB, destruir }\end{array}$ & $\begin{array}{l}\text { Objeto item bibliográfico criado . mensagem (" Item } \\
\text { bibliográfico inserido com sucesso"). ((mensagem ("Item } \\
\text { bibliográfico excluído")). objeto item bibliográfico } \\
\text { destruído. }\end{array}$ & 17 \\
\hline 25 & \begin{tabular}{|l|} 
Create, \\
inserir_item_incompleto
\end{tabular} & $\begin{array}{l}\text { Objeto item bibliográfico criado . mensagem("Item } \\
\text { Bibliográfico incompleto. Deseja (1) completa-lo, (2)inseri- } \\
\text { lo incompletamente ou (3) cancelar a inserção?") }\end{array}$ & 5 \\
\hline
\end{tabular}

Tabela 5.17 - Modelo de Teste da Implementação - Bibliografia.procurar_item

\begin{tabular}{|c|l|c|c|}
\hline $\begin{array}{l}N^{\circ} \text {. Caso } \\
\text { de Teste }\end{array}$ & \multicolumn{1}{|c|}{ Caso de Teste } & $\begin{array}{c}\text { Caminho do Grafo de } \\
\text { Fluxo de Controle }\end{array}$ & $\begin{array}{c}\text { Casos de Teste que } \\
\text { executam o caminho }\end{array}$ \\
\hline 26 & $\begin{array}{l}\text { Item bibliográfico existente } \\
\text { na Bibliografia }\end{array}$ & $1-2-4$ & $5,8,10$ \\
\hline 27 & $\begin{array}{l}\text { Item bibliográfico que não } \\
\text { existe na Bibliografia }\end{array}$ & $1-3-4$ & $3,4,6,7,9,11$ \\
\hline
\end{tabular}

Tabela 5.18 - Modelo de Teste da Implementação - Autorização.validar_usuário

\begin{tabular}{|c|c|c|c|}
\hline $\begin{array}{l}N^{\circ} \text {. Caso } \\
\text { de Teste }\end{array}$ & \multicolumn{1}{|c|}{ Caso de Teste } & $\begin{array}{c}\text { Caminho do Grafo de } \\
\text { Fluxo de Controle }\end{array}$ & $\begin{array}{c}\text { Caso de Teste que } \\
\text { executa o caminho }\end{array}$ \\
\hline 28 & $\begin{array}{l}\text { Código de usuário cadastrado e } \\
\text { senha válida }\end{array}$ & $1-2-4$ & 1 \\
\hline 29 & $\begin{array}{l}\text { Código de usuário cadastrado e } \\
\text { senha inválida }\end{array}$ & $1-3-4$ & 2 \\
\hline
\end{tabular}

\footnotetext{
${ }^{3}$ Não houve necessidade de implementar o método Item_Bibliográfico.alterar_ib porque a classe Bibliografia foi implementada utilizando a classe Vector, disponível no Visual $\mathrm{J}++$, que altera automaticamente os dados dos objetos que fazem parte do vetor.
} 
Tabela 5.19 - Modelo de Teste da Implementação - Item_Bibliográfico.checar_completitude

\begin{tabular}{|c|l|c|c|}
\hline $\begin{array}{l}N^{\circ} \text {. Caso } \\
\text { de Teste }\end{array}$ & \multicolumn{1}{|c|}{ Caso de Teste } & $\begin{array}{c}\text { Caminho do Grafo de } \\
\text { Fluxo de Controle }\end{array}$ & $\begin{array}{c}\text { Caso de Teste que } \\
\text { executa o caminho }\end{array}$ \\
\hline 30 & Atributo autor não foi preenchido & $1-6-7$ & 6 \\
\hline 31 & Atributo título não foi preenchido & $1-2-5-6-7$ & 7 \\
\hline 32 & Item bibliográfico completo & $1-2-3-5-6-7$ & 3 \\
\hline 33 & Item bibliográfico incompleto & $1-2-3-4-5-6-7$ & 4 \\
\hline
\end{tabular}

Dos três métodos usados para ilustrar a aplicação do critério Todos-Ramos todos os caminhos foram cobertos pelo critério Particionamento em Classes de Equivalência. Isso aumenta a evidência de que os critérios funcionais cobrem os critérios de teste de fluxo de controle. No entanto, seria preciso realizar outros estudos empíricos mais bem fundamentados para determinar se existe equivalência entre esses dois tipos de critérios e se essa equivalência é válida também para os critérios de teste de fluxo de dados.

$\mathrm{Na}$ abordagem de teste recomenda-se que seja empregada a Técnica Incremental Hierárquica para reduzir o esforço do teste por meio das relações de herança. Isto não é feito neste exemplo, já que a parte do software que foi testada não inclui nenhuma relação de herança.

\subsection{CONSIDERAÇÕES FINAIS}

Neste capítulo foi apresentada uma abordagem de teste que auxilia na atividade de planejamento do teste do software OO. O SAPES e o ProDeS/UML foram utilizados para ilustrar o uso desta abordagem, que visa a geração de modelos de teste ao longo do desenvolvimento do software. Não se determina qual critério de teste deve ser utilizado em cada uma das fases, porém são apresentados os critérios que podem ser utilizados e são expostas algumas considerações sobre o seu emprego.

Existem muitos critérios de teste de software propostos na literatura, mas poucos são os trabalhos que têm como objetivo auxiliar o engenheiro de software no momento da determinação de qual critério de teste se adequa melhor ao seu ambiente de desenvolvimento.

Ressalta-se a dificuldade existente para a execução das sequiências de teste de integraçāo, uma vez que estas são constituídas de uma sequiência de ativação de métodos e para garantir que essa seqüência seja executada é necessário que o código seja percorrido até que se encontrem valores de dados que sensibilizem um caminho que permita a realização da sequiência de teste.

É preciso aprofundar o estudo sobre a aplicação dos critérios de teste existentes de forma a aumentar a abrangência desta abordagem. É importante também avaliar possíveis adaptaçōes de critérios de teste para software procedimental para o teste de software OO, como por exemplo o critério Análise de Mutantes. O emprego da abordagem de teste proposta neste trabalho seria facilitado pela sua automatização e dessa forma, toda a informação relativa às atividades de teste poderiam ser gerenciadas automaticamente.

Como mencionado anteriormente, nem todos os modelos da especificação do software foram utilizados para a construção dos Modelos de Teste. Certamente existem informações presentes nos outros modelos que poderiam ser transformados em requisitos de teste, sendo 
assim, existe a necessidade de analisar quais informações dos modelos utilizados pelo ProDeS/UML podem ser úteis para o teste do sistema. Por exemplo, pode-se aplicar o critério de teste funcional Análise do Valor Limite sobre as cardinalidades dos Diagramas de Classes. É preciso determinar uma forma de testar a visibilidade entre os objetos definida no Diagrama de Visibilidade. Pode-se também analisar uma forma de testar as pré e pós-condições do Modelo de Operações juntamente com as seqüências de teste extraídas do Modelo de Ciclo de Vida. Enfim, com a verificação de todos os modelos surgiriam novos tipos de requisitos de teste, o que aumentaria a cobertura e a qualidade do teste aplicado.

No próximo capítulo são apresentadas as conclusões deste trabalho bem como propostas de pesquisas que dão continuidade a essa linha de pesquisa. 


\section{CAPÍTULO VI}

\section{CONCLUSĀO}

\subsection{CONSIDERAÇÕES INICIAIS}

Neste trabalho é apresentado o processo de desenvolvimento de software orientado a objetos ProDeS/UML, que tem como principal característica o uso da notação UML. Esse processo é resultado da fusão de processos de alguns métodos orientados a objetos, como o Método Fusion, o TeamFusion, o Objectory e o processo proposto por Larman para usar a notação da UML (Larman, 1997). O ProDeS/UML segue basicamente os mesmos passos introduzidos pelo Fusion, acrescentando-se a fase de Engenharia de Requisitos que inclui o diagrama de casos de uso proposto pelo Objectory. A especificação dos casos de uso, por sua vez, segue o padrão sugerido por Larman (Larman, 1997). As fases do processo e seus modelos foram apresentados no Capítulo 3. Além disso, o processo introduz checagens que devem ser feitas no final de cada fase e apresenta algumas dicas sobre como construir os modelos.

A realização de um estudo de caso contribuiu para o maior detalhamento e aprimoramento do processo. A ferramenta CASE Rational Rose foi utilizada como ferramenta de apoio ao ProDeS/UML, mas observou-se que algumas informações textuais dos modelos devem ser armazenadas na especificação dos elementos do software como texto livre. 
Existe uma grande diversidade de critérios de teste para software orientado a objetos, sendo que a grande maioria deles é baseada na implementação do software. A abordagem de teste incluída no ProDeS/UML além de organizar a atividade de teste, introduz a derivação de requisitos de teste baseados na especificação do software. Esta abordagem de teste divide a atividade de teste em quatro níveis: teste de sistema, de integração, de classe e de unidade, sendo que cada nível de teste é tratado em uma das fases de desenvolvimento do software.

\subsection{CONTRIBUIÇÕES dO TRABALHO}

Este trabalho constitui uma proposta original no que se refere ao processo de desenvolvimento de software, pois apesar de se basear no método Fusion, algumas características de outros métodos foram adicionadas e alguns dos modelos do Fusion foram modificados, além de utilizar a notação UML. Em paralelo ao desenvolvimento deste trabalho foi desenvolvido também o Unified Process, o processo da Rational que também usa a notação UML (Jacobson et all, 1999).

O ProDeS/UML é atualmente um dos poucos processos de desenvolvimento orientado a objetos criado para utilizar a notação UML. Além disso, ele enfoca a atividade de teste de software, introduzindo uma abordagem de teste que tem como objetivo tratar o planejamento do teste e permitir a definição de Modelos de Teste que contém requisitos de teste baseados na especificação do software durante o seu desenvolvimento. São identificados alguns critérios de teste propostos na literatura que podem ser aplicados na geração dos requisitos de teste de sistemas que foram modelados utilizando os diagramas da UML. O Unified Process também envolve a organização da atividade de teste, porém ele não menciona como devem ser gerados os casos de teste.

Duas vantagens de incluir a atividade de teste ao longo do processo de desenvolvimento são: a possibilidade de testar a especificação e corrigir os erros detectados antes de concluir a implementação do software, economizando tempo e custo, e a aplicação de critérios de teste funcional, que segundo Pressman (Pressman, 1992), devem ser usados em complemento aos critérios de teste estrutural para aumentar a qualidade do teste executado e por conseqüência, aumentar a confiabilidade do produto construído.

Como medida de garantia de qualidade, as checagens entre os modelos inseridas pelo método Fusion foram mantidas. Foi também acrescentado o Modelo de Avaliação do Teste, que tem como objetivo revisar os Modelos de Teste gerados levando em conta os modelos do processo e aos modelos de teste das fases anteriores.

\subsection{TRABALHOS FUTUROS}

Existem várias possibilidades de expansão deste trabalho. Enfocando o processo de desenvolvimento proposto, pode-se aplicar o ProDeS/UML no desenvolvimento de outros sistemas para a identificação de pontos que necessitam de melhorias. Sistemas mais complexos que o SAPES podem representar oportunidades para a descoberta de pontos não cobertos por este processo. 
Mesmo sem desenvolver novos estudos de caso, é possível averiguar a possibilidade de expansão do ProDeS/UML de forma a prever a divisão do sistema em componentes e a incorporar recursos da UML que não foram utilizados, como por exemplo, os diagramas de implementação.

Na linha de pesquisa referente a teste de software, pode-se detalhar mais a abordagem de teste. É preciso verificar informações dos outros modelos do processo que podem representar requisitos de teste relevantes. Pode-se também analisar a viabilidade de utilização e/ou adaptação de outros critérios de teste que não foram abordados e inseri-los na abordagem, caso seja possível.

Além da expansão da abordagem de teste, é importante a sua automatização, para agilizar o gerenciamento da atividade de teste. A automatização da abordagem de teste permitiria também a análise de cobertura dos critérios de teste utilizados.

Finalmente, a realização de estudos empíricos para verificar a equivalência de cobertura entre os critérios de teste da técnica funcional e os critérios da técnica estrutural é uma área de pesquisa que merece atenção. Pelos testes realizados pôde-se inferir que o critério Particionamento em Classes de Equivalência provavelmente tem a mesma cobertura que o critério Todos-Ramos, mas uma questão a ser avaliada é a equivalência entre critérios da técnica funcional e critérios da técnica estrutural baseados em fluxo de dados. 


\section{REFERÊNCIAS BIBLIOGRÁFICAS}

(Berard 1992) BERARD, E. V. Essays on Object-Oriented Software Engineering, v. 1, Prentice-Hall, Englewood cliffs, New Jersey, 1992.

(Binder, 1994) BINDER, R. B., Testing Object-Oriented Systems: A Status Report, American Programmer, v. 7, n. ${ }^{\circ}$, April, 1994, p. 22-28.

(Binder, 1995a) BINDER, R. B., State-Based Testing, Object Magazine, v. 5(6), JulyAugust 1995.

(Binder, 1995b) BINDER, R. B., Object-Oriented Testing: Myth and Reality, Object Magazine, v.5, n. ${ }^{\circ}$ 2, http://www.rbsc.com/pages/myths.html, May, 1995, p. 73-75.

(Binder, 1996a) BINDER, R. B., The FREE Approach to Testing Object-Oriented Software: An Overview, http://www.rbsc.com/pages/FREE.html, 1996.

(Binder, 1996b) BINDER, R. V., Modal Testing Strategies for Object-Oriented Software, Computer, v 29, n 11, November 1996, p. 97-99.

(Booch, 1993) BOOCH, G., Object-Oriented Analysis and Design with Applications, 2nd Edition, Addison-Wesley Publishing Company, 1993. 
(Chow, 1978)

(Colanzi \&

Masiero, 1999)

(Coleman et al., 1994)

(D'Souza \&

Leblanc, 1994)

(Doong \& Frankl, 1991)

(Ericksson \&

Penker, 1997)

(Fujiwara et al. 1991)

(Gill, 1962)

(Gönenç, 1970)

(Harel, 1987)

(Harel, 1992)

(Harrold \&

Rothermel, 1994)

(Harrold et al., 1992)

(Jacobson et al., 1994)
CHOW, T. S., Testing Software Design Modeled by Finite-State Machines, IEEE Transactions on Software Engineering, v. SE-4, n. ${ }^{\circ}$, May 1978, p. 178-187.

COLANZI, T.E., MASIERO, P.C., Especificação do SAPES com o ProDeS/UML, Documento de Trabalho, ICMC/USP, São Carlos, SP, 1999.

COLEMAN, D. et al., Object-Oriented Development: THE FUSION $M E T H O D$, Prentice Hall International, Englewood Cliffs, New Jersey, USA, 1994.

D'SOUZA, R. J., LEBLANC, R. J. Jr., Class testing by examining pointers, July-August, 1994, p. 33-39.

DOONG, R., FRANKL, P. G., Case Studies on Testing Object-Oriented Programs, ACM, 1991, p. 165-177.

ERICKSSON, H., PENKER, M., UML Toolkit, John Wiley \& Sons, USA, 1997.

FUJIWARA, S. et al., Test Selection Based on Finite-State Models, IEEE Transactions on Software Engineering, v. 17, n. 6 , June 1991, p. 591-603.

GILL, A., Introduction to the Theory of Finite-State Machines, New York, McGraw-Hill, 1962.

GÖNENÇ, G., A Method for Design of Fault-Detection Experiments, IEEE Transactions on Computers, v. C-19, n. ${ }^{\circ} 6,1970$, p. 551-558.

HAREL, D. , Statecharts: A Visual Formalism for Complex Systems, Science of Computer Programming, vol. 8, 1987, p. 231-274.

HAREL, D., Bitting the Silver Bullet - Toward a Brighter Future for Systems Development, Computer IEEE, January, 1992, p.8-20.

HARROLD, M. J., ROTHERMEL, G., Performing Data Flow Testing on Classes, Proceedings of the Second ACM SIGSOFT Symposium on Foundations of Software Engineering, December 1994, ACM Press, New York. 154-163.

HARROLD, M.J., MCGREGOR, J. D., FITZPATRICK, K.J., "Incremental Testing of Object-Oriented Class Structures", Communications of the ACM, pp. 68-80, 1992.

JACOBSON, I. et al., Object-Oriented Software Engineering - A Use Case Driven Approach, Addison-Wesley Publishing Company, 1994. 
(Jacobson et al., 1999)

(Jorgensen \& Erickson, 1994)

(Khoshafian \& Abnous, 1990)

(Larman, 1997)

(Maldonado et al., 1998)

(Maldonado, 1991)

(Masiero et al., 1998)

(Morandini, 1996)

(Murphy et al., 1994)

(Naito \& Tsunoyama, 1981)

(Nakazato et al., 1994a)

(Nakazato et al., 1994b)
JACOBSON, I., BOOCH, G., RUMBAUGH, J., The Unified Software Development Process, Addison-Wesley Object Technology Series, 1999.

JORGENSEN, P. C., ERICKSON, C., Object-Oriented Integration, Communications of the ACM, Vol. 37 , nº 9, September, 1994, p. 30-38.

KHOSHAFIAN, S., ABNOUS, R., Object Orientation - Concepts, Languages, Databases, User Interfaces", John Wiley \& Sons, 1990.

LARMAN, C., "Applying UML and Patterns - An Introductyon to Object-Oriented Analysis and Design", Prentice Hall, 1997.

MALDONADO, J.C., VINCENZI, A.M.R., BARBOSA, E.F., SOUZA, S.R.S., DELAMARO, M.E., Aspectos Teóricos e Empíricos de Teste de Cobertura de Software, Nota Didática do ICMSC, 1998.

MALDONADO, J.C., Critérios Potenciais Usos: Uma Contribuição ao Teste Estrutural de Software, Tese de Doutorado, DCA-FEEUNICAMP, Julho, 1991.

MASIERO, P.C., GERMANO, F.S.R., MALDONADO, J.C.,Object and Systems Life Cycles Revisited: their Use in Object-Oriented Analysis and Design Methods, Proceedings of the Third CaiSE/IFIP8.1 International Workshop on Evaluation of Modeling Methods in Systems Analysis and Design, Pisa, Italy, June 8-9, 1998, p. 01-12.

MORANDINI, M., Subsídios para o Teste de Software Orientado a Objetos: Definição e Mapeamento de Programas $\mathrm{C}++$ para a $\mathrm{LI++}$, Dissertação de Mestrado, ICMSC/USP, São Carlos, SP, Dezembro, 1996.

MURPHY, G. C., TOWNSEND P., WONG P. S., Experiences with Cluster and Class, Communications of the ACM, v. 37, n. ${ }^{\circ} 9$, September, 1994.

NAITO, S.; TSUNOYAMA, M., Fault Detection for Sequential Machines by Transition-Tours, in Proceedings FTCS- Fault Tolerant Comput. Systems, 1981, p. 238-243.

NAKAZATO, K. K., MALDONADO, J. C., FABBRI, S. C. P. F., MASIERO, P. C., Propriedades de máquinas de estado finito relevantes para critérios de geração de seqüências de teste, Relatório Técnico do ICMSC, n. ${ }^{\circ}$ 27, São Carlos, SP, Outubro, 1994.

NAKAZATO, K.K., MALDONADO, J.C., FABBRI, S.C.P.F., MASIERO, P.C., Aspectos Teóricos e de implementação de critérios de geração de seqüências de teste baseados em máquinas de estado finito, Relatório Técnico, Instituto de Ciências Matemáticas de São Carlos / USP, Outubro, 1994. 
(Nakazato, 1995)

NAKAZATO, K.K., Módulo de Geração de Seqüências de Teste baseadas em Máquinas de Estado Finito, Dissertação de Mestrado, ICMSC-USP, São Carlos, SP, 1995.

(Perry \& Kaiser, PERRY, D. E., KAISER, G. E., Adequate Testing and Object-Oriented 1990)

Programming, JOOP, January-February, 1990, p. 13-19.

(Petrenko \&

Boochmann, 1996)

PETRENKO, A., BOOCHMANN, G.V., On Fault Coverage of Tests for

Finite State Specifications, http://www.iro.umontreal.ca/pub/teleinfo/ TRs/Petr96b.ps.gz, 1996.

(Pressman, 1992) PRESSMAN, R. S., Software Engineering - A Practitioner's Approach, $3^{\mathrm{a}}$ Edição, McGraw Hill, 1992.

(Rapps \&

Weyuker, 1982)

RAPPS, S., WEYUKER, E.J., Data Flow Analysis Techniques for Test Data Selection, In Proc. Int. Conf. Software Engineering, Tokio, Japan, September, 1982, p. 272-278.

(Rapps \&

RAPPS, S., WEYUKER, E.J., Selecting Sofware Test Data using Data Weyuker, 1985)

Flow Information, IEEE Trans. Soft. Engineering, SE-11 (4), April, 1985.

(Rational, 1997a) RATIONAL, UML Summary, versão 1.0, http://www.rational.com, March, 1997.

(Rational, 1997b) RATIONAL, UML Notation Guide, versão 1.0, http://www.rational.com, January, 1997.

(Roper, 1994)

ROPER, Marc, Software Testing (International Software Quality Assurance Series), McGraw Hill, 1994.

(Rumbaugh et al., 1991)

RUMBAUGH, J. et al., Object-Oriented Models and Design, PrenticeHall, Englewood Cliffs, NJ, 1991.

(Sabnani \&

SABNANI, K. K., DAHBURA, A., A Protocol Test Generation Dahbura, 1988)

(Shlaer \& Mellor, 1988)

Procedure, Computer Networks and ISDN Systems, v. 15, 4, 1988, p. 285-297.

SHLAER, S., MELLOR, S., Object-Oriented Systems Analysis: Modeling the World in Data, Yourdon Press Computing Series, Englewood Cliffs, N.J.: Prentice Hall, 1988.

(Smith \& Robson, 1992)

SMITH, M. D., ROBSON, D. J., A Framework for testing objectoriented programs, Microsoft, One Microsoft Way, June, 1992, p. 4552.

(TeamFusion, 1997)

TEAMFUSION, Engineering Process Summary - HP's Latest Improvements to Fusion, HP, July, 1997. 
(Turine, 1996) TURINE, M. A. S., MASIERO, P. C., Especificação de Requisitos: Uma Introdução, Relatório Técnico, ICMC/USP, São Carlos, SP, 1996.

(Vieira \&

VIEIRA, M. E. R., TRAVASSOS, G. H., Apoio Automatizado ao Teste Travassos, 1998) Baseado no Comportamento de Sistemas Orientados a Objetos, Anais do IX CITS- Conferência Internacional de Tecnologia de Software: Qualidade de Software, Curitiba-PR, Junho, 1998, p. 255-267.

(Vilela et al., 1997) VILELA, P.R.S., MALDONADO, J.C., JINO, M., CHAIM, M.L., Uma Visão sobre o Teste Estrutural Baseado em Análise de Fluxo de Dados, Anais do Workshop do Projeto Validação e Teste de Operação, Águas de Lindóia, SP, Janeiro, 1997, p.3-14.

(Vilela, 1998) VILELA, P.R.S., Critérios Potenciais Usos de Integração: Definição e Análise,Tese de Doutorado, UNICAMP, Campinas, SP, 1998.

(Vincenzi et al., VINCENZI, A.M.R., BARBOSA, E.F., DELAMARO, M. E., SOUZA, 1997)

S.R.S., MALDONADO, J.C., Critério Análise de Mutantes: Estado Atual e Perspectivas, Anais do Workshop do Projeto Validação e Teste de Operação, Águas de Lindóia, SP, Janeiro, 1997, p.15-26.

(Weyuker, 1986) WEYUKER, E. J., Axiomatizing Software Test Data Accuracy, IEEE Trans. On Software Engineering, v. SE-12, December, 1986, p. 227-242.

(Weyuker, 1988) WEYUKER, E. J., The Evaluation of Program-Based Software Test Data Accuracy, Communications of the ACM, v. 31, June, 1988, p. 668675.

(Winblad et al. WINBLAD, A. L., EDWARDS, S. D., KING, D. R., Object-Oriented 1990) Software, Addison-Wesley Publishing Company, Inc., 1990.

(Yourdon \& Coad, YOURDON, E. , COAD, P., Object-Oriented Analysis, 2a edição, 1991)

Yourdon Press Computing Series, 1991. 


\section{ANEXO A DOCUMENTO DE REQUISITOS DO SAPES}

\section{Visão Geral do Sistema}

O Sistema de Apoio à Escrita (SAPES) tem como objetivo principal auxiliar a pesquisa bibliográfica. Os usuários deste sistema são, principalmente, pesquisadores que durante a sua pesquisa bibliográfica podem ler publicaçōes (por exemplo: artigos, livros e periódicos) e armazená-las no sistema através de itens bibliográficos, construindo, assim, a sua bibliografia pessoal. Esta bibliografia pode ser alterada e consultada conforme a necessidade do pesquisador, além da possibilidade de fornecer diferentes tipos de relatório. O pesquisador pode também utilizar o sistema durante a redação de textos científicos. Através do documento produzido pelo pesquisador, o sistema reconhece as citações e gera automaticamente a referência bibliográfica. 


\section{REQUISITOS FUNCIONAIS}

\section{PreparaçÃo e MANUTENÇÃo dos ITENS Biblográficos}

1. O sistema deve permitir a inserção, alteração e exclusão de itens bibliográficos, mantendo uma bibliografia.

2. O sistema deve solicitar ao pesquisador os itens de informação necessários para inserir um item bibliográfico na bibliografia. Os itens de informação são: título, autor(es), data(mês/ano), local, resumo da publicação, assunto, numeração física, editora, periódico (volume, número, páginas), congresso e forma de citação.

3. O sistema deve fornecer mensagens de erro quando itens bibliográficos incompletos forem inseridos. Tais mensagens interrogam o pesquisador se deseja cancelar a operação de inserção, completar as informações incompletas ou concluir a inserção assim mesmo.

4. O sistema deve, no caso de ocorrer a tentativa de inserção de um item bibliográfico já existente, comunicar ao pesquisador a existência deste item bibliográfico na bibliografia. Se, neste caso, o pesquisador confirmar a operação de inserção, o sistema deve informar que tal operação irá alterar o item bibliográfico existente.

5. O sistema deve gerar automaticamente a forma de citação (código de citação) seguindo o padrão ABNT (Associação Brasileira de Normas Técnicas) quando o pesquisador inserir um item bibliográfico na bibliografia.

6. O sistema deve fornecer facilidades para a criação e manutenção de uma lista de sinônimos, para os seguintes itens de informação de um item bibliográfico da Bibliografia: autor, editora, periódico e congresso.

7. O sistema deve permitir a alteração dos itens de informação de um item bibliográfico da bibliografia, com exceção do código de citação que é gerado automaticamente pelo sistema. O pesquisador pode acessar/recuperar um item bibliográfico pelos itens de informação: autor, título e pelos sinônimos de autor e título, respectivamente.

8. O sistema deve permitir a exclusão de um item bibliográfico se este item existe na bibliografia. O pesquisador pode acessar/recuperar um item bibliográfico a ser excluído pelos itens de informação: autor, título e pelos sinônimos de autor e título, respectivamente.

9. O sistema deve permitir a inserção de itens bibliográficos importados de bibliografias de outros pesquisadores, através dos itens de informação autor e título e também pelos sinônimos de autor e título, respectivamente. O operação de inserção pode exigir ou não confirmação. A importação de itens pode ser total (todo a bibliografia do pesquisador) ou parcial (somente alguns itens bibliograficos).

10. O sistema não deve permitir a alteração da bibliografia por parte de pesquisadores não autorizados (Segurança de Acesso). 


\section{Consultas Gerais e Emissão de Relatórios}

11. O sistema deve permitir consulta a itens bibliográficos existentes na bibliografia. A busca destes itens bibliográficos pode ser realizada a partir dos seguintes itens de informação ou combinação destes: autor, assunto, editora, periódico, local e ano de publicação. Assim, o sistema apresenta para o pesquisador todos o(s) item(s) bibliográficos que satisfazem o critério de busca.

12. O sistema deve, durante o processo de consulta, averiguar com o pesquisador quais itens de informação ele deseja recuperar. Assim, o sistema pode recuperar itens bibliográficos totais ou parciais.

13. O sistema deve solicitar ao pesquisador, no momento da consulta o tipo do relatório a ser gerado. O relatório contém itens de informação relativos aos itens bibliográficos selecionados pelo pesquisador durante o processo de consulta. Os relatórios podem ser impressos (na tela ou na impressora) ou podem ser gravados em arquivos para posterior análise.

14. O sistema deve ordenar os itens bibliográficos dos relatórios de acordo com a preferência do pesquisador, utilizando as alternativas pelos itens de informação: autor, título e pelos sinônimos de autor e título, respectivamente.

15. O sistema deve fornecer recursos para a criação e impressão de fichas técnicas a partir das informações que o sistema possui sobre os itens bibliográficos. Uma vez geradas as fichas técnicas, o pesquisador pode optar por relatório impresso ou gravação em arquivos. As fichas técnicas contêm além dos itens de informação do item bibliográfico, de forma parcial ou total, anotações do pesquisador a respeito do item bibliográfico.

\section{USO dOS ITENS BIBLIOGRÁFICOS DURANTE A REDAÇÃo DE UM TEXTO CIENTÍFICO}

16. O sistema deve percorrer o documento produzido pelo pesquisador a fim de identificar todas as citações encontradas. A partir destas citações o sistema deve gerar automaticamente a referência bibliográfica seguindo o padrão ABNT, e que posteriormente será anexada ao documento. As citações no documento devem estar na forma ABNT.

17. O sistema deve permitir ao pesquisador ordenar as referências das referências bibliográficas em ordem alfabética por autor ou pela ocorrência da sua respectiva citação no documento.

18. Caso o sistema encontre uma citação no documento que não esteja na bibliografia, o sistema deverá fornecer uma mensagem adequada ao pesquisador alertando a ocorrência de uma possível citação incorreta.

19. O sistema não deve permitir que o pesquisador altere as informações geradas automaticamente pelo sistema. Caso o pesquisador deseje alterar os itens de informação de uma referência das referências bibliográficas por erro ou por não estar completa, ou deseje 
inserir um item bibliográfico não encontrado pelo sistema, este deve proceder com as alterações desejadas na bibliografia e em seguida o sistema deve percorrer novamente o documento gerando uma nova bibliografia. Caso não deseje fazer alterações na bibliografia, deverá então fazer correções diretamente no documento.

\section{Requisitos de Qualidade}

\section{CONFIABILIDADE}

20. O sistema deve ter capacidade para recuperar os dados perdidos da última operação que realizou em caso de falha.

21. O sistema deve fornecer facilidades para a realização de backups dos arquivos do sistema.

\section{EFICIÊNCIA}

22. O tempo de processamento de uma operação de consulta não deve exceder três segundos para uma quantidade inferior a 10 itens bibliográficos.

23. O tempo de resposta para as operações de inserção, alteração e exclusão não deve exceder a três segundos.

\section{PORTABILIDADE}

24. O sistema deve rodar em microcomputadores da linha IBM PC que possuam microprocessador 486 DX ou superior, memória RAM mínima de 8Mbytes e rodam sob Windows 95 .

25. O sistema deve ser facilmente portável para o UNIX. 


\section{ANEXO B}

\section{Côdigo dos Métodos Testados}

Nas Figuras B.1 a B.13 são apresentados, o código, em Java, e os grafos de fluxo de controle dos métodos que foram testados para ilustrar o uso da abordagem de teste.

\section{Classe Autorização}
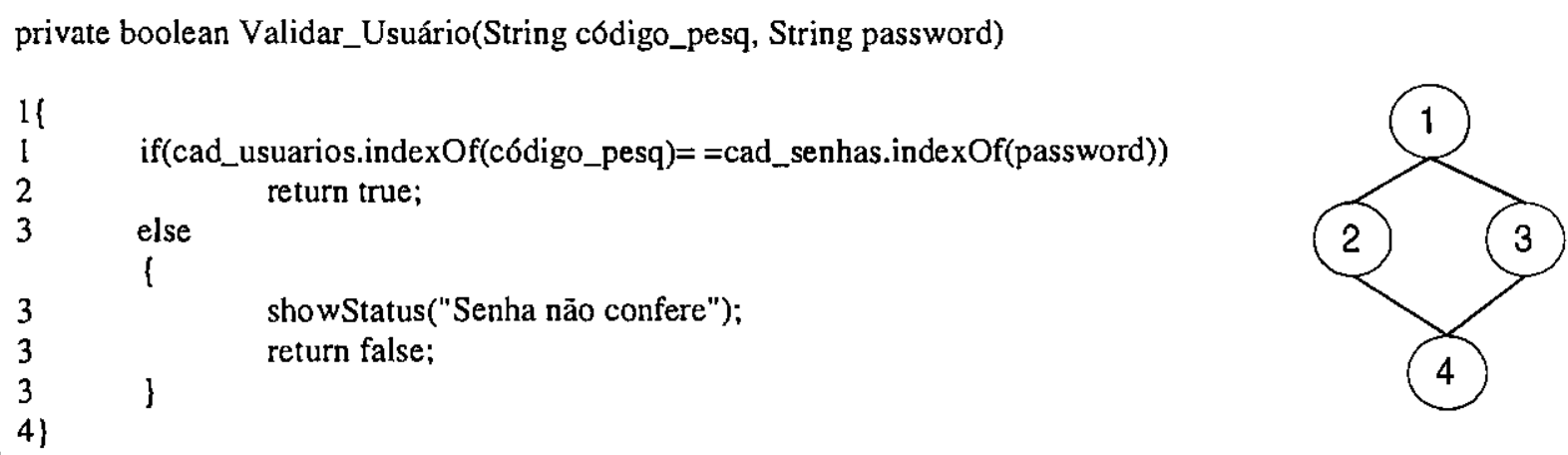

Figura B.1 - Código e grafo de fluxo de controle de Autorização.validar_usuário 


\section{Classe Manut_IB}

public void excluir_item_bibliográfico(String titulo, String autor)

11

1 Item_bibliográfico itens=new Item_bibliográfico(titulo,autor);

1 if (Autorizacao.menu_princ.Bibliogr.procurar_item(titulo,autor))

\{

2 mostrar_item(itens); 2 Mensagem_Resposta msg_resp=new Mensagem_Resposta ("Confirma a

exclusão?", itens);

3 else Mensagem_Video msg = new Mensagem_Video ("Item bibliográfico não encontrado");

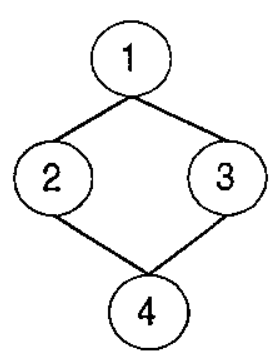

4)

Figura B.2-Código e grafo de fluxo de controle de Manut_IB.excluir_item_bibliográfico

public void alterar_item_bibliográfíco(String titulo, String autor, Event e )

1 (

1 itens=new Item_bibliográfico(titulo,autor);

I if (Autorizacao.menu_princ.Bibliogr.procurar_item(titulo,autor))

1

2 mostrar_item(itens);

2 if (e.target==AltButton)

3 Item_bibliográfico item=new Item_bibliográfico(TituloField.getText(), AutorField.getText(),LocalField.getText(),AnoField.getText(), AnotacaoField.getText(), ResumoField.getText(),AssuntoField.getText(), PeriodicoField.getText(),CongressoField.getText(),EditoraField.getText(), FormaCitField,get Text(), NumFisField.getText());

3 Autorizacao.menu_princ.Bibliogr.alterar_item_bibliográfico(item, itens);

$4\}$ \}

5 else Mensagem_Video msg=new Mensagem_Video("Item bibliográfico não encontrado");

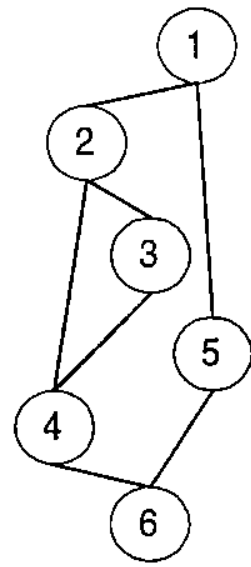
6)

Figura B.3 - Código e grafo de fluxo de controle de Manut_BB.alterar_item_bibliográfico

public void inserir_item_bibliográfico(String aut, String nome, String dat, String anot,

String loc, String res, String ass, String num_fis, String edit, String period. String cong,

String form_cit)

If

1 Mensagem_Video mensagem;

1 if (!(Autorizacao.menu_princ.Bibliogr.procurar_item(nome,aut))) \{

2 Item_bibliográfico i= new Item_bibliográfico(nome, aut, dat, anot, loc, res, ass,num_fis, edit, cong, period, form_cit);

2 if (!(i.checar_completitude(i)))

3 Mensagem_Ins_Incompleta men= new Mensagem_Ins_Incompleta("Item bibliográfico incompleto!", i);

4 else Autorizacao.menu_princ.Bibliogr.inserir_item_bibliográfico(i,true);

$5\}$

6 else mensagem= new Mensagem_Video("Item Bibliográfico já existe"); 7)

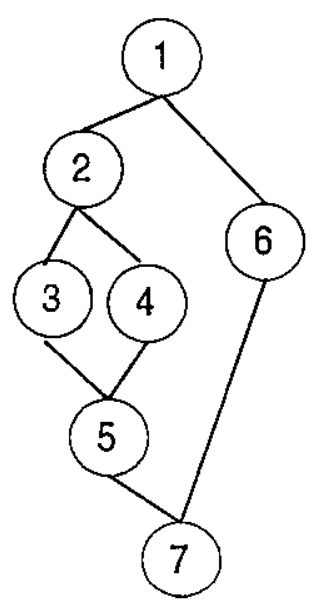

Figura B.4 - Código e grafo de fluxo de controle de Manut_IB.inserir_item_bibliográfico 


\section{Classe Item_Bibliográfico}
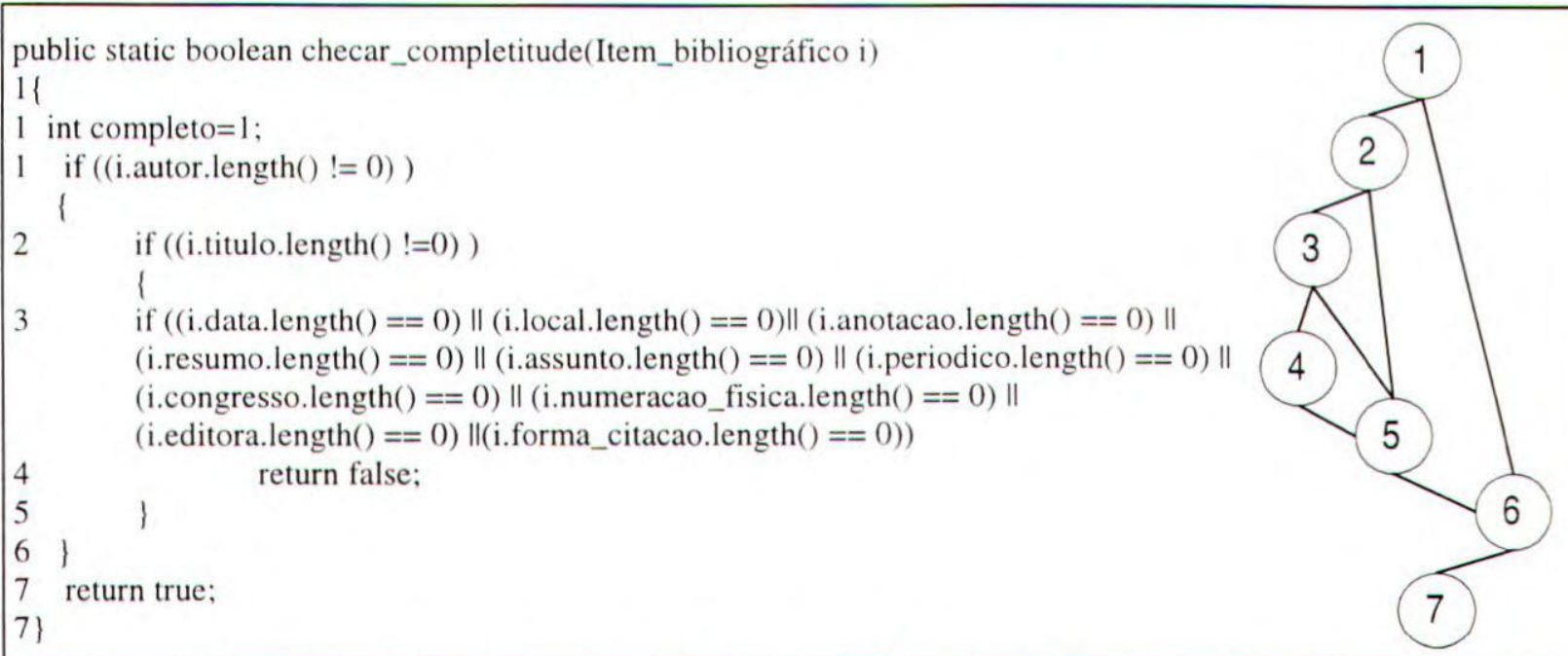

Figura B.5 - Código e grafo de fluxo de controle de Item_Bibliográfico.checar_completitude

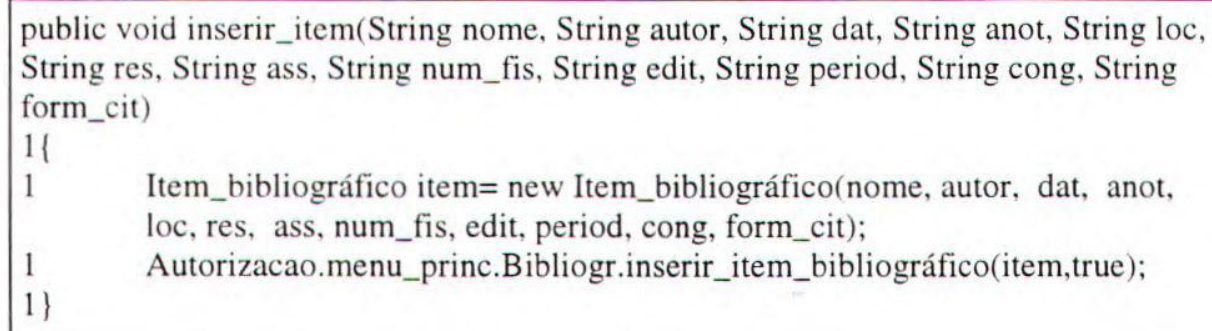

Figura B.6 - Código e grafo de fluxo de controle de Item_Bibliográfico.inserir_item

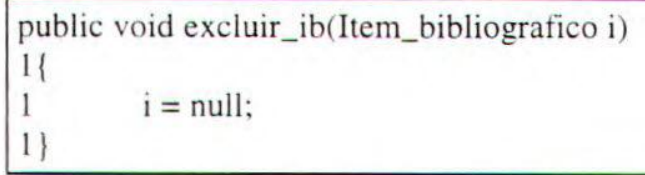

Figura B.7 - Código e grafo de fluxo de controle de Item_Bibliográfico.excluir_ib

\section{Classe Bibliografia}

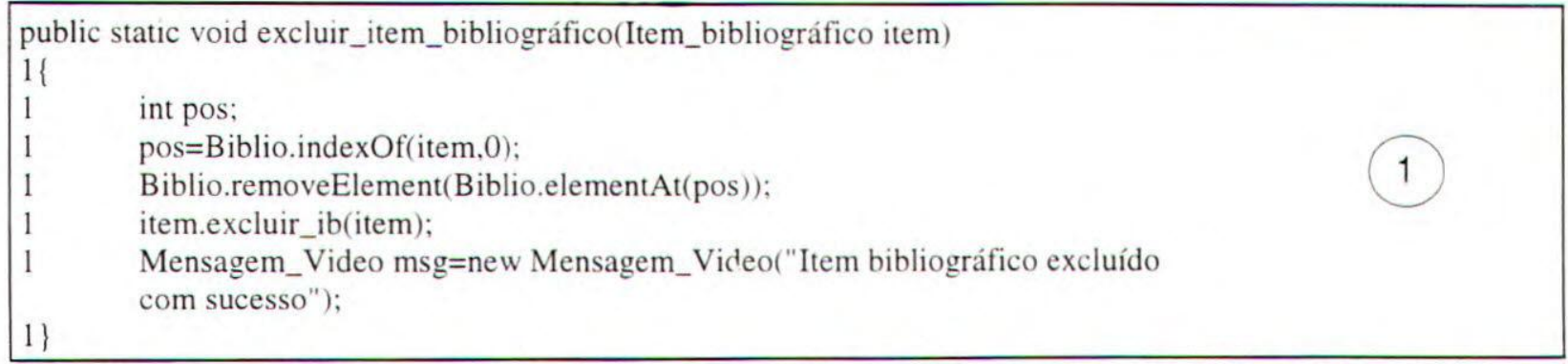

Figura B.8 - Código e grafo de fluxo de controle de Bibliografia.excluir_item_bibliográfico 
public static void alterar_item_bibliográfico(Item_bibliográfico i, Item_bibliográfico itens)

1\{

1 int pos;

$1 \quad$ pos $=$ Biblio.indexOf(itens);

1 Biblio.setElementAt(i, pos);

l Mensagem_Video msg=new Mensagem_Video("Item bibliográfico alterado com sucesso!");

Figura B.9 - Código e grafo de fluxo de controle de Bibliografia.alterar_item_bibliográfico
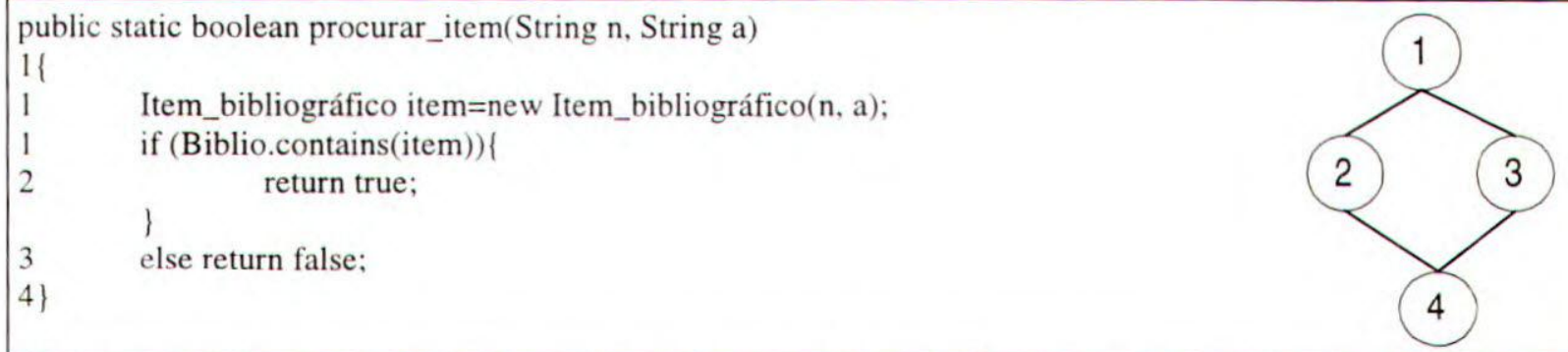

Figura B.10 - Código e grafo de fluxo de controle de Bibliografia.procurar_item

public static void inserir_item_bibliográfico(Item_bibliográfico ib, boolean completo)

1\{

1 Biblio.addElement (ib);

1 if (completo)

2 Mensagem_Video msg= new Mensagem_Video("Item bibliográfico inserido com sucesso");

3 else Mensagem_Video msg= new Mensagem_Video("Item Bibliográfico

4) inserido incompletamente");

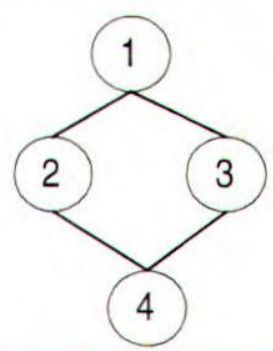

Figura B.11 - Código e grafo de fluxo de controle de Bibliografia.inserir_item

\section{Classe Sinônimo}

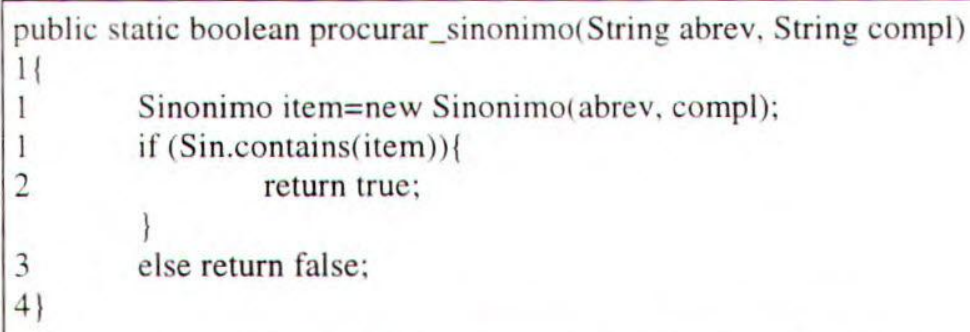

Figura B.12 - Código e grafo de fluxo de controle de Sinônimo.procurar_sinonimo

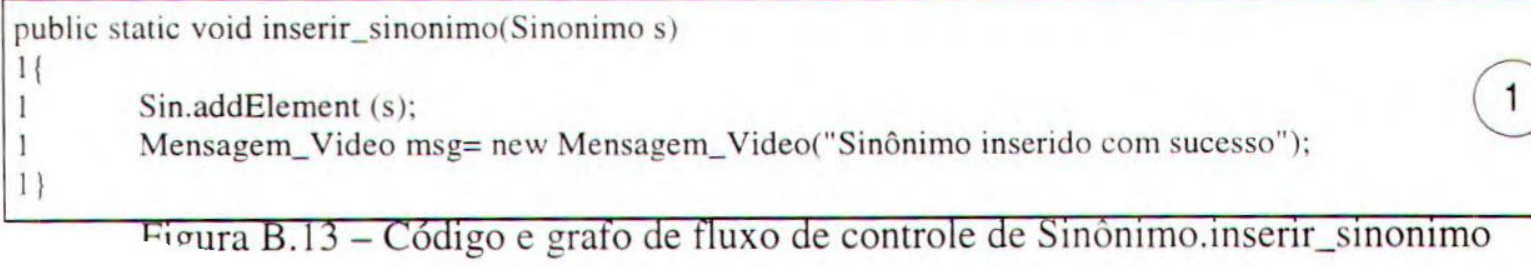

